UNIVERSIDADE DE SÃO PAULO

FACULDADE DE ODONTOLOGIA DE BAURU

Dpto. de Odontopediatria, Ortodontia e Saúde Coletiva

\title{
ESTABILIDADE DA CORREÇÃO DA MÁ OCLUSÃO DE CLASSE II, REALIZADA COM EXTRAÇÃO DE DOIS E DE QUATRO PRÉ-MOLARES
}

\author{
VLADIMIR LEÓN-SALAZAR
}

Dissertação apresentada à Faculdade de Odontologia de Bauru da Universidade de São Paulo, como parte dos requisitos para a obtenção do grau de mestre em Odontologia, área de Ortodontia. 

UNIVERSIDADE DE SÃO PAULO

FACULDADE DE ODONTOLOGIA DE BAURU

Dpto. de Odontopediatria, Ortodontia e Saúde Coletiva

\title{
ESTABILIDADE DA CORREÇÃO DA MÁ OCLUSÃO DE CLASSE II, REALIZADA COM EXTRAÇÃO DE DOIS E DE QUATRO PRÉ-MOLARES
}

\author{
VLADIMIR LEÓN-SALAZAR
}

Dissertação apresentada à Faculdade de Odontologia de Bauru da Universidade de São Paulo, como parte dos requisitos para a obtenção do grau de mestre em Odontologia, área de Ortodontia.

Orientador:

Prof. Dr. Guilherme Janson 


\section{LEÓN-SALAZAR, Vladimir}

L551e Estabilidade da correção da má oclusão de Classe II, realizada com extração de dois e de quatro pré-molares / Vladimir León-Salazar. Bauru, 2006

123 p. + apêndices: il.; 30 cm.

Tese (Mestrado) - Faculdade de Odontologia de Bauru - Universidade de São Paulo.

Orientador: Prof. Dr. Guilherme Janson

Autorizo, exclusivamente para fins acadêmicos e científicos, a reprodução total ou parcial desta dissertação, por processos fotocopiadores e/ou meios eletrônicos

Assinatura do autor:

Data:

Projeto de pesquisa aprovado em 23 de fevereiro de 2005 pelo comitê de Ética da FOB.

$$
\text { Processo no } 144 / 2004
$$




\section{Vladimir León-Salazar}

15 de outubro de 1978

Filiación

1995-2001

2002-2003

2003-2005

2005-2007
Nascimento.

José León Capcha

Roberta Salazar de León

Curso de Graduação em Odontologia, pela Universidad Inca Garcilaso de La Vega Lima-Perú.

Curso de aperfeiçoamento em Ortodontia pela ACOPEN.

Curso de Pós-Graduação em Ortodontia ao nível de Especialização, pela Faculdade de Odontologia de Bauru universidade de São Paulo.

Curso de Pós-Graduação em Ortodontia ao nível de Mestrado, pela Faculdade de Odontologia - Universidade de São Paulo. 
“ Não to mandei eu? Esforça-te e tem bom ânimo; não te atemorizes, nem te espantes, porque o Senhor , teu Deus, é contigo, por onde quer que andares."

Josué 1:9 
Dedicatória 



\section{Dedico este trabalho}

Aos meus pais José e Roberta, que são para mim exemplos vivos de determinação, perseverança e fé, e que nunca pouparam esforços para proporcionar a formação de seus filhos. Devo tudo a eles. A minha eterna gratidão e respeito.

Aos meus irmãos Willian, Rubén e Nancy que também me apoiaram e incentivaram para que eu realizasse este curso, e assim avançasse mais um passo em minha vida profissional e acadêmica.

À minha esposa Juliana pelo seu apoio e incentivo. Seu amor e cumplicidade presentes em todos os momentos são suportes que conseguem transformam nossa casa em um lar, no qual há a paz, a tranqüilidade e a alegria necessária para tornar minha caminhada mais suave. 


\section{Minha profunda gratidão:}

A Deus por ser a fonte na qual encontro forças, significado e direção para minha vida e sem $\mathrm{O}$ qual não teria sentido ir à busca de meus sonhos.

Em Seus braços de Pai posso descansar nas situações adversas e de Suas mãos receber bênçãos sem medida a cada dia. 


\section{Minha admiração e reconhecimento:}

Ao meu orientador Prof. Dr. Guilherme Janson, por sua competência e dedicação à Ortodontia, é para mim um exemplo de pesquisador e profissional. O rigor científico com que tratou esta pesquisa proporcionou-me a aquisição de conhecimentos de fato enriquecedores à minha formação.

Indiscutivelmente foi um grande privilégio haver sido seu orientado. Obrigado por sua amizade e apoio sincero sempre presentes.

Muito Obrigado! 

Agradecimento

Especial 



\section{Meu agradecimento especial:}

À equipe de Professores Doutores da disciplina de Ortodontia da FOBUSP, onde iniciei minha formação ortodôntica, Arnaldo Pinzan, Décio Rodrigues Martins, Guilherme Janson, José Fernando Castanha Henriques, Marcos Roberto de Freitas, e Renato Rodrigues de Almeida, pelos ensinamentos e experiências compartilhados e pela amizade ao longo destes cinco anos. Com certeza foi uma honra conviver neste ambiente acadêmico privilegiado. Obrigado por brindarem-me a oportunidade de ter aprendido com vocês.

Ao Prof. Dr. Arnaldo Pinzan, por proporcionar o desenvolvimento de nosso espírito crítico, pela conversa franca e aberta e os momentos de lazer compartilhados durante a Especialização.

Ao Prof. Dr. Décio Rodrigues Martins, por sua paciência e carinho com que nos ensinou os afazeres da prática docente, mostrando-nos como um exemplo de amor pela docência. Por haver sido meu orientador durante o curso de Especialização.

Ao Prof. Dr. José Fernando Castanha Henriques, por sua dedicação, ensinamentos e convivência que contribuíram de forma relevante à minha formação. Obrigado por todo seu apoio.

Ao Prof. Dr. Marcos Roberto de Freitas, que com sua simpatia e amizade sempre esteve acessível e disposto a ajudar-me não somente nos afazeres acadêmicos, mas também no cotidiano. Guardo em meu coração suas expressões de carinho e prestatividade. 
Ao Prof. Dr. Renato Rodrigues de Almeida, pela grata convivência e pela grande maestria com que compartilhou seus conhecimentos não somente em nossas aulas, mas em situações informais.

Aos colegas e amigos do Curso de Mestrado em Ortodontia da FOB: Caio, Danilo, Douglas, Eduardo, Janine, Leonardo, Luis Filiphe, Luis Fernando, Mayara, Patrícia, Rachelle e Tassiana, pela convivência enriquecedora e o aprendizado proporcionado.

Aos meus amigos Janine, Leonardo e Danilo, especialmente por sua colaboração na coleta de dados e pela ajuda brindada para a elaboração deste trabalho.

Aos meus grandes amigos e companheiros de república Fernando Torres "Ozzy", Rodrigo de Oliveira "Rodrigão", Fábio Sakima "Sakiminha", Wendel Teixeira, Anderson Roberto e Marcelo Zanda, os quais me receberam de maneira mui fraterna e me apoiaram desde minha chegada ao Brasil até o presente momento, ainda não sendo mais morador da república. Com eles compartilhei boa parte de minha estada aqui, desfrutando momentos de muita descontração, alegria e... Muita pizza!

Ao "Ozzi” e ao "Rodrigão" agradeço em especial por sua amizade e prestatividade, paciência e sugestões que muito contribuíram com esta pesquisa.

Aos meus grandes "Irmãos" Dr. Erick Valdivia e o Dr. Miguel Zuñiga, pela amizade e pelo seu apoio e incentivo que sempre me dispensaram, ainda que à distância. Por "torcerem" para que eu alcance meus sonhos. 
Aos amigos Fabrício Valarelli e Karina Freitas, que com muita dedicação compartilharam seus conhecimentos durante a Especialização, contribuindo de maneira significativa em minha formação.

Aos colegas do curso de Doutorado: Carlos Guimarães, Alexandre Nakamura, Kelly Chiqueto, Lívia Freitas, Renata Faria, Fernando Pedrin, Fernando César Torres, Marcus Vinicius Crepaldi, Darwin Vaz de Lima, Sérgio Estelita, Rafael P. Henriques e Paula Oltramari, pela convivência e aprendizado. 

Agradecimentos 



\section{Agradeço também}

À Profa. Dra. Maria Aparecida de Andrade Moreira Machado, presidente da comissão de Pós-graduação por sua dedicação em prol da formação acadêmica dos pós-graduandos da FOB-USP.

Ao Prof. Dr. Luis Fernando Pegoraro, diretor da Faculdade de Odontologia de Bauru - Universidade de São Paulo.

Ao Prof. Dr. José Roberto Lauris pela orientação no tratamento estatístico deste trabalho.

Aos funcionários da disciplina de Ortodontia e da Acopen: Neide, por seu carinho e atenção; Sérgio, pela amizade e longas conversas e que com muita prestatividade e paciência compartilhou de seus conhecimentos de grande valor para meu aprendizado; Daniel (Bonné) por sua amizade e momentos de descontração, apoio técnico e sua prontidão para "quebrar galhos informáticos"; Vera, Cristina, César, Sônia e Luciana pela atenção que sempre me dispensaram.

À "Tia Maria", por sua presença tão agradável e amorosa, por sua dedicação e amizade, por sua alegria e bom humor.

A todos os funcionários da biblioteca: Rita, Vera, Ana Paula, Cybele, Valéria, Ademir, César, pelo profissionalismo e constantes orientações que muito contribuíram para realização desta pesquisa. 
À FAPESP pela concessão da bolsa de estudos durante o último ano do curso de Mestrado que contribuiu significativamente para concretização da presente dissertação.

Aos nossos pacientes participantes da clínica, pela paciência e respeito dispensados durante o período de tratamento.

Enfim, a todos aqueles que de alguma maneira contribuíram para a realização desta pesquisa. 
Sumário 



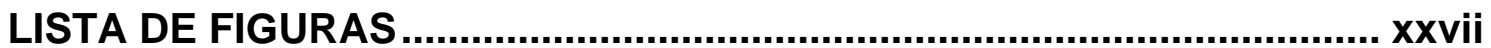

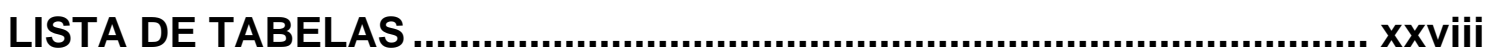

RESUMO

1. INTRODUÇÃO

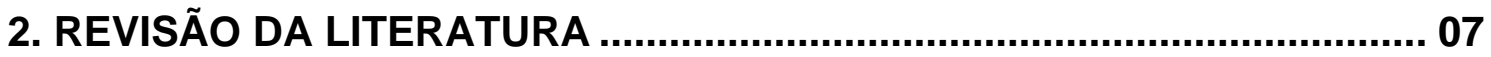

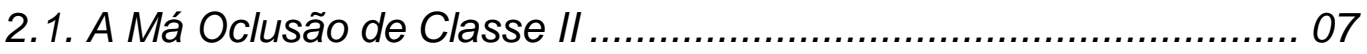

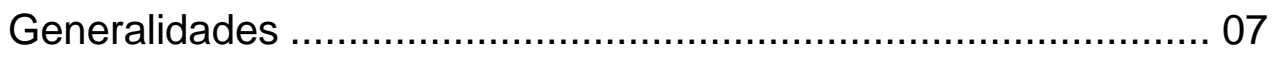

Crescimento Craniofacial e sua relação com o

Desenvolvimento da má oclusão de Classe II ...............................08

Características da Classe II ......................................................10

2.2. Tratamento da Classe II .............................................................. 11

Tratamento da Classe II sem extrações ......................................13

Tratamento com o aparelho extrabucal (AEB)............................13

Tratamento com aparelhos funcionais ......................................14

Tratamento da Classe II com extrações ......................................15

2.3. Estabilidade da Correção da Classe II ....................................... 16

Estabilidade da correção da classe II sem extrações ....................17

Estabilidade da correção da classe II com extração de

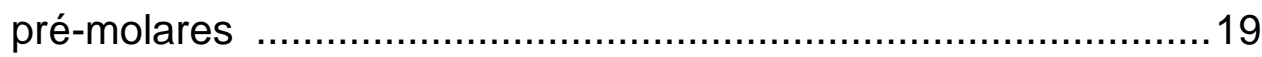

Estabilidade da correção do apinhamento....................................21

Estabilidade da correção do trespasse horizontal ......................... 25

Estabilidade da correção do trespasse vertical.............................. 25

3. PROPOSIÇÃO 


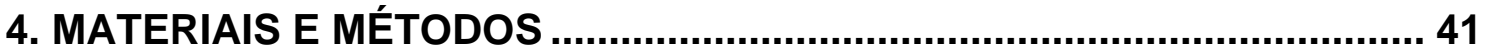

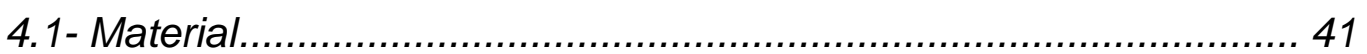

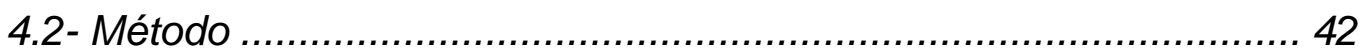

4.2.1- Método cefalométrico …............................................... 42

4.2.2- Avaliação de modelos ..................................................... 53

4.2.3- Análise estatística............................................................. 56

5. RESULTADOS

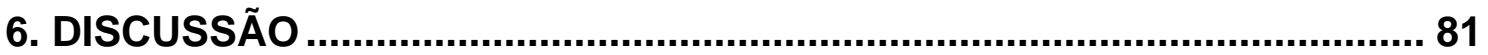

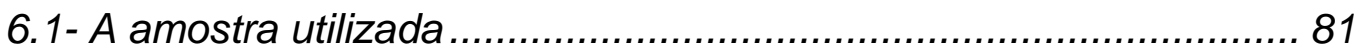

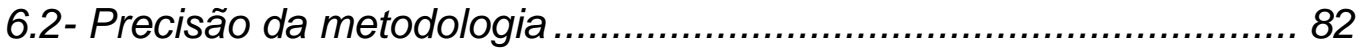

6.2.1- Erro intra-examinador e interexaminador ........................... 82

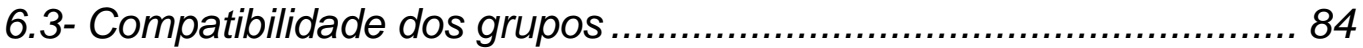

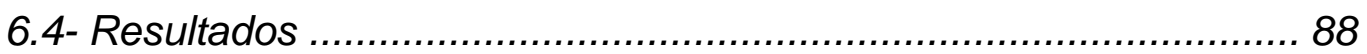

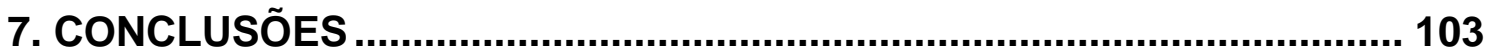

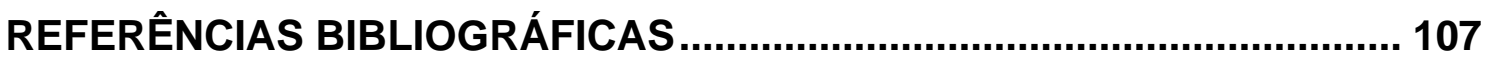

ABSTRACT

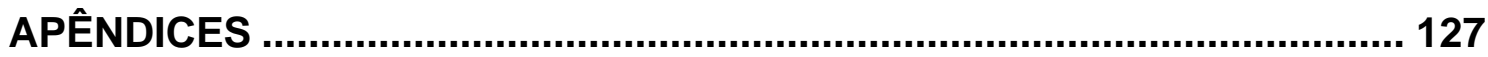




\section{LISTA DE FIGURAS}

Figura 1. Pontos de referência, linhas e planos utilizados. 49

Figura 2. Grandezas cefalométricas esqueléticas 50

Figura 3. Grandezas cefalométricas dentárias 51

Figura 4. Relações dentárias. 52 


\section{LISTA DE TABELAS}

Tabela 1 - Média das idades iniciais e finais dos pacientes nos dois grupos e o tempo médio de observação pós-tratamento

Tabela 2 - Componentes do índice IPT com seus respectivos escores.

Tabela 3 - Resultados do teste $\mathrm{t}$ pareado e da fórmula de Dahlberg, aplicados para a avaliação dos erros intraexaminador.

Tabela 4 - Resultados do teste $t$ pareado e da fórmula de Dahlberg, aplicados para a avaliação dos erros interexaminador

Tabela 5 - Resultados do teste $\mathrm{t}$ independente para avaliar a compatibilidade entre os grupos quanto à idade, severidade da má oclusão e tempo de tratamento

Tabela 6 - Resultados do teste Qui-Quadrado para avaliar a compatibilidade entre os grupos quanto à proporção de gêneros.

Tabela 7 - Resultados do teste Qui-Quadrado para avaliar a compatibilidade entre os grupos quanto à proporção de tipo de má oclusão.

Tabela 8 - Resultados do teste Qui-Quadrado para avaliar a compatibilidade entre os grupos à proporção de pacientes com contenção $3 \times 3$. 
Tabela 9 - Médias, desvios-padrão e resultados do teste t para avaliação das variáveis ao início do tratamento (T1) entre o grupo 1 e o grupo 2 . 65

Tabela 10 - Médias, desvios-padrão e resultados do teste t para avaliação das variáveis ao final do tratamento ortodôntico (T2), entre os grupos 1 e 2 . 66

Tabela 11 - Médias, desvios-padrão e resultados do teste t para avaliação das variáveis entre os grupos 1 e 2 no estágio de observação pós-tratamento (T3).

Tabela 12 - Resultados da comparação das alterações obtidas com o tratamento ortodôntico, entre os grupos 1 e 2 (T2-T1). 68

Tabela 13 - Médias, desvios-padrão e resultados do teste t entre as alterações no período de observação dos grupos 1 e 2 (T3-T2). 69

Tabela 14 - Médias, desvios-padrão e resultados do teste t entre as alterações pós-tratamento (T3-T2) dos grupos 1 e 2 , incluindo somente os pacientes com má oclusão de Classe II, Divisão 1 .

Tabela 15 - Médias, desvios-padrão e resultados do teste t para avaliação das variáveis entre os grupos 1 e 2 no estágio de observação pós-tratamento (T3) excluindo todos os pacientes com contenção $3 \times 3$.

Tabela 16 - Médias, desvios-padrão e resultados do teste t entre as alterações que ocorreram no período póstratamento (T3-T2) dos grupos 1 e GRUPO 2 excluindo todos os pacientes com contenção $3 \times 3$. 
Tabela 17 - Médias, desvios-padrão e resultados do teste t para avaliação das variáveis entre os grupos 1 e 2 no estágio de observação pós-tratamento (T3) incluindo somente pacientes com apinhamento compatível.

Tabela 18 - Médias, desvios-padrão e resultados do teste t entre as alterações que ocorreram no período póstratamento (T3-T2) dos grupos 1 e 2 incluindo somente pacientes com apinhamento compatível.

Tabela 19 - Médias, desvios-padrão e resultados do teste de correlação entre as alterações ocorridas nos grupos 1 e 2 durante o tratamento e no período de observação pós-tratamento.

Tabela 20 - Médias, desvios-padrão e resultado do teste de correlação entre as alterações ocorridas na relação molar durante o tratamento e no período de observação (grupo 1).

Tabela 21 - Médias, desvios-padrão e resultado do teste de correlação entre as alterações ocorridas na relação molar durante o tratamento e no período de observação (grupo 2).

Tabela 22 - Análise da correlação entre a quantidade de recidiva da relação molar e as alterações das variáveis estudadas, no período de observação pós-tratamento (T3-T2), no grupo 1.

Tabela 23 - Análise da correlação entre a quantidade de recidiva da relação molar e as alterações das variáveis estudadas, no período de observação pós-tratamento (T3-T2), no grupo 2. 
Resumo 



\section{RESUMO}

O objetivo deste estudo retrospectivo foi comparar cefalométricamente a estabilidade das alterações decorrentes do tratamento da má oclusão de Classe II completa, realizada com extração de dois e de quatro pré-molares, após um período médio de 9,42 anos pós-tratamento. Para tanto, foram selecionados 60 pacientes que apresentavam inicialmente má oclusão de Classe II completa e que foram tratados com um dos protocolos propostos. A amostra foi divida em dois grupos. O grupo 1 foi composto por 30 pacientes, tratados com extração de dois pré-molares superiores, sendo 17 do gênero masculino e 13 do gênero feminino, com idade inicial média de 12,87 anos que apresentavam má oclusão de Classe II completa. O grupo 2 foi constituído por 30 pacientes, 14 do gênero masculino e 16 do gênero feminino com idade inicial média de 13,64 anos tratados com extrações de dois pré-molares superiores e dois inferiores. Ambos os grupos foram tratados com aparelho fixo, utilizando a mecânica edgewise simplificada. As telerradiografias foram obtidas e avaliadas em três estágios: inicial (T1), final (T2) e pós-tratamento (T3), também se realizou a avaliação das alterações ocorridas nos períodos de tratamento (T2 - T1) e pós-tratamento (T3 - T2). $\mathrm{O}$ teste $t$ dependente e a fórmula de Dalhberg foram utilizados para a avaliação dos erros sistemáticos e casuais respectivamente. A compatibilidade dos grupos quanto à proporção dos gêneros, tipo de má oclusão e proporção de pacientes com contenção $3 \times 3$ foi avaliada pelo teste do qui-quadrado. As variáveis diretamente relacionadas à estabilidade foram comparadas por médio do teste $t$ independente. Os resultados demonstraram que houve uma maior recidiva da protrusão de incisivos superiores e da relação molar no grupo tratado com extrações de quatro pré-molares. O padrão de crescimento vertical, a redução do ângulo SNB e a recidiva da correção da relação maxilomandibular apresentaram uma correlação significante com a recidiva da relação molar. Em ambos os grupos a recidiva do trespasse horizontal, vertical e da relação de caninos mostraram uma correlação estatisticamente significante e diretamente proporcional a sua correção.

Palavras-chave: Extração dentária; Má oclusão de Angle Classe II; Recidiva; Ortodontia corretiva. 

Introdução 



\section{INTRODUÇÃO}

O estabelecimento e manutenção da oclusão normal constituem objetivos importantes do tratamento ortodôntico quer seja preventivo, interceptor ou corretivo. Entretanto, a estabilidade dos resultados em longo prazo é uma das metas de maior dificuldade a ser alcançada por esta terapia $^{112,113,156,178}$.

ANGLE ${ }^{4}$, em 1907, já afirmava que as recidivas ocorrerão se os dentes não permanecerem, ao final do tratamento, em oclusão normal. Os objetivos a serem alcançados para a correção das más oclusões, segundo ele, são: estética facial e dentária, saúde periodontal, funcionamento ideal dos dentes e um resultado estável. Esses princípios do tratamento ortodôntico foram traçados no início do século XX, porém, são validos até os dias atuais.

O tratamento da Classe II de Angle pode ser realizado em diferentes estágios do desenvolvimento, tanto em pacientes com crescimento ativo, como em pacientes com mínimo potencial de crescimento. Dependendo das características inerentes a cada paciente esta má oclusão pode ser tratada com e sem extrações de dentes permanentes.

No caso de optar-se por extração de pré-molares, este protocolo pode incluir apenas extrações de dois pré-molares superiores ${ }^{40,89,131}$ ou de quatro pré-molares $^{5,20,21,23,177}$, sendo que, dois são superiores e dois inferiores.

Historicamente, se considerava que para obter sucesso do tratamento da Classe II, a relação molar teria que permanecer sempre em Classe I no final do tratamento, para assim garantir a estabilidade dos resultados e obter uma oclusão normal sem prejuízo da articulação temporomandibular ${ }^{175,176}$. Anos depois, alguns ortodontistas admitiram a possibilidade de finalizar o tratamento da Classe II com uma relação molar de Classe II, pelo qual a extração de dois pré-molares superiores seria suficiente para reduzir a protrusão maxilar, a eliminação da sobremordida e sobressaliência excessivas, permitindo assim, o estabelecimento da atividade normal da musculatura peribucal ${ }^{67,89,110}$.

Ainda hoje, existem autores que afirmam que se o molar permanecer em uma relação de Classe II no final do tratamento, este é instável, e, portanto, não é bem sucedido ${ }^{119,180}$. 
Entretanto, é conhecido que os fatores que influenciam a estabilidade da correção da má oclusão de Classe II são diversos, e as recidivas que podem ocorrer podem ser tanto esqueléticas como dentárias. Porém, a recidiva esquelética nem sempre é acompanhada de recidiva dentária.

A presente revisão da literatura foi desenvolvida objetivando uma melhor compreensão da estabilidade das alterações decorrentes da correção da má oclusão de Classe II de Angle, quando tratada com diferentes protocolos que incluem ou não a realização de extrações dentárias. 


\section{Revisão da Literatura}





\section{2-REVISÃO DA LITERATURA}

Objetivando uma melhor compreensão a revisão da literatura foi desenvolvida abordando os seguintes tópicos:

\subsection{A má oclusão de Classe II}

2.2 Tratamento da Classe II

2.3 Estabilidade da correção da Classe II

\subsection{A MÁ OCLUSÃO DE CLASSE II}

\section{Generalidades}

$\mathrm{ANGLE}^{3}$, em 1899, baseando-se na relação dos primeiros molares permanentes apresentou uma classificação das más oclusões, dividindo-as em Classe I, II ou III. Antes dessa data utilizava-se o termo "irregulatities of the teeth" para descrever as alterações na oclusão. ANGLE baseava sua classificação na posição do primeiro molar superior, que ele considerava imutável em relação ao inferior, a partir dali determinou os três tipos de más oclusões no sentido sagital. Apesar de ser muito prática, esta classificação não levava em consideração as alterações nos sentidos vertical e transversal, e nem as relacionava com as estruturas esqueléticas ou tecidos moles adjacentes. Esta classificação, embora seja dentária é bem aceita e amplamente utilizada na literatura até os dias atuais.

Nessa ocasião a Classe II foi definida como uma relação ânteroposterior deficiente dos arcos dentários, caracterizada por uma relação distal do primeiro molar inferior em relação ao primeiro molar superior, propiciando uma desarmonia acentuada na região dos incisivos e nas linhas faciais ${ }^{3}$. Segundo o autor, nesta má oclusão, o arco superior apresenta-se atrésico e os incisivos superiores protuídos, acompanhados de função anormal dos lábios e alguma forma de obstrução nasal e respiração bucal. Em 1907, ANGLE ${ }^{4}$ simplificou a definição da Classe II, esta seria definida como uma relação distal do arco superior em relação distal ao superior, apresentando incisivos superiores em protrusão e inicialmente associados à respiração bucal. O autor atribuía a etiologia dessa má-oclusão somente para a mandíbula. Desta forma 
a Classe II pode ainda ser individualizada em Classe II, divisão 1 que possui como característica principal o trespasse horizontal acentuado, evidenciando na maioria dos casos, um perfil facial acentuadamente convexo, e a Classe II, divisão 2 geralmente acompanhada de um trespasse vertical acentuado.

\section{Crescimento Craniofacial e sua relação com o Desenvolvimento da má oclusão de Classe II}

Muitas das alterações dentárias e esqueléticas descritas como resultado de determinados tratamentos ortopédicos ou ortodônticos da Classe II derivam do crescimento e desenvolvimento craniofacial normal. $\mathrm{O}$ atual conhecimento acerca das dimensões faciais e do crescimento e desenvolvimento da maxila e mandíbula nos casos de Classe II, ainda apresentam controvérsias na literatura, enquanto alguns autores relatam que alguns tipos de tratamento provocam alterações significativas nos componentes esqueléticos $^{58,151,184,185,187,191}$, e nas dimensões faciais ${ }^{187,188}$ outros estudos mostram que os efeitos são mínimos ou restritos ao complexo dentoalveolar ${ }^{15,16}$.

Os estudos longitudinais sobre crescimento obtiveram um grande impulso apartir de 1931, com o advento do cefalostato por BROADBENT ${ }^{30}$, nos Estados Unidos e HOFRATH ${ }^{66}$ na Alemanha, permitindo a obtenção de telerradiografias padronizadas e tornando os investigadores capacitados para conduzi-los com mais confiabilidade. Os primeiros trabalhos cefalométricos foram publicados por BRODIE et al. ${ }^{31}$ em 1938, quem demonstrou que as principais direções do crescimento maxilar e mandibular são para acima e para atrás. A partir desse estudo surgiram muitos outros trabalhos clássicos sobre crescimento $^{25,27,35,36,54}$.

As características morfológicas da má oclusão de Classe II começam a evidenciar num período bastante precoce do desenvolvimento ${ }^{7,40,101}$, entretanto o padrão das alterações decorrentes do crescimento apresentam semelhantes

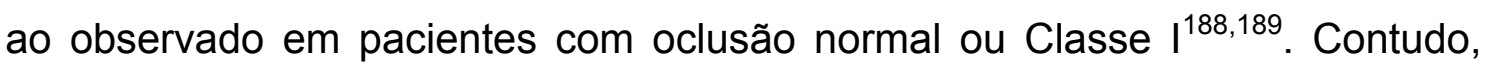
nos pacientes com Classe II, Divisão 1 pode ser observado uma taxa menor de crescimento mandibular dos 6 aos 10 anos, Porém, a partir dos 10 anos de idade a velocidade de crescimento para a oclusão normal e má oclusão de 
Classe II, são semelhantes ${ }^{25,35}$. Por outro lado, o posicionamento da maxila, neste período permanece inalterado uma vez que o movimento para anterior do ponto Násio e do ponto $A$ são equivalentes ${ }^{18}$.

Os resultados do estudo de CARTER $^{38}$ em 1987, mostraram que em pacientes com Classe II, Divisão 1 o ângulo SNB aumenta com o crescimento, porém apresentou-se dismorfismo entre os gêneros, sendo que no gênero masculino o aumento do comprimento mandibular foi de três vezes maior em relação ao feminino. Entretanto essa diferença pode estar relacionada ao fato que a época do surto pubescente se apresenta mas precocemente no gênero feminino, dificultando a comparação entre os gêneros num mesmo período de tempo.

Embora que com o crescimento se observe um aumento nos ângulos ANB e SNB a correção da relação dentária de Classe II não ocorre. O posicionamento anterior do ponto $B$ e do pogônio contribuem para a melhora da convexidade facial, porém sem alterar a relação dentária ${ }^{36}$. Uma possível explicação para este fato, é que durante o crescimento a mandíbula se movimenta mais para anterior do que a maxila, porém a intercuspidação conduz o arco dentário superior em direção anterior na mesma sincronia do arco dentário inferior, perenizando-se desta forma a discrepância ânteroposterior ou inclusive intensificando-a ao longo do tempo ${ }^{18}$.

Outra característica observada nos pacientes de Classe II em crescimento é a diminuição do ângulo SNB decorrente da rotação mandibular em sentido horário, promovendo retrusão esquelética da mandíbula ${ }^{7}$. O padrão de crescimento nestes pacientes denota um aumento da altura facial ânteroinferior, e um vetor de crescimento vertical mais pronunciado ${ }^{35,95,161}$.

Quanto à influência do crescimento no posicionamento dentário, alguns estudos verificaram um aumento da inclinação para vestibular dos incisivos superiores e inferiores, esta aumento na inclinação corresponde à diferença na inclinação dos incisivos decíduos aos incisivos permanentes. Segundo KERR ${ }^{97}$, em 1979, estas alterações são bastante variáveis e se encontram na dependência de fatores como comprimento e tônus dos tecidos moles e presença de hábitos. Além disso, os incisivos inferiores permanentes se tornam mais protruídos como resposta a um mecanismo compensatório da Classe II, 
reduzindo o trespasse horizontal e vertical e compensando a discrepância ântero-posterior entre as bases ${ }^{95}$.

A maioria dos autores coincidem em afirmar que como resultado do crescimento e desenvolvimento normal os molares superiores e inferiores sofrem uma extrusão e mesialização promovendo uma diminuição do comprimento do $\operatorname{arco}^{124}$. Os molares superiores apresentam essa movimentação para mesial como resultado do fechamento do "leeway space" e do crescimento da tuberosidade maxilar para permitir a irrupção do segundo molar. Além disso, durante o crescimento da face os molares permanentes superiores acompanham o deslocamento do maxilar no qual estão inseridos, exibindo, portanto, uma trajetória para frente e para baixo. Os molares inferiores apresentam a mesma tendência de movimento para mesial mantendo desta forma a relação oclusal estabelecida ${ }^{18}$. Porém, existem resultados, que divergem com estas afirmações, que mostram uma melhora na relação molar e de incisivos assim como do trespasse horizontal e vertical ${ }^{54,95}$.

\section{Características da Classe II}

A Classe II pode ser dentoalveolar, esquelética ou uma combinação de ambas. Com relação à etiologia da má oclusão de Classe II ela é multifatorial, ou seja, diversos fatores que interagindo e operando dentro de um potencial de crescimento inerente a cada indivíduo, promovem essa má oclusão. Dentre esses fatores estão: o padrão de crescimento maxilar, mandibular e o desenvolvimento dentoalveolar ${ }^{48}$. Por tanto, a Classe II não constitui uma alteração morfológica homogênea causada por alguma entidade clínica específica na base craniana ou nos maxilares. Ela é o resultado da somatória de diversas alterações clínicas com variados graus de severidade ${ }^{95}$.

Atualmente sabe-se que a má oclusão de Classe II tem um envolvimento das bases ósseas no sentido sagital, vertical e transversal; caracterizada morfologicamente, por uma discrepância maxilomandibular, mau relacionamento do arco superior e inferior, originada esqueléticamente a partir de uma protrusão maxilar, de uma retrusão mandibular ou pela combinação de ambas características. 
Avaliando as alterações Classe II, ainda que não exista um comum acordo na literatura, a grande maioria de autores concorda que esta apresenta prognatismo maxilar ${ }^{155,157,181}$ isolada ou em combinação com retrognatismo mandibular, retrusão dos dentes inferiores e protrusão dentária superior ${ }^{155}$. Sendo o retrognatismo mandibular considerado como um dos maiores responsáveis por esta má oclusão ${ }^{7,48}$.

Pode também existir um excesso de desenvolvimento vertical da maxila $^{7,77,95,161}$, especialmente da altura facial anterior ${ }^{35}$, ou uma deficiência transversal desta base óssea, denotando, portanto, a presença de alterações nos três planos: horizontal, vertical e transversal. Esta má oclusão pode também estar acompanhada de uma função anormal dos lábios e de alguma forma de obstrução nasal e respiração bucal ${ }^{4}$.

Entretanto, a grande parte das pesquisas discorda quanto ao posicionamento da maxila em relação à base do crânio. Alguns autores relatam uma protrusão esquelética ${ }^{155,157,181}$, retrusão esquelética ou um bom posicionamento da mesma ${ }^{149}$. A deficiência mandibular ${ }^{22,38,48,54}$, é tanto em tamanho ${ }^{95,143}$ como em posição ${ }^{147,157},{ }^{38,95}$, em relação a base do crânio. Essa variedade de achados pode ser explicada, pelas diferentes medidas cefalométricas utilizadas, assim como pelas diferentes populações e padrões com que se compara a amostra de Classe II.

\subsection{TRATAMENTO DA CLASSE II}

A desarmonia ântero-posterior das bases ósseas presentes na má oclusão de Classe II, podem se apresentar precocemente ${ }^{7}$, prejudicando algumas funções essenciais, como a mastigação, deglutição e a fonação. Além disso, na maioria dos casos influencia desfavoravelmente na estética e na auto-estima dos pacientes, atraindo o interesse dos pesquisadores no seu estudo e nas tentativas de elaborar formas mais adequadas de tratamento.

A prevalência da Classe II se apresenta em aproximadamente $42 \%$ da população brasileira ${ }^{164}$, o que explica o grande porcentual de pacientes com está má oclusão que procuram pelo tratamento ortodôntico ${ }^{60}$. Ainda que a má oclusão de Classe II seja um dos assuntos mais estudados na literatura, o tratamento desta má oclusão continua sendo um assunto controverso, em 
função dos diferentes tipos de aparelhos disponíveis e da época ideal para o início do tratamento, destacando-se o tratamento em uma e em duas fases.

As opções de tratamento da má oclusão de Classe II incluem: 1modificação do crescimento com força extrabucal ${ }^{47,108,171}$, aparelhos removíveis funcionais ${ }^{2,58,68}$, ou propulsores mandibulares fixos ${ }^{133,187,188} ; 2$-tratamento sem extrações que demandem alterações dentárias compensatórias ${ }^{4,6,92,187,188}$; 3Tratamento de camuflagem com extração de pré-molares ${ }^{40,67,72,89,175,176}$; 4cirurgia ortognática após completar o crescimento ${ }^{160}$.

Assim, a escolha do protocolo de tratamento da Classe II, depende das características associadas ao problema, como a idade do paciente, severidade da discrepância ântero-posterior, discrepância dente-osso ${ }^{21,32,117}$, do comprometimento estético e oclusal ${ }^{159}$, além da colaboração do paciente.

A fase em que o tratamento é iniciado é de extrema importância. Alguns autores propõem $\mathrm{o}$ início do tratamento precocemente com aparelhos ortopédicos funcionais ${ }^{58,187}$, visando corrigir a discrepância maxilomandibular nos sentidos ântero-posterior e transversal, o que contribui na melhora da relação entre as bases apicais e na harmonia do perfil facial. Há um consenso na literatura no que diz respeito à efetividade destes aparelhos na correção da má oclusão de Classe II em pacientes jovens ${ }^{127,146,172,179}$.

A principal diferença no tratamento ortodôntico entre um paciente adolescente e um adulto é a presença de crescimento. No adolescente a correção da discrepância ântero-posterior ocorre pela somatória de movimentação dentária e o crescimento mandibular ${ }^{180}$. Já, num paciente adulto, a correção da má oclusão de Classe II conta exclusivamente com a movimentação dentária, devido à ausência de manifestação de crescimento mandibular exigindo maior esforço mecânico para a manutenção ou distalização dos molares superiores ${ }^{6,28}$.

O plano de tratamento, pode incluir a realização de extrações dentárias com o intuito principal de corrigir a má oclusão de Classe $\|^{67,86}$. Geralmente os dentes escolhidos para serem extraídos são os primeiros pré-molares ${ }^{177}$. Sendo que, os protocolos de extração podem consistir de somente dois prémolares superiores ${ }^{40,67,88,89,110}$, ou de dois pré-molares superiores e dois inferiores $^{102,168,170,177}$. 


\section{Tratamento da Classe II sem extrações}

O Tratamento da Classe II sem extrações pode ser realizado mediante a combinação do uso de aparelhos ortopédicos numa primeira fase, seguida da utilização de aparelhos ortodônticos fixos. A primeira fase do tratamento está orientada a estabelecer uma relação normal entre as bases ósseas, eliminar as alterações neuromusculares, e guiar o desenvolvimento da oclusão ${ }^{58,59}$. A segunda fase está destinada a realizar movimentos dentários individuais para obter uma oclusão e alinhamento ideais ${ }^{9,11}$.

\section{Tratamento com o aparelho extrabucal (AEB)}

O uso do aparelho extrabucal foi introduzido por CELLIER em 1802, mas foram KINGSLEY ${ }^{99}$, em 1875, e FARRAR ${ }^{66}$, em 1886, quem começaram a utilizá-lo com finalidade ortodôntica. Posteriormente, foi demonstrada sua efetividade nas alterações ortopédicas na maxila e na distalização dos molares superiores, chegando a ser bastante utilizado principalmente como reforço de ancoragem na correção da Classe II.

Existe uma grande variabilidade das respostas ao tratamento precoce da Classe II com o aparelho extrabucal, porém há consenso na literatura que o uso deste aparelho promove uma restrição do deslocamento anterior da maxila ${ }^{37,46,74,106}$ e, restrição do deslocamento mesial normal dos primeiros molares superiores $37,46,74,91,106,179,187$. A melhora no relacionamento sagital maxilomandibular de Classe II ao final do tratamento é o resultado da soma dos efeitos produzidos pelo aparelho extrabucal com o crescimento normal da mandíbula.

Os aparelhos extrabucais são classificados segundo a direção da força de tração, eles podem ser de tração alta ou parietal, media ou occipital e tração baixa ou cervical. Alguns autores ${ }^{37,106,179,187}$ relatam que o uso do aparelho extrabucal com força cervical promove a extrusão dos molares superiores e deslocamento para baixo da porção anterior do plano palatino, provocando assim uma rotação horária da mandíbula. Entretanto, os efeitos verticais desfavoráveis do AEB cervical, principalmente em pacientes que apresentam padrão vertical, podem ser atenuados quando se utiliza o AEB de tração média 
ou alta, o que possibilita um maior controle vertical da maxila, em função do direcionamento póstero-superior do vetor da força extrabucal, aliado a sua maior proximidade ao centro de resistência ${ }^{68}$.

O aparelho extrabucal pode ser utilizado também em combinação com os aparelhos funcionais, potencializando seus efeitos e proporcionando melhores resultados ${ }^{68,91,106}$.

\section{Tratamento com aparelhos funcionais}

A grande variedade dos aparelhos ortopédicos se desenvolveu originalmente para o tratamento da má oclusão de Classe II por causa de sua grande prevalência e devido aos problemas estéticos e funcionais que ocasiona.

O primeiro autor a posicionar a mandíbula anteriormente para corrigir a Classe II foi KINGSLEY ${ }^{99}$, em 1879. O aparelho que ele utilizava consistia numa placa adaptada ao arco superior, com um plano inclinado projetado inferiormente por lingual dos incisivos, o qual mantinha a mandíbula numa posição mais protruída. A partir dessa data novos aparelhos removíveis ${ }^{2,58,69,153}$ e fixos ${ }^{80,133}$ foram concebidos para promover o avanço mandibular.

A utilização dos aparelhos ortopédicos, durante a correção da má oclusão de Classe II, promove efeitos dentoalveolares e esqueléticos, entre eles: 1- redirecionamento ou restrição do crescimento horizontal da maxila; 2rotação ântero-inferior da maxila; 3- alterações ântero-posteriores dos arcos dentários; 4- rotação mandibular; 5- remodelação do côndilo mandibular; 6remodelação da fossa mandibular, 7- inclinações dos incisivos; 8- alteração da erupção dentária nos segmentos posteriores ${ }^{8,11,37,45,53,74,83,135,145,184,185,190,191}$

No entanto, As modificações no complexo côndilo-fossa, favoráveis a correção da relação maxilomandibular são efetivas enquanto o aparelho esta sendo utilizado $8,135,145,184$. Após a remoção tanto as alterações em quantidade e quanto em velocidade retornam aos padrões prévios observados ao início do tratamento.

Embora as características morfológicas da Classe II, sejam evidentes numa idade bastante precoce ${ }^{7,101}$, existe grande controvérsia na literatura sobre a melhor época de tratamento ${ }^{144}$. Autores como WEST ${ }^{186}$, BISHARA $^{24}$ et 
al. sugerem que em pacientes que apresentam características oclusais de Classe II, na dentição decídua, o tratamento deveria começar tão logo que o clínico e o paciente estiverem dispostos a iniciar o tratamento.

WIESLANDER ${ }^{187}$, em 1984, propôs realizar a correção da distooclusão no início da dentadura mista utilizando aparelho extrabucal cervical associado ao aparelho de Herbst. FRÄNKEL e FRÄNKEL ${ }^{59}$, em 1989, recomendaram o tratamento da má oclusão de Classe II quando está associada a desequilíbrios esqueléticos e neuromusculares, precocemente na dentadura mista utilizando reguladores de função.

Segundo PFEIFFER ${ }^{141}$, o tratamento ortodôntico deve-se iniciar antes do surto do crescimento pubescente e deve terminar antes ou durante esse mesmo surto de crescimento, desde que todos os dentes permanentes já estejam presentes. Este fato contribui para uma melhor estabilidade do tratamento em longo prazo em razão da capacidade de adaptação dos tecidos moles.

Entre os benefícios que proporcionaria o tratamento ortopédico na correção da Classe II, são relatados na literatura: Coordenação do crescimento das bases ósseas ${ }^{187}$, equilíbrio precoce da musculatura peribucal ${ }^{141}$, redução da diminuição do porcentual de pacientes que necessitam de correção ortocirúrgica, redução significativa das extrações para a correção do trespasse horizontal, menor quantidade de movimentação dentaria na fase corretiva e melhora da auto-estima do paciente ${ }^{11,68}$.

\section{Tratamento da Classe II com extrações}

As extrações dentárias são amplamente utilizadas em ortodontia. Existem registros de sua utilização com a finalidade estética de corrigir apinhamentos dos dentes anteriores desde o século XVIII.

Entre as principais indicações de extração dentária na má oclusão de Classe II estão: 1- a biprotrusão, em especial aquelas que possuem protrusão do lábio superior, com os dentes inferiores e a mandíbula bem posicionados $^{40,175,180}$, 2- presença de apinhamento ${ }^{6,67,180}$; 3- correção da relação molar ${ }^{177,180} ; 4$ - crescimento vertical $^{192}$. 
Quando a decisão tende para a extração, há ainda que se decidir qual dente seria preferencial, de acordo com benefícios mecânicos que poderiam promover. A decisão depende dos seguintes fatores: 1. A gravidade da má oclusão; 2. O crescimento dos maxilares; 3 . Idade do paciente ${ }^{170}$. A decisão poderá então contemplar a extração de dois pré-molares superiores ou de quatro pré-molares, sendo que dois são no arco superior e dois no arco inferior.

Obviamente a presença de apinhamento considerável é um dos principais critérios para a decisão do protocolo de extração de pré-molares. Porém, há outros parâmetros que também devem ser levados em consideração: protrusão labial, inclinação dos incisivos, tipo de mecânica que vai ser utilizada, potencial de crescimento do paciente e a severidade da discrepância ântero-posterior e vertical ${ }^{20}$.

A realização da extração de somente dois pré-molares superiores está geralmente indicada quando não há apinhamento ou discrepância cefalométrica no arco dentário inferior ${ }^{21,154}$. Já, a utilização da mecânica de extrações de quatro pré-molares na Classe II está indicada quando o arco dentário apresenta apinhamento dentário, discrepância cefalométrica ou uma combinação destas características e quando o paciente ainda se encontra na fase de crescimento ${ }^{6,21,177}$.

\subsection{ESTABILIDADE DA CORREÇÃO DA CLASSE II}

Os fatores que influenciam a estabilidade da correção da má oclusão de Classe II são diversos, e as recidivas que podem ocorrer podem ser tanto esqueléticas $^{191}$ como dentárias $^{49}$. A recidiva dentária pode ser atribuída a uma tensão residual no ligamento periodontal, falta de adaptação funcional à nova posição, à tendência de crescimento e interferências funcionais ${ }^{158}$. A falta de selamento labial e a postura incorreta da língua apresentam-se também associadas à recidiva dentária. Além disso, a utilização de elásticos intermaxilares, pode gerar mordida dupla, considerada também como causa de recidiva $^{136,158}$. Esse fato demonstraria uma atividade muscular desequilibrada, demonstrando o insucesso do tratamento. 


\section{Estabilidade da correção da Classe II sem extrações}

O primeiro estudo cefalométrico para avaliar os resultados do tratamento ortodôntico foi realizado em 1938 por BRODIE et $\mathrm{al}^{31}$. Os autores observaram que a utilização de elásticos intermaxilares provocava alterações no plano oclusal, mas este exibia uma tendência a retornar à sua posição original inicial.

A correção da Classe II ocorre principalmente por alterações dentoalveolares, sendo a rotação horária da mandíbula um dos fatores desfavoráveis mais citados para que ocorra a recidiva do trespasse horizontal $^{129,188}$.

Numa mostra de 20 pacientes, LITOWITZ ${ }^{109}$, em 1948, estudou o movimento dos incisivos inferiores e de molares superiores e inferiores durante e após o tratamento de más oclusões de Classe I e II, com a mecânica de edgewise. Os resultados mostraram que há uma rotação horária da mandíbula provocada pela distalização e a extrusão dos molares superiores durante o tratamento. Além, disso existe uma tendência forte à recidiva da relação molar inicial, sendo que esses dentes tendem a retornar em direção a sua posição original. Desse modo, os molares readquirem suas inclinações axiais, ocorre uma rotação anti-horária da mandíbula e um aumento do trespasse vertical. Os incisivos inferiores também mostraram a mesma tendência à recidiva em longo prazo.

Segundo os estudos em longo prazo de SADOWSKI; SAKOLS ${ }^{156}, 1982$, a recidiva das relações dentárias podem ocorrer em $72 \%$ dos casos tratados ortodonticamente. Segundo os autores, o aumento moderado do trespasse horizontal e vertical foram os responsáveis, na maioria dos casos, por esta recidiva. Além disso, as alterações oclusais pós-tratamento ocorrem principalmente logo após o término do tratamento, observando-se até $90 \%$ destas alterações nos seis primeiros meses pós-tratamento ${ }^{137}$. Concordando com os resultados reportados previamente por BRESONIS; GREWE ${ }^{29}$, em 1974. Os autores deste estudo constataram que os casos de Classe II, divisão 1 , demonstraram a maior recidiva do trespasse vertical e horizontal em relação aos outros tipos de má oclusão estudados. Entretanto, essa recidiva, em média, não excedeu $2 \mathrm{~mm}$ em nenhuma das duas variáveis, considerando-se dentro dos limites clinicamente aceitáveis. 
Alguns trabalhos também demonstraram que existe uma correlação positiva significante entre a recidiva do trespasse vertical e horizontal com a quantidade de correção durante o tratamento, ou seja, quanto maior a redução do trespasse horizontal ou vertical durante o tratamento maior seria a tendência à recidiva $29,89,156,178$. De acordo com estes resultados há necessidade de sobrecorreção do trespasse horizontal e do trespasse vertical ao final do tratamento.

Adicionalmente, NASHED; REYNOLDS ${ }^{126}$, em 1989, constataram também que os incisivos inferiores, que foram vestibularizados durante 0 tratamento, exibiram uma recidiva em direção a sua inclinação pré-tratamento. Entretanto, outros autores ${ }^{125}$, sugerem que nos casos de Classe II, divisão 1, a vestibularização dos incisivos inferiores pode permanecer estável em alguns casos em que os incisivos inferiores tenham sido lingualizados por um hábito de suç̧ão de polegar, ou interposição de lábio inferior.

Quanto á relação molar, a tendência à recidiva, é atribuída ás adaptações dentoalveolares, principalmente em decorrência de uma mesialização excessiva dos molares superiores após o tratamento ${ }^{57}$. Assim também, PANCHERZ; ANEHUS-PANCHERZ ${ }^{134}$ em 1980, verificaram que a recidiva da relação molar, apresentava-se associada a uma intercuspidação instável ao final do tratamento. Evidenciou-se também, uma rápida irrupção dos molares superiores, após o tratamento enquanto que a irrupção dos molares inferiores apresentou-se menos pronunciada ${ }^{56}$. Segundo outros autores, apesar de apresentar uma tendência à recidiva, a relação molar de Classe II, se mantém estável após a correção, não se relacionando ao fato do tratamento ter sido realizado com ou sem extrações ${ }^{109,178}$.

Os aparelhos ortopédicos são capazes de influenciar a direção de crescimento do complexo facial, porém, o padrão de crescimento retoma sua direção de crescimento natural após o tratamento. A maxila demonstra um deslocamento em direção oposta à aplicação da força, ou seja, para anterior e para baixo ${ }^{56,64}$. Tem sido demonstrado que a rotação horária do complexo maxilar é instável e tende à recidiva quando a força extrabucal é interrompida. Portanto, quanto menor a rotação horária do complexo maxilar, mais estável será a retração maxilar após o tratamento ${ }^{11} \mathrm{~A}$ relação maxilomandibular também apresenta alterações, verificada pelo aumento do ângulo ANB e NAP 
na fase pós-tratamento. Esse aumento se deve, à redução do crescimento mandibular, enquanto que a maxila retoma o seu desenvolvimento normal após a remoção dos aparelhos ${ }^{62}$.

Após o tratamento com aparelho extrabucal cervical, pode ocorrer uma suave rotação horária da mandíbula, com maior aumento do ângulo do plano mandibular ${ }^{187}$. Porém, a rotação mandibular associada a esta terapia é temporária na maioria dos pacientes que se encontram em fase de crescimento $^{55}$.

Assim como o tratamento ortopédico com aparelhos funcionais, o tratamento ortodôntico com aparelhos fixos apresenta efeitos predominantemente dentoalveolares ${ }^{91,136,188,190}$ que levam à correção da má oclusão de Classe II. Entretanto, a interrupção de um desenvolvimento dentário desfavorável juntamente com uma melhora do padrão muscular e da relação oclusal podem influenciar o padrão de crescimento da maxila e mandíbula, com uma melhora continua na fase pós-tratamento ${ }^{187}$. Portanto, pode-se esperar a estabilidade das alterações ortopédicas, principalmente relacionados ao crescimento e posicionamento da mandíbula, quando existe um equilíbrio funcional e estrutural no novo padrão homeostático estabelecido ${ }^{11,45}$.

Compulsada a literatura, verifica-se que maioria dos efeitos dos aparelhos ortopédicos são temporários ${ }^{7,45,57,91,106,129,188,190,191}$, fato que não compromete o sucesso do tratamento a longo prazo, uma vez que os ortodontistas não corrigem dimensões e sim o relacionamento das estruturas dentárias e esqueléticas. Além disso, a correção da Classe II ocorre por diversas alterações de natureza dentária e esquelética que se somam para alcançar uma oclusão equilibrada e uma face harmoniosa

\section{Estabilidade da correção da Classe II com extração de pré-molares}

O tratamento da Classe II com extrações é realizado mais freqüentemente no final da dentadura mista, ou numa faixa etária mais avançada, na dentição permanente completa, quando o potencial de crescimento do paciente é mínimo ou esta finalizando. Portanto, os resultados obtidos são dependentes exclusivamente de modificações compensatórias dentoalveolares e, a recidiva das características iniciais da má oclusão é 
principalmente dentária, pois nenhuma ou poucas alterações esqueléticas são obtidas durante o tratamento. $\mathrm{O}$ crescimento desfavorável como fator de risco para a recidiva é limitado ou está ausente nestes pacientes.

Sendo que são poucas as pesquisas realizadas sobre o tratamento com extração de dois pré-molares ${ }^{9,34,89,115}$ não há relatos na literatura no que se refere à estabilidade da correção discrepância ântero-posterior com este protocolo de extrações em relação ao tratamento com extrações de quatro prémolares. Uma vez que a principal diferença entre os dois protocolos localiza-se na realização de duas extrações inferiores a menos, nos casos tratados com extrações de dois pré-molares superiores, parece lógico esperar que estes casos apresentem uma menor movimentação dentária com o tratamento, diminuindo o risco de recidiva, em relação ao tratamento realizado com quatro extrações $^{89,126}$.

Comparando o protocolo de extrações de dois pré-molares superiores com o protocolo de extrações de dois pré-molares superiores e dois prémolares inferiores, a correção da má oclusão de Classe II completa com duas extrações na maxila permite obter uma maior proporção de sucesso das relações oclusais. ${ }^{28,88}$.

Em casos de Classe II divisão 1, sem apinhamento inferior a extração de quatro pré-molares pode não ser a melhor escolha por exigir maior controle mecânico de ancoragem, um maior controle do trespasse vertical ${ }^{67}$ além de muita cooperação dos pacientes. É nestes casos que a extração de somente dois pré-molares superiores ${ }^{28,67,89,115}$, torna-se uma opção para a redução do trespasse horizontal excessiva e correção da relação dos caninos, porém, finalizando em relação Classe II de molares. A estabilidade da correção ânteroposterior pode ser favorecida nestes casos, pois a relação molar de Classe II inicial não será modificada durante o tratamento.

Tem que ser considerado também que quanto mais avançada é a idade do paciente, a correção da relação ântero-posterior dos arcos dentários tornase mais difícil, principalmente quando se planeja corrigir a relação molar, dificultando enormemente a mecânica e aumentando o tempo de tratamento ${ }^{6,89,117}$. Porém, sempre que mais de um protocolo de tratamento pode ser utilizado na correção de um mesmo tipo de má oclusão, a decisão 
deverá recair sobre o protocolo que se mostra mais eficiente, e que propicia resultados mais estáveis a longo prazo.

\section{Estabilidade da correção do apinhamento}

Uma questão envolvendo o tratamento e a estabilidade da Classe II que tradicionalmente sustenta muito debate são as extrações dentárias inferiores. É uma visão comum aceitar que o tratamento sem extrações dentárias, em que a expansão do arco dentário inferior e a vestibularização dos incisivos para corrigir o apinhamento ou uma curva de Spee acentuada pode comprometer os resultados do tratamento em longo prazo ${ }^{177}$. Dessa forma, a concepção da maior dificuldade em manterem-se os resultados obtidos leva os profissionais a procurarem diferentes abordagens terapêuticas. Por outro lado, as extrações de pré-molares no arco inferior para obter a retração e verticalização dos incisivos inferiores sobre o osso basal tornam mais difícil a correção do trespasse horizontal, trespasse vertical e discrepância ântero-posterior na má oclusão de Classe $\|^{28,89}$. Entretanto, o segmento ântero-inferior é descrito como o segmento mais provável de exibir recidiva após o tratamento ortodôntico ativo e a remoção da contenção ${ }^{60,61,177}$.

Numa perspectiva histórica, era uma crença comum que as extrações dos pré-molares durante o tratamento ortodôntico garantiam a estabilidade do alinhamento dos incisivos. Após examinar $70 \%$ de seus pacientes após 6.5 anos de prática ortodôntica, durante o qual seguiu a filosofia de ANGLE, TWEED $^{177}$, em 1944, verificou que somente vinte por cento dos seus pacientes alcançaram os seus objetivos do tratamento ortodôntico: estabilidade dos resultados obtidos, saúde dos tecidos periodontais, eficiência mastigatória e estética facial. Após essa experiência, TWEED começou a tratar casos similares de biprotrusões dentárias com e sem extrações de pré-molares, e verificou que, quando os incisivos inferiores se encontravam corretamente verticalizados no osso basal (somente obtido por meio de extrações) os casos não apresentavam recidiva marcante após um ano da remoção das contenções.

Em 1976, RIEDEL ${ }^{150}$ sugeriu que a remoção dos pré-molares inferiores "nem sempre, e talvez não comumente se encontre relacionada com a 
minimização do apinhamento dos incisivos inferiores em longo prazo". Foi com essa argumentação que se promoveu uma mudança em direção à abordagem não-extracionista do tratamento ortodôntico, que antes se baseava no dogma de que as extrações de pré-molares inferiores ofereciam estabilidade do alinhamento dos incisivos.

LITTLE; WALLEN; RIEDEL ${ }^{113}$, em 1981, avaliaram a recidiva do apinhamento ântero-inferior em 65 pacientes Classes I e II tratados com extrações dos quatro primeiros pré-molares após 10 anos da remoção da contenção. Eles reportaram uma proporção de sucesso (isto é, um índice de irregularidade abaixo de $3.5 \mathrm{~mm}$ ) em menos de $30 \%$ dos pacientes, sendo que $20 \%$ apresentaram apinhamento marcante. Pôde-se concluir que nenhum parâmetro singular, como gênero, idade, classificação de Angle, tempo de uso da contenção, ou valores derivados da análise de modelo, foram úteis para predizer a estabilidade futura. Da mesma forma, as combinações desses parâmetros também provaram ser de pouco valor na predição dos resultados em longo prazo. A estenderam o período de observação de 10 para 20 anos após a remoção da contenção inferior ${ }^{112}$, a proporção de sucesso deteriorou para $10 \%$ da amostra.

Uma complementação do trabalho de $1981^{113}$ objetivou esclarecer se existe alguma relação entre valores cefalométricos ou de modelos e a recidiva do apinhamento ântero-inferior. SHIELDS; LITTLE; CHAPKO ${ }^{163}$, em 1985, concluíram que nenhum parâmetro cefalométrico específico ou a combinação dos valores cefalométricos pré ou pós-tratamento foram capazes de predizer a irregularidade dos incisivos inferiores em longo prazo.

Os estudos da Universidade de Washington ${ }^{112,113,163}$ são o resultado da coleta de mais de 800 conjuntos de exames de pacientes por mais de 40 anos, e mostram resultados preocupantes das extrações dentárias sobre a estabilidade dos incisivos inferiores em longo prazo. Apesar de se alcançar normas cefalométricas sugeridas e aceitas, e apesar de se aderir aos padrões clínicos usuais de forma do arco, trespasse vertical e horizontal, pode-se concluir que as extrações no arco inferior não asseguram o correto alinhamento dos incisivos inferiores em longo prazo.

As alterações em longo prazo de 96 pacientes com Classe I ou II, tratados com ou sem extrações, após o mínimo de 12 anos da remoção das 
contenções, foram analisadas por SADOWSKY; SAKOLS ${ }^{156}$, em 1982. Ao início do tratamento, $35 \%$ dos casos apresentavam apinhamento ântero-inferior não-aceitável clinicamente (maior que $3 \mathrm{~mm}$ ), enquanto que após o período de acompanhamento, esse valor foi de $15 \%$, apresentando, dessa forma, um quadro mais positivo do alinhamento dos incisivos inferiores ${ }^{113}$.

Um ano depois, UHDE; SADOWSKY ${ }^{178}$ conduziram uma pesquisa em busca dos fatores que podem influenciar a estabilidade do alinhamento dos incisivos inferiores 20 anos após a remoção da contenção. Para tanto, selecionaram 72 pacientes da amostra do trabalho anterior ${ }^{156}$. Nenhuma diferença significante no apinhamento ântero-inferior foi observada entre os tratamentos com ou sem extrações de pré-molares, para as más oclusões Classe I e II. O seu modelo de regressão (alterações após a remoção da contenção da distância intercaninos superior e inferior, distância intermolares superior e inferior, trespasse horizontal, trespasse vertical, relação molar e apinhamento ântero-superior) conseguiu explicar $41 \%$ da variabilidade encontrada na sua população de pacientes. A distância intercaninos inferior foi o fator responsável por $12.5 \%$ da variabilidade.

GLENN; SINCLAIR; ALEXANDER ${ }^{64}$, em 1987, avaliaram 28 casos tratados ortodonticamente sem extrações de pré-molares (14 casos com Classe I, e 14 casos com Classe II, divisão 1) 8 anos após a remoção da contenção. Os seus resultados foram comparados ao trabalho de LITTLE; WALLEN; RIEDEL ${ }^{113}$, de casos tratados com extrações. É interessante notar que a quantidade de irregularidade dos incisivos inferiores foi mais que o dobro nos casos tratados com extrações de pré-molares $(2.9 \mathrm{~mm})$, comparado aos casos tratados sem extrações $(1.2 \mathrm{~mm})$. Entretanto, deve-se salientar que 0 apinhamento inicial de sua amostra tratada sem extrações $(2.9 \mathrm{~mm})$ diferia grandemente da amostra tratada com extrações ${ }^{113}$ (7.3mm).

PAQUETTE; BEATTIE; JOHNSTON ${ }^{138}$, em 1992, ao compararem em longo prazo duas amostras de Classe II, divisão 1, considerados "limítrofes", verificaram que $\mathrm{o}$ tratamento sem extrações produziu uma dentadura mais protruída cerca de $2 \mathrm{~mm}$ tanto ao final como 14 anos após a remoção da contenção. Como resultado, as duas alternativas produziram alterações póstratamento bastante semelhantes quanto ao apinhamento dos incisivos inferiores. Metade dos pacientes tratados sem extrações e três quartos dos 
pacientes tratados com extrações apresentaram apinhamento dos incisivos inferiores menor que $3.5 \mathrm{~mm}$, demonstrando uma estabilidade relativa.

LUPPANAPORNLARP; JOHNSTON ${ }^{117}$, em 1993, compararam os resultados 15 anos após o final do tratamento ortodôntico com e sem extrações de 62 pacientes com Classe II "não-limítrofes". Como resultados, encontraram que as mudanças ocorridas em longo prazo foram essencialmente as mesmas, morfológica ou funcionalmente. O índice de irregularidade de LITTLE foi de $2.6 \mathrm{~mm}$ no grupo tratado com extrações e de $3.1 \mathrm{~mm}$ no grupo tratado sem extrações. Sendo assim, concluíram que não existe a preocupação ou urgência de alguns clínicos por alternativas de tratamento a despeito das extrações de pré-molares.

ARTUN; GAROL; LITTLE ${ }^{5}$ não verificaram diferença estatística na estabilidade do alinhamento ântero-inferior no tratamento de pacientes com Classe II, divisão 1, com ou sem extrações de pré-molares. Foram selecionados os casos tratados com sucesso e avaliados 14 anos após a remoção da contenção. Na amostra tratada sem extrações a recidiva do apinhamento chegou a $3.36 \mathrm{~mm}$, excedendo o apinhamento inicial de $2.77 \mathrm{~mm}$, e a recidiva dos pacientes tratados com extrações foi de $4.05 \mathrm{~mm}$, chegando próximo ao valor pré-tratamento de $5.27 \mathrm{~mm}$. Os autores concluem que as chances de se manter o alinhamento dos incisivos é menor do que $50 \%$, apesar dos bons resultados oclusais ao final do tratamento. Ressaltaram que o aumento da distância intercaninos durante o tratamento e a sua diminuição após a remoção da contenção se encontravam associados à recidiva.

BUSATO $^{34,90}$, em 2003, comparou a estabilidade do apinhamento ântero-inferior em 66 pacientes com Classe II tratados com extrações de dois ou de quatro pré-molares. Apesar de ocorrer vestibularização suave dos incisivos inferiores com o protocolo de extrações de dois pré-molares, passados 5 anos do término do tratamento, as alterações no alinhamento dos incisivos inferiores, no comprimento e na largura do arco inferior foram semelhantes entre os grupos. Os resultados sugerem e corroboram a tendência da ortodontia contemporânea, da não realização de extrações de pré-molares com a intenção única de corrigir discrepâncias cefalométricas ou de assegurar maior estabilidade dos resultados ${ }^{60,61,113,163}$. 


\section{Estabilidade da correção do Trespasse Horizontal}

A má oclusão de Classe II, divisão 1 se caracteriza por um trespasse horziontal acentuado, dessa forma um dos procedimentos mais comuns durante o tratamento é a sua redução. Por outro lado, a estabilidade dessa característica depende de fatores do diagnóstico e das formas de intervenção utilizadas.

As avaliações em longo prazo da correção do trespasse horizontal apresentam resultados conflitantes. Alguns autores afirmam que a Classe II apresenta mais recidiva no trespasse horizontal que as outras más oclusões ${ }^{29,113}$. Outros autores concluem que a recidiva do trespasse horizontal independe do tipo de má oclusão ${ }^{49,178}$ ou mesmo se foram realizadas extrações dentárias ${ }^{55,138,139}$.

BRESONIS; GREWE ${ }^{29}$, em 1974, constataram que a recidiva do trespasse vertical e horizontal era maior na Classe II em relação aos outros tipos de má oclusão. Os resultados mostraram que na Classe I a recidiva do trespasse horizontal foi de $5 \%$ enquanto que na Classe II, divisão 1 , a recidiva foi de $10 \%$. Entretanto a recidiva, em média, não excedeu $2 \mathrm{~mm}$, considerandose dentro dos limites clinicamente aceitáveis.

EL-MANGOURY ${ }^{49}$, em 1979, avaliou a estabilidade do trespasse horizontal e vertical em 30 pacientes tratados com extrações dos pré-molares (12 portadores de Classe I e 18 portadores de Classe II) e 20 pacientes Classe II tratados sem extrações. Após 2 anos da remoção da contenção, ao comparar os pacientes que apresentaram recidiva com os que se mantiveram estáveis, não verificou diferenças na quantidade de recidiva entre a Classe I e a Classe II, ou se foram realizadas ou não extrações dentárias.

UHDE; SADOWSKY; BEGOLE ${ }^{178}$, em 1983, avaliaram a estabilidade do tratamento ortodôntico 12 anos após a remoção da contenção, numa amostra composta por 72 casos de má oclusão de Classe I e II, tratados sem e com extrações dos pré-molares. De modo geral, as relações dentárias tenderam a retornar aos valores iniciais, mas ainda preservou-se boa correção. Houve uma tendência não-significante de aumento do trespasse horizontal após a remoção dos dispositivos de contenção. $O$ valor médio da recidiva do trespasse horizontal de 0.5 e $0.97 \mathrm{~mm}$ para os casos de Classe I e II, 
respectivamente. O valor médio da recidiva do trespasse horizontal nos casos tratados sem extrações foi de $0.8 \mathrm{~mm}$, comparado a $0.63 \mathrm{~mm}$ nos casos com extrações dentárias.

Enquanto à estabilidade da correção da relação molar ele, Houve uma tendência significante dos molares retornarem a sua posição inicial após o tratamento, mas segundo, $\mathrm{UHDE}^{178}$, não há diferença significante no potencial de recidiva da relação de Classe II entre os grupos tratados com e sem extração. Mesmo que as alterações que ocorrem nas posições dentárias após o tratamento são consideráveis, a maioria destas alterações ocorre devido ao crescimento das bases ósseas. De acordo com esa lógica, o crescimento maxilar é responsável pela movimentação para mesial dos primeiros molares superiores ${ }^{63}$, enquanto que a rotação em sentido horário da mandíbula contribui para a recidiva da relação molar de Classe II. Porém, o posicionamento distal da maxila alcançado durante o tratamento permanece mais estável quando o tratamento é realizado com extrações ${ }^{46}$.

NASHED; REYNOLDS ${ }^{126}$, em 1989, tencionaram analisar os fatores que pudessem predizer o sucesso para a redução do trespasse horizontal após 2 anos de finalizado o tratamento ortodôntico. Ao avaliar 50 pacientes com Classe II acentuada (10 a 15mm), envolvendo casos tratados sem ou com extrações dentárias e incluindo aparelhos fixos e removíveis, $25 \%$ da correção do trespasse horizontal recidivou. Os casos em que o valor do trespasse diminuiu para $4 \mathrm{~mm}$ ou menos apresentaram maior recidiva. Apesar de não poder predizer características pré-tratamento do sucesso ou falha na redução do trespasse horizontal, constataram que quanto maior a redução deste durante o tratamento, maior a recidiva. Os incisivos superiores que foram inclinados para palatino e os incisivos inferiores que foram inclinados para vestibular durante o tratamento exibiram recidiva em direção aos valores iniciais, e foram correlacionados à recidiva do trespasse horizontal. No entanto, os incisivos inferiores que foram lingualizados durante o tratamento e após o tratamento apresentaram recidiva, contribuíram para o abrandamento da recidiva ântero-posterior.

PAQUETTE; BEATTIE; JOHNSTON ${ }^{138}$, em 1992, compararam 63 pacientes com Classe II, divisão 1 , tratados com e sem extrações de prémolares, após 14.5 anos da remoção do aparelho. Os pacientes foram 
selecionados pela análise discriminante de serem igualmente suscetíveis às duas estratégias ("limítrofes"). Em longo prazo, o padrão de recidiva foi essencialmente idêntico aos dois grupos, não relacionado com os efeitos do tratamento, mas sim, com o crescimento diferencial da mandíbula em relação à maxila.

No ano seguinte, devido à preocupante busca dos ortodontistas por formas de tratamento sem extrações, às vezes mesmo naqueles pacientes com protrusão dentária ou apinhamento acentuado, LUPPANAPORNLARP; JOHNSTON ${ }^{117}$ compararam os resultados 15 anos após o final do tratamento ortodôntico com e sem extrações de 62 pacientes com Classe II "nãolimítrofes". Utilizando este critério de seleção, as indicações para se extrair ou não os pré-molares foram inequívocas e sem críticas ${ }^{138}$. Os autores observaram que muitos dos componentes dentários da correção da relação molar e do trespasse horizontal apresentaram uma correlação significante com o crescimento ântero-posterior e/ou deslocamento da mandíbula. deslocamento mesial dos dentes no grupo com extrações foi significativamente maior. Dessa forma, o resultado ortodôntico em longo prazo pode ser visto como uma compensação dentoalveolar para o padrão de crescimento e/ou deslocamento mandibular pós-tratamento combinado com o impacto do tratamento escolhido pelo clínico.

FIDLER et al. ${ }^{55}$, em 1995 , verificaram semelhança na estabilidade de pacientes com Classe II tratados com ou sem extrações de pré-molares, após 14 anos da remoção da contenção. Oitenta e oito pacientes foram selecionados utilizando-se o "sucesso do tratamento" como critério de seleção. A relação molar e o trespasse horizontal experimentaram recidiva suave que, embora com diferença estatística, apresentaram pouca repercussão clínica. Os autores não encontraram nenhuma característica cefalométrica inicial, final ou de alterações com o tratamento associado com a recidiva da trespasse horizontal. As alterações esqueléticas após o término do tratamento também não influenciaram o aumento deste trespasse. Foi verificada associação, entretanto, com a recidiva da intercuspidação dos dentes posteriores, recidiva do trespasse vertical, e a vestibularização dos incisivos superiores e lingualização dos incisivos inferiores após o final do tratamento ortodôntico. 
Em um estudo de SIQUEIRA ${ }^{166}$, em 1997, dos 48 pacientes estudados, 30 apresentaram recidiva da correção do trespasse horizontal de pelo menos $0.5 \mathrm{~mm}$ após 5 anos do término do tratamento. Todos os pacientes apresentavam má oclusão de Classe II, divisão 1, e foram tratados com extrações dos quatro primeiros pré-molares. Os pacientes que apresentaram estabilidade da correção do trespasse horizontal compuseram o grupo controle. Como resultado, ocorreram alterações nas inclinações dos incisivos superiores e inferiores nos pacientes que apresentaram recidiva do trespasse horizontal, embora não estatisticamente significantes. As medidas cefalométricas que avaliam o crescimento também não demonstraram diferenças significantes entre os grupos.

PARKINSON et al. ${ }^{139}$, em 2001, procuraram identificar o relacionamento entre a oclusão dos dentes posteriores e a estabilidade de algumas características oclusais. Vinte e três pacientes com Classe I e 26 pacientes com Classe II, tratados com extrações de quatro pré-molares, foram avaliados 14 anos após a finalização do tratamento. A relação molar permaneceu imutável em ambas as classes e, no entanto, houve recidiva do trespasse horizontal. Verificou também a existência de correlação positiva entre o aumento do trespasse horizontal e do trespasse vertical $(r=.47)$, assim também, houve correlação negativa entre a área de contato oclusal dos dentes posteriores e o trespasse vertical, concluíram que indiretamente a área de contato oclusal pode se encontrar relacionada com a recidiva do trespasse horizontal.

LUNARDI $^{116}$, em 2003, avaliou cefalometricamente a estabilidade do trespasse horizontal em 27 pacientes com Classe I e II de Angle tratados com extrações de quatro pré-molares. Após cinco anos do final do tratamento, observou-se recidiva de $18 \%$ do trespasse horizontal inicial, no entanto, sem apresentar diferença estatística. Verificou-se correlação positiva entre a quantidade de correção do trespasse horizontal e sua subseqüente recidiva. A vestibularização dos incisivos superiores, lingualização dos incisivos inferiores e o aumento do ângulo interincisivos foram relacionados com o aumento do trespasse horizontal. Não houve associação da recidiva do trespasse horizontal com as alterações esqueléticas após o tratamento ortodôntico. 


\section{Estabilidade da correção do Trespasse Vertical}

A maior freqüência do trespasse vertical acentuado em pacientes com má oclusão de Classe II direcionou os trabalhos enfocando a sua correção e estabilidade dos resultados. Em especial, devido às extrações de pré-molares promoverem alterações distintas no relacionamento dentoesquelético, despertou-se particular interesse sobre as suas conseqüências em longo prazo.

COLE $^{42}$, em 1948, verificou em 21 pacientes tratados com a mecânica Edgewise que o trespasse vertical acentuado tende a aumentar em longo prazo nos pacientes em que o tratamento foi realizado com as extrações dos quatro primeiros pré-molares. O aumento do trespasse vertical foi atribuído à posição mais anterior dos molares inferiores para o espaço das extrações. 0 autor verificou correlação entre a diminuição do ângulo do plano mandibular e o aumento do trespasse vertical.

LEVIN $^{107}$, em 1977, avaliou a estabilidade do trespasse vertical e horizontal em 30 pacientes, com más oclusões de Classe I e II, um ano após a remoção da contenção. Todos os pacientes foram tratados pela técnica de $\mathrm{BEGG}^{17}$ e foram realizadas as extrações de quatro pré-molares. A recidiva do trespasse vertical pode ser relacionada com os seguintes fatores: rotação antihorária do plano oclusal após o término do tratamento, aumento do trespasse horizontal, verticalização dos incisivos inferiores e o aumento do ângulo interincisivos. O crescimento do côndilo no sentido vertical se relacionou com o aumento do trespasse vertical acentuado, enquanto que o crescimento em direção sagital foi associado com a sua estabilidade. A correção do trespasse horizontal apresentou maior estabilidade que a correção do trespasse vertical acentuado.

Em seu artigo de revisão sobre os trabalhos realizados na UCLA (“University of California, Los Angeles") e na "Loma Linda University”, ENGEL et al. ${ }^{52}$, em 1980, reportaram um correlação direta da recidiva do trespasse vertical com o ângulo interincisivos. Os casos finalizados com um ângulo interincisivos entre $125^{\circ}$ e $135^{\circ}$ apresentaram maior estabilidade. Entretanto, os casos que finalizavam com ângulos interincisivos extremos - menor que $125^{\circ}$ ou maior que $135^{\circ}$ - apresentaram maior recidiva do trespasse vertical. 
Em adição, verificou-se que uma recidiva de $1 \mathrm{~mm}$ pode ser esperada para uma média de intrusão de $3 \mathrm{~mm}$. Dessa forma, podem-se esperar aproximadamente dois terços da intrusão alcançada ao final do tratamento.

PINZAN $^{142}$, em 1982, objetivou verificar as alterações do trespasse vertical e das curvas de Spee e ocluso-incisal. Vinte e cinco pacientes com Classe II, divisão 1 , tratados com extrações de quatro pré-molares foram comparados com 23 indivíduos não-tratados, possuidores de oclusão normal. Ao avaliar os modelos de estudo 3 anos após o final do tratamento, verificou-se recidiva significante do trespasse vertical acentuado e recidiva não-significante da profundidade da curva de Spee. A curva ocluso-incisal, ao contrário, apresentou diminuição espontânea não-significante. Contudo, considerou-se satisfatória a correção do trespasse vertical em longo prazo.

UHDE; SADOWSKY; BEGOLE ${ }^{178}$, em 1983, estudaram como as relações dentárias, medidas no modelo de estudo, se comportavam após o tratamento ortodôntico. Os autores verificaram correlação significante entre a diminuição do trespasse vertical durante o tratamento e o seu aumento após 12 anos de observação. Entretanto, não se observou relação da recidiva com o tipo de má oclusão inicial e com a realização ou não de extrações.

HELLEKANT; LAGERSTRÖM; GLEERUP ${ }^{78}$, em 1989, ao comparar 20 pacientes com Classe II, tratados com extrações dos quatro primeiros prémolares, com outros 20 pacientes tratados sem extrações após 2 anos de controle, encontraram equivalência entre os grupos em relação à recidiva do trespasse horizontal e vertical. Os autores observaram que os casos com estabilidade satisfatória do trespasse horizontal estavam associados com a boa estabilidade da distância intercaninos e a angulação do incisivo inferior em relação à linha A-Pog. Já os casos que apresentaram mais de $50 \%$ de recidiva da quantidade de correção do trespasse vertical apresentaram diminuição da distância intercaninos e lingualização dos incisivos inferiores.

$\mathrm{KONDO}^{103}, \mathrm{em} \mathrm{1998}$, apresentou um artigo onde verificou-se a estabilidade de dois casos de Classe II com trespasse vertical acentuado onde foram realizadas extrações dos quatro primeiros molares. Em um caso o período pós-contenção observado foi de 29 anos e no outro foi de 16 anos. Para o autor, as características para um caso de Classe II com trespasse vertical acentuado, em pacientes em crescimento, apresentar estabilidade são: 
finalizar com os incisivos em uma relação topo a topo, terminar com o plano oclusal funcional perpendicular à linha $A B$, proporcionar uma excelente intercuspidação ao término do tratamento e promover um equilíbrio da musculatura peribucal e da língua.

KIM; LITTLE $^{98}$, em 1999, avaliaram a estabilidade da correção do trespasse vertical acentuado em 62 pacientes com má oclusão de Classe II, divisão 2 (29 pacientes tratados sem extrações e 23 tratados com extrações de quatro pré-molares), após um período médio de 15 anos de observação. Os resultados mostraram que as extrações dentárias não causaram maior recidiva do trespasse vertical acentuado. Casos que apresentavam os incisivos superiores e inferiores verticalizados ao início do tratamento possuíam também maior trespasse vertical inicial, e demonstraram uma tendência de retornar ao seu relacionamento original, quando avaliados em longo prazo. Pela análise de regressão múltipla, o trespasse vertical acentuado inicial foi selecionado como o fator mais importante a fim de prever a estabilidade do trespasse vertical.

$\mathrm{KAWAUCHI}^{96}$, em 1999, estudou o relacionamento dos fatores esqueléticos e dentários envolvidos com a recidiva do trespasse vertical acentuado 5 anos após o tratamento ortodôntico. Para tanto, foram avaliados 48 jovens com Classe I e II, divisão 1, tratados com extrações dos quatro primeiros pré-molares. Os fatores dentários relacionados com a recidiva do trespasse vertical acentuado foram o trespasse horizontal acentuado, a movimentação dos incisivos e dos molares e o ângulo interincisivos. O fator esquelético que apresentou correlação significante foi a altura facial anterior total. Verificou-se uma correlação direta da quantidade de correção com a quantidade de recidiva do trespasse vertical.

PARKINSON et al. ${ }^{139}$, em 2001, avaliaram a relação entre a oclusão dos dentes posteriores com as alterações oclusais após o tratamento ortodôntico. Como resultado, verificaram que os pacientes com as maiores áreas de contato entre os dentes posteriores ao final do tratamento obtiveram menor aumento do trespasse vertical em longo prazo. Para os autores, os pacientes com maior contato oclusal entre os dentes posteriores ao final do tratamento experimentam menor acomodação da oclusão no sentido vertical. Dessa forma, pode-se esperar menor aumento do trespasse vertical. 
Como a manutenção de uma curva de Spee suave é um importante fator para a longevidade da correção do trespasse vertical acentuado, SHANNON; NANDA $^{162}$, em 2004, se propuseram a avaliar os fatores associados com a sua estabilidade 2 anos após o tratamento. Cinqüenta pacientes, entre más oclusões de Classe I, e Classe II, divisão 1 e 2, foram selecionados. Em 20 pacientes foram realizadas extrações dentárias. Ao início do tratamento, verificou-se correlação positiva entre $\circ$ trespasse vertical e $\circ$ trespasse horizontal com as curvas de Spee acentuadas. Para os autores, isso poderia sugerir que, na ausência de contato oclusal entre os incisivos, eles continuaram a se desenvolverem verticalmente, e dessa forma aprofundando a curva ${ }^{161}$. A mesma explicação torna-se válida para o fato de que os pacientes com Classe II apresentavam curvas mais profundas em relação aos pacientes com Classe I. Contudo, apesar da correlação existente entre a quantidade de correção da curva de Spee e a sua recidiva, não se observou diferença significante entre as diferentes classes de más oclusões. Além disso, apesar de o tratamento com extrações resultar em verticalização dos incisivos inferiores e aumento do ângulo interincisivos, e o tratamento sem extrações ocasionar vestibularização dos incisivos inferiores e diminuição do ângulo interincisivos, não houve diferença na recidiva da curva de Spee.

Diante da revisão realizada, a avaliação da estabilidade do tratamento da Classe II sem extrações e com extração de quatro pré-molares encontrase bem documentada na literatura, entretanto, os fatores relacionados à recidiva ortodôntica são contraditórios. Observa-se que diversos fatores influenciam na estabilidade da correção da Classe II e, o potencial de recidiva não está diretamente relacionado ao fato de o tratamento ter sido realizado com ou sem extração de pré-molares. O restabelecimento de uma oclusão funcional normal, em harmonia com um adequado padrão funcional de toda a musculatura peribucal e da língua, assim como da inclinação axial e angulação normal dos dentes, parecem favorecer à manutenção dos resultados obtidos ao final do tratamento.

Embora o tratamento da Classe II, realizada com extração de prémolares seja amplamente aceita, considerando que as extrações podem variar entre dois e quatro pré-molares, existe uma carência na literatura de estudos que comparem a estabilidade a longo prazo da correção da Classe II por meio 
de estes protocolos. Sendo que a estabilidade é um dos objetivos principais do tratamento ortodôntico, considerou-se importante realizar a presente pesquisa a fim de contribuir para o entendimento dos fatores relacionados à estabilidade da correção do tratamento ortodôntico da Classe II, quando realizado utilizando estes dois protocolos de extrações. 

Dronosição 



\section{PROPOSIÇÃO}

O objetivo deste trabalho é testar a seguinte hipótese nula: não há diferença na estabilidade da correção das relações dentárias da Classe II completa, realizado com duas ou com quatro extrações de pré-molares, em longo prazo pós-tratamento. Para tanto serão utilizadas telerradiografias laterais tomadas no início e ao final de tratamento e tomadas após um período médio de 9,42 anos do término do mesmo. Serão também avaliadas as influências das alterações de variáveis dentoalveolares e esqueléticas nos resultados obtidos. 

Material e
Métodos 



\section{MATERIAL E MÉTODOS}

\subsection{MATERIAL}

Para constituírem a amostra deste trabalho foram selecionados em caráter retrospectivo, pacientes com má oclusão de Classe II completa, com características semelhante, tratados com a extração de dois pré-molares superiores ou de dois pré-molares superiores e dois pré-molares inferiores, nos cursos de Pós-Graduação e Especialização da Disciplina de Ortodontia da Faculdade de Odontologia de Bauru - USP.

A amostra constituiu-se de telerradiografias iniciais, finais e telerradiografias de controle com um tempo médio de 9,42 anos pós-tratamento (tabela 1), de um total de 60 pacientes, que foram então divididos em dois grupos experimentais, grupo 1 e grupo 2, de acordo com o protocolo de extrações utilizado para a realização do tratamento ortodôntico.

O grupo 1 foi composto por 30 pacientes sendo 17 do gênero masculino $(56,67 \%)$ e 13 do gênero feminino (43,33\%), com idade inicial média de 12,87 anos (tabela 1) (mínima de 10,90 e máxima de 16, 62 anos) que apresentavam má oclusão de Classe II completa. Dos 30 pacientes, 23 apresentavam Classe II, Divisão 1 e 7 pacientes apresentavam Classe II, Divisão 2; e todos eles foram tratados com a terapêutica utilizando extrações de dois pré-molares superiores.

O grupo 2 foi constituído por 30 pacientes, 14 do gênero masculino $(46,66 \%)$ e 16 do gênero feminino (53,33\%) com idade inicial média de 13,64 anos (tabela 1) (mínima de 10,75 e máxima de 20,37 anos). Neste grupo todos os pacientes apresentaram má oclusão de Classe II, Divisão 1 completa, sendo que estes foram tratados com extrações de dois pré-molares superiores e dois inferiores. Ambos os grupos foram tratados com aparelho fixo, utilizando a mecânica edgewise simplificada.

Os critérios básicos utilizados para a seleção da amostra dos grupos, foram os seguintes: presença da relação molar de Classe II completa bilateral, dentes permanentes até os primeiros molares, ausência de anodontias ou dentes supranumerários, ao final do tratamento deveriam apresentar uma redução do trespasse horizontal. 
Foram compulsadas as fichas clínicas presentes nas pastas ortodônticas de cada paciente para a obtenção de alguns dados adicionais relevantes para a realização deste trabalho. A partir destas foram obtidas as datas de nascimento, a data de início e término do tratamento. Assim também foram obtidas as datas de obtenção das telerradiografias e modelos ortodônticos em cada fase. Estes dados, em conjunto permitiram a avaliação exata da idade ao início do tratamento, idade ao final de tratamento, assim como a duração do mesmo.

Tabela 1: Média das idades iniciais e finais dos pacientes nos dois grupos e o tempo médio de observação pós-tratamento.

\begin{tabular}{c|c|c|c}
\hline Grupos & $\begin{array}{c}\text { Idade Inicial } \\
\text { Média }\end{array}$ & $\begin{array}{c}\text { Idade Final } \\
\text { Média }\end{array}$ & $\begin{array}{c}\text { Tempo de } \\
\text { Observação } \\
\text { Pós-tratamento }\end{array}$ \\
\hline G1 (Xp 2pré) & 12,87 & 15,40 & 9,25 \\
\hline G2 (Xp 4pré) & 13,64 & 16,21 & 9,58 \\
\hline
\end{tabular}

\subsection{MÉTODOS}

\subsubsection{Método cefalométrico}

As telerradiografias obtidas foram realizadas de acordo com as normas técnicas de obtenção e revelação preconizadas pela Disciplina de Radiologia da Faculdade de Odontologia de Bauru da Universidade de São Paulo, com o objetivo de padronizá-las. Desta forma a cabeça do paciente foi posicionada no cefalostato de Broadbent ${ }^{30}$ com os lábios em posição de repouso e em máxima intercuspidação habitual. Como as telerradiografias foram obtidas em épocas distintas, e em alguns casos com aparelhos diferentes, foi preciso realizar a determinação da magnificação de cada aparelho radiográfico.

\section{Traçados e medição das radiografias}

Os traçados cefalométricos foram realizados em folhas de papel "ultraphan" de 0,07mm de espessura e $17,5 \mathrm{~cm} \times 17,5 \mathrm{~cm}$, adaptadas nas telerradiografias. O traçado anatômico e a demarcação dos pontos de 
referência dento esqueléticos e tegumentares foram efetuados manualmente pelo autor com lapiseira de $0,5 \mathrm{~mm}$, sobre um negatoscópio, em uma sala escurecida. $\mathrm{O}$ traçado anatômico e os pontos de referência demarcados foram digitalizados com o auxilio de uma mesa digitalizadora Numonics AccuGrid XNT, modelo A30TL. $\mathrm{F}^{1}$, interligada a um microcomputador.

O programa utilizado para a medição das grandezas cefalométricas foi o Dentofacial Planner $7.02^{\mathrm{b}}$, efetuando-se por meio do mesmo, a correção da magnificação da imagem radiográfica que variou entre $6 \%$ e 10,94\%.

\section{Traçado anatômico (figura 1)}

Foram delimitadas as seguintes estruturas dento esqueléticas:

- Perfil da glabela e dos ossos nasais

- Sela túrcica

- Meato acústico externo

- Órbita

- Maxila

- Contorno da mandíbula

- Caninos superiores e inferiores

- Incisivos centrais e primeiros molares permanentes superiores e inferiores.

Para todas as estruturas bilaterais foi efetuado o traçado médio.

\section{Pontos de referência (figura 1)}

Os pontos de referência anatômicos foram demarcados seguindo as especificações de KROGMAN ${ }^{104}$, RIOLO $^{152}$, MCNAMARA ${ }^{121}$, JACOBSON $^{87}$, LEGAN $^{105}$ e STEINER ${ }^{169}$.

1- S (sela túrcica): o ponto mais central da sela túrcica;

2- N (násio): o ponto mais anterior da sutura frontonasal;

3- Or (orbitário): a média dos pontos mais inferiores das margens inferiores das órbitas;

\footnotetext{
${ }^{1}$ Numonics Corp., Montgomeryville, Pennsylvania, United States of America.

${ }^{b}$ Dentofacial Planner Software Inc., Toronto, Ontario, Canada
} 
4- ENA (espinha nasal anterior): o ponto mais anterior da espinha nasal anterior;

5- ENP (espinha nasal posterior): o ponto mais posterior do assoalho da fossa nasal;

6- Ponto A (subspinhal): o ponto mais profundo da concavidade da pré-maxila, entre a espinha nasal anterior e o próstio;

7- Ponto B (supramentoniano): o ponto mais profundo da concavidade da sínfise mentoniana;

8- Pog (pogônio): o ponto mais anterior do contorno do mento ósseo;

9- Gn (gnátio): o ponto mais inferior e anterior do contorno do mento ósseo, delimitado pela bissetriz das linhas Npog e o plano mandibular (GoMe);

10-Me (mentoniano): o ponto médio mais inferior da sínfise mentoniana;

11-Go (gônio): o ponto mais posterior e inferior da curvatura entre o corpo e o ramo da mandíbula;

12-Po (pório anatômico): o ponto mais superior do meato acústico externo;

13-Co (condílio): o ponto mais superior e posterior do côndilo mandibular;

14-BIS (borda incisal superior): o ponto mais inferior da borda incisal do incisivo central superior;

15-AIS (ápice incisal superior): o ponto mais superior do ápice radicular do incisivo central superior;

16-BIl (borda incisal do incisivo inferior): o ponto mais superior da borda incisal do incisivo central inferior;

17-All (ápice incisal inferior): o ponto mais inferior do ápice radicular do incisivo central inferior;

18-SMPMS (superfície mesial do primeiro molar superior): o ponto mais anterior da coroa do primeiro molar permanente superior;

19-CMPMS (cúspide mesial do primeiro molar superior): o ponto mais inferior da cúspide mesial do primeiro molar permanente superior;

20-SMPMI (superfície mesial do primeiro molar inferior): o ponto mais anterior da coroa do primeiro molar permanente inferior;

21-CMPMI (cúspide mesial do primeiro molar inferior): o ponto mais superior da cúspide mesial do primeiro molar permanente inferior;

22-COM (contato oclusal molar): o ponto médio da superfície de intercuspidação dos primeiros molares; 
23-COPM (contato oclusal pré-molar): ponto médio da superfície de intercuspidação dos primeiros pré-molares;

24- $\mathrm{CCl}$ (cúspide do canino inferior) o ponto mais superior da cúspide do canino inferior;

25-ACl (ápice do canino inferior) o ponto mais inferior do ápice radicular do canino inferior;

26-CCS (cúspide do canino superior) o ponto mais inferior da cúspide do canino superior;

27-ACS (ápice do canino superior) o ponto mais superior do ápice radicular do canino superior;

Além destes pontos, foram construídos dois pontos para efeitos de digitalização:

28-ENAperp (ponto espinha nasal anterior perpendicular): ponto localizado arbitrariamente, porém perpendicular ao plano palatino, a partir do ponto ENA;

29-Pogperp (ponto pogônio perpendicular): ponto localizado arbitrariamente, porém perpendicular ao plano Go-Me, a partir do ponto Pog.

\section{Linhas e Planos (figura 1)}

\section{Horizontais:}

A- Linha SN: do ponto sela ao násio;

B- FH (Plano horizontal de Frankfurt): do ponto pório anatômico ao orbitário;

C- PP (plano palatino): do ponto ENA ao ENP

D- POF (plano oclusal funcional): do contato oclusal pré-molar ao contato oclusal molar;

E- GoGn (plano mandibular): do ponto gônio ao gnátio;

F- GoMe (plano mandibular): do ponto gônio ao mentoniano.

\section{Verticais:}

G- Linha NA: une o ponto násio ao ponto $A$;

$\mathrm{H}$ - Linha NB: une o ponto násio ao ponto $B$;

I- Linha BIS-AIS (longo eixo do incisivo superior): une os pontos correspondentes da borda incisal ao ápice dos incisivos centrais superiores; 
J- Linha Bll-All (longo eixo do incisivo inferior): une os pontos correspondentes da borda incisal ao ápice dos incisivos centrais inferiores;

K- Linha Nperp: linha perpendicular ao plano de Frankfurt, passando pelo ponto násio;

L- Linha Pogperp: linha perpendicular ao plano mandibular Go-Me, passando pelo ponto pogônio;

M- Linha ENAperp: linha perpendicular ao plano palatino, passando pela espinha nasal anterior.

\section{Grandezas cefalométricas esqueléticas (figura 2)}

\section{Maxilares:}

1- SNA: ângulo formado pelas linhas SN e NA. Indica a relação sagital da maxila, em relação à base do crânio, e seu aumento indica um aumento da protrusão maxilar;

2- CO-A: distância entre os pontos condílio e A. Representa o comprimento efetivo da face média (maxila);

3- A-Nperp: distância entre o ponto A e a linha násio perpendicular. Define a posição sagital da maxila, e seu aumento também indica um aumento da protrusão maxilar.

\section{Mandibulares:}

4- SNB: ângulo formado pelas linhas $S N$ e NB. Indica a relação sagital da mandíbula, em relação à base do crânio, e seu aumento indica um aumento da protrusão mandibular;

5- Co-Gn: distância entre os pontos condílio e gnátio. Define o comprimento efetivo mandibular;

\section{Maxilomandibulares:}

6- ANB: ângulo entre as linhas NA e NB. Representa o grau de discrepância sagital entre a maxila e mandíbula; sua diminuição indica um melhor relacionamento intermaxilar;

7- Wits: distância entre as projeções perpendiculares dos pontos A e B sobre o plano oclusal funcional. Define o relacionamento sagital entre a maxila e mandíbula. Sua diminuição indica um melhor relacionamento intermaxilar; 


\section{Padrão de Crescimento:}

8- FMA: ângulo formado pelos planos horizontal de Frankfurt e mandibular (Go-Me). Define basicamente a orientação do padrão de crescimento facial;

9- SN.GoGn : ângulo formado pela linha SN e o plano mandibular GoGn. Usando pontos cefalométricos diferentes, também define a orientação do padrão de crescimento facial;

10-AFAl (ENA-Me): distância entre os pontos espinha nasal anterior e mentoniano. Indica a altura posterior da face. Indica a altura do terço inferior da face.

\section{Grandezas cefalométricas dentárias (figura 3)}

\section{Superiores:}

1- 1.PP: ângulo formado entre o longo eixo do incisivo central superior e o plano palatino. Relaciona a inclinação do incisivo superior à maxila;

2- 1-ENAperp: distância entre o ponto mais anterior da coroa do incisivo central superior e a linha espinha nasal anterior perpendicular. Determina a posição ântero-posterior do incisivo superior em relação à maxila. Valores posteriores a esta linha são positivos, e anteriores são negativos. O seu aumento indica retrusão dos incisivos;

3- 1-PP: distância entre a borda incisal do incisivo central superior e o plano palatino. Determina a altura do processo alveolar superior, em sua região anterior;

4- 6-PP: distância entre a cúspide mesiovestibular do primeiro molar superior e o plano palatino. Avalia a altura do processo alveolar, em sua região posterior;

5- 6-ENAperp: distância entre a face mesial do primeiro molar superior e a linha espinha nasal anterior perpendicular. Determina a posição ânteroposterior do primeiro molar superior, em relação à maxila, sendo que seu aumento indica uma distalização do molar.

\section{Inferiores:}

6- IMPA: ângulo formado entre o longo eixo do incisivo central inferior e o plano mandibular GoMe. Indica a inclinação deste dente em relação à mandíbula; 
7- 1.NB: ângulo entre o longo eixo do incisivo central inferior e a linha NB. Relaciona a inclinação deste dente com a mandíbula e o násio;

8- 1-NB: distância entre o ponto mais anterior da coroa do incisivo central inferior e a linha NB. Relaciona a posição sagital do incisivo inferior em relação à mandíbula e ao násio.

9- 1-Pogperp: distância entre o ponto mais anterior da coroa do incisivo central inferior e a linha pogônio perpendicular. Determina a posição ânteroposterior do incisivo central inferior em relação à mandíbula, sendo que seu aumento indica uma protrusão do incisivo;

10-1-GoMe: distância entre a borda incisal do incisivo inferior e o plano mandibular. Determina a altura do processo alveolar inferior, em sua região anterior;

11-6-Pogperp: distância entre a face mesial do primeiro molar inferior e a linha pogônio perpendicular. Determina a posição ântero-posterior do primeiro molar inferior em relação à mandíbula, sendo que seu aumento indica uma mesialização do molar;

12-6-GoMe: distância entre a cúspide mésiovestibular do primeiro molar inferior e o plano mandibular. Determina a altura do processo alveolar inferior, em sua região posterior.

\section{Relações dentárias (figura 4)}

1- Trespasse horizontal: distância da borda incisal do incisivo inferior à borda incisal do incisivo superior, medida paralelamente ao plano oclusal funcional;

2- Trespasse vertical: distância da borda incisal do incisivo inferior à borda incisal do incisivo superior, medida paralelamente ao plano de Frankfurt;

3- Relação molar: distância da superfície mesial do primeiro molar superior à superfície mesial do primeiro molar inferior, medida paralelamente ao plano de Frankfurt. Seu aumento indica uma maior mesialização do molar inferior em relação ao superior;

4- Relação de caninos: distância da ponta da cúspide do canino superior à cúspide do canino inferior, medida paralelamente ao plano oclusal. 


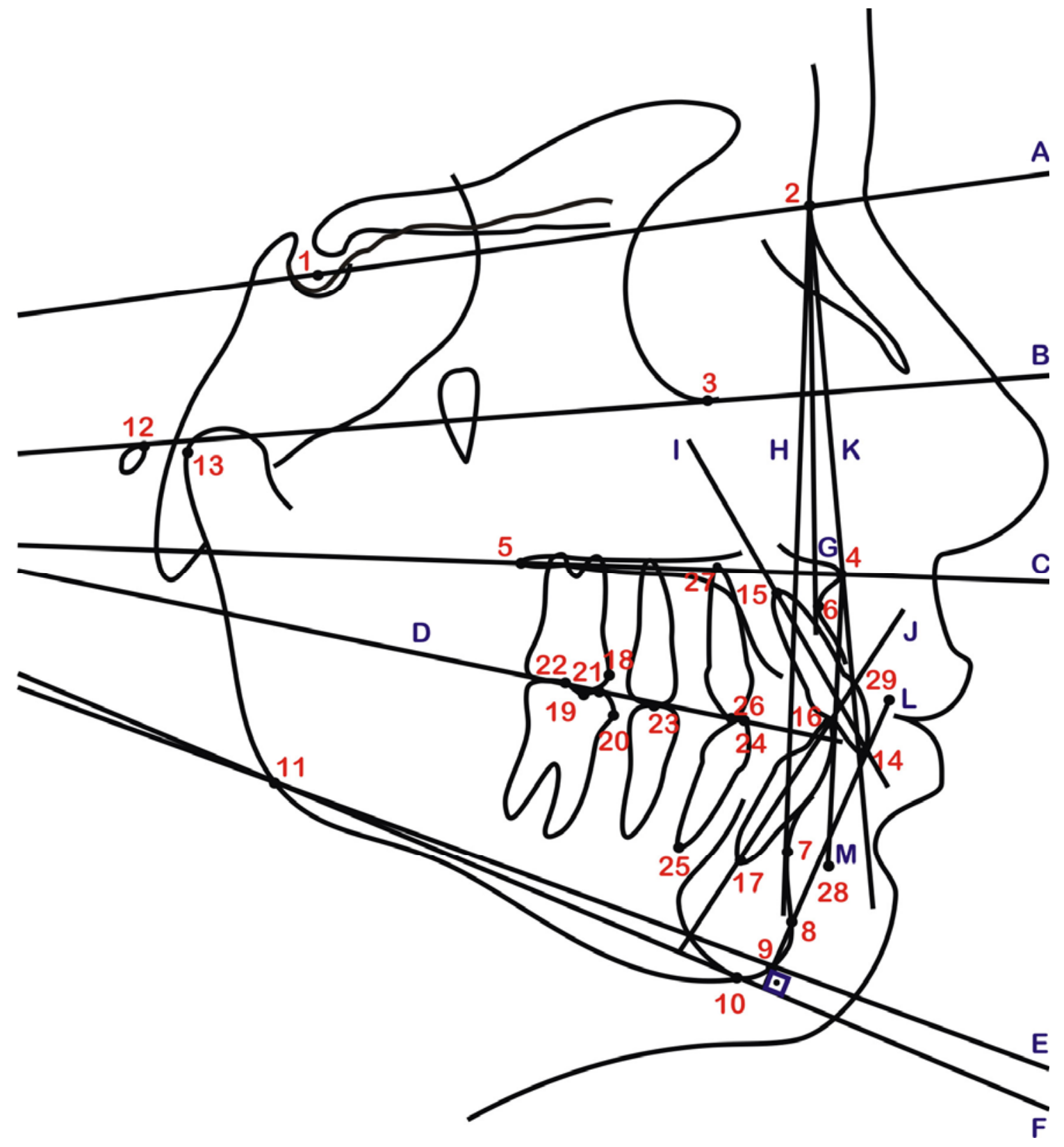

Figura 1. Pontos de referência, linhas e planos utilizados. 


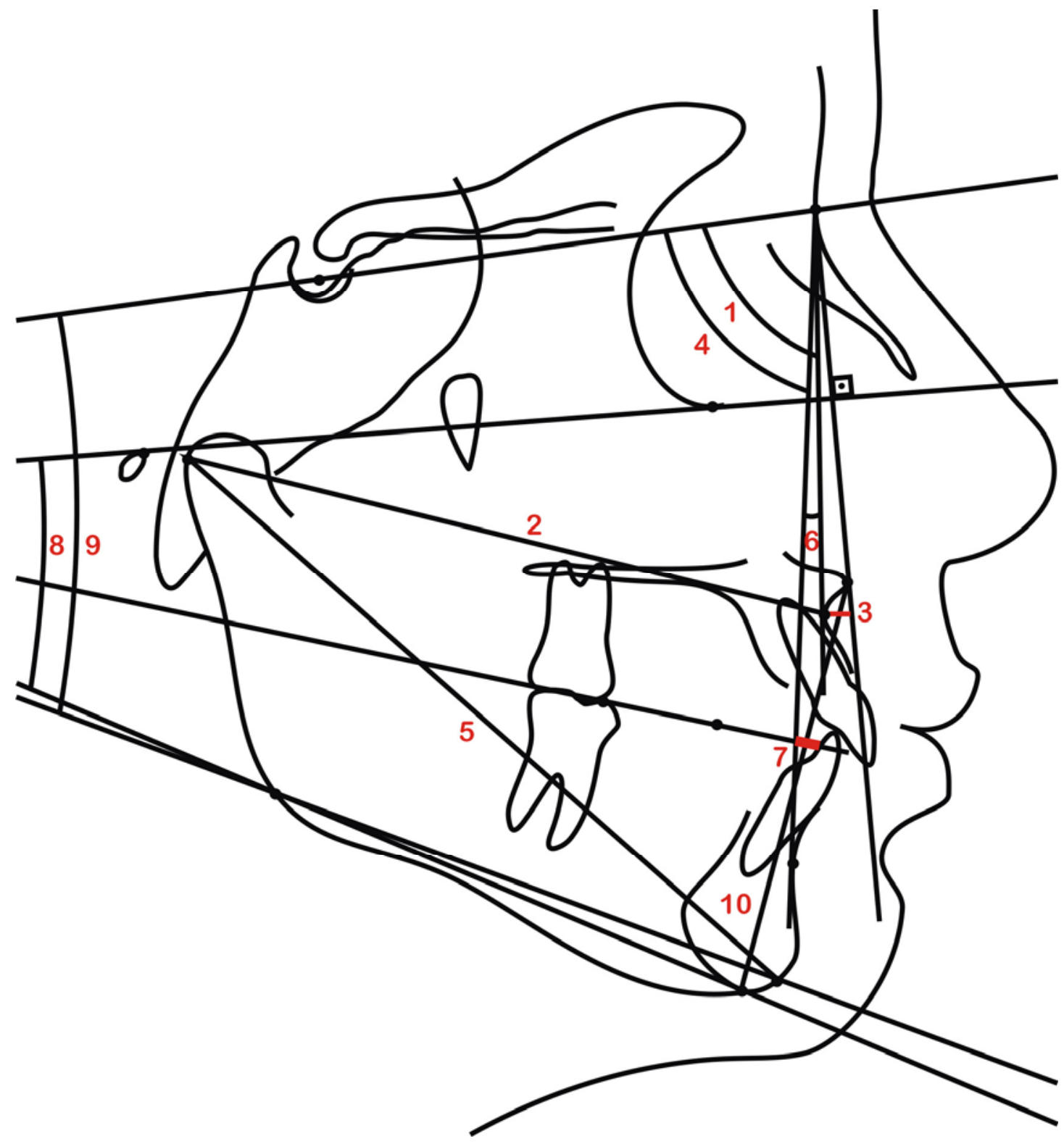

Figura 2. Grandezas cefalométricas esqueléticas 1) SNA; 2) Co-A; 3) ANperp; 4) SNB; 5) Co-Gn; 6) ANB; 7) Wits; 8) FMA; 9)SN.GoGn; 10) AFAI (ENA-Me). 


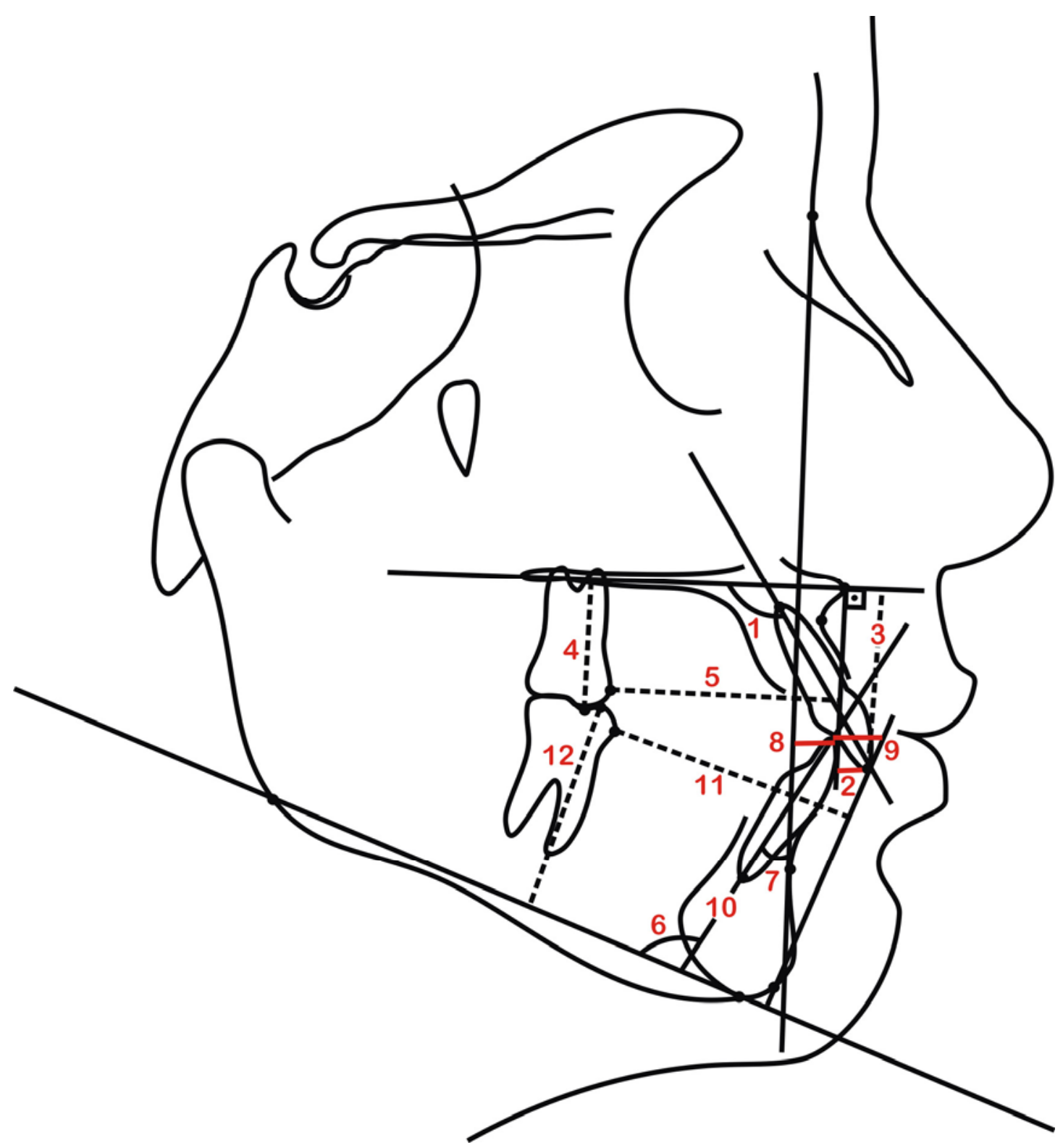

Figura 3. Grandezas cefalométricas dentárias

1) 1.PP; 2) 1-ENAperp; 3) 1-PP; 4) 6-PP; 5) 6-ENAperp; 6) IMPA; 7) 1.NB; 8) 1-NB; 9) 1-Pogperp; 10) 1-GoMe; 11) 6-Pogperp; 12) 6-GoMe. 

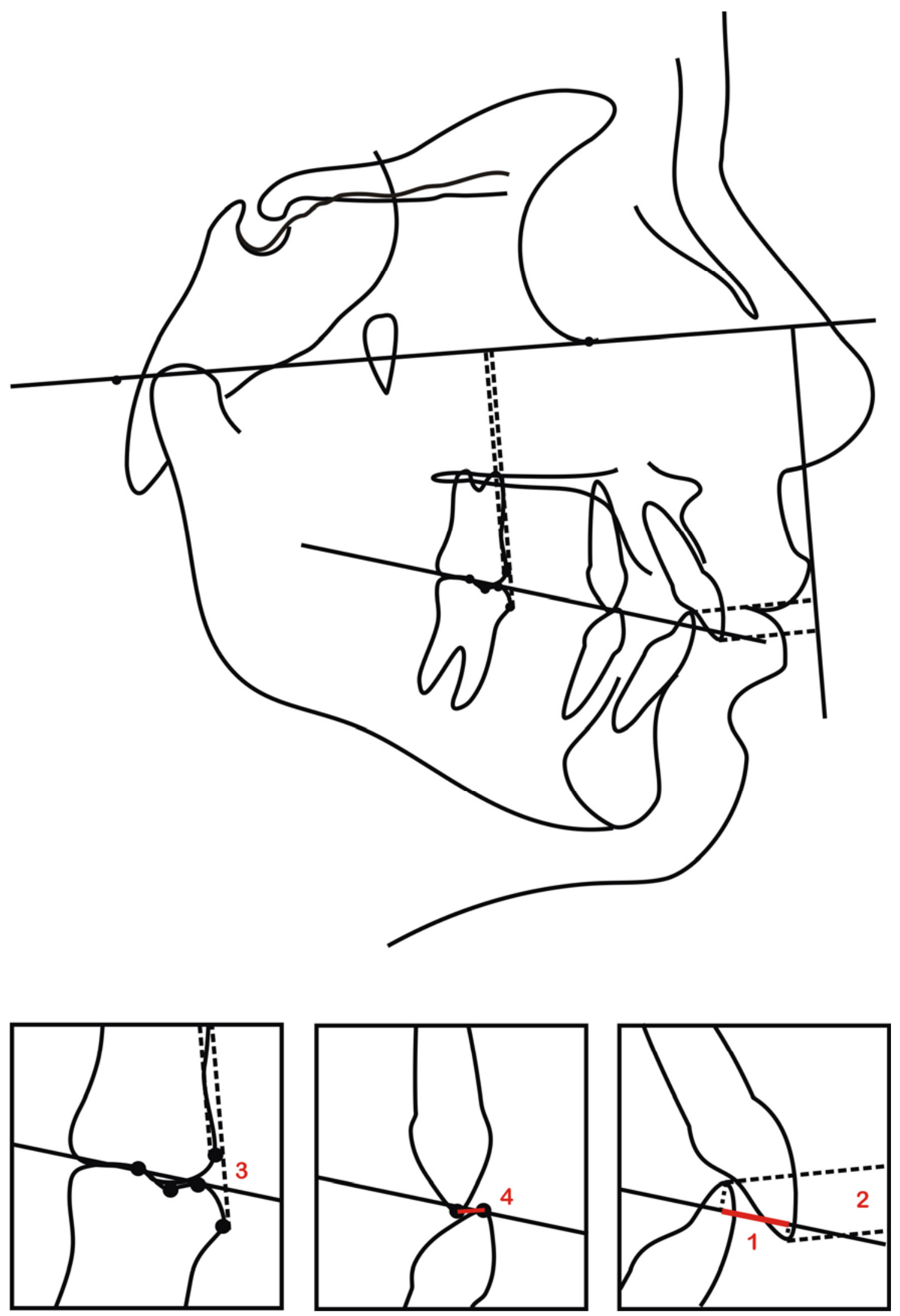

Figura 4. Relações dentárias

1) Trespasse horizontal; 2) Trespasse vertical; 3) Relação molar; 4) Relação de caninos. 


\subsubsection{Avaliação de modelos}

Nesta pesquisa além da avaliação radiográfica, foram avaliados os modelos de estudos pré e pós-tratamento de cada paciente. A partir de estes foi possível obter os valores do apinhamento inicial, índice de prioridade de tratamento inicial (IPT i), e Índice de prioridade final (IPT f).

O índice IPT foi eleito dentre vários outros, por ser confiável e principalmente por possibilitar: 1) avaliar a severidade da má oclusão previamente ao tratamento ortodôntico, 2) avaliar a melhora da má oclusão após o tratamento ortodôntico e 3) comparar a melhora da má oclusão entre os dois grupos selecionados, alcançando assim, avaliar a compatibilidade quanto à severidade da má oclusão ao início do tratamento e a quantidade de correção da má oclusão.

\section{Obtenção do índice de Prioridade de Tratamento}

O Índice de Prioridade de Tratamento - IPT, utilizado nesse trabalho, foi elaborado, em 1967, por GRAINGER ${ }^{70}$ e utilizado por outros autores ${ }^{9,28,89}$ demonstrando sua reprodutibilidade e eficácia como um indicador de severidade da má oclusão. A forma de obtenção do IPT foi realizada a partir de uma tabela (tabela 2) e será descrita a seguir.

Primeiramente verifica-se a relação molar do modelo inicial do paciente para selecionar a coluna mais apropriada da tabela 2. Como os grupos 1 e 2 deste trabalho apresentavam uma má oclusão de Classe II completa, todos os casos de pacientes selecionados foram marcados na primeira coluna da tabela 2 .

Escolhida a coluna apropriada para o tipo de má oclusão, o próximo passo foi a mensuração, em milímetros, da quantidade de sobressaliência, no sentido ântero-posterior tomando-se como referência a incisal dos incisivos superiores em relação à face vestibular aos inferiores. A partir do valor desta medida pode-se estimar o escore correspondente na tabela.

A sobremordida foi calculada tomando como referência a quantidade de terços da coroa clínica dos incisivos inferiores que se encontravam encobertos 
pelos incisivos superiores e foi então marcado na tabela o escore correspondente na mesma coluna da relação molar marcada inicialmente.

O próximo item analisado está relacionado com o deslocamento dentário em relação à posição ideal (apinhamento) e/ou rotação dentária que recebeu também o escore correspondente como explicado na tabela 2. A mordida cruzada foi avaliada pelo número de dentes posteriores superiores cruzados por vestibular ou por lingual. Aplicou-se também um escore para esse item. Dados os escores a todos os itens da tabela somou-se a esses valores a constante fornecida para cada tipo de má oclusão presente em cada coluna da tabela 2. A soma final constitui o valor do IPT que representa a severidade da má oclusão.

Foram necessárias duas cópias da tabela 2 para calcular os IPTs de cada paciente. Na primeira, o valor encontrado correspondeu aos modelos iniciais do paciente, ou seja, à severidade da má oclusão inicial e a segunda tabela foi utilizada para os dados do par de modelos finais do paciente que evidencia a condição oclusal final, obtida com o tratamento ortodôntico.

A melhora da má oclusão foi calculada como a diferença entre o IPT inicial e o final. Com isso, as abreviaturas para este índice, utilizadas durante o trabalho, estão representadas da seguinte maneira:

- IPT i: valor obtido para o Índice de Prioridade de Tratamento utilizando os modelos iniciais;

- IPT f: valor obtido para o Índice de Prioridade de Tratamento utilizando os modelos finais;

- IPT i - IPT f: valor resultante da diferença do IPT inicial e final, que representa a melhora da má oclusão com o tratamento. 
Tabela 2: Componentes do índice IPT com seus respectivos escores ${ }^{70}$.

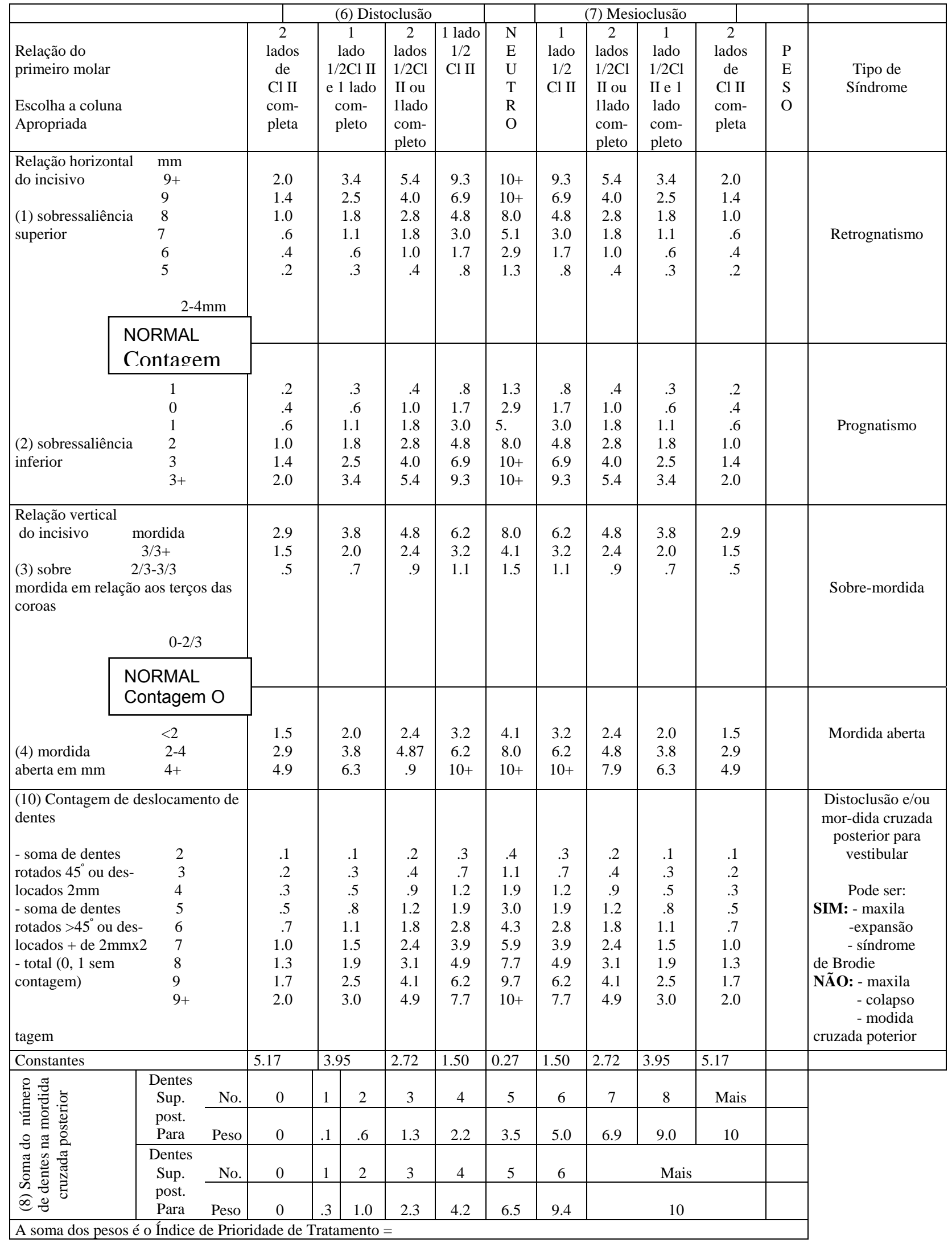




\subsubsection{Análise estatística}

\section{Erro do método}

Para análise do erro intra-examinador, foram selecionadas aleatoriamente 18 telerradiografias entre os dois grupos de estudo. Após um intervalo de 30 dias da primeira medição foram obtidos novamente os traçados cefalométricos e seguidamente estes foram digitalizados para a obtenção das medidas propostas.

Para a avaliação do erro inter-examinador foram comparadas 44 telerradiografias, sendo que 22 foram traçadas pelo avaliador 1 e 22 pelo avaliador 2, determinou-se desse modo a calibração de ambos os pesquisadores. Após de realizados a demarcação dos pontos e digitalização dos traçados cefalométricos foi utilizado o teste $t$ para amostras dependentes para a avaliação dos erros sistemáticos ${ }^{12,84,148}$. Os erros casuais foram avaliados por meio da fórmula matemática proposta por Dahlberg ${ }^{44}\left(S^{2}=\right.$ $\left.\Sigma d^{2} / 2 n\right)$.

\section{Comparação entre os grupos e variáveis}

O teste $\mathrm{t}$ foi utilizado para avaliar a compatibilidade entre os grupos, quanto ao apinhamento inicial, idade inicial, idade final e a severidade inicial da má oclusão. A comparação das características oclusais presentes ao final do tratamento (IPT f), quantidade de melhora (IPT f - IPT i) assim como tempo de tratamento e de observação pós-tratamento foram realizadas de forma semelhante.

O teste não paramétrico do Qui-quadrado foi utilizado para avaliar a compatibilidade dos dois grupos estudados quanto à distribuição por gêneros, proporção dos tipos de má oclusão de Classe II (Classe II, Divisão 1 e 2) e dos pacientes com contenção $3 \times 3$.

Para avaliar as variáveis entre os dois grupos nos três estágios ( $T 1$, T2,T3), assim como a diferença entre as alterações ocorridas em ambos períodos de avaliação (T2 -T1; T3 -T2) também foi utilizado o teste t. 
Tendo em consideração que a diferença entre os grupos quanto a proporção de má oclusão de Classe II e a proporção de pacientes com contenção $3 \times 3$ poderia influenciar no comportamento das variáveis em longo prazo, e assim comprometer os resultados deste estudo, compatibilizou-se os grupos quanto a estas duas variáveis e, em seguida, se aplicou o teste t para comparar todas as medidas no estagio pós-tratamento (T3) e as alterações que ocorreram nelas durante o período de observação pós-tratamento (T3 - T2).

Foi realizado também o teste de correlação de Pearson, para avaliar o grau de correlação entre as alterações que ocorreram nas relações dentárias durante o tratamento e aquelas que ocorreram no período pós-tratamento. Da mesma forma, foi avaliada a relação da recidiva da relação molar com a recidiva das outras variáveis estudadas.

Foram considerados estatisticamente significantes resultados com valor de $p<0,05$. 

Resultados 



\section{RESULTADOS}

Os resultados estão apresentados sob forma de tabelas. A tabela 3 apresenta os valores dos erros casuais e sistemáticos do teste intraexaminador, por meio da aplicação do teste $t$ pareado e da fórmula de Dahlberg $^{44}$, aplicadas a todas as variáveis estudadas. Na tabela 4 encontramse os valores dos erros casuais e sistemáticos do teste interexaminador. $\mathrm{Na}$ tabela 5 encontram-se a compatibilidade dos grupos ao início do tratamento quanto ao apinhamento, idade, severidade da má oclusão (IPT), tempo de tratamento e tempo de controle pós-tratamento. Os resultados da avaliação da compatibilidade dos grupos quanto à proporção dos tipos de má oclusão de Classe II (Classe II, Divisão 1 e 2), proporção dos gêneros e a proporção dos pacientes portadores de contenção inferior $3 \times 3$, avaliados pelo teste do QuiQuadrado, são apresentados nas tabelas 6, 7 e 8 respectivamente.

Na tabela 9 encontram-se os resultados da comparação das variáveis ao início do tratamento entre os grupos 1 e 2 (T1). A tabela 10 representa a comparação das variáveis ao final do tratamento(T2). A tabela 11 corresponde à comparação das variáveis entre os grupos 1 e 2 na avaliação no estágio de observação pós-tratamento(T3). A tabela 12 mostra os resultados da comparação das alterações obtidas com o tratamento ortodôntico, entre os grupos 1 e 2 (T2-T1). A tabela 13 representa a comparação entre os grupos das alterações acontecidas no período de observação pós-tratamento(T3-T2). A tabela 14 contém as médias, desvios-padrão e resultados do teste t entre as alterações pós-tratamento (T3-T2) dos grupos 1 e 2, incluindo somente os pacientes com má oclusão de Classe II, Divisão 1. Na tabela 15 são apresentadas as médias, desvios-padrão e resultados do teste t para avaliação das variáveis entre os grupos 1 e 2 no estágio de observação póstratamento(T3) e no período de observação pós-tratamento excluindo todos os pacientes com contenção $3 \times 3$. Na tabela 16 apresenta os resultados do teste $t$ entre as alterações que ocorreram no período pós-tratamento (T3-T2) do grupo 1 e do grupo 2, excluindo todos os pacientes com contenção $3 \times 3$. Na tabela 17 e 18 são apresentados os resultados do teste $t$ para avaliação das variáveis entre os grupos 1 e 2 no estágio de observação pós-tratamento (T3) e as alterações ocorridas no período pós-tratamento, incluindo somente pacientes com apinhamento compatível. Na tabela 19 são apresentados os resultados da correlação das alterações ocorridas nas relações dentárias em ambos os 
grupos durante o tratamento e no período de observação pós-tratamento. Nas tabelas 20 e 21 encontram-se os resultados da análise de correlação entre as alterações ocorridas na relação molar durante o tratamento e no período de observação pós-tratamento do grupo 1 e do grupo 2 respectivamente. Nas tabelas 22 e 23 são apresentados os resultados da análise de correlação entre a quantidade de recidiva da relação molar es as alterações das variáveis estudadas, no período de observação pós-tratamento (T3-T2), no grupo 1 e 2 respectivamente.

Tabela 3: Resultados do teste t pareado e da fórmula de Dahlberg ${ }^{44}$, aplicados para a avaliação dos erros intra-examinador.

\begin{tabular}{|c|c|c|c|c|c|c|c|}
\hline \multirow[b]{2}{*}{ VARIÁVEIS } & \multicolumn{2}{|c|}{$\begin{array}{c}1^{\circ} \text { TRAÇADO } \\
(n=18)\end{array}$} & \multicolumn{2}{|c|}{$\begin{array}{c}2^{\circ} \text { TRAÇADO } \\
(n=18)\end{array}$} & \multirow[b]{2}{*}{ G. L } & \multirow[b]{2}{*}{$\mathbf{P}$} & \multirow[b]{2}{*}{ Dahlberg } \\
\hline & MÉDIA & $d p$ & MÉDIA & dp & & & \\
\hline \multicolumn{8}{|c|}{ Componente Maxilar } \\
\hline SNA & 78,14 & 2,81 & 78,95 & 2,74 & 17,00 & 0,060 & 1,31 \\
\hline CoA & 83,59 & 5,25 & 84,43 & 5,32 & 17,00 & 0,165 & 1,79 \\
\hline A-Nperp & $-1,69$ & 3,77 & $-1,17$ & 3,14 & 17,00 & 0,383 & 1,74 \\
\hline \multicolumn{8}{|c|}{ Componente mandibular } \\
\hline SNB & 74,02 & 3,17 & 74,17 & 3,23 & 17,00 & 0,666 & 1,00 \\
\hline CoGn & 109,83 & 6,77 & 110,18 & 6,83 & 17,00 & 0,586 & 1,86 \\
\hline \multicolumn{8}{|c|}{ Relação maxilomandibular } \\
\hline ANB & 4,12 & 3,02 & 4,78 & 2,58 & 17,00 & 0,114 & 1,24 \\
\hline Wits & 3,40 & 3,59 & 4,06 & 3,07 & 17,00 & 0,240 & 1,65 \\
\hline \multicolumn{8}{|c|}{ Padrão de crescimento } \\
\hline FMA & 30,32 & 6,27 & 30,04 & 5,88 & 17,00 & 0,819 & 3,49 \\
\hline SNGoGn & 37,84 & 6,87 & 37,44 & 6,47 & 17,00 & 0,682 & 2,85 \\
\hline AFAI & 68,91 & 4,99 & 69,43 & 5,30 & 17,00 & 0,008 & 0,62 \\
\hline \multicolumn{8}{|c|}{ Componente dentoalveolar superior } \\
\hline 1.PP & 109,58 & 5,41 & 109,27 & 5,17 & 17,00 & 0,733 & 2,58 \\
\hline 1-ENAperp & $-3,94$ & 2,85 & $-3,82$ & 2,28 & 17,00 & 0,832 & 1,58 \\
\hline 1-pp & 30,01 & 2,41 & 30,37 & 2,46 & 17,00 & 0,001 & 0,37 \\
\hline 6-pp & 25,24 & 2,13 & 25,52 & 2,21 & 17,00 & 0,165 & 0,60 \\
\hline 6-ENAperp & $-25,64$ & 2,91 & $-25,81$ & 2,76 & 17,00 & 0,715 & 1,31 \\
\hline \multicolumn{8}{|c|}{ Componente dentoalveolar inferior } \\
\hline IMPA & 90,76 & 6,33 & 90,84 & 6,97 & 17,00 & 0,946 & 3,53 \\
\hline 1.NB & 25,30 & 4,72 & 24,94 & 5,32 & 17,00 & 0,583 & 1,90 \\
\hline 1-NB & 4,59 & 1,89 & 4,57 & 2,12 & 17,00 & 0,857 & 0,35 \\
\hline 1-pog per & $-10,98$ & 4,02 & $-11,28$ & 4,33 & 17,00 & 0,539 & 1,41 \\
\hline 1-GoMe & 40,55 & 2,66 & 40,58 & 2,61 & 17,00 & 0,902 & 0,65 \\
\hline 6-pogper & $-24,98$ & 3,37 & $-25,26$ & 3,52 & 17,00 & 0,348 & 0,86 \\
\hline 6-GoMe & 31,61 & 2,28 & 31,79 & 2,45 & 17,00 & 0,348 & 0,57 \\
\hline \multicolumn{8}{|c|}{ Relações dentárias } \\
\hline Thor & 4,96 & 1,52 & 4,92 & 1,63 & 17,00 & 0,861 & 0,64 \\
\hline T ver & 3,95 & 1,52 & 3,83 & 1,30 & 17,00 & 0,715 & 0,96 \\
\hline Rel mol & $-0,18$ & 1,09 & $-0,34$ & 0,84 & 17,00 & 0,344 & 0,48 \\
\hline Rel can & 0,09 & 1,29 & 0,75 & 1,43 & 17,00 & 0,071 & 1,09 \\
\hline
\end{tabular}


Tabela 4: Resultados do teste t pareado e da fórmula de Dahlberg ${ }^{44}$, aplicados para a avaliação dos erros interexaminador.

\begin{tabular}{|c|c|c|c|c|c|c|c|}
\hline \multirow[b]{2}{*}{ VARIÁVEIS } & \multicolumn{2}{|c|}{$\begin{array}{l}\text { EXAMINADOR } 1 \\
(n=22)\end{array}$} & \multicolumn{2}{|c|}{$\begin{array}{c}\text { EXAMINADOR } 2 \\
(n=22)\end{array}$} & \multirow[b]{2}{*}{ G.L } & \multirow[b]{2}{*}{ p } & \multirow[b]{2}{*}{ Dahlberg } \\
\hline & MÉDIA & $d p$ & MÉDIA & $d p$ & & & \\
\hline \multicolumn{8}{|c|}{ Componente Maxilar } \\
\hline SNA & 78,65 & 3,74 & 78,60 & 3,81 & 21,00 & 0,900 & 1,39 \\
\hline CoA & 83,14 & 3,87 & 83,58 & 4,08 & 21,00 & 0,444 & 1,84 \\
\hline A-Nperp & $-1,25$ & 3,11 & $-0,56$ & 3,81 & 21,00 & 0,244 & 1,90 \\
\hline \multicolumn{8}{|c|}{ Componente mandibular } \\
\hline SNB & 73,34 & 2,20 & 73,30 & 2,57 & 21,00 & 0,910 & 0,90 \\
\hline CoGn & 106,01 & 5,43 & 106,81 & 5,66 & 21,00 & 0,170 & 1,91 \\
\hline \multicolumn{8}{|c|}{ Relação maxilomandibular } \\
\hline ANB & 5,32 & 2,91 & 5,28 & 2,92 & 21,00 & 0,945 & 1,69 \\
\hline Wits & 4,51 & 4,17 & 3,95 & 4,47 & 21,00 & 0,354 & 1,95 \\
\hline \multicolumn{8}{|c|}{ Padrão de crescimento } \\
\hline FMA & 32,28 & 4,47 & 31,25 & 4,50 & 21,00 & 0,280 & 3,09 \\
\hline SNGoGn & 40,30 & 4,03 & 39,25 & 3,85 & 21,00 & 0,121 & 2,22 \\
\hline AFAI & 68,65 & 5,27 & 67,68 & 6,14 & 21,00 & 0,177 & 2,35 \\
\hline \multicolumn{8}{|c|}{ Componente dentoalveolar superior } \\
\hline 1.PP & 111,14 & 9,30 & 112,76 & 8,81 & 21,00 & 0,323 & 5,30 \\
\hline 1-ENAperp & $-3,46$ & 4,23 & $-3,60$ & 3,92 & 21,00 & 0,874 & 2,84 \\
\hline 1-pp & 29,45 & 2,46 & 28,80 & 2,96 & 21,00 & 0,199 & 1,64 \\
\hline 6-pp & 24,37 & 2,19 & 23,58 & 2,58 & 21,00 & 0,115 & 1,65 \\
\hline 6-ENAperp & $-28,20$ & 2,65 & $-28,18$ & 2,97 & 21,00 & 0,979 & 1,63 \\
\hline \multicolumn{8}{|c|}{ Componente dentoalveolar inferior } \\
\hline IMPA & 88,90 & 5,84 & 90,82 & 5,49 & 21,00 & 0,124 & 4,12 \\
\hline 1.NB & 24,65 & 4,81 & 26,21 & 3,85 & 21,00 & 0,127 & 3,37 \\
\hline 1-NB & 5,06 & 1,48 & 4,39 & 1,70 & 21,00 & 0,022 & 1,00 \\
\hline 1-pog per & $-13,40$ & 3,45 & $-11,57$ & 2,60 & 21,00 & 0,007 & 2,36 \\
\hline 1-GoMe & 40,15 & 1,82 & 39,63 & 2,41 & 21,00 & 0,134 & 1,15 \\
\hline 6-pogper & $-29,59$ & 2,72 & $-28,35$ & 2,56 & 21,00 & 0,001 & 1,39 \\
\hline 6-GoMe & 30,02 & 2,32 & 29,78 & 2,25 & 21,00 & 0,562 & 1,34 \\
\hline \multicolumn{8}{|c|}{ Relações dentárias } \\
\hline T hor & 6,18 & 3,56 & 6,28 & 3,61 & 21,00 & 0,626 & 0,63 \\
\hline T ver & 3,72 & 1,75 & 3,46 & 1,77 & 21,00 & 0,514 & 1,25 \\
\hline Rel mol & 1,32 & 2,59 & 1,57 & 2,28 & 21,00 & 0,402 & 0,98 \\
\hline Rel can & 0,78 & 2,97 & 2,26 & 2,41 & 21,00 & 0,000 & 1,53 \\
\hline
\end{tabular}


Tabela 5: Resultados do teste $t$ independente para avaliar a compatibilidade entre os grupos quanto à idade, severidade da má oclusão e tempo de tratamento.

\begin{tabular}{l|c|c|c|c|c|c}
\hline \multirow{2}{*}{ VARIÁVEIS } & \multicolumn{2}{|c|}{$\begin{array}{c}\text { GRUPO 1 } \\
\text { (Xp 2pré) } \\
\mathbf{n = 3 0}\end{array}$} & \multicolumn{2}{c|}{$\begin{array}{c}\text { GRUPO 2 } \\
\text { (Xp 4pré) } \\
\mathbf{n = 3 0}\end{array}$} & \multirow{2}{*}{ G.L } & p \\
\cline { 2 - 6 } & Média & $\mathrm{dp}$ & Média & $\mathrm{dp}$ & & \\
\hline Apinhamento & $\mathbf{0 , 7 7}$ & $\mathbf{1 , 3 8}$ & $\mathbf{3 , 5 5}$ & $\mathbf{2 , 8 5}$ & $\mathbf{5 8}$ & $\mathbf{0 , 0 0 0}$ \\
\hline Idade i & 12,87 & 1,49 & 13,64 & 2,26 & 58 & 0,125 \\
\hline Idade f & 15,40 & 1,71 & 16,21 & 2,35 & 58 & 0,131 \\
\hline IPT i & 7,84 & 1,11 & 7,82 & 1,21 & 58 & 0,965 \\
\hline IPT f & 0,71 & 0,79 & 1,17 & 1,20 & 58 & 0,082 \\
\hline IPT i-IPT f & 7,13 & 1,48 & 6,65 & 1,81 & 58 & 0,268 \\
\hline Tempo de tratamento & 2,53 & 0,72 & 2,57 & 0,65 & 58 & 0,816 \\
\hline Tempo de Observação & 9,25 & 3,52 & 9,58 & 4,24 & 58 & 0,743 \\
\hline
\end{tabular}

Tabela 6: Resultados do teste Qui-Quadrado para avaliar a compatibilidade entre os grupos quanto à proporção de gêneros.

\begin{tabular}{|c|c|c|c|}
\hline GÊNERO & GRUPO 1 & GRUPO 2 & TOTAL \\
\hline Feminino & 13 & 16 & 29 \\
\hline Masculino & 17 & 14 & 31 \\
\hline Total & 30 & 30 & 60 \\
\hline$X^{2}=0,6$ & & $=1$ & 0,438 \\
\hline
\end{tabular}

Tabela 7: Resultados do teste Qui-Quadrado para avaliar a compatibilidade entre os grupos quanto à proporção de tipo de má oclusão.

\begin{tabular}{l|r|r|r}
\hline OCLUSÃO & GRUPO 1 & GRUPO 2 & TOTAL \\
\hline Classe II div.1 & 23 & 30 & 53 \\
\hline Classe II div.2 & 7 & 0 & 7 \\
\hline Total & 30 & 30 & 60 \\
\hline $\mathrm{X}^{2}=10,631$ & $\mathrm{df}=1$ & \multicolumn{2}{|c|}{$\mathbf{0 , 0 0 1}$} \\
\hline
\end{tabular}

Tabela 8: Resultados do teste Qui-Quadrado para avaliar a compatibilidade entre os grupos quanto à proporção de pacientes com contenção $3 \times 3$.

\begin{tabular}{l|r|r|r}
\hline CONTENÇÃO & GRUPO 1 & GRUPO 2 & \multicolumn{1}{l}{ TOTAL } \\
\hline Pacientes sem 3x3 & 17 & 28 & 45 \\
\hline Pacientes com 3x3 & 13 & 2 & 15 \\
\hline Total & 30 & 30 & 60 \\
\hline$X^{2}=11,731$ & $\mathrm{df}=1$ & $\mathbf{p = 0 , 0 0 1}$ \\
\hline
\end{tabular}


Tabela 9: Médias, desvios-padrão e resultados do teste t para avaliação das variáveis ao início do tratamento (T1) entre o grupo 1 e o grupo 2.

\begin{tabular}{|c|c|c|c|c|c|c|}
\hline \multirow[b]{2}{*}{ VARIÁVEIS } & \multicolumn{2}{|c|}{$\begin{array}{c}\text { GRUPO } 1 \\
\text { (Xp 2pré) } \\
n=30\end{array}$} & \multicolumn{2}{|c|}{$\begin{array}{c}\text { GRUPO } 2 \\
\text { (Xp 4pré) } \\
n=30\end{array}$} & \multirow[b]{2}{*}{ G. L } & \multirow[b]{2}{*}{$\mathbf{P}$} \\
\hline & MÉDIA & $d p$ & MÉDIA & Dp & & \\
\hline \multicolumn{7}{|c|}{ Componente Maxilar } \\
\hline SNA & 81,21 & 3,54 & 81,03 & 2,96 & 58 & 0,832 \\
\hline Côa & 86,52 & 5,07 & 84,03 & 5,14 & 58 & 0,064 \\
\hline A-Nperp & $-0,03$ & 3,79 & 0,24 & 2,74 & 58 & 0,750 \\
\hline \multicolumn{7}{|c|}{ Componente mandibular } \\
\hline SNB & 76,20 & 2,51 & 74,78 & 2,69 & 58 & 0,039 \\
\hline CoGn & 107,73 & 6,34 & 104,53 & 5,45 & 58 & 0,041 \\
\hline \multicolumn{7}{|c|}{ Relação maxilomandibular } \\
\hline ANB & 5,00 & 2,53 & 6,25 & 2,31 & 58 & 0,052 \\
\hline Wits & 4,91 & 2,24 & 6,69 & 3,73 & 58 & 0,029 \\
\hline \multicolumn{7}{|c|}{ Padrão de crescimento } \\
\hline FMA & 26,03 & 4,77 & 29,72 & 6,38 & 58 & 0,014 \\
\hline SNGoGn & 32,80 & 5,17 & 36,65 & 6,24 & 58 & 0,012 \\
\hline AFAI & 64,14 & 4,70 & 65,67 & 6,51 & 58 & 0,300 \\
\hline \multicolumn{7}{|c|}{ Componente dentoalveolar superior } \\
\hline 1.PP & 112,01 & 7,64 & 117,44 & 7,69 & 58 & 0,008 \\
\hline 1-ENAperp & $-0,70$ & 2,93 & 0,44 & 3,26 & 58 & 0,157 \\
\hline 1-pp & 28,47 & 2,53 & 27,96 & 2,75 & 58 & 0,457 \\
\hline 6-pp & 23,23 & 2,62 & 23,44 & 2,26 & 58 & 0,745 \\
\hline 6-ENAperp & $-28,24$ & 2,25 & $-27,61$ & 3,09 & 58 & 0,373 \\
\hline \multicolumn{7}{|c|}{ Componente dentoalveolar inferior } \\
\hline IMPA & 94,49 & 6,47 & 92,08 & 7,26 & 58 & 0,179 \\
\hline 1.NB & 25,39 & 6,46 & 25,80 & 4,99 & 58 & 0,783 \\
\hline 1-NB & 4,87 & 2,55 & 5,87 & 2,15 & 58 & 0,105 \\
\hline 1-pog per & $-9,85$ & 3,11 & $-10,04$ & 4,38 & 58 & 0,852 \\
\hline 1-GoMe & 38,92 & 2,60 & 40,27 & 3,01 & 58 & 0,067 \\
\hline 6-pogper & $-30,74$ & 2,36 & $-28,74$ & 3,27 & 58 & 0,009 \\
\hline 6-GoMe & 28,19 & 1,98 & 28,71 & 2,51 & 58 & 0,383 \\
\hline \multicolumn{7}{|c|}{ Relações dentárias } \\
\hline T hor & 7,51 & 2,39 & 8,66 & 2,74 & 58 & 0,089 \\
\hline T ver & 4,58 & 2,65 & 4,29 & 1,96 & 58 & 0,636 \\
\hline Rel mol & 3,73 & 0,64 & 3,36 & 0,95 & 58 & 0,079 \\
\hline Rel can & 4,02 & 1,46 & 3,71 & 1,19 & 58 & 0,370 \\
\hline
\end{tabular}


Tabela 10: Médias, desvios-padrão e resultados do teste t para avaliação das variáveis ao final do tratamento ortodôntico (T2), entre os grupos 1 e 2.

\begin{tabular}{|c|c|c|c|c|c|c|}
\hline \multirow[b]{2}{*}{ VARIÁVEIS } & \multicolumn{2}{|c|}{$\begin{array}{c}\text { GRUPO } 1 \\
\text { (Xp 2pré) } \\
n=30\end{array}$} & \multicolumn{2}{|c|}{$\begin{array}{c}\text { GRUPO } 2 \\
\text { (Xp 4pré) } \\
n=30\end{array}$} & \multirow[b]{2}{*}{ G. L } & \multirow[b]{2}{*}{$\mathbf{P}$} \\
\hline & MÉDIA & $d p$ & MÉDIA & $d p$ & & \\
\hline \multicolumn{7}{|c|}{ Componente Maxilar } \\
\hline SNA & 79,39 & 3,36 & 78,54 & 3,84 & 58 & 0,364 \\
\hline CoA & 86,27 & 5,42 & 83,90 & 5,28 & 58 & 0,092 \\
\hline A-Nperp & $-2,54$ & 3,85 & $-2,46$ & 3,65 & 58 & 0,937 \\
\hline \multicolumn{7}{|c|}{ Componente mandibular } \\
\hline SNB & 76,55 & 2,76 & 74,62 & 3,31 & 58 & 0,017 \\
\hline CoGn & 111,94 & 6,39 & 109,16 & 6,12 & 58 & 0,091 \\
\hline \multicolumn{7}{|c|}{ Relação maxilomandibular } \\
\hline ANB & 2,85 & 2,19 & 3,93 & 2,55 & 58 & 0,083 \\
\hline Wits & 2,87 & 2,03 & 2,31 & 3,44 & 58 & 0,443 \\
\hline \multicolumn{7}{|c|}{ Padrão de crescimento } \\
\hline FMA & 26,62 & 5,54 & 30,03 & 7,30 & 58 & 0,046 \\
\hline SNGoGn & 32,59 & 6,06 & 36,71 & 6,90 & 58 & 0,017 \\
\hline AFAI & 67,13 & 4,54 & 68,49 & 6,59 & 58 & 0,357 \\
\hline \multicolumn{7}{|c|}{ Componente dentoalveolar superior } \\
\hline 1.PP & 112,96 & 7,11 & 107,57 & 7,07 & 58 & 0,005 \\
\hline 1-ENAperp & $-2,62$ & 2,22 & $-4,80$ & 3,68 & 58 & 0,007 \\
\hline 1-pp & 27,67 & 3,11 & 29,51 & 2,98 & 58 & 0,023 \\
\hline 6-pp & 24,71 & 2,07 & 24,76 & 2,66 & 58 & 0,936 \\
\hline 6-ENAperp & $-25,41$ & 2,23 & $-26,87$ & 2,66 & 58 & 0,025 \\
\hline \multicolumn{7}{|c|}{ Componente dentoalveolar inferior } \\
\hline IMPA & 95,37 & 7,69 & 91,08 & 6,21 & 58 & 0,021 \\
\hline 1.NB & 26,45 & 6,87 & 24,77 & 5,26 & 58 & 0,293 \\
\hline 1-NB & 5,55 & 2,23 & 4,59 & 2,27 & 58 & 0,103 \\
\hline 1-pog per & $-9,95$ & 3,06 & $-12,06$ & 4,55 & 58 & 0,040 \\
\hline 1-GoMe & 40,29 & 2,57 & 39,62 & 3,18 & 58 & 0,375 \\
\hline 6-pogper & $-31,03$ & 2,71 & $-27,19$ & 3,33 & 58 & 0,000 \\
\hline 6-GoMe & 30,78 & 2,27 & 31,48 & 2,46 & 58 & 0,259 \\
\hline \multicolumn{7}{|c|}{ Relações dentárias } \\
\hline T hor & 3,18 & 0,80 & 3,55 & 0,75 & 58 & 0,070 \\
\hline T ver & 1,85 & 0,94 & 2,97 & 1,08 & 58 & 0,000 \\
\hline Rel mol & 4,17 & 0,63 & $-0,88$ & 0,78 & 58 & 0,000 \\
\hline Rel can & $-2,00$ & 0,94 & $-1,28$ & 1,28 & 58 & 0,016 \\
\hline
\end{tabular}


Tabela 11: Médias, desvios-padrão e resultados do teste t para avaliação das variáveis entre os grupos 1 e 2 no estágio de observação pós-tratamento (T3).

\begin{tabular}{|c|c|c|c|c|c|c|}
\hline \multirow[b]{2}{*}{ VARIÁVEIS } & \multicolumn{2}{|c|}{$\begin{array}{c}\text { GRUPO } 1 \\
\text { (Xp 2pré) } \\
n=30\end{array}$} & \multicolumn{2}{|c|}{$\begin{array}{c}\text { GRUPO } 2 \\
\text { (Xp 4pré) } \\
n=30\end{array}$} & \multirow[b]{2}{*}{ G. L } & \multirow[b]{2}{*}{$\mathbf{P}$} \\
\hline & MÉDIA & $d p$ & MÉDIA & $d p$ & & \\
\hline \multicolumn{7}{|c|}{ Componente Maxilar } \\
\hline SNA & 81,29 & 3,34 & 78,78 & 3,52 & 58 & 0,006 \\
\hline CoA & 88,28 & 4,95 & 85,19 & 5,53 & 58 & 0,026 \\
\hline A-Nperp & $-0,14$ & 3,05 & $-1,19$ & 3,59 & 58 & 0,226 \\
\hline \multicolumn{7}{|c|}{ Componente mandibular } \\
\hline SNB & 77,36 & 3,39 & 75,03 & 3,71 & 58 & 0,013 \\
\hline CoGn & 114,15 & 6,74 & 111,67 & 7,36 & 58 & 0,179 \\
\hline \multicolumn{7}{|c|}{ Relação maxilomandibular } \\
\hline ANB & 3,93 & 1,82 & 3,75 & 2,80 & 58 & 0,773 \\
\hline Wits & 3,64 & 1,37 & 2,90 & 3,48 & 58 & 0,281 \\
\hline \multicolumn{7}{|c|}{ Padrão de crescimento } \\
\hline FMA & 24,23 & 5,40 & 27,65 & 7,47 & 58 & 0,047 \\
\hline SNGoGn & 30,45 & 6,78 & 35,20 & 7,59 & 58 & 0,013 \\
\hline AFAI & 67,66 & 5,46 & 68,17 & 6,58 & 58 & 0,744 \\
\hline \multicolumn{7}{|c|}{ Componente dentoalveolar superior } \\
\hline 1.PP & 113,37 & 7,14 & 109,07 & 6,36 & 58 & 0,017 \\
\hline 1-ENAperp & $-3,20$ & 2,93 & $-3,91$ & 3,52 & 58 & 0,404 \\
\hline 1-pp & 28,26 & 3,13 & 29,48 & 2,93 & 58 & 0,125 \\
\hline 6-pp & 24,85 & 2,32 & 25,11 & 2,31 & 58 & 0,665 \\
\hline 6-ENAperp & $-24,60$ & 2,31 & $-25,37$ & 3,30 & 58 & 0,299 \\
\hline \multicolumn{7}{|c|}{ Componente dentoalveolar inferior } \\
\hline IMPA & 95,71 & 7,01 & 91,48 & 6,04 & 58 & 0,015 \\
\hline 1.NB & 25,84 & 6,20 & 24,23 & 5,09 & 58 & 0,276 \\
\hline 1-NB & 5,27 & 2,31 & 3,87 & 2,32 & 58 & 0,022 \\
\hline 1-pog per & $-9,09$ & 3,44 & $-10,95$ & 3,78 & 58 & 0,051 \\
\hline 1-GoMe & 41,02 & 3,09 & 40,20 & 3,40 & 58 & 0,331 \\
\hline 6-pogper & $-29,00$ & 2,76 & $-25,16$ & 2,99 & 58 & 0,000 \\
\hline 6-GoMe & 32,04 & 2,35 & 31,93 & 2,86 & 58 & 0,867 \\
\hline \multicolumn{7}{|c|}{ Relações dentárias } \\
\hline T hor & 3,73 & 0,98 & 4,71 & 1,37 & 58 & 0,002 \\
\hline T ver & 2,89 & 1,28 & 3,85 & 1,50 & 58 & 0,010 \\
\hline Rel mol & 4,28 & 0,95 & $-0,27$ & 1,04 & 58 & 0,000 \\
\hline Rel can & $-0,76$ & 1,29 & 0,16 & 1,33 & 58 & 0,009 \\
\hline
\end{tabular}


Tabela 12: Resultados da comparação das alterações obtidas com 0 tratamento ortodôntico, entre os grupos 1 e 2 (T2-T1).

\begin{tabular}{|c|c|c|c|c|c|c|}
\hline \multirow[b]{3}{*}{ VARIÁVEIS } & \multirow{2}{*}{\multicolumn{2}{|c|}{$\begin{array}{c}\begin{array}{c}\text { GRUPO 1 } \\
\text { (Xp 2pré) }\end{array} \\
n=30\end{array}$}} & \multirow{2}{*}{\multicolumn{2}{|c|}{$\begin{array}{c}\begin{array}{c}\text { GRUPO 2 } \\
\text { (Xp 4pré) }\end{array} \\
n=30\end{array}$}} & \multirow[b]{3}{*}{ G. L } & \multirow[b]{3}{*}{$\mathbf{P}$} \\
\hline & & & & & & \\
\hline & MÉDIA & $d p$ & MÉDIA & $d p$ & & \\
\hline \multicolumn{7}{|c|}{ Componente Maxilar } \\
\hline SNA & $-1,81$ & 1,86 & $-2,49$ & 2,19 & 58 & 0,203 \\
\hline CoA & $-0,25$ & 2,37 & $-0,14$ & 2,13 & 58 & 0,842 \\
\hline A-Nperp & $-2,51$ & 2,34 & $-2,70$ & 2,50 & 58 & 0,754 \\
\hline \multicolumn{7}{|c|}{ Componente mandibular } \\
\hline SNB & 0,34 & 1,02 & $-0,16$ & 1,22 & 58 & 0,088 \\
\hline CoGn & 4,22 & 3,62 & 4,63 & 3,20 & 58 & 0,638 \\
\hline \multicolumn{7}{|c|}{ Relação maxilomandibular } \\
\hline ANB & $-2,16$ & 1,64 & $-2,32$ & 2,21 & 58 & 0,751 \\
\hline Wits & $-2,04$ & 2,29 & $-4,38$ & 3,81 & 58 & 0,005 \\
\hline \multicolumn{7}{|c|}{ Padrão de crescimento } \\
\hline FMA & 0,59 & 2,33 & 0,32 & 2,33 & 58 & 0,651 \\
\hline SNGoGn & $-0,21$ & 2,26 & 0,06 & 1,98 & 58 & 0,620 \\
\hline AFAI & 2,99 & 2,61 & 2,82 & 2,34 & 58 & 0,784 \\
\hline \multicolumn{7}{|c|}{ Componente dentoalveolar superior } \\
\hline 1.PP & 0,95 & 9,37 & $-9,87$ & 10,16 & 58 & 0,000 \\
\hline 1-ENAperp & $-1,92$ & 2,96 & $-5,24$ & 3,66 & 58 & 0,000 \\
\hline 1-pp & $-0,80$ & 1,59 & 1,56 & 1,89 & 58 & 0,000 \\
\hline 6-pp & 1,48 & 1,43 & 1,32 & 1,85 & 58 & 0,715 \\
\hline 6-ENAperp & 2,83 & 1,83 & 0,74 & 2,10 & 58 & 0,000 \\
\hline \multicolumn{7}{|c|}{ Componente dentoalveolar inferior } \\
\hline IMPA & 0,87 & 5,67 & $-0,99$ & 6,51 & 58 & 0,241 \\
\hline 1.NB & 1,06 & 5,63 & $-1,03$ & 6,43 & 58 & 0,186 \\
\hline 1-NB & 0,68 & 1,28 & $-1,28$ & 2,09 & 58 & 0,000 \\
\hline 1-pog per & $-0,10$ & 1,81 & $-2,02$ & 2,67 & 58 & 0,002 \\
\hline 1-GoMe & 1,37 & 2,27 & $-0,65$ & 1,87 & 58 & 0,000 \\
\hline 6-pogper & $-0,28$ & 1,53 & 1,55 & 2,38 & 58 & 0,001 \\
\hline 6-GoMe & 2,59 & 1,41 & 2,77 & 1,80 & 58 & 0,662 \\
\hline \multicolumn{7}{|c|}{ Relações dentárias } \\
\hline T hor & $-4,33$ & 2,47 & $-5,11$ & 2,73 & 58 & 0,251 \\
\hline T ver & $-2,73$ & 2,53 & $-1,33$ & 1,73 & 58 & 0,015 \\
\hline Rel mol & 0,44 & 0,69 & $-4,24$ & 1,32 & 58 & 0,000 \\
\hline Rel can & $-6,02$ & 1,56 & $-4,99$ & 1,32 & 58 & 0,008 \\
\hline
\end{tabular}


Tabela 13: Médias, desvios-padrão e resultados do teste t entre as alterações no período de observação dos grupos1 e 2 (T3-T2).

\begin{tabular}{|c|c|c|c|c|c|c|}
\hline \multirow[b]{2}{*}{ VARIÁVEIS } & \multicolumn{2}{|c|}{$\begin{array}{c}\text { GRUPO } 1 \\
\text { (Xp 2pré) } \\
n=30\end{array}$} & \multicolumn{2}{|c|}{$\begin{array}{c}\text { GRUPO } 2 \\
\text { (Xp 4pré) } \\
n=30\end{array}$} & \multirow[b]{2}{*}{ D. L } & \multirow[b]{2}{*}{$\mathbf{P}$} \\
\hline & MÉDIA & $\mathrm{dp}$ & MÉDIA & $d p$ & & \\
\hline \multicolumn{7}{|c|}{ Componente Maxilar } \\
\hline SNA & 1,90 & 1,84 & 0,24 & 1,94 & 58 & 0,001 \\
\hline CoA & 2,02 & 2,60 & 1,29 & 2,82 & 58 & 0,306 \\
\hline A-Nperp & 2,40 & 2,82 & 1,27 & 2,94 & 58 & 0,134 \\
\hline \multicolumn{7}{|c|}{ Componente mandibular } \\
\hline SNB & 0,82 & 1,47 & 0,41 & 1,54 & 58 & 0,295 \\
\hline CoGn & 2,21 & 3,35 & 2,51 & 4,61 & 58 & 0,774 \\
\hline \multicolumn{7}{|c|}{ Relação maxilomandibular } \\
\hline ANB & 1,08 & 1,76 & $-0,18$ & 2,00 & 58 & 0,012 \\
\hline Wits & 0,77 & 2,57 & 0,59 & 2,88 & 58 & 0,799 \\
\hline \multicolumn{7}{|c|}{ Padrão de crescimento } \\
\hline FMA & $-2,39$ & 2,99 & $-2,38$ & 3,78 & 58 & 0,994 \\
\hline SNGoGn & $-2,14$ & 2,92 & $-1,51$ & 2,83 & 58 & 0,402 \\
\hline AFAI & 0,53 & 1,92 & $-0,32$ & 2,78 & 58 & 0,177 \\
\hline \multicolumn{7}{|c|}{ Componente dentoalveolar superior } \\
\hline 1.PP & 0,41 & 3,73 & 1,50 & 4,78 & 58 & 0,330 \\
\hline 1-ENAperp & $-0,58$ & 2,10 & 0,89 & 3,08 & 58 & 0,034 \\
\hline 1-pp & 0,59 & 1,33 & $-0,03$ & 1,54 & 58 & 0,098 \\
\hline 6-pp & 0,15 & 1,50 & 0,36 & 1,71 & 58 & 0,616 \\
\hline 6-ENAperp & 0,81 & 2,06 & 1,50 & 2,51 & 58 & 0,250 \\
\hline \multicolumn{7}{|c|}{ Componente dentoalveolar inferior } \\
\hline IMPA & 0,34 & 3,86 & 0,40 & 4,30 & 58 & 0,955 \\
\hline 1.NB & $-0,60$ & 4,11 & $-0,54$ & 3,72 & 58 & 0,950 \\
\hline 1-NB & $-0,28$ & 0,93 & $-0,72$ & 1,24 & 58 & 0,121 \\
\hline 1-pog per & 0,86 & 1,71 & 1,11 & 2,04 & 58 & 0,619 \\
\hline 1-GoMe & 0,73 & 1,17 & 0,57 & 1,88 & 58 & 0,699 \\
\hline 6-pogper & 2,02 & 1,82 & 2,03 & 1,92 & 58 & 0,984 \\
\hline 6-GoMe & 1,26 & 1,39 & 0,45 & 2,54 & 58 & 0,131 \\
\hline \multicolumn{7}{|c|}{ Relações dentárias } \\
\hline T hor & 0,55 & 1,19 & 1,16 & 1,54 & 58 & 0,090 \\
\hline T ver & 1,04 & 1,26 & 0,88 & 1,24 & 58 & 0,615 \\
\hline Rel mol & 0,11 & 0,96 & 0,61 & 0,76 & 58 & 0,029 \\
\hline Rel can & 1,23 & 1,51 & 1,43 & 1,88 & 58 & 0,651 \\
\hline
\end{tabular}


Tabela 14: Médias, desvios-padrão e resultados do teste t entre as alterações pós-tratamento (T3-T2) dos grupos 1 e 2, incluindo somente os pacientes com má oclusão de Classe II, Divisão 1.

\begin{tabular}{|c|c|c|c|c|c|c|}
\hline \multirow[b]{3}{*}{ VARIÁVEIS } & \multirow{2}{*}{\multicolumn{2}{|c|}{$\begin{array}{c}\begin{array}{c}\text { GRUPO } 1 \\
\text { (Xp 2pré) }\end{array} \\
n=23\end{array}$}} & \multirow{2}{*}{\multicolumn{2}{|c|}{$\begin{array}{c}\text { GRUPO } 2 \\
\text { (Xp 4pré) } \\
n=30\end{array}$}} & \multirow[b]{3}{*}{ D. $L$} & \multirow[b]{3}{*}{$\mathbf{P}$} \\
\hline & & & & & & \\
\hline & MÉDIA & dp & MÉDIA & $d p$ & & \\
\hline \multicolumn{7}{|c|}{ Componente Maxilar } \\
\hline SNA & 1,76 & 1,91 & 0,24 & 1,94 & 51 & 0,006 \\
\hline CoA & 2,01 & 2,71 & 1,29 & 2,82 & 51 & 0,356 \\
\hline A-Nperp & 2,54 & 2,80 & 1,27 & 2,94 & 51 & 0,118 \\
\hline \multicolumn{7}{|c|}{ Componente mandibular } \\
\hline SNB & 0,65 & 1,54 & 0,41 & 1,54 & 51 & 0,574 \\
\hline CoGn & 2,37 & 3,39 & 2,51 & 4,61 & 51 & 0,903 \\
\hline \multicolumn{7}{|c|}{ Relação maxilomandibular } \\
\hline ANB & 1,11 & 1,79 & $-0,18$ & 2,00 & 51 & 0,019 \\
\hline Wits & 1,01 & 2,51 & 0,59 & 2,88 & 51 & 0,579 \\
\hline \multicolumn{7}{|c|}{ Padrão de crescimento } \\
\hline FMA & $-2,50$ & 3,11 & $-2,38$ & 3,78 & 51 & 0,901 \\
\hline SNGoGn & $-1,96$ & 3,20 & $-1,51$ & 2,83 & 51 & 0,590 \\
\hline AFAI & 0,44 & 1,87 & $-0,32$ & 2,78 & 51 & 0,267 \\
\hline \multicolumn{7}{|c|}{ Componente dentoalveolar superior } \\
\hline 1.PP & 0,55 & 3,90 & 1,50 & 4,78 & 51 & 0,443 \\
\hline 1-ENAperp & $-0,52$ & 2,18 & 0,89 & 3,08 & 51 & 0,067 \\
\hline 1-pp & 0,62 & 1,32 & $-0,03$ & 1,54 & 51 & 0,111 \\
\hline 6-pp & 0,25 & 1,49 & 0,36 & 1,71 & 51 & 0,810 \\
\hline 6-ENAperp & 1,01 & 2,05 & 1,50 & 2,51 & 51 & 0,452 \\
\hline \multicolumn{7}{|c|}{ Componente dentoalveolar inferior } \\
\hline IMPA & 0,15 & 3,92 & 0,40 & 4,30 & 51 & 0,827 \\
\hline 1.NB & $-0,80$ & 4,32 & $-0,54$ & 3,72 & 51 & 0,815 \\
\hline 1-NB & $-0,31$ & 0,98 & $-0,72$ & 1,24 & 51 & 0,201 \\
\hline 1-pog per & 0,93 & 1,67 & 1,11 & 2,04 & 51 & 0,738 \\
\hline 1-GoMe & 0,73 & 1,19 & 0,57 & 1,88 & 51 & 0,735 \\
\hline 6-pogper & 2,35 & 1,72 & 2,03 & 1,92 & 51 & 0,539 \\
\hline 6-GoMe & 1,10 & 1,43 & 0,45 & 2,54 & 51 & 0,273 \\
\hline \multicolumn{7}{|c|}{ Relações dentárias } \\
\hline T hor & 0,67 & 1,22 & 1,16 & 1,54 & 51 & 0,216 \\
\hline T ver & 1,13 & 1,30 & 0,88 & 1,24 & 51 & 0,472 \\
\hline Rel mol & 0,14 & 1,00 & 0,61 & 0,76 & 51 & 0,056 \\
\hline Rel can & 1,44 & 1,44 & 1,43 & 1,88 & 51 & 0,990 \\
\hline
\end{tabular}


Tabela 15: Médias, desvios-padrão e resultados do teste t para avaliação das variáveis entre os grupos 1 e 2 no estágio de observação pós-tratamento (T3) excluindo todos os pacientes com contenção $3 \times 3$.

\begin{tabular}{|c|c|c|c|c|c|c|}
\hline \multirow[b]{3}{*}{ VARIÁVEIS } & \multirow{2}{*}{\multicolumn{2}{|c|}{$\begin{array}{c}\text { GRUPO } 1 \\
\text { (Xp 2pré) } \\
n=17\end{array}$}} & \multirow{2}{*}{\multicolumn{2}{|c|}{$\begin{array}{c}\text { GRUPO } 2 \\
\text { (Xp 4pré) } \\
n=28\end{array}$}} & \multirow[b]{3}{*}{ D. L } & \multirow[b]{3}{*}{ p } \\
\hline & & & & & & \\
\hline & MÉDIA & $\mathrm{dp}$ & MÉDIA & dp & & \\
\hline \multicolumn{7}{|c|}{ Componente Maxilar } \\
\hline SNA & 80,82 & 3,56 & 79,01 & 3,50 & 43 & 0,102 \\
\hline CoA & 88,50 & 5,51 & 85,62 & 5,27 & 43 & 0,088 \\
\hline A-Nperp & 0,04 & 3,10 & $-1,23$ & 3,67 & 43 & 0,241 \\
\hline \multicolumn{7}{|c|}{ Componente mandibular } \\
\hline SNB & 77,21 & 3,58 & 75,39 & 3,54 & 43 & 0,103 \\
\hline CoGn & 115,31 & 6,62 & 111,98 & 7,03 & 43 & 0,122 \\
\hline \multicolumn{7}{|c|}{ Relação maxilomandibular } \\
\hline ANB & 3,60 & 1,79 & 3,62 & 2,69 & 43 & 0,981 \\
\hline Wits & 4,20 & 1,19 & 2,69 & 3,41 & 43 & 0,087 \\
\hline \multicolumn{7}{|c|}{ Padrão de crescimento } \\
\hline FMA & 23,79 & 5,45 & 27,49 & 7,64 & 43 & 0,089 \\
\hline SNGoGn & 30,76 & 6,55 & 34,76 & 7,57 & 43 & 0,079 \\
\hline AFAl & 68,56 & 4,04 & 68,24 & 6,81 & 43 & 0,862 \\
\hline \multicolumn{7}{|c|}{ Componente dentoalveolar superior } \\
\hline 1.PP & 113,92 & 7,71 & 108,83 & 5,87 & 43 & 0,016 \\
\hline 1-ENAperp & $-2,89$ & 3,02 & $-4,10$ & 3,54 & 43 & 0,251 \\
\hline 1-pp & 28,54 & 3,17 & 29,67 & 2,91 & 43 & 0,226 \\
\hline 6-pp & 25,73 & 2,10 & 25,13 & 2,39 & 43 & 0,398 \\
\hline 6-ENAperp & $-24,32$ & 2,09 & $-25,71$ & 3,14 & 43 & 0,113 \\
\hline \multicolumn{7}{|c|}{ Componente dentoalveolar inferior } \\
\hline IMPA & 94,42 & 6,44 & 91,39 & 6,25 & 43 & 0,127 \\
\hline 1.NB & 24,63 & 5,31 & 24,07 & 5,20 & 43 & 0,731 \\
\hline 1-NB & 5,32 & 2,41 & 3,64 & 2,16 & 43 & 0,020 \\
\hline 1-pog per & $-9,31$ & 3,18 & $-11,12$ & 3,76 & 43 & 0,105 \\
\hline 1-GoMe & 41,64 & 2,42 & 40,12 & 3,50 & 43 & 0,122 \\
\hline 6-pogper & $-29,11$ & 2,53 & $-25,41$ & 2,68 & 43 & 0,000 \\
\hline 6-GoMe & 32,04 & 1,78 & 31,79 & 2,88 & 43 & 0,753 \\
\hline \multicolumn{7}{|c|}{ Relações dentárias } \\
\hline T hor & 3,78 & 0,96 & 4,82 & 1,35 & 43 & 0,008 \\
\hline T ver & 2,70 & 1,51 & 3,99 & 1,40 & 43 & 0,006 \\
\hline Rel mol & 4,35 & 1,13 & $-0,29$ & 1,03 & 43 & 0,000 \\
\hline Rel can & $-0,71$ & 1,29 & 0,18 & 1,38 & 43 & 0,038 \\
\hline
\end{tabular}


Tabela 16: Médias, desvios-padrão e resultados do teste t entre as alterações que ocorreram no período pós-tratamento (T3-T2) dos grupos 1 e 2, excluindo todos os pacientes com contenção $3 \times 3$.

\begin{tabular}{|c|c|c|c|c|c|c|}
\hline \multirow[b]{3}{*}{ VARIÁVEIS } & \multirow{2}{*}{\multicolumn{2}{|c|}{$\begin{array}{l}\text { GRUPO } 1 \\
\text { (Xp 2pré) }\end{array}$}} & \multirow{2}{*}{\multicolumn{2}{|c|}{$\begin{array}{c}\text { GRUPO } 2 \\
\text { (Xp 4pré) } \\
n=28\end{array}$}} & \multirow[b]{3}{*}{ D. L } & \multirow[b]{3}{*}{ p } \\
\hline & & & & & & \\
\hline & MÉDIA & dp & MÉDIA & dp & & \\
\hline \multicolumn{7}{|c|}{ Componente Maxilar } \\
\hline SNA & 1,77 & 1,91 & 0,41 & 1,84 & 43 & 0,022 \\
\hline CoA & 2,07 & 2,48 & 1,41 & 2,88 & 43 & 0,435 \\
\hline A-Nperp & 2,22 & 2,76 & 1,24 & 3,03 & 43 & 0,281 \\
\hline \multicolumn{7}{|c|}{ Componente mandibular } \\
\hline SNB & 77,21 & 3,58 & 75,39 & 3,54 & 43 & 0,103 \\
\hline CoGn & 115,31 & 6,62 & 111,98 & 7,03 & 43 & 0,122 \\
\hline \multicolumn{7}{|c|}{ Relação maxilomandibular } \\
\hline ANB & 1,09 & 1,95 & $-0,21$ & 2,07 & 43 & 0,042 \\
\hline Wits & 1,20 & 2,06 & 0,62 & 2,61 & 43 & 0,441 \\
\hline \multicolumn{7}{|c|}{ Padrão de crescimento } \\
\hline FMA & $-1,99$ & 3,21 & $-2,38$ & 3,92 & 43 & 0,733 \\
\hline SNGoGn & $-1,86$ & 2,95 & $-1,68$ & 2,79 & 43 & 0,838 \\
\hline AFAI & 0,38 & 1,79 & $-0,21$ & 2,81 & 43 & 0,444 \\
\hline \multicolumn{7}{|c|}{ Componente dentoalveolar superior } \\
\hline 1.PP & 1,02 & 3,97 & 1,61 & 4,91 & 43 & 0,677 \\
\hline 1-ENAperp & $-0,55$ & 2,23 & 0,95 & 3,17 & 43 & 0,094 \\
\hline 1-pp & 0,55 & 1,30 & 0,12 & 1,48 & 43 & 0,325 \\
\hline 6-pp & 0,44 & 1,36 & 0,49 & 1,65 & 43 & 0,926 \\
\hline 6-ENAperp & 0,79 & 2,39 & 1,46 & 2,59 & 43 & 0,397 \\
\hline \multicolumn{7}{|c|}{ Componente dentoalveolar inferior } \\
\hline IMPA & $-0,62$ & 3,71 & 0,48 & 4,13 & 43 & 0,377 \\
\hline 1.NB & $-1,45$ & 3,26 & $-0,45$ & 3,52 & 43 & 0,351 \\
\hline 1-NB & $-0,35$ & 0,56 & $-0,72$ & 1,27 & 43 & 0,269 \\
\hline 1-pog per & 0,97 & 1,60 & 1,08 & 2,09 & 43 & 0,856 \\
\hline 1-GoMe & 0,81 & 0,99 & 0,63 & 1,92 & 43 & 0,724 \\
\hline 6-pogper & 2,01 & 1,76 & 2,00 & 1,94 & 43 & 0,997 \\
\hline 6-GoMe & 0,78 & 1,37 & 0,39 & 2,44 & 43 & 0,547 \\
\hline \multicolumn{7}{|c|}{ Relações dentárias } \\
\hline Thor & 0,62 & 1,11 & 1,24 & 1,53 & 43 & 0,156 \\
\hline T ver & 1,25 & 1,53 & 0,98 & 1,17 & 43 & 0,495 \\
\hline Rel mol & 0,37 & 0,98 & 0,59 & 0,78 & 43 & 0,421 \\
\hline Rel can & 1,36 & 1,47 & 1,41 & 1,93 & 43 & 0,933 \\
\hline
\end{tabular}


Tabela 17: Médias, desvios-padrão e resultados do teste t para avaliação das variáveis entre os grupos 1 e 2 no estágio de observação pós-tratamento (T3) incluindo somente pacientes com apinhamento compatível.

\begin{tabular}{|c|c|c|c|c|c|c|}
\hline \multirow[b]{3}{*}{ VARIÁVEIS } & \multicolumn{2}{|c|}{$\begin{array}{l}\text { GRUPO } 1 \\
\text { (Xp 2pré) }\end{array}$} & \multirow{2}{*}{\multicolumn{2}{|c|}{$\begin{array}{l}\text { GRUPO } 2 \\
\text { (Xp 4pré) } \\
n=19\end{array}$}} & \multirow[b]{3}{*}{ D. L } & \multirow[b]{3}{*}{ p } \\
\hline & \multicolumn{2}{|c|}{$n=20$} & & $n=19$ & & \\
\hline & MÉDIA & $d p$ & MÉDIA & $d p$ & & \\
\hline \multicolumn{7}{|c|}{ Componente Maxilar } \\
\hline SNA & 80,98 & 3,40 & 78,35 & 3,02 & 37 & 0,015 \\
\hline CoA & 87,94 & 5,22 & 84,32 & 5,57 & 37 & 0,043 \\
\hline A-Nperp & $-0,39$ & 3,43 & $-1,24$ & 2,79 & 37 & 0,402 \\
\hline \multicolumn{7}{|c|}{ Componente mandibular } \\
\hline SNB & 77,37 & 3,28 & 74,06 & 3,89 & 37 & 0,007 \\
\hline CoGn & 114,51 & 6,87 & 111,03 & 7,98 & 37 & 0,152 \\
\hline \multicolumn{7}{|c|}{ Relação maxilomandibular } \\
\hline ANB & 3,62 & 1,79 & 4,29 & 2,95 & 37 & 0,394 \\
\hline Wits & 3,70 & 1,24 & 3,81 & 3,69 & 37 & 0,905 \\
\hline \multicolumn{7}{|c|}{ Padrão de crescimento } \\
\hline FMA & 24,94 & 5,46 & 28,91 & 7,94 & 37 & 0,075 \\
\hline SNGoGn & 31,17 & 6,51 & 36,79 & 8,09 & 37 & 0,022 \\
\hline AFAI & 67,91 & 5,94 & 68,93 & 6,68 & 37 & 0,616 \\
\hline \multicolumn{7}{|c|}{ Componente dentoalveolar superior } \\
\hline 1.PP & 113,08 & 7,07 & 107,85 & 6,54 & 37 & 0,022 \\
\hline 1-ENAperp & $-3,66$ & 2,88 & $-5,26$ & 3,11 & 37 & 0,102 \\
\hline 1-pp & 28,17 & 3,32 & 29,54 & 2,97 & 37 & 0,181 \\
\hline 6-pp & 24,98 & 2,63 & 25,27 & 2,12 & 37 & 0,704 \\
\hline -ENAperp & $-24,97$ & 2,02 & $-26,22$ & 3,24 & 37 & 0,154 \\
\hline
\end{tabular}

Componente dentoalveolar inferior

\begin{tabular}{c|c|c|c|c|c|c}
\hline IMPA & $\mathbf{9 3 , 9 5}$ & $\mathbf{6 , 8 4}$ & $\mathbf{8 9 , 5 1}$ & $\mathbf{5 , 1 8}$ & $\mathbf{3 7}$ & $\mathbf{0 , 0 2 9}$ \\
\hline 1.NB & 24,84 & 5,91 & 22,88 & 4,46 & 37 & 0,253 \\
\hline 1-NB & 4,78 & 2,00 & 3,46 & 2,38 & 37 & 0,069 \\
\hline 1-pog per & $-10,11$ & 2,63 & $-12,16$ & 3,10 & 37 & 0,032 \\
\hline 1-GoMe & 40,92 & 3,25 & 40,26 & 3,49 & 37 & 0,550 \\
\hline 6-pogper & $-29,72$ & 1,93 & $-25,54$ & 3,11 & 37 & 0,000 \\
\hline 6-GoMe & 31,54 & 2,19 & 31,85 & 3,15 & 37 & 0,720 \\
\hline \multicolumn{7}{|c|}{ Relações dentárias } \\
\hline T hor & 3,80 & 1,09 & 4,94 & 1,53 & 37 & 0,010 \\
\hline T ver & 2,76 & 1,37 & 3,86 & 1,60 & 37 & 0,026 \\
\hline Rel mol & 4,35 & 1,03 & $-0,08$ & 1,00 & 37 & 0,000 \\
\hline Rel can & $-0,87$ & 1,47 & 0,39 & 1,18 & 37 & 0,006 \\
\hline
\end{tabular}


Tabela 18: Médias, desvios-padrão e resultados do teste t entre as alterações que ocorreram no período pós-tratamento (T3-T2) dos grupos 1 e 2 incluindo somente pacientes com apinhamento compatível.

\begin{tabular}{|c|c|c|c|c|c|c|}
\hline \multirow[b]{3}{*}{ VARIÁVEIS } & \multirow{2}{*}{\multicolumn{2}{|c|}{$\begin{array}{c}\text { GRUPO } 1 \\
\text { (Xp 2pré) } \\
n=20\end{array}$}} & \multirow{2}{*}{\multicolumn{2}{|c|}{$\begin{array}{l}\text { GRUPO } 2 \\
\text { (Xp 4pré) } \\
n=19\end{array}$}} & \multirow[b]{3}{*}{ D. $\mathbf{L}$} & \multirow[b]{3}{*}{$\mathbf{P}$} \\
\hline & & & & & & \\
\hline & MÉDIA & $d p$ & MÉDIA & $d p$ & & \\
\hline \multicolumn{7}{|c|}{ Componente Maxilar } \\
\hline SNA & 1,67 & 1,63 & 0,10 & 2,13 & 37 & 0,013 \\
\hline CoA & 2,13 & 2,73 & 1,64 & 2,78 & 37 & 0,587 \\
\hline A-Nperp & 2,58 & 2,88 & 0,95 & 2,74 & 37 & 0,079 \\
\hline \multicolumn{7}{|c|}{ Componente mandibular } \\
\hline SNB & 0,64 & 1,51 & 0,22 & 1,69 & 37 & 0,418 \\
\hline CoGn & 2,92 & 3,47 & 3,06 & 4,90 & 37 & 0,913 \\
\hline \multicolumn{7}{|c|}{ Relação maxilomandibular } \\
\hline ANB & 1,04 & 1,57 & $-0,13$ & 2,25 & 37 & 0,068 \\
\hline Wits & 1,12 & 2,25 & 0,97 & 3,05 & 37 & 0,865 \\
\hline \multicolumn{7}{|c|}{ Padrão de crescimento } \\
\hline FMA & $-2,42$ & 3,33 & $-1,81$ & 3,09 & 37 & 0,561 \\
\hline SNGoGn & $-1,71$ & 2,93 & $-1,07$ & 3,07 & 37 & 0,515 \\
\hline AFAI & 0,85 & 2,04 & $-0,34$ & 3,07 & 37 & 0,163 \\
\hline \multicolumn{7}{|c|}{ Componente dentoalveolar superior } \\
\hline 1.PP & 0,24 & 3,70 & 2,03 & 5,45 & 37 & 0,235 \\
\hline 1-ENAperp & $-0,82$ & 2,14 & 0,92 & 2,95 & 37 & 0,041 \\
\hline 1-pp & 0,65 & 1,36 & $-0,09$ & 1,69 & 37 & 0,137 \\
\hline 6-pp & 0,51 & 1,48 & 0,37 & 1,58 & 37 & 0,790 \\
\hline 6-ENAperp & 0,61 & 1,77 & 1,15 & 2,05 & 37 & 0,382 \\
\hline \multicolumn{7}{|c|}{ Componente dentoalveolar inferior } \\
\hline IMPA & 0,17 & 4,11 & $-0,85$ & 3,75 & 37 & 0,427 \\
\hline 1.NB & $-0,56$ & 4,44 & $-1,61$ & 3,38 & 37 & 0,416 \\
\hline 1-NB & $-0,30$ & 1,11 & $-0,99$ & 1,05 & 37 & 0,051 \\
\hline 1-pog per & 0,62 & 1,56 & 0,72 & 1,83 & 37 & 0,861 \\
\hline 1-GoMe & 0,75 & 1,11 & 0,70 & 1,61 & 37 & 0,902 \\
\hline 6-pogper & 1,94 & 1,59 & 1,78 & 1,75 & 37 & 0,765 \\
\hline 6-GoMe & 1,12 & 1,45 & 0,25 & 2,86 & 37 & 0,239 \\
\hline \multicolumn{7}{|c|}{ Relações dentárias } \\
\hline T hor & 0,53 & 1,37 & 1,51 & 1,64 & 37 & 0,051 \\
\hline T ver & 0,80 & 1,28 & 1,05 & 1,30 & 37 & 0,546 \\
\hline Rel mol & 0,07 & 0,96 & 0,70 & 0,68 & 37 & 0,023 \\
\hline Rel can & 1,41 & 1,64 & 1,72 & 1,57 & 37 & 0,542 \\
\hline
\end{tabular}


Tabela 19: Médias, desvios-padrão e resultados do teste de correlação entre as alterações ocorridas nos grupos 1 e 2 durante o tratamento e no período de observação pós-tratamento.

\begin{tabular}{c|c|c|c|c|c|c}
\hline \multirow{2}{*}{ VARIÁVEIS } & \multicolumn{2}{|c|}{ T2-T1 } & \multicolumn{2}{c|}{ T3-T2 } & \multirow{2}{*}{} \\
\cline { 2 - 6 } & MÉDIA & dp & MÉDIA & dp & r & p \\
\hline \multicolumn{7}{|c|}{ Relações dentárias } \\
\hline T hor & $-4,72$ & 2,61 & 0,86 & 1,4 & $-0,46$ & 0,000 \\
\hline T ver & $-2,03$ & 2,26 & 0,96 & 1,24 & $-0,28$ & 0,028 \\
\hline Rel can & $-5,51$ & 1,53 & 1,33 & 1,69 & $-0,36$ & 0,004 \\
\hline
\end{tabular}

Tabela 20: Médias, desvios-padrão e resultado do teste de correlação entre as alterações ocorridas na relação molar durante o tratamento e no período de observação (grupo 1).

\begin{tabular}{c|c|c|c|c|c|c}
\multicolumn{7}{c}{ GRUPO 1 (Xp 2pré) } \\
\hline \multirow{2}{*}{ VARIÁVEIS } & T2-T1 & \multicolumn{2}{|c|}{ T3-T2 } & & \\
\cline { 2 - 5 } & MÉDIA & $\mathbf{d p}$ & MÉDIA & $\mathbf{d p}$ & $\mathbf{r}$ & $\mathbf{p}$ \\
\hline Relação Molar & 0,44 & 0,69 & 0,11 & 0,96 & $-0,03$ & 0,864 \\
\hline
\end{tabular}

Tabela 21: Médias, desvios-padrão e resultado do teste de correlação entre as alterações ocorridas na relação molar durante o tratamento e no período de observação (grupo 2).

GRUPO 2 (Xp 4pré)

\begin{tabular}{c|c|c|c|c|c|c}
\hline \multirow{2}{*}{ VARIÁVEIS } & \multicolumn{2}{|c|}{ T2-T1 } & \multicolumn{2}{c|}{ T3-T2 } & & \multirow{2}{*}{} \\
\cline { 2 - 7 } & MÉDIA & $\mathbf{d p}$ & MÉDIA & $\mathbf{d p}$ & $\mathbf{r}$ & $\mathbf{p}$ \\
\hline Relação Molar & $-4,24$ & 1,32 & 0,61 & 0,76 & $-0,26$ & 0,165 \\
\hline
\end{tabular}


Tabela 22: Análise da correlação entre a quantidade de recidiva da relação molar e as alterações das variáveis estudadas, no período de observação póstratamento (T3-T2), no grupo 1.

\begin{tabular}{|c|c|c|c|}
\hline \multicolumn{4}{|c|}{ GRUPO 1 (Xp 2pré) } \\
\hline \multicolumn{2}{|r|}{ VARIÁVEIS } & \multirow{2}{*}{$\frac{\mathbf{r}}{-0,292}$} & \multirow{2}{*}{$\frac{\mathbf{p}}{0,117}$} \\
\hline & SNA & & \\
\hline & CoA & $-0,256$ & 0,173 \\
\hline & A-Nperp & $-0,213$ & 0,258 \\
\hline & \multicolumn{3}{|c|}{ Componente mandibular } \\
\hline & SNB & $-0,396$ & 0,030 \\
\hline & CoGn & $-0,309$ & 0,096 \\
\hline & \multicolumn{2}{|c|}{ Relação maxilomandibula } & \\
\hline & ANB & 0,0168 & 0,93 \\
\hline & Wits & $-0,0706$ & 0,711 \\
\hline & \multicolumn{3}{|c|}{ Padrão de crescimento } \\
\hline & FMA & 0,367 & 0,046 \\
\hline & SNGoGn & 0,271 & 0,148 \\
\hline & AFAI & $-0,087$ & 0,646 \\
\hline $\begin{array}{l}\text { RELAÇÃO } \\
\text { MOLAR }\end{array}$ & \multicolumn{3}{|c|}{ Componente dentoalveolar superior } \\
\hline & 1.PP & 0,025 & 0,895 \\
\hline & 1-ENAperp & $-0,081$ & 0,671 \\
\hline & 1-pp & 0,041 & 0,829 \\
\hline & 6-pp & $-0,025$ & 0,895 \\
\hline & 6-ENAperp & $-0,027$ & 0,888 \\
\hline & \multicolumn{3}{|c|}{ Componente dentoalveolar inferior } \\
\hline & IMPA & 0,023 & 0,903 \\
\hline & 1.NB & 0,118 & 0,534 \\
\hline & 1-NB & 0,035 & 0,855 \\
\hline & 1-pog per & 0,171 & 0,367 \\
\hline & 1-GoMe & -154 & 0,418 \\
\hline & 6-pogper & $-0,059$ & 0,757 \\
\hline & 6-GoMe & $-0,156$ & 0,409 \\
\hline & \multicolumn{3}{|c|}{ Relações dentárias } \\
\hline & T hor & 0,271 & 0,147 \\
\hline & T ver & 0,014 & 0,941 \\
\hline & Rel can & 0,316 & 0,089 \\
\hline
\end{tabular}


Tabela 23: Análise da correlação entre a quantidade de recidiva da relação molar e as alterações das variáveis estudadas, no período de observação póstratamento (T3-T2), no grupo 2.

\begin{tabular}{|c|c|c|c|}
\hline \multicolumn{4}{|c|}{ GRUPO 2 (Xp 4pré) } \\
\hline & VARIÁVEIS & $\mathbf{r}$ & $\mathbf{P}$ \\
\hline & SNA & 0,132 & 0,486 \\
\hline & CoA & 0,113 & 0,553 \\
\hline & A-Nperp & 0,297 & 0,111 \\
\hline & \multicolumn{3}{|c|}{ Componente mandibular } \\
\hline & SNB & $-0,401$ & 0,028 \\
\hline & CoGn & $-0,174$ & 0,359 \\
\hline & \multicolumn{3}{|c|}{ Relação maxilomandibular } \\
\hline & ANB & 0,437 & 0,016 \\
\hline & Wits & 0,178 & 0,347 \\
\hline & \multicolumn{3}{|c|}{ Padrão de crescimento } \\
\hline & FMA & 0,067 & 0,725 \\
\hline & SNGoGn & 0,3129 & 0,092 \\
\hline & AFAI & $-0,202$ & 0,285 \\
\hline $\begin{array}{c}\text { RELAÇÃO } \\
\text { MOLAR }\end{array}$ & \multicolumn{3}{|c|}{ Componente dentoalveolar superior } \\
\hline & 1.PP & $-0,109$ & 0,566 \\
\hline & 1-ENAperp & $-0,006$ & 0,976 \\
\hline & 1-pp & $-0,167$ & 0,377 \\
\hline & 6-pp & $-0,509$ & 0,004 \\
\hline & 6-ENAperp & $-0,069$ & 0,716 \\
\hline & \multicolumn{3}{|c|}{ Componente dentoalveolar inferior } \\
\hline & IMPA & $-0,1299$ & 0,494 \\
\hline & 1.NB & $-0,094$ & 0,622 \\
\hline & 1-NB & $-0,3719$ & 0,043 \\
\hline & 1-pog per & $-0,051$ & 0,789 \\
\hline & 1-GoMe & $-0,276$ & 0,139 \\
\hline & 6-pogper & $-0,255$ & 0,174 \\
\hline & 6-GoMe & $-0,267$ & 0,153 \\
\hline & \multicolumn{3}{|c|}{ Relações dentárias } \\
\hline & Thor & 0,387 & 0,035 \\
\hline & T ver & $-0,017$ & 0,929 \\
\hline & Rel can & 0,587 & 0,001 \\
\hline
\end{tabular}



Discussão 



\section{DISCUSSÃO}

Para uma melhor compreensão e interpretação dos resultados obtidos com esta pesquisa, este capítulo foi divido em tópicos, serão discutidos, seqüencialmente, a precisão do método, a amostra utilizada, a metodologia aplicada e os resultados obtidos.

\subsection{A AMOSTRA UTILIZADA}

A amostra conformada por dois grupos foi selecionada seguindo inicialmente os seguintes critérios de inclusão: casos que apresentavam inicialmente relação de Classe II completa bilateral, tratados ortodonticamente com aparelhos fixos com a extração de dois pré-molares superiores ou de dois pré-molares superiores e dois inferiores; presença de todos os dentes permanentes até pelo menos os primeiros molares, ausência de anomalias dentária de forma ou número. Ao final do tratamento deveriam apresentar redução significante do trespasse horizontal. A razão para o estabelecimento destes critérios foi a necessidade de preservação da compatibilidade entre os grupos. Não houve a preocupação em se diferenciar se foram extraídos primeiros ou segundos pré-molares nos casos a serem avaliados, pois todos os casos preencheram os requisitos, e a probabilidade de extrações de segundos pré-molares serem encontrados nos diferentes grupos era semelhante.

Considerando todos os critérios de inclusão já mencionados, a seleção da amostra no presente estudo foi obtida a partir de amostras utilizadas em estudos prévios ${ }^{9,28,93}$ que utilizaram amostras de Classe II com características semelhantes, realizadas na disciplina de ortodontia da Faculdade de odontologia de Bauru. O total de pacientes destas amostras foi de 131, sendo 81 deles foram tratados com a terapêutica utilizando extrações de dois prémolares superiores e os outros 50 pacientes foram tratados com extrações de dois pré-molares superiores e dois inferiores.

A partir desse número inicial, iniciou-se a procura de casos que apresentassem a documentação ortodôntica completa inicial, telerradiografia inicial e final e modelos iniciais e finais, além das radiografias de controle póstratamento. Nos casos em que houve a falta de controle radiográfico pós- 
tratamento ou um controle pós-tratamento menor de 2,25 anos, os pacientes foram contatados para a realização das radiografias de controle atuais, porém houve uma grande parte de pacientes que não foram localizados ou se recusaram à realização desta documentação, fatos que contribuíram para a diminuição do número de componentes da amostra.

Embora a avaliação da estabilidade da má-oclusão de Classe II fosse realizada em telerradiografias, os modelos iniciais e finais foram utilizados para que os grupos a comparar fossem compatíveis. Para tanto, os dados como IPT inicial e apinhamento, fornecidos por pesquisas prévias foram utilizados ou obtidos a partir da documentação dos pacientes constantes no arquivo da disciplina.

Sendo assim, foi obtida uma amostra de 60 pacientes (30 de cada grupo) que observavam os critérios de seleção e contavam com a documentação requerida para a realização do presente estudo. Dos dados presentes na fichas clínicas foram obtidas as idades inicias e finais dos pacientes, além da proporção dos gêneros. Embora para tanto foram avaliados nos modelos. É importante salientar que os critérios estabelecidos para a seleção da amostra eliminaram uma grande parte dos casos de pacientes potenciais.

A representatividade de uma amostra é importante para que os dados coletados sejam extrapolados para a população, portanto, amostras compostas por grandes números de pacientes são preferíveis. Entretanto, os estudos longitudinais, apesar de sua grande importância no contexto científico, apresentam algumas limitações quanto ao tamanho da amostra ${ }^{103,123,188}$. Assim, levando-se em consideração que estudos prévios utilizaram tamanho de amostras semelhantes à presente pesquisa, o número de pacientes utilizados pode-se considerar suficiente para conferir confiabilidade aos resultados obtidos $^{45,91,123,129,138}$.

\subsection{PRECISÃO DA METODOLOGIA}

\subsubsection{Erro intra-examinador e interexaminador}

O método cefalométrico embora seja amplamente utilizado em pesquisas relacionadas à estabilidade do tratamento ortodôntico, apresenta certas 
limitações devido à dificuldade de identificação de estruturas anatômicas e alto grau de subjetividade, o que pode acarretar uma imprecisão nos diversos procedimentos envolvidos tais como no traçado cefalométrico, ou na demarcação e na digitalização dos pontos, limitando a precisão dos valores cefalométricos obtidos $^{84}$. Por conseguinte, a avaliação dos erros sistemáticos e casuais são recursos indispensáveis em pesquisas cientificas que utilizam esta metodologia ${ }^{65}$.

Neste estudo foram avaliados a telerradiografia inicial (T1), telerradiografia final (T2) e telerradiografia de observação pós-tratamento (T3) de cada um dos 60 pacientes pertencentes aos dois grupos de pacientes que compõem a amostra. Foram mensuradas 26 variáveis em cada uma das 180 radiografias totalizando 4680 medidas.

Das 180 radiografias cefalométricas, 130 foram utilizadas em estudo prévio $^{93}$. Logo, foram avaliados tanto os erros intra-examinador quanto os erros interexaminador, para avaliar os erros metodológicos casuais ou sistemáticos que poderiam ter surgido durante as diversas fases que envolvem a avaliação cefalométrica, ou devido ao fato que as avaliações foram feitas em tempos distintos e por dois avaliadores diferentes ${ }^{12,13,65}$.

Para a avaliação dos erros casuais e sistemáticos utilizou-se $o$ teste $t$ pareado e a fórmula proposta por Dahlberg ${ }^{44}$. De acordo com HOUSTON ${ }^{84}$, idealmente as medições deveriam ser realizadas duas vezes para cada radiografia. No entanto, esta avaliação não é aplicável na maioria dos estudos.

Assim sendo, para avaliação do erro intra-examinador foram selecionadas aleatoriamente 18 radiografias, correspondente a $36 \%$ das radiografias avaliadas inicialmente. Após um período de 30 dias foram realizadas novamente as medições das 18 telerradiografias selecionadas.

$\mathrm{Na}$ tabela 3 pode-se observar que os erros casuais intra-examinador deste estudo foram reduzidos, no entanto algumas variáveis apresentaram valores superiores a $1 \mathrm{~mm}$ ou 1 grau. Os valores mais elevados encontram-se em medidas que utilizam pontos de difícil visualização e um grau de subjetividade muito grande como o condílio, ponto A ou subnasal. Porém os erros casuais apresentam valores semelhantes ou inferiores quando comparados com diversos estudos ${ }^{91}$ que utilizaram telerradiografias e uma metodologia similar. 
Quanto aos erros sistemáticos, houve diferenças estatisticamente significantes para $p<0,05$ em apenas duas variáveis (AFAI, 1-pp) dentre 26 variáveis, o que é bastante satisfatório ${ }^{84}$.

A avaliação do erro interexaminador (tabela 4) foi verificada selecionando aleatoriamente 44 telerradiografias, 22 das quais correspondiam ao primeiro examinador ao segundo.

Entretanto na avaliação dos erros interexaminador os erros causais apresentaram-se em maior proporção que na avaliação intra-examinador. Das 26 variáveis, houve diferença estatisticamente significante ao nível de $p<0,05$ em 4 variáveis. Das 4 variáveis só a relação de caninos (Rel can) refere-se à discrepância ântero-posterior dentária, principal objeto de estudo do presente trabalho. Esta diferença na relação de caninos pode ter decorrido do maior grau de dificuldade que representa a identificação dos caninos numa telerradiografia lateral ${ }^{65}$. Porém deve-se ressaltar que as avaliações radiográficas realizadas em tempos diferentes e por mais de um examinador demonstram uma maior tendência de apresentar erros sistemáticos ${ }^{84}$.

Com o propósito de minimizar os erros durante os traçados das telerradiografias, os traçados de um mesmo paciente foram realizados em série. Este procedimento facilita a identificação das estruturas e a realização do traçado anatômico nas radiografias. ${ }^{84}$.

Em geral os resultados do erro intra-examinador e interexaminador demonstram que houve precisão na demarcação dos pontos cefalométricos, garantindo a confiabilidade dos dados obtidos.

\subsection{COMPATIBILIDADE DOS GRUPOS}

Como o objetivo deste estudo era comparar a estabilidade de dois protocolos de tratamento da má oclusão de Classe II, torna-se condição que as características fossem semelhantes em ambos os grupos. Para tanto, os dois grupos foram compatibilizados quanto ao apinhamento inicial, idade inicial e final, IPT inicial e final, redução do IPT, tempo de tratamento e tempo de observação pós-tratamento (tabela 5). Além destas variáveis, os grupos foram comparados quanto ao gênero, ao tipo de Classe II, e quanto a proporção dos 
pacientes que ainda utilizavam contenção $3 \times 3$ inferior no estágio de observação pós-tratamento (tabelas 6, 7, 8).

De uma maneira geral, os grupos apresentaram uma compatibilidade inicial satisfatória quanto à idade, severidade da má oclusão e tempo de tratamento (tabela 5). No entanto, das 8 variáveis só o apinhamento inicial mostrou diferença estatisticamente significante, entretanto é de se esperar que no grupo II os pacientes apresentem maior grau de apinhamento ao início do tratamento, o que teria influenciado na decisão do protocolo de tratamento a ser empregado. Entretanto, tem sido sugerido que um maior grau de apinhamento ântero-inferior inicial poderia influenciar na estabilidade da relação dentária em sentido sagital e conseqüentemente nos resultados dessa comparação.

Por este motivo, houve a necessidade da compatibilização do apinhamento inicial para dirimir qualquer dúvida que pudesse surgir, devido a essa diferença entre os graus de apinhamento iniciais. Desta forma, realizou-se a eliminação de 10 pacientes no grupo 1, os quais apresentavam os menores apinhamentos antes do início do tratamento, e de 11 pacientes do grupo 2, os quais apresentavam os maiores apinhamentos antes do início de tratamento, permitindo que os dois protocolos de tratamento fossem comparados a partir de uma paridade inicial desta variável. O resultado da comparação entre os grupos compatibilizados quanto ao apinhamento mostrou que para efeito da avaliação cefalométrica da estabilidade de Classe II a diferença no grau de apinhamento inicial não influenciou no comportamento pós-contenção das variáveis estudadas, e conseqüentemente não comprometeu os resultados dessa comparação.

Com relação à proporção dos tipos de Classe II nota-se que o grupo 1 incluiu 7 pacientes com má oclusão de Classe II, divisão 2, o que comprometeu a compatibilidade inicial dos grupos nesta variável (tabela 7). Devido às características distintas destes dois tipos de más oclusões os resultados da avaliação da comparação entre os grupos poderiam ser questionados ${ }^{29,98,161}$. Portanto foi necessário realizar a comparação das alterações no período de observação pós-tratamento (T3-T2) incluindo somente os pacientes com má oclusão de Classe II, divisão 1 (tabela 14). O comportamento das variáveis 
neste período apresentou-se semelhante ao observado quando se consideram todos pacientes da amostra (tabela 13).

O fato das amostras apresentarem diferenças estatisticamente significantes quanto à proporção de pacientes que ainda utilizavam contenção fixa tipo 3X3 inferior no estágio T3 poderia gerar dúvidas com relação aos resultados, já que alguns autores afirmam que a utilização de contenção fixa durante um período prolongado tem influencia no comportamento em longo prazo das relações dentárias em sentido ântero-posterior ${ }^{178}$, o que poderia influenciar nos resultados deste estudo no sentido de favorecer a obtenção de maior estabilidade no grupo que apresenta maior quantidade de pacientes com contenção (tabela 8). Por este motivo foi realizado um segundo teste estatístico comparando ambos grupos no estágio T3 e no período de observação pós-tratamento (T3-T2) considerando a compatibilidade dos grupos quanto a proporção de pacientes com contenção $3 \times 3$. O resultado mostrou que as alterações que ocorreram no período pós-tratamento foram compatíveis em ambos os grupos (tabela 15 e 16).

Mesmo que os grupo sejam semelhantes quanto a idade, gênero, severidade da má oclusão há possibilidade de os mesmos apresentarem outras características que possam dificultar a mecânica selecionada condicionando os resultados do tratamento ortodôntico o que dificultaria avaliar as alterações que ocorreram exclusivamente no período de observação. Para tentar diminuir essa possibilidade, foram comparadas também as variáveis cefalométricas a serem estudadas, ao início do tratamento (tabela 9). A seguir são discutidos os resultados destas comparações:

Na tabela 9 pode-se observar que houve um alto grau de compatibilidade das variáveis do componente maxilar, o posicionamento em relação à base de crânio (SNA), o comprimento linear da maxila (CoA) e o posicionamento sagital da maxila com a base do crânio (A-Nperp) se apresentaram semelhantes em ambos os grupos.

Quanto ao componente mandibular, a mandíbula apresentou-se mais retruida em relação à base do crânio no grupo 2, o comprimento linear do corpo mandibular mostrou uma diferença estatisticamente significante entre os grupos quando comparados neste estágio. Esta característica pode estar 
relacionada ao padrão de crescimento mais vertical conforme mostram as variáveis FMA e SN.GOGN.

A relação maxilomandibular no grupo 2 apresentou uma maior discrepância em relação ao grupo 1. Isto poderia ser provavelmente conseqüência da diferença significante observada no tamanho mandibular entre os grupos, além da posição mais retruida da mesma no grupo 2.

Em relação ao padrão de crescimento, o grupo 2 mostrou um padrão de crescimento vertical significativamente maior que o grupo 1. Esta diferença no padrão de crescimento provavelmente poderia influenciar nas diferenças observadas no tamanho mandibular observada entre os grupos 1 e 2 como relatado por alguns autores ${ }^{19,41}$. Eles observaram que em indivíduos com tendência de crescimento vertical portadores de má oclusão de Classe II os comprimentos lineares do corpo da maxila e mandíbula eram menores. Estudos prévios têm demonstrado que é praticamente impossível a obtenção de grupos totalmente compatíveis uma vez que o crescimento não ocorre de maneira linear e nem constante, apresentando grandes variações individuais $^{140}$. Por outro lado, serão comparadas as alterações entre grupos, o que minimiza a necessidade de se obter compatibilidade entre todas s variáveis de ambos os grupos ${ }^{188}$.

Com relação às grandezas dentárias superiores, observa-se que houve valores semelhantes para a maioria das variáveis com exceção da variável 1.pp que se apresentou menor no grupo 1. Esta diferença estatisticamente significante pode ser explicada pela inclusão de casos de má oclusão de Classe II divisão 2 neste grupo, o que pode ter influenciado na diminuição do valor médio da variável 1.pp nesse estágio.

As variáveis do componente dentoalveolar inferior mostraram-se bastante semelhantes no estágio pré-tratamento. Só uma variável referente ao posicionamento dos molares no plano horizontal (6-pogper) apresentou valores diferentes estatisticamente significantes. No grupo 2 os molares se apresentavam mais mesializados provavelmente devido à maior prevalência de pacientes com apinhamento neste grupo, $n=17$, enquanto no grupo 1 a prevalência era praticamente um terço, $n=6$

As relações dentárias na fase inicial se apresentaram semelhantes em ambos os grupos. Essas semelhanças demonstram a compatibilidade dos 
grupos quanto à severidade das más oclusões, permitindo, portanto, a comparação entre os mesmos.

\subsection{RESULTADOS}

A realização do tratamento ortodôntico com extrações para a correção da Classe II é amplamente descrita na literatura ${ }^{9,14,21,28,40,89,177}$. A correção da discrepância ântero-posterior que se apresenta na má oclusão Classe II é possível de ser corrigida utilizando diversos aparelhos, entre os quais encontram-se os aparelhos fixos, aparelhos ortopédicos funcionais ${ }^{2,47,68,108,175,176,187}$. A correção é obtida pela alteração esquelética ou dentoalveolar que estes aparelhos promovem, em maior ou menor proporção dependendo da época de realização do tratamento e do tipo de aparelho empregado ${ }^{133,141,184,185,190}$. Entretanto, estas alterações encontram-se sujeitas à recidiva ${ }^{57,109,137,156,178}$. Considerando que o foco do presente trabalho consiste em avaliar a estabilidade dos resultados obtidos por dois protocolos de tratamento, serão discutidas primordialmente as alterações ocorridas no período de observação pós-tratamento e em seguida as que ocorreram durante o tratamento, assim como a relação entre ambas. A discussão será apresentada a seguinte ordem: componente maxilar, componente mandibular, relação maxilomandibular, padrão de crescimento, componente dentoalveolar superior, componente dentoalveolar inferior e relações dentárias.

\section{Componente maxilar}

No período pós-tratamento, ao se comparar as alterações entre o grupo 1 e grupo 2, só as alterações em SNA apresentaram diferenças estatisticamente significantes (tabela 13), uma das explicações desta maior tendência em direção anterior no grupo 1, possivelmente se deve ao fato de que as alterações neste grupo foram principalmente alterações dentoalveolares decorrentes da utilização dos aparelhos fixos. Já no grupo 2 a maior restrição do deslocamento anterior da maxila observada durante o tratamento (Tabela 12), embora não estatisticamente significante, foi provocada pela maior necessidade de utilização de aparelhos de ancoragem extra-bucais, para se 
atingir uma relação molar de Classe I ao final do tratamento, influenciando desta forma no ponto $\mathrm{A}^{11,23,28,89,91}$.

$\mathrm{Na}$ literatura é um consenso comum de que o aparelho extrabucal causa um efeito ortopédico sobre a maxila, restringindo o seu deslocamento em direção anterior ${ }^{79}$. Embora, alguns autores ${ }^{46,56}$ tenham observado uma recidiva das alterações esqueléticas da maxila após a interrupção da força extrabucal, outros trabalhos ${ }^{55}$ demonstraram que a inibição do crescimento maxilar permaneceu estável após o tratamento.

As alterações em CoA e A-Nperp, embora não demonstrem uma diferença estatisticamente significante entre os dois grupos, apresentaram um ligeiro aumento durante a fase de pós-tratamento, revelando uma tendência em direção à recidiva. No entanto, pode-se inferir que as alterações no complexo maxilar na fase pós-tratamento fazem parte do crescimento e desenvolvimento normal. A maxila retomou o seu padrão de crescimento normal, sem se apresentar uma contribuição significativa para a recidiva da correção da relação ântero-posterior em ambos os grupos.

\section{Componente mandibular}

O comportamento do componente mandibular merece uma atenção especial considerando-se que o retrognatismo $0^{38,95,120,147,157}$ e a deficiência do tamanho mandibular ${ }^{95,143}$ são os principais componentes da má oclusão de Classe $\|^{21,22,38,48,54}$.

Ao se comparar as alterações no complexo mandibular entre os dois grupos no período pós-tratamento, observa-se que as alterações são bastante semelhantes (tabela 13). No presente estudo dentro da mecanoterapia empregada não constava a utilização de aparelhos funcionais que possam estimular no crescimento real da mandíbula. A mecânica utilizando aparelhos fixos com ou sem extrações não são capazes de produzir alterações significantes no posicionamento ou comprimento mandibular, restringido seu efeito na rotação e na alteração no ponto $B$, decorrente do posicionamento dos incisivos inferiores ${ }^{172}$. Por tanto, as alterações observadas no componente mandibular nas três fases correspondem à expressão do potencial de 
crescimento e desenvolvimento normal dos pacientes que compõem a amostra, sem influência do tratamento ser realizado com dois ou quatro extrações ${ }^{95}$.

\section{Relação maxilomandibular}

A relação maxilomandibular apresentou um maior aumento do ângulo ANB no grupo 1 estatisticamente significante quando comparado ao grupo 2 (tabela 13). Essa diferença pode significar uma ligeira tendência à recidiva da melhora da relação maxilomandibular no grupo tratado com extração de dois pré-molares, porém esta alteração corresponde a $1,08^{\circ}$ o que determinaria sua pouca significância clínica ${ }^{1}$. Esta maior tendência à recidiva pode se devido ao efeito ortopédico restrito provocado durante o tratamento com 2 extrações de pré-molares superiores. Nestes pacientes a inibição do crescimento maxilar é mínimo pelo uso limitado de força extrabucal, o que promoveria alterações limitadas aos processos dentoalveolares para obter a correção da relação maxilomandibular (tabela 12). Desta forma, o grupo 2 também demonstrou uma maior redução da relação da relação maxilomandibular (Wits) neste mesmo período quando comparado ao grupo 1.

Sabendo que o tratamento da Classe II com 4 extrações requer maior quantidade de movimentação dentária tanto no arco superior como no arco inferior, isto poderia ter influenciado os pontos $A$ e $B^{28,91,183}$. Durante o período de observação pós-tratamento a variável Wits também evidenciou um aumento em ambos os grupos, porém não apresentou diferenças estatisticamente significantes (tabela 13). Assim, os resultado mostram que a melhora da relação maxilomandibular, apresentou uma tendência à recidiva em ambos os grupos, ligeiramente maior no grupo 1, porém com pouca significância clínica.

\section{Padrão de crescimento}

As alterações ocorridas no padrão de crescimento do paciente, no período pós-tratamento foram semelhantes nos dois grupos experimentais (tabela 13). Entretanto, observa-se uma rotação anti-horária da mandíbula em ambos os grupos principalmente considerando os ângulos FMA e o ângulo SNGOGN. Esses ângulos demonstraram uma redução semelhante em ambos os grupos, 
com o crescimento, é normal ocorrer um fechamento desses ângulos devido a um maior desenvolvimento da altura facial posterior quando comparada à altura facial ântero-inferior ${ }^{38,76}$.

Embora no grupo 2 tenha-se apresentado uma maior tendência de crescimento vertical ao início do tratamento, a realização de extrações de dois pré-molares no arco inferior contribuiu para compensar o aumento do AFAI durante a fase pós-tratamento, tornando-se semelhante ao grupo 1. Percebese também, pelos valores médios iniciais, que os pacientes desta pesquisa apresentavam um padrão de crescimento equilibrado (tabela 9). De acordo com alguns autores, os resultados mais satisfatórios e estáveis são obtidos nos pacientes com padrão de crescimento equilibrado ou horizontal ${ }^{46}$ onde $\mathrm{o}$ crescimento mandibular apresenta-se favorável, tanto durante como após o tratamento. Assim, a direção de crescimento terminal é muito importante para a manutenção dos resultados obtidos com o tratamento ortodôntico. $50,51,82,106,109,132$. O crescimento mandibular deficiente em sentido anterior contribui para a recidiva. Portanto, um dos fatores principais para a correção da Classe II e sua estabilidade seria o crescimento equilibrado em sentido ânteroinferior $^{82}$.

\section{Componente dentoalveolar superior}

Os resultados mostram que há diferença estatisticamente significante na alteração da protrusão dos incisivos superiores no período de observação (1ENAperp) (tabela 13) entre os grupos 1 e 2. Enquanto no grupo tratado com duas extrações existe uma tendência à inclinação para lingual o grupo 2 mostra uma suave tendência à inclinação para vestibular. Entretanto, mesmo com esta tendência, constata-se uma estabilidade do posicionamento ântero-posterior dos incisivos, corroborando com os resultados de outros estudos ${ }^{5,85,103,161}$. Poderia se especular que a inclusão de casos de Classe II divisão 2 no grupo 1 poderia ter influenciando na direção das inclinações dos incisivos no período de observação. No entanto, pode-se observar o mesmo padrão de alteração e direção da recidiva quando foram comparados somente os casos de Classe II divisão 1 de ambos grupos (Tabela 14). 
O resultado poderia ser esperado, pois a quantidade de retração dos incisivos superiores nos casos de Classe II completa é maior quando tratados com extração de 4 pré-molares ${ }^{28,89}$. Esta afirmação é coerente com os resultados da comparação destas variáveis no período de tratamento (tabela 12). Nessa tabela observa-se também que decorrente da maior inclinação dentária, os incisivos superiores sofreram também maior extrusão.

Por outro lado, estudos prévios mostram que existe uma correlação significante entre as alterações ocorridas no período de tratamento (T2-T1) e no período de observação (T3-T2) das variáveis do componente dentoalveolar superior, mostrando que, quanto mais se verticalizam ou retraem os incisivos superiores, menor será a estabilidade no período de observação ${ }^{61,136}$.

Com relação aos molares, comparando as alterações que ocorreram durante o período pós-tratamento, ambos exibiram uma suave mesialização, porém não se observou diferença estatisticamente significante entre os dois grupos. Esta mesialização dos molares pode ser atribuída ao crescimento maxilar, concordando com a maioria de estudos ${ }^{38,63,134}$. No entanto, no período de tratamento a mesialização do molar superior foi maior no grupo tratado com extração de dois pré-molares superiores. Este resultado era esperado, já que no tratamento da Classe II completa com extração de quatro pré-molares, 0 segmento posterior deve, não apenas ser mantido no local, mas também ser distalizado para que se obtenha uma relação molar de Classe I ao final do tratamento, enquanto que no grupo 1 os molares foram mantidos na mesma posição $^{9,28,88,89}$.

\section{Componente dentoalveolar inferior}

Ao se comparar as alterações relacionadas ao componente dentoalveolar inferior, verificou-se que não houve diferenças estatisticamente significantes para nenhuma medida no período de observação pós-tratamento(tabela 13). Ambos os tratamentos parecem não influenciar, de modo estatisticamente significante na recidiva do posicionamento sagital dos incisivos inferiores. Porém, deve-se ressaltar que ambos protocolos promoveram alterações diferentes durante o período de tratamento na posição dos incisivos inferiores. No grupo 1 houve aumento dos valores angulares e lineares conseqüente à 
protrusão dentária para correção da curva de Spee ou apinhamento. No grupo 2 ocorreu o oposto, as medidas 1-Pogper; 1-GoMe; mostram que os incisivos foram retruidos e sofreram menor extrusão. Os estudos de forma geral relatam uma certa instabilidade quanto à vestibularização desses dentes durante o tratamento ${ }^{63,107,109,125,126}$. Provavelmente, no grupo 1, a reduzida alteração no posicionamento ântero-posterior dos incisivos inferiores, ocorrida durante o tratamento, contribuiu para uma certa estabilidade na fase pós-tratamento, ${ }^{5,113}$. Portanto, durante o tratamento ortodôntico deve-se evitar uma vestibularização exagerada desses dentes, desrespeitando os limites dos tecidos moles, a fim de obter uma maior estabilidade. A incompatibilidade observada na proporção de pacientes que ainda utilizavam contenção tipo $3 \times 3$ no estágio de observação pós-tratamento (T3) poderia obscurecer os resultados quanto á recidiva do posicionamento dos incisivos; para eliminar a influência que poderia ter o uso de contenção nos resultados obtidos. Realizou-se uma nova comparação das alterações que ocorreram no período de observação póstratamento (T3-T2), desta vez excluindo de ambos os grupos todos os pacientes que ainda utilizavam contenção no estágio T3. Ainda assim, nenhuma das medidas mostrou diferenças significantes, mostrando também que o comportamento das alterações foi similar às observadas quando foram comparados todos os pacientes da amostra (tabelas 3 e 16).

Em relação aos molares inferiores, na fase pós-tratamento, exibiram uma suave mesialização (6-pogper) semelhante nos dois grupos. Esta mesialização não pode ser interpretada como uma recidiva, e sim como um movimento favorável para estabilidade da relação molar. Os molares inferiores continuaram a se desenvolver verticalmente na fase pós-tratamento de forma semelhante nos dois grupos. Entretanto, estas alterações são o resultado do crescimento e desenvolvimento normal dos pacientes. O desenvolvimento vertical dos molares foi semelhante em ambos os grupos (tabelas 12 e 13). Em ambos molares observou-se uma maior extrusão dos molares durante 0 período de tratamento, este efeito foi provavelmente devido à correção da curva de Spee e ao uso de elásticos intermaxilares de Classe II durante a mecânica ortodôntica ${ }^{43,89,167,175,176}$ e também provocada pelo próprio crescimento $^{25,26,155}$. 


\section{Relações dentárias}

Considera-se que a estabilidade da correção do trespasse horizontal e vertical, assim como a relação de caninos e de molares constituem objetivos primordiais de um tratamento ortodôntico bem sucedido.

Neste estudo, observa-se que todas as variáveis encontram-se intimamente relacionadas. O trespasse horizontal e vertical após o tratamento ortodôntico, guarda relação com a relação molar conseguida.

Os objetivos nas relações molares das duas terapêuticas empregadas eram distintos, pois em casos de Classe II com extrações de quatro prémolares os molares devem finalizar em Classe I, enquanto que nos casos tratados com extrações de dois pré-molares superiores a finalização do molar é em Classe II completa. O objetivo da relação dos caninos é o mesmo. De acordo com esta explicação poderia se esperar uma diferença significante na estabilidade dos casos tratados com estes dois protocolos de extrações. Entretanto, no presente estudo verificou-se que o trespasse horizontal o trespasse vertical e a relação dos caninos apresentam alterações semelhantes no período pós-tratamento.

No que se refere a avaliações em longo prazo da correção da sobressaliência a literatura mostra resultados conflitantes. Alguns autores afirmam que a Classe II apresenta mais recidiva na sobressaliência que as outras más oclusões ${ }^{113} ;{ }^{29}$. Outros autores concluem que a recidiva do trespasse horizontal independe do tipo de má oclusão ${ }^{49,178}$ ou mesmo se foram realizadas extrações dentárias ${ }^{55,138}$.

Ao se comparar as alterações que aconteceram no trespasse horizontal observa-se que em ambos os grupos houve um aumento do mesmo durante 0 período de observação pós-tratamento, sendo maior no grupo 2, 0,99 mm em média, embora não estatisticamente significante. Outros estudos longitudinais mostram também que embora a melhora da sobressaliência acentuada possa ser obtida com o tratamento ortodôntico, as alterações em longo prazo ocorrem na direção contrária das efetuadas com o tratamento, ou seja, em direção à má oclusão original ${ }^{55,78,163,178}$.

A recidiva do trespasse horizontal após o tratamento ortodôntico parece ocorrer devido principalmente às mudanças dentárias, com pouca influência 
das alterações esqueléticas ${ }^{55}$. Alguns autores relatam que a recidiva do trespasse horizontal se encontra associado principalmente com a recidiva da sobremordida profunda, ao aumento do ângulo interincisivos, e a lingualização dos incisivos inferiores que vestibularizaram durante o tratamento ${ }^{107,116}$.

Entretanto, vários trabalhos mostram que a recidiva da sobressaliência nos casos tratados com extrações de 4 pré-molares é bastante semelhante com os casos tratados sem extrações ${ }^{5,51,55,138,139,163,178}$. Deve-se ressaltar que a movimentação dos incisivos inferiores nas duas formas de tratamento ocorre em sentidos opostos. Nos casos de Classe II tratados sem extrações ou com extrações de dois pré-molares superiores, ocorre aumento do comprimento do arco inferior durante o tratamento devido à vestibularização dos incisivos, que é conseqüência da correção de apinhamentos suaves ou do nivelamento da curva de Spee. Considerando que as alterações após o final do tratamento ocorrem em direção às posições iniciais ${ }^{178}$, existe uma tendência à lingualização dos incisivos inferiores conduzindo ao aumento do trespasse horizontal. Dessa forma, resultados considerados satisfatórios ao final do tratamento, onde o mecanismo compensatório dos incisivos ocultou as discrepâncias apicais, podem sofrer alterações marcantes com o decorrer do tempo devido à recidiva destes posicionamentos dentários nem sempre estar em equilíbrio com a musculatura ${ }^{111}$.

De maneira contrária, na Classe II tratada com extrações de pré-molares no arco inferior, durante a mecânica de fechamento dos espaços, ocorre inclinação em direção lingual dos incisivos inferiores. Após a remoção dos dispositivos de contenção, a tendência de movimentação para as posições iniciais, em direção vestibular, reduziria o trespasse horizontal ${ }^{126}$. Dentro dessa idéia, na observação do arco inferior somente, poder-se-ia esperar que o trespasse horizontal se apresentasse mais estável com a realização de extrações dentárias, o que não foi observado neste estudo.

Devido à Classe II apresentar como traço distinto o trespasse horizontal acentuado, poderia presumir-se que a maior severidade desta característica ao início do tratamento e conseqüentemente a maior quantidade de correção durante o tratamento teria influência sobre a manutenção dos resultados em longo prazo ${ }^{29,33,126}$. Os resultados decorrentes da análise de correlação entre as alterações ocorridas nos grupos 1 e 2 durante o período de observação pós- 
tratamento permitiram verificar que houve uma correlação direta entre a quantidade de correção do trespasse horizontal e a quantidade de recidiva da mesma(tabela 19). No entanto, alguns trabalhos ${ }^{55},{ }^{116,178}$ não verificaram existir esta relação..

Quanto à correção do trespasse vertical pode-se observar que este ocorreu principalmente por restrição do desenvolvimento vertical dos incisivos e pelo desenvolvimento vertical dos molares (tabela 12). Os resultados desta tabela também evidenciam que no grupo 1 houve uma melhora da correção do trespasse vertical, assim como na correção da relação dos caninos estatisticamente significante quando comparado com o grupo 2. Alguns trabalhos mostram que a manutenção da correção do trespasse vertical esta relacionado com a sua forma de correção. Esses trabalhos sugerem também que a correção da sobremordida profunda por meio da extrusão de molares é bastante estável quando não ocorre violação do espaço interoclusal ${ }^{10,39,71,122,128}$. Já as mecânicas de intrusão dos incisivos, indicadas para o tratamento de pacientes adultos, com padrão de face vertical e exposição excessiva dos incisivos, se mostram efetivas na manutenção dos resultados obtidos, podendo-se esperar $1 \mathrm{~mm}$ de recidiva para uma média de intrusão de $3 \mathrm{~mm}^{130}$.

O tratamento com extrações dentárias tradicionalmente é criticado como um fator para a recidiva do trespasse horizontal. Por isso, muitos clínicos hesitam ou avaliam de maneira crítica ao prescrever extrações de pré-molares em casos de sobremordida profunda.

A influência das extrações dentárias sobre a manutenção de um correto trespasse vertical em longo prazo ainda permanece controversa. Alguns estudos $^{42}{ }^{114}, 8194$ verificaram que o tratamento com extrações de pré-molares predispunha a uma maior recidiva do trespasse vertical acentuado. No entanto, a maioria dos trabalhos ${ }^{23,42,78,118,138,165,173}$ não encontrou diferença nos resultados em longo prazo entre os pacientes tratados com ou sem extrações de pré-molares.

LITTLE; WALLEN; RIEDEL ${ }^{113}$, 1981, verificaram um aumento estatisticamente significante do trespasse vertical em 65 pacientes tratados com extrações. Entretanto, o aumento do trespasse horizontal foi somente de $0.76 \mathrm{~mm}$, com pouca relevância clínica. A partir deste resultado, poder-se-ia 
supor que o menor trespasse horizontal observado no grupo 1 no estágio T3 (tabela 11) foi devido à diferença na quantidade de extrações entre os dois grupos.

Outros fatores, e não somente as extrações dentárias, podem ser identificados como influenciadores na estabilidade da correção do trespasse horizontal, sejam características inerentes ao paciente ou relacionados ao tratamento.

É possível que a recidiva do trespasse horizontal se encontre relacionada com a recidiva do trespasse horizontal ${ }^{55,107,139,178}$.

A recidiva do trespasse horizontal devido à vestibularização dos incisivos superiores e lingualização dos incisivos inferiores durante o tratamento pode distanciar os pontos de contato entre os dentes anteriores e assim permitir a extrusão dos incisivos em longo prazo ${ }^{161}$. Dessa forma, poder-se-ia especular que a recidiva do trespasse horizontal na Classe II apresentasse também um aumento maior do trespasse vertical acentuado que a Classe I ${ }^{75}, 165.64$. Entretanto, a maioria dos trabalhos ${ }^{113,118,163,174,178}$ não verificou diferenças entre as classes quanto à recidiva da sobremordida. Bresonis, Grewe ${ }^{29}$ verificaram maior recidiva do trespasse vertical acentuado nos casos de Classe II, divisão 1 do que nos de Classe I, porém, a diferença das alterações entre os grupos foi pequena $(0.2 \mathrm{~mm})$ e, portanto, de pouca significância clínica.

Durante o tratamento da Classe II, divisão 2, entretanto, pode-se esperar maior quantidade de recidiva do trespasse vertical ${ }^{98}$. Acredita-se que um ângulo interincisivos amplo ao final do tratamento tenha relação com a recidiva da correção desta variável ${ }^{161}$. Dessa forma, no tratamento da Classe II, divisão 2, a correção da relação dos incisivos deve visar, além da diminuição do trespasse vertical acentuado, de mudanças também na inclinação dentária ${ }^{100}$. Acredita-se que, ao atingir a correta inclinação dos incisivos com o tratamento, as forças funcionais passam a serem direcionadas próximas às bordas incisais e assim pode-se minimizar a tendência desses dentes de sofrerem verticalização com o crescimento mandibular remanescente. Além desse fator, Shields, Little et al. $^{163}$ observaram uma associação das características cefalométricas iniciais e finais nos casos de Classe II, divisão 2, o que sugere que as características neuromusculares desse grupo podem ser um fator etiológico na recidiva do trespasse vertical acentuado. 
Alguns estudos evidenciaram que existe uma correlação positiva significante entre a quantidade de alteração do trespasse vertical acentuado durante o tratamento e o seu aumento após a remoção do aparelho ${ }^{114,178}$. Esta correlação também foi observada em ambos os grupos do presente estudo (tabela 19). Além disso, SADOWSKY; SAKOLS ${ }^{156}$ constataram que o trespasse vertical acentuado $(\geq 5.5 \mathrm{~mm}$ ) freqüentemente se encontraria associada à recidiva, enquanto a trespasse vertical moderado (3.5 a $5 \mathrm{~mm}$ ) nem sempre; entretanto, a sobremordida normal se manteria estável ou tenderia a sofrer um ligeiro aumento. Isso significa que os casos com trespasse vertical mais acentuado devem ser sobrecorrigidos, na probabilidade de que ocorra maior recidiva.

A incompatibilidade dos grupos quanto à proporção de pacientes com contenção inferior poderia afetar os resultado deste estudo no sentido de favorecer a obtenção de maior estabilidade no trespasse horizontal e vertical no grupo com extração de 2 pré-molares, devido a que este grupo apresentava um maior número de pacientes com contenção no estágio T3. Porém, constatou-se que os resultados da comparação destas variáveis excluindo os pacientes portadores de contenção foram similares às observadas quando foram comparados todos os pacientes da amostra (tabelas 15, 16).

No presente estudo, das 4 variáveis estudadas correspondentes à relação dentária a relação molar foi a única variável que apresentou uma diferença estatisticamente significante nas alterações que ocorreram durante o período pós-tratamento nos grupos 1 e 2. Os resultados desta comparação mostram que o grupo 2 apresentou uma recidiva maior em decorrência da mesialização dos molares superiores ${ }^{136}$ (tabelas 11). Entretanto, as alterações no posicionamento dos molares, embora significantes não podem ser avaliados desde o mesmo ponto de vista, pois os molares inferiores no grupo 1 não foram movimentados durante a mecânica, podendo sofrer no máximo movimentos de inclinação, enquanto que no grupo 2 era de esperar uma correção da relação molar para assim finalizar em uma relação molar de Classe I, o que precisaria da realização de modificações significantes durante o tratamento devido à mecânica com extrações inferiores instituída e a correção da relação molar esperada. Nesse sentido, alguns autores sugeriram que a maior movimentação ocorrida nos molares durante o período de tratamento nos pacientes com má 
oclusão de Classe II tratados com 4 extrações, poderia influenciar de forma desfavorável na manutenção dos resultados obtidos ao final do tratamento 28,89,123. Corroborando essas especulações, os resultados obtidos (tabela 19) demonstraram uma correlação estatisticamente significante entre as alterações da relação molar durante e após o tratamento, ou seja, quanto maior a alteração da relação molar durante o tratamento, maior será a recidiva, como também verificado por outros estudos ${ }^{137,178}$.

$\mathrm{O}$ crescimento maxilar ${ }^{63} \mathrm{e}$ a rotação em sentido horário da mandíbula são fatores que contribuem para a recidiva da relação molar de Classe $1{ }^{46}$. Os resultados da análise de correlação entre quantidade de recidiva da relação molar e as alterações das variáveis estudadas, no período pós-tratamento corroboram estas afirmações (tabela 22, 23). Em ambos os grupos nota-se que existe uma correlação negativa entre a relação molar o ângulo SNB, quer dizer que quanto mais diminui este ângulo maior será a recidiva da relação molar, ou seja, quanto mais rotação em sentido horário ocorrer na mandíbula, maior será a recidiva da relação molar. Neste sentido, os resultados, mostram uma correlação positiva entre a recidiva da relação molar e o aumento do ângulo FMA. É preciso, portanto, muita cautela com os pacientes que apresentam padrão de crescimento vertical. Esses pacientes continuam a demonstrar uma rotação horária da mandíbula no período pós-tratamento, sendo que essa rotação é considerada a principal causa da recidiva da relação de Classe II por alguns autores ${ }^{50,51,82,109,132}$

A recidiva da sobressaliência parece também se encontrar associada com a recidiva do relacionamento entre os dentes posteriores ${ }^{55,109,139}$, como pode ser observado na tabela 23. No entanto, embora possa haver suave tendência da relação molar recidivar após o tratamento com extrações dentárias $^{29,64,113,116,178}$, existe estabilidade satisfatória na correção anteroposterior da Classe II. Quando comparada com a má oclusão de Classe I, a manutenção da correção da relação molar na Classe II se apresenta equivalente ${ }^{49,139,163}$.

Quanto à relação dos caninos, embora que as alterações no período de observação pós-tratamento tenham sido semelhantes entre os grupos, na tabela 10 pode-se observar que no grupo tratado com a extração de 2 prémolares a relação de caninos foi mais próxima de Classe I. Esta melhor 
finalização em sentido ântero-posterior dos caninos provavelmente seja devido a que essa abordagem requer uma menor necessidade de colaboração do paciente em utilizar os reforços de ancoragem extrabucais, possibilitando desta forma uma melhor terminação oclusal ${ }^{9,28,89}$. Corroborando esta afirmação, os resultados das comparações das alterações durante o período de tratamento (T2-T1) permite apreciar uma diferença significante na melhora da relação de caninos no grupo 1. Enquanto que nesse grupo a redução foi de $6,02 \mathrm{~mm}$ em média no grupo 2 foi de $-4,99 \mathrm{~mm}$ (tabela 12). Poderia se esperar que essa maior correção observada no grupo 1 poderia favorecer uma maior quantidade de recidiva, porém, no estágio pós-tratamento pode-se observar que os pacientes do grupo 1 continuaram mantendo uma relação de caninos mais favorável (tabela 11). Todavia, constatou-se que em ambos os grupos houve uma correlação positiva estatisticamente significante entre as alterações da relação de caninos durante e após o tratamento, ou seja, quanto maior a correção durante o tratamento maior será a recidiva (tabela 19). Por outro lado, no grupo 2, os resultados demonstram uma correlação positiva entre a recidiva da relação molar e a recidiva da relação de caninos. Isso parece confirmar a importância de se finalizar o tratamento com a melhor intercuspidação possível $^{73,136,182}$.

Cabe ressaltar que não foi encontrado nenhum trabalho na literatura, que compare casos de Classe II tratados com extrações de dois e de quatro prémolares, e assim, utilizou-se para esta discussão, somente artigos que comparam a estabilidade da correção da má oclusão de Classe II, abordada com e sem a extração de pré-molares. 
Conclusões 



\section{CONCLUSÕES}

Com base nos resultados apresentados e na metodologia empregada, a hipótese nula, não há diferença na estabilidade da correção das relações dentárias da Classe II completa, realizado com duas ou quatro extrações de pré-molares, foi rejeitada uma vez que o tratamento com extrações de dois prémolares superiores apresentou um maior grau de estabilidade quando comparado ao protocolo de tratamento com quatro extrações. Evidenciou-se também que a recidiva do trespasse horizontal, do trespasse vertical e da relação de caninos apresentaram uma relação diretamente proporcional à quantidade da sua correção. 



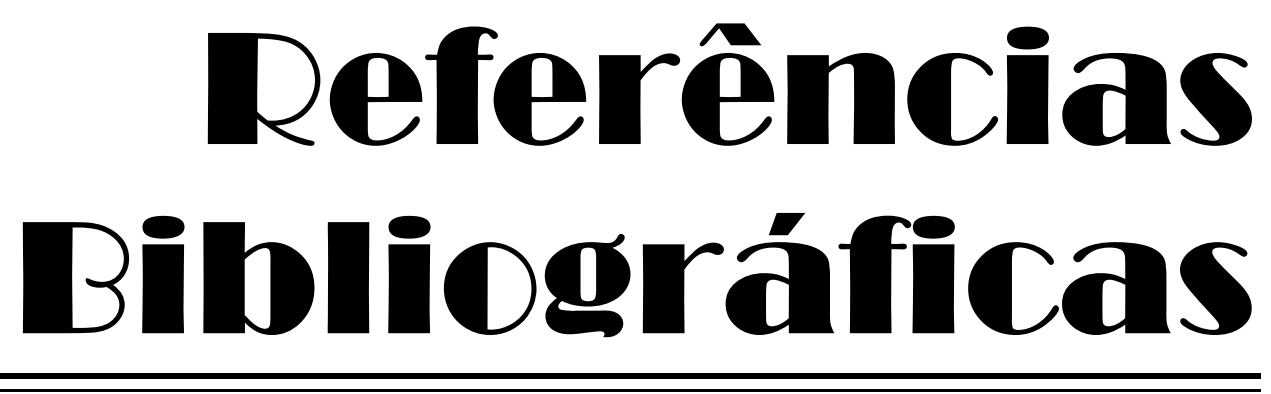





\section{REFERÊNCIAS BIBLIOGRÁFICAS}

1. Aelbers CM, Dermaut LR. Orthopedics in orthodontics: Part I, Fiction or reality--a review of the literature. Am J Orthod Dentofacial Orthop. 1996;110(5):513-9.

2. Andresen V. The Norwegian System of functional Gnatho-Orthopedics. Acta Gnathol. 1936;1:1-36.

3. Angle EH. Classification of malocclusion. Dental Cosmos. 1899;41:248357.

4. Angle EH. Treatment of malocclusion of the teeth. 7ed ed. Philadelphia: S.S. White Dental Manufacturing Co; 1907.

5. Artun J, Garol JD, Little RM. Long-term stability of mandibular incisors following successful treatment of Class II, Division 1, malocclusions. Angle Orthod. 1996;66(3):229-38.

6. Arvystas MG. Nonextraction treatment of Class II, division 1 malocclusions. Amer J Orthod. 1985;88(5):380-95.

7. Baccetti T, Franchi L, McNamara JA, Jr., Tollaro I. Early dentofacial features of Class II malocclusion: a longitudinal study from the deciduous through the mixed dentition. Am J Orthod Dentofacial Orthop. 1997;111(5):502-9.

8. Baltromejus $S$, Ruf $S$, Pancherz $\mathrm{H}$. Effective temporomandibular joint growth and chin position changes: Activator versus Herbst treatment. A cephalometric roentgenographic study. Eur J Orthod. 2002;24(6):627-37.

9. Barros SEC. Avaliação do grau de eficiência do tratamento da Classe II realizado sem extrações e com extrações de dois pré-molares superiores [Dissertação (Mestrado)]. Bauru: Faculdade de Odontologia de Bauru, Universidade de São Paulo; 2004.

10. Barton JJ. A cephalometric comparison of cases treated with edgewise and Begg techniques. Angle Orthod. 1973;43(1):119-26.

11. Bass NM. Orthopedic coordination of dentofacial development in skeletal Class II malocclusion in conjunction with edgewise therapy. Part II. Am J Orthod. 1983;84(6):466-90.

12. Baumrind S, Frantz RC. The reliability of head film measurements. 1. Landmark identification. Am J Orthod. 1971;60(2):111-27.

13. Baumrind S, Frantz RC. The reliability of head film measurements. 2 . Conventional angular and linear measures. Am $\mathrm{J}$ Orthod. 1971;60(5):505-17. 
14. Baumrind S, Korn EL, Boyd RL, Maxwell R. The decision to extract: Part II. Analysis of clinicians' stated reasons for extraction. Am J Orthod Dentofacial Orthop. 1996;109(4):393-402.

15. Baumrind S, Molthen R, West EE, Miller DM. Mandibular plane changes during maxillary retraction. Am J Orthod. 1978;74(1):32-40.

16. Baumrind S, Molthen R, West EE, Miller DM. Mandibular plane changes during maxillary retraction. Part 2. Am J Orthod. 1978;74(6):603-20.

17. Begg PR. Begg orthodontic theory and technique. Philadelphia; 1971.

18. Bernstein M, Rosol ML, Jr., Gianelly AA. A biometric study of orthopedically directed treatment of class II malocclusion. Am J Orthod. 1976;70(6):683-9.

19. Bishara SE, Augspurger EF, Jr. The role of mandibular plane inclination in orthodontic diagnosis. Angle Orthod. 1975;45(4):273-81.

20. Bishara SE, Bayati P, Zaher AR, Jakobsen JR. Comparisons of the dental arch changes in patients with Class II, division 1 malocclusions: extraction vs nonextraction treatments. Angle Orthod. 1994;64(5):351-8.

21. Bishara SE, Cummins DM, Jakobsen JR. The morphologic basis for the extraction decision in Class II, division 1 malocclusions: a comparative study. Am J Orthod Dentofacial Orthop. 1995;107(2):129-35.

22. Bishara SE, Cummins DM, Jakobsen JR, Zaher AR. Dentofacial and soft tissue changes in Class II, division 1 cases treated with and without extractions. Am J Orthod Dentofacial Orthop. 1995;107(1):28-37.

23. Bishara SE, Cummins DM, Zaher AR. Treatment and posttreatment changes in patients with Class II, Division 1 malocclusion after extraction and nonextraction treatment. Am J Orthod Dentofacial Orthop. 1997;111(1):18-27.

24. Bishara SE, Hoppens BJ, Jakobsen JR, Kohout FJ. Changes in the molar relationship between the deciduous and permanent dentitions: a longitudinal study. Am J Orthod Dentofacial Orthop. 1988;93(1):19-28.

25. Bishara SE, Jakobsen JR, Vorhies B, Bayati P. Changes in dentofacial structures in untreated Class II division 1 and normal subjects: a longitudinal study. Angle Orthod. 1997;67(1):55-66.

26. Bishara SE, Zaher AR, Cummings DR, Jakobsen JR. Effects of orthodontic treatment on the growth of individuals with Class II division 1 malocclusion. Angle Orthod. 1994;64(3):221-30.

27. Björk A. Variations in the growth pattern of the human mandible: longitudinal radiographic study by the implant method. J Dent Res. 1963;42(1):400-11. 
28. Brambilla AC. Comparação dos resultados oclusais do tratamento da Classe II realizado com extrações de dois pré-molares, com a terapêutica utilizando as extrações de quatro pré-molares [Dissertação (Mestrado)]. Bauru: Faculdade de odontologia de Bauru, Universidade de São Paulo; 2002.

29. Bresonis WL, Grewe JM. Treatment and posttreatment changes in orthodontic cases: overbite and overjet. Angle Orthod. 1974;44(4):295-9.

30. Broadbent BH. A new $x$-ray technique and its application to orthodontia. Angle Orthod. 1931;1(2):45-56.

31. Brodie AG, Downs WB, Goldstein A, Myer E. Cephalometric appraisal of orthodontic results: a preliminary report. Angle Orthod. 1938;8(4):261351.

32. Buchin ID. Facial esthetics and cephalometric criteria as the determinants in the extraction decision. J Clin Orthod. 1971;5(8):421-34.

33. Burden DJ, McGuinness N, Stevenson M, McNamara T. Predictors of outcome among patients with class II division 1 malocclusion treated with fixed appliances in the permanent dentition. Am J Orthod Dentofacial Orthop. 1999;116(4):452-9.

34. Busato MCA. Estabilidade da correção do apinhamento ântero-inferior na má oclusão de classe II de Angle tratada com a extração de dois e quatro pré-molares [Dissertação (Mestrado)]. Bauru: Faculdade de Odontologia de Bauru, Universidade de São Paulo; 2003.

35. Buschang PH, Tanguay R, Demirjian A, LaPalme L, Turkewicz J. Mathematical models of longitudinal mandibular growth for children with normal and untreated Class II, division 1 malocclusion. Eur J Orthod. 1988;10(3):227-34.

36. Buschang PH, Tanguay R, Turkewicz J, Demirjian A, La Palme L. A polynomial approach to craniofacial growth: description and comparison of adolescent males with normal occlusion and those with untreated Class II malocclusion. Am J Orthod Dentofacial Orthop. 1986;90(5):43742.

37. Cangialosi TJ, Meistrell ME, Leung MA, Ko JY. A cephalometric appraisal of edgewise Class II nonextraction treatment with extraoral force. Am J Orthod Dentofacial Orthop. 1988;93(4):315-24.

38. Carter NE. Dentofacial Changes in untreated Class II, division 1 subjects. Brit J Orthod. 1987;14(4):225-34.

39. Carter NE. First premolar extractions and fixed appliances in the Class II division 1 malocclusion. Br J Orthod. 1988;15(1):1-10.

40. Case SC. The question of extraction in orthodontia. Amer J Orthod. 1964;50(9):660-91. 
41. Chung $\mathrm{CH}$, Wong WW. Craniofacial growth in untreated skeletal Class II subjects: a longitudinal study. Am J Orthod Dentofacial Orthop. 2002;122(6):619-26.

42. Cole HJ. Certain results of extraction in the treatment of malocclusion. Angle Orthod. 1948;18(3/4):103-13.

43. Cusimano $\mathrm{C}$, McLaughlin RP, Zernik JH. Effects of first bicuspid extractions on facial height in high-angle cases. J Clin Orthod. 1993;27(11):594-8.

44. Dahlberg G. Statistical methods for medical and biological students. New York: Interscience publications; 1940.

45. De Vincenzo JP. Changes in mandibular length before, during, and after successful orthopedic correction of Class II malocclusions, using a functional appliance. Am J Orthod Dentofacial Orthop. 1991;99(3):24157.

46. Derringer K. A cephalometric study to compare the effects of cervical traction and Andresen therapy in the treatment of Class II division 1 malocclusion. Part 1--Skeletal changes. Br J Orthod. 1990;17(1):33-46.

47. Draker HL. Handicapping labio-lingual deviations: a proposed index for public health purposes. Amer J Orthod Dentofac Orthop. 1960;46:295305.

48. Drelich RC. A cephalometric study of untreated Class II, division 1 malocclusion. Angle Orthodont. 1948;18(3-4):70-5.

49. El-Mangoury $\mathrm{NH}$. Orthodontic relapse in subjects with varying degrees of anteroposterior and vertical dysplasia. Am J Orthod. 1979;75(5):548-61.

50. Elms TN, Buschang PH, Alexander RG. Long-term stability of Class II, division 1, nonextraction cervical face-bow therapy: I. Model analysis. Am J Orthod Dentofacial Orthop. 1996;109(3):271-6.

51. Elms TN, Buschang PH, Alexander RG. Long-term stability of Class II, division 1, nonextraction cervical face-bow therapy: II. Cephalometric analysis. Am J Orthod Dentofacial Orthop. 1996;109(4):386-92.

52. Engel G, Cornforth G, Damerell JM, Gordon J, Levy P, McAlpine J, et al. Treatment of deep-bite cases. Am J Orthod. 1980;77(1):1-13.

53. Faltin KJ, Faltin RM, Baccetti T, Franchi L, Ghiozzi B, McNamara JA, Jr. Long-term effectiveness and treatment timing for Bionator therapy. Angle Orthod. 2003;73(3):221-30.

54. Feldmann I, Lundstrom F, Peck S. Occlusal changes from adolescence to adulthood in untreated patients with Class II Division 1 deepbite malocclusion. Angle Orthod. 1999;69(1):33-8. 
55. Fidler BC, Artun J, Joondeph DR, Little RM. Long-term stability of Angle Class II, Division 1 malocclusions with successful occlusal results at end of active treatment. Am J Orthod Dentofacial Orthop. 1995;107(3):27685.

56. Fotis V, Melsen B, Williams S. Posttreatment changes of skeletal morphology following treatment aimed at restriction of maxillary growth. Am J Orthod. 1985;88(4):288-96.

57. Franchi L, Baccetti T, McNamara JA. Treatment and posttreatment effectsof acrylic splint herbst appliance therapy. Amer $\mathrm{J}$ Orthod Dentofacial Orthop. 1999;115(4):429-38.

58. Fränkel R. The treatment of Class II, division 1 malocclusion with functional corretors. Am J Orthod Dentofacial Orthop. 1969;55(3):265-75.

59. Fränkel R, Fränkel C. Orofacial orthopedics with the function regulator. Munich: karger; 1989.

60. Freitas KMS. Estudo da recidiva do apinhamento ântero-inferior de casos tratados ortodonticamente sem extrações no arco inferior e mecânica edgewise, na fase pós-contenção [Dissertação (Mestrado)]. Bauru: Faculdade de Odontologia de Bauru, Universidade de São Paulo; 2002.

61. Freitas KMS, Freitas MR, Henriques JFC, Pinzan A, Janson G. Postretention relapse of mandibular anterior crowding in patients treated without mandibular premolar extraction. Am J Orthod Dentofacial Orthop. $2004 ; 125(4): 480-7$.

62. Freitas MR, Beltrão RTS, Janson G, Henriques JFC, Cançado RH. Longterm stability of anterior open bite extraction treatment in the permanent dentition. Am J Orthod Dentofacial Orthop. 2004;125(1):78-87.

63. Gardner R, Harris E, Vaden J. Postorthodontic dental changes: a longitudinal study. Am J Orthod Dentofacial Orthop. 1998;114(5):581-86.

64. Glenn G, Sinclair PM, Alexander RG. Nonextraction orthodontic therapy: posttreatment dental and skeletal stability. Am J Orthod Dentofacial Orthop. 1987;92(4):321-8.

65. Goldreich HN, Martins JCR, Martins LP, Sakima PR. Considerações sobre os erros em cefalometria. Rev Dent Press Ortodon Ortop Facial. 1998;3(1):81-90.

66. Graber TM. Current orthodontic concepts and techniques. Philadelphia: W. B. Saunders Company; 1969.

67. Graber TM. Maxillary second molar extraction in Clas II malocclusion. Amer J Orthod. 1969;56(4):331-58. 
68. Graber TM. Combinação de força extrabucal e aparelhos funcionais. In: Graber TM, T R, Petrovic AG. Ortopedia dentofacial com aparelhos funcionais. 2 ed. Rio de Janeiro: Guanabara Koogan; 1999. p. 500.

69. Graber TM, Neumann B. Aparelhos ortodônticos removíveis. 2da ed. São Paulo: Panamericana; 1987.

70. Grainger RM. Orthodontic treatment priority index. Vital Health Stat. $1967 ; 25(2): 1-49$.

71. Grano DJ. A radiographic cephalometric study of certain tooth movements observed in the postretention period of deep overbite cases treated with the Begg technique. Am J Orthod. 1971;60(2):202-3.

72. Gray AS, Demirjian A. A indexing occlusion for dental public health programs. Amer J Orthod. 1977;72(2):191-7.

73. Hansen k, Pancherz H, Hagg U. Long-terms of the Herbst appliance in relation to the treatment growth period: a cephalometric study. Eur $\mathrm{J}$ Orthod. 1991;13(6):471-81.

74. Haralabakis NB, Halazonetis DJ, Sifakakis IB. Activator versus cervical headgear: superimpositional cephalometric comparison. Am J Orthod Dentofacial Orthop. 2003;123(3):296-305.

75. Harris EF, Behrents RG. The intrinsic stability of Class I molar relationship: a longitudinal study of untreated cases. Am J Orthod Dentofacial Orthop. 1988;94(1):63-7.

76. Harris EF, Vaden JL, Dunn KL, Behrents RG. Effects of patient age on postorthodontic stability in Class II, division 1 malocclusions. Am J Orthod. 1994;105(1):25-34.

77. Harvorld EP, Vargervik K. Morphogenetic response to activador treatment. Amer J Orthod Dentofacial Orthop. 1971;60(1):77-82.

78. Hellekant M, Lagerström L, Gleerup A. Overbite and overjet correction in a Class II, division 1 sample treated with edgewise therapy. Eur J Orthod. 1989;11(2):91-106.

79. Henriques JFC. Estudo cefalométrico comparativo de três tipos de ancoragem extrabucal, sobre as estruturas dentoesqueléticas em pacientes com Classe II, $1^{\text {a }}$ divisão [Tese (Livre-Docência)]. Bauru: Faculdade de Odontologia de Bauru, Universidade de São Paulo; 1993.

80. Herbst E. Atlas und gundriss der zahnarztlichen orthopadie. Munchen: J.F Lehmann; 1910.311-15.

81. Hernandez JL. Mandibular bicanine width relative to overbite. Am J Orthod. 1969;56(5):455-67. 
82. Herzberg R. A cephalometric study of Class II relapse. Angle Orthod. 1973;43(1):112-8.

83. Hirzel HC, Grewe JM. Activators: a practical approach. Am J Orthod. 1974;66(5):557-70.

84. Houston WJ. The analysis of errors in orthodontic measurements. Am J Orthod. 1983;83(5):382-90.

85. Huggins D, Birch R. A cephalometric investigation of stability of upper incisors following their retraction. Amer J Orthod. 1964;74(11):852-6.

86. Ishikawa $\mathrm{H}$. The effect of anchorage bends and Class II elastics on the lower anterior teeth and the anchor molars with the Begg technique. Odontology. 1977;65:628-46.

87. Jacobson A. The wits appraisal of jaw disharmony. Amer J Orthod. 1975;67(10):125-38.

88. Janson G, Janson MR, Cruz KS, Henriques JF, de freitas MR. Unusual orthodontic retreatment. Amer $\mathrm{J}$ Orthod Dentofac Orthop. 2003;123(4):468-75.

89. Janson G, Brambilla AC, Henriques JF, de Freitas MR, Neves LS. Class II treatment success rate in 2- and 4-premolar extraction protocols. Am J Orthod Dentofacial Orthop. 2004;125(4):472-9.

90. Janson G, Busato MC, Henriques JF, de Freitas MR, de Freitas LM. Alignment stability in Class II malocclusion treated with 2- and 4premolar extraction protocols. Am J Orthod Dentofacial Orthop. 2006;130(2):189-95.

91. Janson G, Caffer DC, Henriques JF, de Freitas MR, Neves LS. Stability of Class II, division 1 treatment with the headgear-activator combination followed by the edgewise appliance. Angle Orthod. 2004;74(5):594-604.

92. Janson G, de Souza JE, de Freitas MR, Henriques JF, Cavalcanti CT. Occlusal changes of Class II malocclusion treatment between Frankel and the eruption guidance appliances. Angle Orthod. 2004;74(4):521-5.

93. Janson MR. Influência das características cefalométricas na proporção de sucesso do tratamento da Classe II com extrações de dois e de quatro pré-molares [Mestrado]. Bauru: Faculdade de Odontologia de Bauru-Universidade de São Paulo; 2005.

94. Kahl-Nieke B, Fischbach H, Schwarze CW. Post-retention crowding and incisor irregularity: a long-term follow-up evaluation of stability and relapse. Br J Orthod. 1995;22(3):249-57.

95. Karlsen AT, Krogstad O. Morphology and growth in convex profile facial patterns: a longitudinal study. Angle Orthod. 1999;69(4):334-44. 
96. Kawauchi MY. Avaliação da recidiva da sobremordida profunda. Estudo longitudinal cefalométrico e de modelos [Tese (Doutorado) ]. Bauru: Faculdade de Odontologia de Bauru, Universidade de São Paulo; 1999.

97. Kerr WJ. A longitudinal cephalometric study of dento-facial growth from 5 to 15 years. Br J Orthod. 1979;6(3):115-21.

98. Kim TW, Little RM. Postretention assessment of deep overbite correction in Class II Division 2 malocclusion. Angle Orthod. 1999;69(2):175-86.

99. Kingsley NW. Oral deformities. New York: Appleton \& Co; 1880.

100. Kinzel J, Aberschek P, Mischak I, Droschl H. Study of the extent of torque, protrusion and intrusion of the incisors in the context of Class II, division 2 treatment in adults. J Orofac Orthop. 2002;63(4):283-99.

101. Klocke A, Nanda RS, Kahl-Nieke B. Skeletal Class II patterns in the primary dentition. Am J Orthod Dentofacial Orthop. 2002;121(6):596-601.

102. Kloehn SJ. Guiding alveolar growth and eruption of teeth to reduce treatment time and produce a more balanced denture and face. Angle Orthodo. 1947;17(1):10-23.

103. Kondo E. Occlusal stability in Class II, Division 1, deep bite cases followed up for many years after orthodontic treatment. Am J Orthod Dentofacial Orthop. 1998;114(6):611-30.

104. Krogman WNS, V.A. A sillabus in rontgenographic cephalometry. Philadelphia, Philadelphia Center for Research in Child Growth; 1957. p. 45-103.

105. Legan HL, Burstone CJ. Soft tissue cephalometric analysis for orthognatic surgery. J Oral Surg. 1980;38(10):744-51.

106. Lehman R, Romulli $\mathrm{A}$, Baker V. Five year treatment results with a headgear- activator combination. Eur J Orthod. 1988;10(4):309-18.

107. Levin RI. Treatment results with the Begg technique. Am J Orthod. 1977;72(3):239-60.

108. Lewis EA, Albino JE, Cunat JJ, Tedesco LA. Reability and validity of clinical assessments of malocclusion. Amer J Orthod. 1982;81(6):473-7.

109. Litowitz R. A study of the movements of certain teeth during and following orthodontic treatment. Angle Orthod. 1948;18(3/4):113-32.

110. Litt RA, Nielsen IL. Class II, division 2 malocclusion. To extract--or not extract? Angle Orthod. 1984;54(2):123-38.

111. Little RM. Stability and relapse of dental arch alignment. Br J Orthod. 1990;17(3):235-41. 
112. Little RM, Riedel RA, Artun J. An evaluation of changes in mandibular anterior alignment from 10 to 20 years postretention. Am J Orthod Dentofacial Orthop. 1988;93(5):423-8.

113. Little RM, Wallen TR, Riedel RA. Stability and relapse of mandibular anterior alignment-first premolar extraction cases treated by traditional edgewise orthodontics. Am J Orthod. 1981;80(4):349-65.

114. Ludwig MK. An analysis of anterior overbite relationship changes during and following orthodontic treatment. Angle Orthod. 1966;36(3):204-10.

115. Luecke PE, 3rd, Johnston LE, Jr. The effect of maxillary first premolar extraction and incisor retraction on mandibular position: testing the central dogma of "functional orthodontics". Am J Orthod Dentofacial Orthop. 1992;101(1):4-12.

116. Lunardi DB. Estudo longitudinal cefalométrico e de modelos para avaliação da recidiva da sobressaliência em pacientes com ângulo ANB maior ou igual a $4^{\circ}$ ao final do tratamento ortodôntico [Dissertação (Mestrado)]. Bauru: Faculdade de Odontologia de Bauru, Universidade de São Paulo; 2003.

117. Luppanapornlarp S, Johnston LE, Jr. The effects of premolar extraction: a long-term comparison of outcomes in "clear-cut" extraction and nonextraction Class II patients. Angle Orthod. 1993;63(4):257-72.

118. Magill JM. Changes in the anterior overbite relationship following orthodontic treatment in extraction cases. Am J Orthod. 1960;46(10):75588.

119. Mailankody J. Enigma of Class II molar finishing. Am J Orthod Dentofacial Orthop. 2004;126(6):A15-6; author reply A6-7.

120. McNamara JA. Components of Class malocclusion in children 8-10 of age. Angle Orthodont. 1981;51(3):177-202.

121. McNamara JA. A method of cephalometric evaluation. Amer J Orthod. 1984;86(6):449-69.

122. Menezes DM. Change in tooth position and vertical dimension in severe Class II division 1 cases during Begg treatment. $\mathrm{Br} \mathrm{J}$ Orthod. 1975;2(2):85-91.

123. Mihalik CA, Proffit WR, Phillips C. Long-term follow-up of Class II adults treated with orthodontic camouflage: a comparison with orthognathic surgery outcomes. Am J Orthod Dentofacial Orthop. 2003;123(3):266-78.

124. Mills CM, Holman RG, Graber TM. Heavy intermittent cervical traction in class II treatment: a longitudinal cephalometric assessment. Am J Orthod. 1978;74(4):361-79. 
125. Mills JR. The long-term results of the proclination of lower incisors. $\mathrm{Br}$ Dent J. 1966;120(8):355-63.

126. Nashed RR, Reynolds IR. A cephalometric investigation of overjet changes in fifty severe Class II division I malocclusions. $\mathrm{Br} \mathrm{J}$ Orthod. $1989 ; 16(1): 31-7$.

127. Nelson C, Harkness M, Herbison P. Mandibular changes during functional appliance treatment. Amer $\mathrm{J}$ Orthod Dentofacial Orthop. 1993;104(2):153-61.

128. O'Reilly MT. Treatment and posttreatment changes with the Begg appliance. Am J Orthod. 1979;75(5):535-47.

129. Omblus J, Malmgren O, Pancherz H, Hagg U, Hansen K. Long-term effects of Class II correction in Herbst and Bass therapy. Eur J Orthod. 1997;19(2):185-93.

130. Otto RL, Anholm JM, Engel GA. A comparative analysis of intrusion of incisor teeth achieved in adults and children according to facial type. Am J Orthod. 1980;77(4):437-46.

131. Owman G, Bjerklin K, Kurol J. Mandibular incisor stability after orthodontic treatment in the upper arch. Eur J Orthod. 1989;11(4):34150 .

132. Pancherz H. Relapse after activator treatment. A biometric, cephalometric, and electromyographic study of subjects with and without relapse of overjet. Am J Orthod. 1977;72(5):499-512.

133. Pancherz H. Treatment of class II malocclusions by jumping the bite with the Herbst appliance. A cephalometric investigation. Am J Orthod. 1979;76(4):423-42.

134. Pancherz H, Anehus-Pancherz M. Muscle activity in class II, division 1 malocclusions treated by bite jumping with the Herbst appliance. An electromyographic study. Am J Orthod. 1980;78(3):321-9.

135. Pancherz H, Fischer S. Amount and direction of temporomandibular joint growth changes in Herbst treatment: a cephalometric long-term investigation. Angle Orthod. 2003;73(5):493-501.

136. Pancherz $H$, Hagg $U$. Dentofacial orthopedics in relation to somatic maturation. An analysis of 70 consecutive cases treated with the Herbst appliance. Am J Orthod. 1985;88(4):273-87.

137. Pancherz $\mathrm{H}$, Hansen $\mathrm{K}$. Occlusal changes during and after Herbst treatment: a cephalometric investigation. Eur J Orthod. 1986;8(4):215-28.

138. Paquette DE, Beattie JR, Johnston LE, Jr. A long-term comparison of nonextraction and premolar extraction edgewise therapy in "borderline" Class II patients. Am J Orthod Dentofacial Orthop. 1992;102(1):1-14. 
139. Parkinson CE, Buschang PH, Behrents RG, Throckmorton GS, English JD. A new method of evaluating posterior occlusion and its relation to posttreatment occlusal changes. Am J Orthod Dentofacial Orthop. 2001;120(5):503-12.

140. Petrovic A, Stutzmann J. Research methodology and findings in applied craniofacial growth studies. In Graber TM, Rakosi T, Petrovic AG. Dentofacial Orthopedics with functional appliances. 2 ed. ed. St. Louis: Mosby; 1997. p. 13-63.

141. Pfeiffer JP. Should orthopaedic treatment of severe class II malocclusions be related to growth? Eur J Orthod. 1980;2(4):249-56.

142. Pinzan A. Estudo comparativo da sobremordida e da profundidade das curvas de Spee e ocluso-incisal em jovens leucodermas brasileiras, com oclusão normal e com Classe II, div. 1, tratadas ortodonticamente [Tese (Doutorado)]. Bauru: Faculdade de Odontologia de Bauru, Universidade de São Paulo; 1982.

143. Proffit WR. Orthodontic treatment planning: limitations and special problems. In: Proffit WR. Comtemporary orthodontics. 2ed ed. St. Louis: Mosby; 1993. p. 225-64.

144. Proffit WR, Tulloch JF. Preadolecents Class II problems: treat now or wait? Am J Orthod Dentofacial Orthop. 2002;121(6):560-2.

145. Rabie ABM, Hägg U. Functional appliance therapy accelerates and enhances condylar growth. Am J Orthod Dentofacial Orthop. 2003;123(1):40-8.

146. Remmer KR, Mamandras AR, Hunter WS, Way DC. Cephalometric changes associated with treatment using the activator, the Fränkel appliance. Amer J Orthod Dentofac Orthop. 1985;88(5):363-72.

147. Renfroe EW. A study of the facial patterns associated with Class I, Classll, division 1, and Class II, division 2 malocclusions. Angle Orthodont. 1948;18(1-2):12-5.

148. Richardson A. A comparison of traditional and computerized methods of cephalometric analysis. Eur J Orthod. 1981;3(1):15-20.

149. Riedel RA. The relation of maxillary structures to cranium in malocclusion and in normal occlusion. Angle Orthodont. 1952;22(3):142-5.

150. Riedel RA. Interviews on retention and relapse. J Clin Orthod. 1976;10(6):454-76.

151. Righellis EG. Treatment effects of Frankel, activator and extraoral traction appliances. Angle Orthod. 1983;53(2):107-21.

152. Riolo ML. An atlas of craniofacial growth: cephalometric standards from the University School Growth Study. Ann Arbor: The University of 
Michigan, Ann Arbor, Center for Human Growth and Development.; 1974.1-8.

153. Robin P. Observation sur un nouvel appareil de redressement. La Revue Stomatologie. 1902;9:423-33.

154. Rock WP. Treatment of Class II malocclusion with removable appliances. Part.4, Class II, division 2 treatment. Brit Dent J. 1990;168:298-302.

155. Rothstein T, Yoon-Tarlie C. Dental and facial skeletal characteristics and growth of males and females with Class II, division 1 malocclusion between the age 10 and 14 (revisited) - part I: characteristics of size, form and position. Amer J Orthod Dentofacial Orthop. 2000;117(3):32032.

156. Sadowsky C, Sakols El. Long-term assessment of orthodontic relapse. Am J Orthod. 1982;82(6):456-63.

157. Salzmann JA. Criteria for extraction in orthodontic therapy related to dentofacial development. Amer J Orthod. 1949;35(8):584-610.

158. Salzmann JA. An evaluation of retention and relapse following orthodontic therapy. Amer J Orthod. 1965;51(10):779-81.

159. Salzmann JA. Practice of orthodontics. Philadelphia: J.B. Lippincott Company; 1996.701-24.

160. Sarver D, Yanosky M. Combined orthodontic, orthognathic, and plastic surgical treatment of an adult Class II malocclusion. J Clin Orthod. 2005;39(4):209-13.

161. Schudy GF. Posttreatment craniofacial growth: its implications in orthodontic treatment. Am J Orthod. 1974;65(1):39-57.

162. Shannon KR, Nanda RS. Changes in the curve of Spee with treatment and at 2 years posttreatment. Am J Orthod Dentofacial Orthop. 2004;125(5):589-96.

163. Shields TE, Little RM, Chapko MK. Stability and relapse of mandibular anterior alignment: a cephalometric appraisal of first premolar extraction cases treated by traditional edgewise orthodontics. Am J Orthod. 1985;87(1):27-38.

164. Silva Filho OG. Prevalência de oclusão normal e má oclusão em escolares da cidade de Bauru (São Paulo): parte I- relação sagital Rev Odont USP. 1990;4(2):130-7.

165. Simons ME, Joondeph DR. Change in overbite: a ten-year postretention study. Am J Orthod. 1973;64(4):349-67. 
166. Siqueira VCV. Avaliação da recidiva da sobressaliência, em pacientes com classe II, $1^{\text {a }}$ divisão, submetidos à extrações dos quatro primeiros pré-molares : estudo cefalométrico longitudinal, realizado ao início, final e anos após o tratamento ortodôntico [Tese (Doutorado)]. Bauru: Faculdade de Odontologia de Bauru, Universidade de São Paulo; 1997.

167. Staggers JA. A comparison of results of second molar and first premolar extraction treatment. Am J Orthod Dentofacial Orthop. 1990;98(5):430-6.

168. Stallard $\mathrm{H}$. The general prevalence of gross symptoms of malocclusion. Dental Cosmos. 1932;74:29-37.

169. Steiner CL. Cephalometric as a clinical tool. Vistas in Orthodontics. Philadelphia: Lea \& Fabiger; 1962. p. 131-61.

170. Strang RHW. Tratado de ortodoncia. Buenos Aires: Editorial Bibliográfica Argentina; 1957.

171. Summers CJ. A system for identifying and scoring occlusal disorders. Am J Orthod. 1971;59(6):552-67.

172. $T$ W, Harkness $M$, Herbison $P$. Associations between changes in selected facial dimensions and the outcome of orthodontic treatment. Amer J Orthod Dentofacial Orthop. 1996;110(1):46-53.

173. Thompson DJ. A cephalometric evaluation of vertical dimension. Am J Orthod. 1966;52(11):859-60.

174. Trouten JC, Enlow DH, Rabine M, Phelps AE, Swedlow D. Morphologic factors in open bite and deep bite. Angle Orthod. 1983;53(3):175-211.

175. Tweed $\mathrm{CH}$. The application of the principles of the edgewise arch in the treatment of Class II, division 1 malocclusion: part 2. Angle Orthodont. 1936;6:255-7.

176. Tweed $\mathrm{CH}$. The application of the principles of the edgewise arch in the treatment of Class II, Division 1 malocclusion: part. 1. Angle Orthodont. 1936;6:198-208.

177. Tweed $\mathrm{CH}$. Indications for the extraction of teeth in orthodontic procedure. Am J Orthod. 1944;30(8):405-28.

178. Unde MD, Sadowsky C, BeGole EA. Long-term stability of dental relationships after orthodontic treatment. Angle Orthod. 1983;53(3):24052.

179. Ursi WJS. Alteração clínica da face em crescimento: uma comparação cefalométrica entre os aparelhos extrabucal cervical, Fränkel(FR-2) e Herbst no tratamento das oclusões de Classe II, primeira divisão de Angle. [ (doutorado)]. Bauru: Universidade de São Paulo; 1993. 
180. Vaden JL. Sequential directional forces treatment: two Class II case reports. Am J Orthod Dentofacial Orthop. 1991;99(6):491-504.

181. Vale DM, Martins DR. Avaliação cefalométrica das estruturas dentofaciais esqueléticas em jovens portadores de Classe II, div. 1, brasileiros, leucodermas e de origem mediterrânea. Ortodontia. $1987 ; 20(1): 5-17$.

182. Van der Linden FPGM. Classe II, divisão 1. In: VAN DER LINDEN FPGM. Ortopedia dentofacial prática. São Paulo: Quintessence; 1998. p. 77-96.

183. Vaught RA. Treatment of a Class II Division 1 malocclusion with a high mandibular angle. Am J Orthod Dentofacial Orthop. 2000;118(3):341-6.

184. Voudouris JC, Woodside DG, Altuna G, Angelopoulos G, Bourque PJ, Lacouture $\mathrm{CY}$, et al. Condyle-fossa modifications and muscle interactions during Herbst treatment, Part 2. Results and conclusions. Am J Orthod Dentofacial Orthop. 2003;124(1):13-29.

185. Voudouris JC, Woodside DG, Altuna G, Kuftinec MM, Angelopoulos G, Bourque PJ. Condyle-fossa modifications and muscle interactions during herbst treatment, part 1. New technological methods. Am J Orthod Dentofacial Orthop. 2003;123(6):604-13.

186. West E. Treatment objetives in the deciduous dentition. Am J Orthod. 1969;55:617-32.

187. Wieslander L. Intensive treatment of severe Class II malocclusions with a headgear-Herbst appliance in the early mixed dentition. Am J Orthod. 1984;86(1):1-13.

188. Wieslander L. Long-term effect of treatment with the headgear-Herbst appliance in the early mixed dentition. Stability or relapse? Am J Orthod Dentofacial Orthop. 1993;104(4):319-29.

189. Wieslander L, Buck DL. Physiologic recovery after cervical traction therapy. Am J Orthod. 1974;66(3):294-301.

190. Woodside DG. Do functional appliances have an orthopedic effect? Am J Orthod Dentofacial Orthop. 1998;113(1):11-4.

191. Woodside DG, Metaxas A, Altuna G. The influence of functional appliance therapy on glenoid fossa remodeling. Am J Orthod Dentofacial Orthop. 1987;92(3):181-98.

192. Yamaguchi K, Nanda RS. The effects of extraction and nonextraction treatment on the mandibular position. Am J Orthod Dentofacial Orthop. 1991;100(5):443-52. 
Abstract 



\section{ABSTRACT}

\section{Stability of Class II treatment with two and four premolar extractions}

The aim of this retrospective study was to compare cephalometrically the stability of the alterations originated from the treatment of the complete Class II malocclusion, carried out by extracting two and four premolars, after an average period of 9.42 post-treatment years. For this reason, 60 patients were selected and they initially presented complete Class II malocclusion. Such patients were treated by means of one of the proposed protocols. The sample was divided into two groups. Group 1 consisted of 30 patients treated with the extraction of two superior premolars, being 17 male patients and 13 female, at an initial average age of 12.87 years old, presenting full Class II malocclusion. Group 2 consisted of 30 patients, 14 male and 16 female, at an initial average age of 13.64 years old, treated with extractions of two superior and two inferior premolars. Both groups were treated with fixed appliance, by using the simplified edgewise mechanics. The teleradiographies were then obtained and evaluated at three stages: initial (T1), final (T2) and post-treatment (T3). The evaluation of the alterations which occurred in the treatment periods (T2 - T1) and post-treatment periods (T3 -T2) was also carried out. The dependent $t$ test and the Dalhberg's formula were used in order to evaluate the systematic and casual errors, respectively. The compatibility of the groups regarding gender ratio, malocclusion type and patient ratio with $3 \times 3$ contention was evaluated by the qui-square test. The variables directly related with the stability were compared by means of the independent $t$ test. The results demonstrated that there was a significant relapse of superior incisive teeth protrusion and of molar relationship in the group treated with extractions of four premolars. The vertical growth pattern, the reduction of the SNB angle and the recurrence of the maxillomandibular relationship correction presented a significant correlation with the relapse of the molar relationship. In both groups, the relapse of the overjet and overbite and of the canine relationship showed a statistically significant and directly proportional relationship with their correction.

Keywords: Tooth Extraction; Angle Class II, Malocclusion; Relapse; Orthodontics, Corrective. 

Apêndices 



\section{APÊNDICES}

As tabelas A-1 a A-36 referem-se aos valores individuais de cada variável, para cada paciente, dos grupos 1 e 2 em cada fase de avaliação 
TABELA A-1

\begin{tabular}{|c|c|c|c|c|c|c|c|c|c|c|}
\hline Pacientes & $\mathbf{N}$ & Grupo & Nasc. & Início tto & Final tto & Controle & Tempo tto & tempo controle & Idade inicial & Idade final \\
\hline A.C. L & 1 & 1 & $2 / 11 / 1969$ & 8/8/1983 & $12 / 8 / 1985$ & 9/3/1989 & 2,01 & 3,58 & 13,77 & 15,79 \\
\hline A. B. J. & 2 & 1 & $22 / 7 / 1976$ & $12 / 4 / 1991$ & $11 / 10 / 1995$ & $23 / 3 / 2006$ & 4,50 & 10,45 & 14,73 & 19,23 \\
\hline A. R. & 3 & 1 & $12 / 7 / 1983$ & 21/2/1995 & $21 / 2 / 1997$ & $10 / 5 / 2006$ & 2,00 & 9,22 & 11,62 & 13,62 \\
\hline A. P. L. & 4 & 1 & $18 / 8 / 1966$ & $25 / 6 / 1979$ & $7 / 6 / 1982$ & 2/9/1985 & 2,95 & 3,24 & 12,86 & 15,81 \\
\hline A. L. B. & 5 & 1 & $11 / 9 / 1979$ & $28 / 3 / 1991$ & $22 / 10 / 1993$ & $10 / 2 / 2006$ & 2,57 & 12,31 & 11,55 & 14,12 \\
\hline A. G. B. & 6 & 1 & $14 / 11 / 1976$ & $22 / 4 / 1991$ & $27 / 10 / 1993$ & $15 / 3 / 2006$ & 2,52 & 12,39 & 14,44 & 16,96 \\
\hline B. L. L. & 7 & 1 & 26/12/1983 & 28/3/1995 & 12/4/1999 & $16 / 3 / 2006$ & 4,04 & 6,93 & 11,26 & 15,30 \\
\hline C. S. Z. & 8 & 1 & 6/2/1981 & $15 / 9 / 1992$ & $6 / 7 / 1994$ & $6 / 10 / 1997$ & 1,81 & 3,25 & 11,61 & 13,42 \\
\hline E. J. D. & 9 & 1 & $1 / 9 / 1975$ & 19/4/1989 & $25 / 2 / 1991$ & $22 / 3 / 2006$ & 1,85 & 15,08 & 13,64 & 15,50 \\
\hline E. S.P. & 10 & 1 & 9/2/1982 & $18 / 3 / 1997$ & $4 / 5 / 1999$ & $16 / 3 / 2006$ & 2,13 & 6,87 & 15,11 & 17,24 \\
\hline H. S. S. & 11 & 1 & $3 / 6 / 1982$ & 23/4/1993 & $7 / 11 / 1994$ & $9 / 2 / 2006$ & 1,54 & 11,27 & 10,90 & 12,44 \\
\hline I. A. F. M. & 12 & 1 & $17 / 12 / 1975$ & 11/4/1989 & 23/11/1990 & $17 / 3 / 2006$ & 1,62 & 15,32 & 13,33 & 14,95 \\
\hline J. A. T. & 13 & 1 & 9/9/1984 & 10/11/1995 & 6/3/1998 & $22 / 3 / 2006$ & 2,32 & 8,05 & 11,18 & 13,50 \\
\hline L. F. D. & 14 & 1 & $8 / 2 / 1980$ & $27 / 4 / 1993$ & $30 / 6 / 1995$ & $23 / 3 / 2006$ & 2,18 & 10,74 & 13,22 & 15,40 \\
\hline L. M. & 15 & 1 & $10 / 5 / 1977$ & $22 / 4 / 1991$ & $16 / 9 / 1993$ & $20 / 2 / 2006$ & 2,41 & 12,44 & 13,96 & 16,36 \\
\hline L. A. B. P. & 16 & 1 & 19/1/1983 & $3 / 6 / 1997$ & 24/3/1999 & $10 / 3 / 2006$ & 1,81 & 6,97 & 14,38 & 16,19 \\
\hline L. A. S. & 17 & 1 & $20 / 12 / 1980$ & $22 / 6 / 1994$ & $19 / 2 / 1998$ & $9 / 2 / 2006$ & 3,67 & 7,98 & 13,51 & 17,18 \\
\hline L. E. B. & 18 & 1 & 13/12/1976 & 4/4/1989 & 4/3/1991 & $19 / 4 / 2006$ & 1,92 & 15,14 & 12,32 & 14,23 \\
\hline M. M. B. & 19 & 1 & $6 / 4 / 1986$ & $29 / 4 / 1997$ & 15/10/1999 & $17 / 3 / 2006$ & 2,46 & 6,42 & 11,07 & 13,53 \\
\hline M. E. B. & 20 & 1 & $16 / 8 / 1972$ & $25 / 3 / 1989$ & 16/8/1991 & $8 / 3 / 2006$ & 2,39 & 14,57 & 16,62 & 19,01 \\
\hline M. C. M. B. & 21 & 1 & $21 / 5 / 1978$ & $12 / 5 / 1993$ & 23/4/1996 & $8 / 3 / 2006$ & 2,95 & 9,88 & 14,99 & 17,94 \\
\hline M. F. Z. C. & 22 & 1 & 4/7/1983 & 20/4/1995 & 29/4/1997 & $8 / 2 / 2006$ & 2,03 & 8,79 & 11,80 & 13,83 \\
\hline P. C. C. & 23 & 1 & $11 / 4 / 1980$ & 20/4/1993 & 19/7/1996 & $4 / 4 / 2006$ & 3,25 & 9,72 & 13,03 & 16,28 \\
\hline R. C. C. & 24 & 1 & $5 / 8 / 1977$ & 22/4/1991 & $14 / 9 / 1993$ & $14 / 8 / 2002$ & 2,40 & 8,92 & 13,72 & 16,12 \\
\hline R. H. C. & 25 & 1 & $7 / 10 / 1981$ & $15 / 9 / 1992$ & $28 / 3 / 1996$ & $10 / 12 / 2001$ & 3,53 & 5,71 & 10,95 & 14,48 \\
\hline R. P. O. & 26 & 1 & $17 / 5 / 1982$ & $18 / 3 / 1995$ & $19 / 6 / 1998$ & $29 / 3 / 2006$ & 3,26 & 7,78 & 12,84 & 16,10 \\
\hline R. L. P. & 27 & 1 & $14 / 12 / 1981$ & $15 / 7 / 1993$ & $26 / 3 / 1996$ & $9 / 3 / 2006$ & 2,70 & 9,96 & 11,59 & 14,29 \\
\hline S. A. & 28 & 1 & 1/3/1981 & 20/4/1993 & 24/7/1995 & $10 / 3 / 2006$ & 2,26 & 10,64 & 12,15 & 14,41 \\
\hline T. T. F. & 29 & 1 & $12 / 6 / 1982$ & 18/5/1993 & $30 / 5 / 1995$ & $16 / 3 / 2006$ & 2,03 & 10,80 & 10,94 & 12,97 \\
\hline W. B. & 30 & 1 & $25 / 6 / 1966$ & 2/7/1979 & $16 / 4 / 1982$ & $18 / 6 / 1985$ & 2,79 & 3,18 & 13,03 & 15,82 \\
\hline
\end{tabular}


TABELA A-2

\begin{tabular}{|c|c|c|c|c|c|c|c|c|c|c|}
\hline Pacientes & $\mathbf{N}$ & Grupo & Nasc. & Início tto & Final tto & Controle & Tempo tto & tempo controle & Idade inicial & Idade final \\
\hline A. L L. P. & 31 & 2 & $16 / 11 / 1970$ & $13 / 8 / 1981$ & $15 / 2 / 1984$ & $17 / 11 / 1989$ & 2,51 & 5,76 & 10,75 & 13,26 \\
\hline B. N. & 32 & 2 & $17 / 3 / 1965$ & 20/6/1977 & $19 / 12 / 1979$ & $20 / 3 / 1990$ & 2,50 & 10,26 & 12,27 & 14,77 \\
\hline C. A. A. & 33 & 2 & $4 / 9 / 1964$ & $12 / 8 / 1977$ & $5 / 12 / 1979$ & $2 / 3 / 1984$ & 2,32 & 4,24 & 12,95 & 15,26 \\
\hline C. B. & 34 & 2 & $20 / 6 / 1955$ & $5 / 11 / 1975$ & $16 / 3 / 1977$ & $11 / 6 / 1982$ & 1,36 & 5,24 & 20,39 & 21,75 \\
\hline C. M. & 35 & 2 & $7 / 12 / 1979$ & $17 / 6 / 1992$ & $7 / 12 / 1995$ & $17 / 11 / 2000$ & 3,47 & 4,95 & 12,54 & 16,01 \\
\hline C. M. L. & 36 & 2 & $2 / 7 / 1964$ & $27 / 11 / 1975$ & $14 / 4 / 1978$ & $8 / 3 / 1990$ & 2,38 & 11,91 & 11,41 & 13,79 \\
\hline D. B. & 37 & 2 & $24 / 8 / 1978$ & 10/10/1992 & 9/5/1995 & $14 / 11 / 1998$ & 2,58 & 3,52 & 14,14 & 16,72 \\
\hline E. M. & 38 & 2 & $29 / 4 / 1967$ & $14 / 6 / 1980$ & $8 / 11 / 1982$ & $2 / 5 / 2000$ & 2,40 & 17,49 & 13,14 & 15,54 \\
\hline E. P. C. & 39 & 2 & $26 / 6 / 1967$ & $10 / 10 / 1979$ & $24 / 11 / 1982$ & 10/11/1993 & 3,13 & 10,97 & 12,30 & 15,42 \\
\hline F. P. L. & 40 & 2 & $4 / 10 / 1974$ & $13 / 4 / 1989$ & $3 / 6 / 1991$ & $21 / 9 / 2000$ & 2,14 & 9,31 & 14,53 & 16,67 \\
\hline H. C. G. & 41 & 2 & $10 / 10 / 1968$ & 12/8/1981 & $25 / 4 / 1984$ & $14 / 10 / 1993$ & 2,70 & 9,48 & 12,85 & 15,55 \\
\hline J. B. S. & 42 & 2 & $20 / 6 / 1976$ & $5 / 4 / 1989$ & $3 / 7 / 1991$ & $16 / 9 / 1999$ & 2,24 & 8,21 & 12,80 & 15,04 \\
\hline J. C. N. & 43 & 2 & $12 / 11 / 1962$ & $15 / 8 / 1977$ & $2 / 12 / 1980$ & $15 / 3 / 1990$ & 3,30 & 9,29 & 14,77 & 18,07 \\
\hline J. L.T. C. & 44 & 2 & $27 / 6 / 1957$ & 23/11/1973 & $16 / 11 / 1976$ & $17 / 2 / 1979$ & 2,98 & 2,25 & 16,42 & 19,40 \\
\hline J. I. J. & 45 & 2 & $3 / 10 / 1958$ & 21/11/1973 & $4 / 3 / 1976$ & $14 / 8 / 1990$ & 2,28 & 14,45 & 15,15 & 17,43 \\
\hline K. S. C. & 46 & 2 & $11 / 12 / 1961$ & $29 / 10 / 1975$ & $11 / 11 / 1977$ & $30 / 1 / 1984$ & 2,04 & 6,22 & 13,89 & 15,93 \\
\hline L. B. & 47 & 2 & $1 / 4 / 1968$ & 4/4/1983 & $18 / 12 / 1985$ & $3 / 4 / 2000$ & 2,71 & 14,30 & 15,02 & 17,73 \\
\hline L. C. M. & 48 & 2 & $27 / 7 / 1963$ & $27 / 6 / 1977$ & $22 / 10 / 1980$ & 25/10/1985 & 3,32 & 5,01 & 13,93 & 17,25 \\
\hline M. S. & 49 & 2 & $8 / 5 / 1970$ & $10 / 8 / 1981$ & $6 / 5 / 1983$ & $5 / 5 / 1994$ & 1,74 & 11,01 & 11,27 & 13,00 \\
\hline M. P.M. S. & 50 & 2 & $2 / 5 / 1971$ & $6 / 7 / 1983$ & $3 / 5 / 1985$ & $1 / 7 / 1988$ & 1,83 & 3,16 & 12,19 & 14,01 \\
\hline M. C. C. A. & 51 & 2 & $1 / 6 / 1961$ & 23/11/1973 & $23 / 5 / 1975$ & $3 / 12 / 1982$ & 1,50 & 7,54 & 12,49 & 13,98 \\
\hline M. G. M. & 52 & 2 & $2 / 3 / 1960$ & 20/11/1973 & $25 / 1 / 1977$ & $20 / 1 / 1991$ & 3,18 & 13,99 & 13,73 & 16,91 \\
\hline P.M.M. & 53 & 2 & $24 / 2 / 1963$ & 4/7/1983 & $6 / 5 / 1986$ & $9 / 6 / 2000$ & 2,84 & 14,10 & 20,37 & 23,21 \\
\hline R. M. & 54 & 2 & $7 / 10 / 1963$ & 30/10/1975 & $26 / 9 / 1977$ & $15 / 3 / 1990$ & 1,91 & 12,47 & 12,07 & 13,98 \\
\hline S. S. & 55 & 2 & $2 / 3 / 1960$ & $20 / 11 / 1973$ & 29/1/1976 & $28 / 6 / 1990$ & 2,19 & 14,42 & 13,73 & 15,92 \\
\hline S. M. & 56 & 2 & $25 / 10 / 1963$ & 30/10/1975 & $22 / 6 / 1978$ & $8 / 3 / 1990$ & 2,65 & 11,72 & 12,02 & 14,67 \\
\hline V. G. & 57 & 2 & $25 / 6 / 1959$ & $14 / 11 / 1973$ & 20/3/1978 & $15 / 3 / 1990$ & 4,35 & 11,99 & 14,40 & 18,75 \\
\hline V.P. & 58 & 2 & $29 / 8 / 1963$ & 29/10/1975 & $9 / 2 / 1978$ & $15 / 3 / 1990$ & 2,28 & 12,10 & 12,18 & 14,46 \\
\hline V. G. & 59 & 2 & $12 / 3 / 1967$ & $2 / 7 / 1981$ & $29 / 6 / 1984$ & $23 / 11 / 2000$ & 2,99 & 16,41 & 14,32 & 17,31 \\
\hline V.A. B. & 60 & 2 & 9/5/1981 & $13 / 8 / 1992$ & $5 / 12 / 1995$ & $28 / 8 / 2001$ & 3,31 & 5,73 & 11,27 & 14,58 \\
\hline
\end{tabular}


TABELA A-3

\begin{tabular}{|c|c|c|c|c|c|c|c|c|c|}
\hline Pacientes & $\mathbf{N}$ & Grupo & IPT [I] & IPT [F] & IPT [I-F] & Gênero & Classe II & Apinhamento (mm) & Contenção 3×3 \\
\hline A.C. L & 1 & 1 & 7,77 & 1,5 & 6,27 & $\mathrm{~F}$ & 1 & 0 & $\mathrm{n}$ \\
\hline A. B. J. & 2 & 1 & 7,47 & 0 & 7,47 & $\mathrm{M}$ & 1 & 0 & $\mathrm{n}$ \\
\hline A. R. & 3 & 1 & 10,27 & 0 & 10,27 & $\mathrm{~F}$ & 1 & 0 & $\mathrm{n}$ \\
\hline A. P. L. & 4 & 1 & 8,37 & 2,6 & 5,77 & $\mathrm{~F}$ & 1 & 0 & $\mathrm{n}$ \\
\hline A. L. B. & 5 & 1 & 6,37 & 0,27 & 6,1 & $\mathrm{M}$ & 1 & 0 & $\mathrm{n}$ \\
\hline A. G. B. & 6 & 1 & 7,27 & 1,77 & 5,5 & $\mathrm{M}$ & 1 & 0 & $\mathrm{~s}$ \\
\hline B. L. L. & 7 & 1 & 7,17 & 0,27 & 6,9 & $\mathrm{M}$ & 2 & 2 & $\mathrm{~s}$ \\
\hline C. S. Z. & 8 & 1 & 7,67 & 0 & 7,67 & $\mathrm{~F}$ & 2 & 3 & $\mathrm{~S}$ \\
\hline E. J. D. & 9 & 1 & 7,37 & 1,27 & 6,1 & $\mathrm{M}$ & 1 & 3 & $\mathrm{~s}$ \\
\hline E. S. P. & 10 & 1 & 7,07 & 0,27 & 6,8 & $\mathrm{M}$ & 2 & 0 & $\mathrm{n}$ \\
\hline H. S. S. & 11 & 1 & 7,77 & 0,27 & 7,5 & $\mathrm{~F}$ & 1 & 0 & $\mathrm{n}$ \\
\hline I. A. F. M. & 12 & 1 & 8,47 & 1,5 & 6,97 & $\mathrm{M}$ & 2 & 3 & $\mathrm{~s}$ \\
\hline J. A. T. & 13 & 1 & 7,37 & 0,27 & 7,1 & $\mathrm{M}$ & 1 & 3 & $\mathrm{n}$ \\
\hline L. F. D. & 14 & 1 & 7,57 & 0 & 7,57 & $\mathrm{M}$ & 1 & 0 & $\mathrm{n}$ \\
\hline L. M. & 15 & 1 & 8,27 & 1,5 & 6,77 & $\mathrm{~F}$ & 1 & 0 & $\mathrm{n}$ \\
\hline L. A. B. P. & 16 & 1 & 7,17 & 1,77 & 5,4 & $\mathrm{~F}$ & 1 & 4 & $\mathrm{n}$ \\
\hline L. A. S. & 17 & 1 & 7,17 & 0,27 & 6,9 & $M$ & 2 & 0 & $S$ \\
\hline L. E. B. & 18 & 1 & 6,87 & 1,5 & 5,37 & $M$ & 1 & 0 & $\mathrm{n}$ \\
\hline M. M. B. & 19 & 1 & 6,07 & 1,5 & 4,57 & $\mathrm{M}$ & 1 & 0 & $\mathrm{n}$ \\
\hline M. E. B. & 20 & 1 & 8,47 & 1,5 & 6,97 & $\mathrm{M}$ & 1 & 0 & $\mathrm{n}$ \\
\hline M. C. M. B. & 21 & 1 & 8,77 & 0 & 8,77 & $\mathrm{~F}$ & 1 & 0 & $\mathrm{~s}$ \\
\hline M. F. Z. C. & 22 & 1 & 8,07 & 1,5 & 6,57 & $\mathrm{~F}$ & 1 & 0 & $\mathrm{~s}$ \\
\hline P. C. C. & 23 & 1 & 6,87 & 0 & 6,87 & $\mathrm{~F}$ & 2 & 0 & $\mathrm{~s}$ \\
\hline R. C. C. & 24 & 1 & 7,37 & 1,5 & 5,87 & $\mathrm{~F}$ & 1 & 0 & $\mathrm{n}$ \\
\hline R. H. C. & 25 & 1 & 9,97 & 0 & 9,97 & $\mathrm{M}$ & 1 & 4 & $\mathrm{~s}$ \\
\hline R. P. O. & 26 & 1 & 7,27 & 0,27 & 7 & $M$ & 2 & 1 & $\mathrm{~s}$ \\
\hline R. L. P. & 27 & 1 & 9,17 & 0 & 9,17 & $\mathrm{~F}$ & 1 & 0 & $\mathrm{~s}$ \\
\hline S. A. & 28 & 1 & 6,07 & 0 & 6,07 & $\mathrm{M}$ & 1 & 0 & $\mathrm{n}$ \\
\hline T. T. F. & 29 & 1 & 9,47 & 0 & 9,47 & $\mathrm{~F}$ & 1 & 0 & $\mathrm{~s}$ \\
\hline W. B. & 30 & 1 & 10,07 & 0 & 10,07 & $\mathrm{M}$ & 1 & 0 & $\mathrm{n}$ \\
\hline
\end{tabular}


TABELA A-4

\begin{tabular}{|c|c|c|c|c|c|c|c|c|c|}
\hline Pacientes & $\mathbf{N}$ & Grupo & IPT [I] & IPT [F] & IPT [I-F] & Gênero & Classe II & Apinhamento (mm) & Contenção $3 \times 3$ \\
\hline A. L L. P. & 31 & 2 & 8,17 & 1,6 & 6,57 & $\mathrm{~F}$ & 1 & 0 & $\mathrm{n}$ \\
\hline B. N. & 32 & 2 & 8,77 & 1,77 & 7 & $\mathrm{~F}$ & 1 & 8 & $\mathrm{n}$ \\
\hline C. A. A. & 33 & 2 & 8,27 & 0,27 & 8 & M & 1 & 4,46 & $\mathrm{n}$ \\
\hline C. B. & 34 & 2 & 7,97 & 5,67 & 2,3 & $M$ & 1 & 7 & $\mathrm{n}$ \\
\hline C. M. & 35 & 2 & 8,67 & 0,27 & 8,4 & $\mathrm{~F}$ & 1 & 8 & $\mathrm{n}$ \\
\hline C. M. L. & 36 & 2 & 9,67 & 0 & 9,67 & $\mathrm{~F}$ & 1 & 4 & $\mathrm{n}$ \\
\hline D. B. & 37 & 2 & 8,67 & 1,77 & 6,9 & $\mathrm{~F}$ & 1 & 4 & $\mathrm{~s}$ \\
\hline E. M. & 38 & 2 & 9,67 & 1,77 & 7,9 & $M$ & 1 & 8 & $\mathrm{n}$ \\
\hline E. P.C. & 39 & 2 & 7,87 & 0,27 & 7,6 & $M$ & 1 & 5,34 & $\mathrm{n}$ \\
\hline F. P. L. & 40 & 2 & 6,27 & 1,5 & 4,77 & $M$ & 1 & 4 & $\mathrm{n}$ \\
\hline H. C. G. & 41 & 2 & 7,07 & 0,27 & 6,8 & $\mathrm{M}$ & 1 & 3 & $\mathrm{n}$ \\
\hline J. B. S. & 42 & 2 & 8,17 & 1,5 & 6,67 & $\mathrm{~F}$ & 1 & 6 & $\mathrm{n}$ \\
\hline J. C. N. & 43 & 2 & 5,97 & 0,27 & 5,7 & $M$ & 1 & 1,38 & $\mathrm{n}$ \\
\hline J. L.T. C. & 44 & 2 & 7,17 & 2,6 & 4,57 & $M$ & 1 & 0 & $\mathrm{n}$ \\
\hline J. I. J. & 45 & 2 & 8,17 & 0 & 8,17 & $M$ & 1 & 0 & $\mathrm{n}$ \\
\hline K. S. C. & 46 & 2 & 7,07 & 0,27 & 6,8 & $\mathrm{~F}$ & 1 & 7,61 & $\mathrm{n}$ \\
\hline L. B. & 47 & 2 & 6,67 & 2,72 & 3,95 & $\mathrm{~F}$ & 1 & 1,4 & $\mathrm{n}$ \\
\hline L. C. M. & 48 & 2 & 10,97 & 0,57 & 10,4 & $\mathrm{M}$ & 1 & 4,72 & $\mathrm{n}$ \\
\hline M. S. & 49 & 2 & 6,17 & 1,77 & 4,4 & $M$ & 1 & 0 & $\mathrm{n}$ \\
\hline M. P.M. S. & 50 & 2 & 8,77 & 1,5 & 7,27 & $M$ & 1 & 6,47 & $\mathrm{n}$ \\
\hline M. C. C. A. & 51 & 2 & 7,77 & 1,77 & 6 & $\mathrm{~F}$ & 1 & 0 & $\mathrm{n}$ \\
\hline M. G. M. & 52 & 2 & 7,17 & 1,77 & 5,4 & $\mathrm{~F}$ & 1 & 0 & $\mathrm{n}$ \\
\hline P.M.M. & 53 & 2 & 8,27 & 0,27 & 8 & $\mathrm{M}$ & 1 & 0 & $\mathrm{~s}$ \\
\hline R. M. & 54 & 2 & 9,77 & 0 & 9,77 & $\mathrm{M}$ & 1 & 7 & $\mathrm{n}$ \\
\hline S. S. & 55 & 2 & 7,37 & 1,5 & 5,87 & $\mathrm{~F}$ & 1 & 4,44 & $\mathrm{n}$ \\
\hline S. M. & 56 & 2 & 6,87 & 0,27 & 6,6 & $\mathrm{~F}$ & 1 & 3,74 & $\mathrm{n}$ \\
\hline V. G. & 57 & 2 & 6,27 & 1,5 & 4,77 & $\mathrm{~F}$ & 1 & 2,79 & $\mathrm{n}$ \\
\hline V.P. & 58 & 2 & 6,97 & 0 & 6,97 & $\mathrm{~F}$ & 1 & 0 & $\mathrm{n}$ \\
\hline V. G. & 59 & 2 & 6,67 & 1,77 & 4,9 & $\mathrm{~F}$ & 1 & 2 & $\mathrm{n}$ \\
\hline V.A B. & 60 & 2 & 7,37 & 0 & 7,37 & $\mathrm{~F}$ & 1 & 3 & $\mathrm{n}$ \\
\hline
\end{tabular}


TABELA A-5

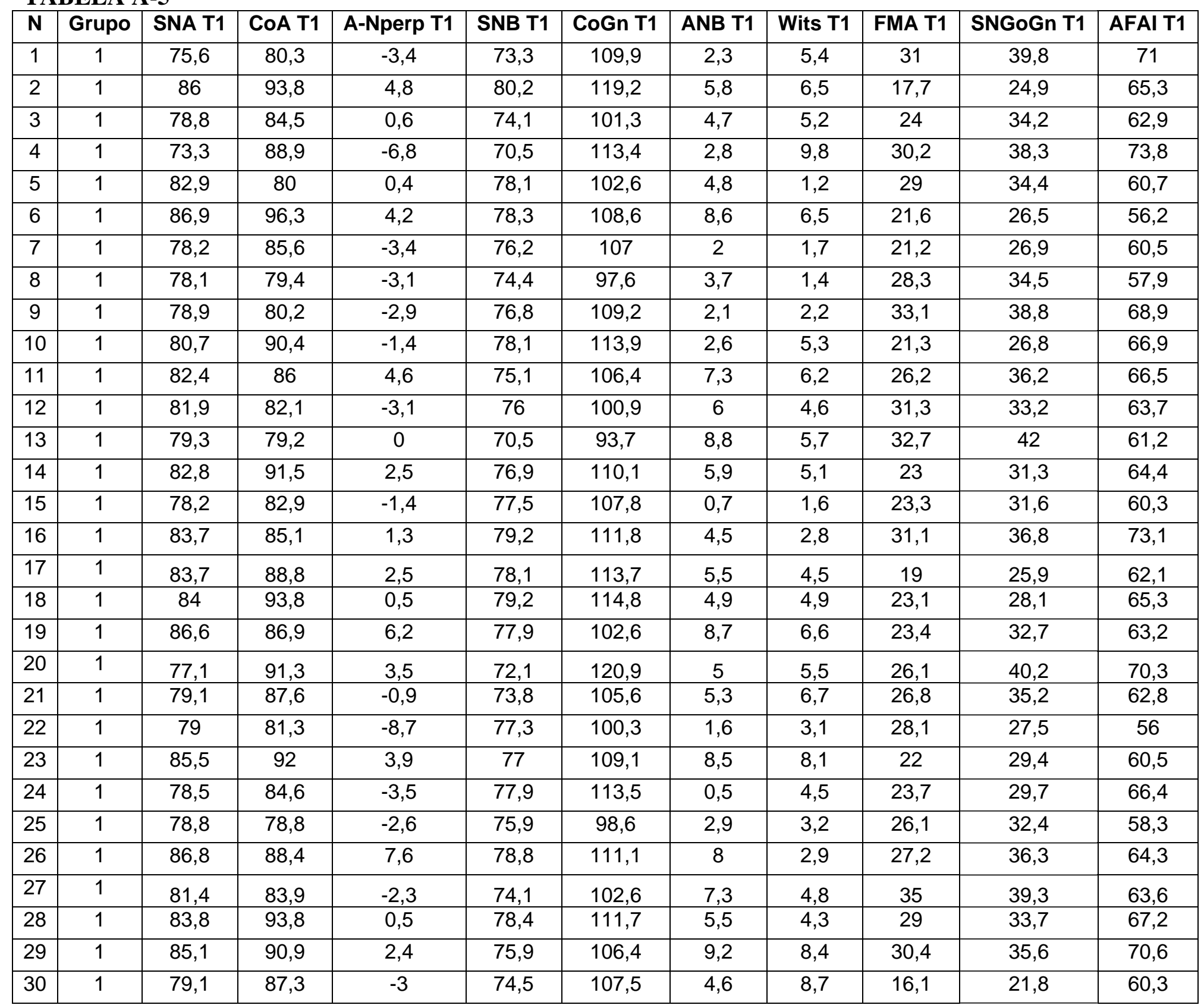


TABELA A-6

\begin{tabular}{|c|c|c|c|c|c|c|c|c|c|c|c|}
\hline $\mathbf{N}$ & Grupo & SNA T1 & CoA T1 & A-Nperp T1 & SNB T1 & CoGn T1 & ANB T1 & Wits T1 & FMA T1 & SNGoGn T1 & AFAI T1 \\
\hline 31 & 2 & 84,3 & 87 & 0,2 & 74,6 & 102,3 & 9,6 & 5,8 & 37,5 & 41,1 & 73 \\
\hline 32 & 2 & 77,6 & 78,8 & $-0,7$ & 72,4 & 101,7 & 5,2 & 1,9 & 34,1 & 44,6 & 65,2 \\
\hline 33 & 2 & 84,5 & 85,8 & 4,2 & 81,2 & 105,5 & 3,3 & 4,2 & 18,8 & 25,8 & 55,3 \\
\hline 34 & 2 & 82,5 & 92,3 & 1,4 & 76,1 & 109,7 & 6,4 & 10,7 & 13,7 & 21,9 & 62,2 \\
\hline 35 & 2 & 81,4 & 82,4 & 3,7 & 73,9 & 106,4 & 7,5 & 6 & 31,2 & 41,9 & 71,3 \\
\hline 36 & 2 & 77,7 & 77,8 & -2 & 73,8 & 103,5 & 3,9 & 4,9 & 36,2 & 44,2 & 67,8 \\
\hline 37 & 2 & 84,3 & 76,5 & 3,6 & 73,2 & 98,3 & 11,1 & 11 & 33,1 & 40,5 & 63,9 \\
\hline 38 & 2 & 85,8 & 87,2 & 1,2 & 78,7 & 108,1 & 7,2 & 6,1 & 31 & 34,2 & 63 \\
\hline 39 & 2 & 82 & 85,5 & $-1,7$ & 72,6 & 104,5 & 9,4 & 14,3 & 35,3 & 38,8 & 71,9 \\
\hline 40 & 2 & 79,1 & 91,2 & $-0,9$ & 72,8 & 116 & 6,3 & 11,1 & 29 & 36,5 & 81,3 \\
\hline 41 & 2 & 81,1 & 79,9 & $-0,3$ & 76,3 & 104,1 & 4,8 & 4,8 & 36,9 & 43,2 & 69,6 \\
\hline 42 & 2 & 79,8 & 81,5 & $-3,5$ & 76,4 & 100,7 & 3,4 & 4,7 & 33,3 & 37,9 & 63,4 \\
\hline 43 & 2 & 85,8 & 96,5 & 4,9 & 81,1 & 111 & 4,6 & 7,5 & 14,2 & 21,1 & 54,6 \\
\hline 44 & 2 & 86,4 & 92,2 & 2,8 & 75,1 & 110,5 & 11,4 & 17,1 & 33,9 & 38,2 & 73,8 \\
\hline 45 & 2 & 78,9 & 85 & $-0,3$ & 71,4 & 102,7 & 7,6 & 7,5 & 29,5 & 36,6 & 64,2 \\
\hline 46 & 2 & 83 & 83,8 & 2,9 & 75,8 & 99,9 & 7,2 & 3,2 & 24,2 & 31,6 & 59,6 \\
\hline 47 & 2 & 80,2 & 84,9 & $-1,2$ & 76 & 102,8 & 4,2 & 6,8 & 19,1 & 25,2 & 57,2 \\
\hline 48 & 2 & 82,6 & 88,7 & 0,8 & 76,9 & 114,8 & 5,7 & 3,6 & 35 & 39,7 & 76,6 \\
\hline 49 & 2 & 78,7 & 82,8 & $-1,7$ & 75,6 & 107,5 & 3,1 & 1,6 & 28 & 34,8 & 67,5 \\
\hline 50 & 2 & 84,6 & 88,1 & 3 & 76,6 & 106,6 & 8 & 10,3 & 31,7 & 37,5 & 66,2 \\
\hline 51 & 2 & 78,8 & 79,3 & $-2,9$ & 73,5 & 94,3 & 5,3 & 5,9 & 27,4 & 33,4 & 60,1 \\
\hline 52 & 2 & 80,8 & 85,1 & 4,4 & 72,9 & 105 & 7,9 & 9,2 & 26,3 & 37,6 & 62,5 \\
\hline 53 & 2 & 77 & 87,2 & $-0,3$ & 71,9 & 110,3 & 5,1 & 5,2 & 28,1 & 38,9 & 64,7 \\
\hline 54 & 2 & 75,6 & 82,7 & $-2,7$ & 70,3 & 96,2 & 5,3 & 6,5 & 26,4 & 35,8 & 57,3 \\
\hline 55 & 2 & 79,8 & 79,4 & 1,5 & 72,7 & 102,9 & 7,1 & 6 & 31,7 & 41,2 & 65,8 \\
\hline 56 & 2 & 81,4 & 79,2 & 2,9 & 74,3 & 94,6 & 7,1 & 7 & 29,3 & 38,7 & 60,6 \\
\hline 57 & 2 & 77,6 & 78,5 & $-6,2$ & 74 & 104,2 & 3,5 & 4,3 & 30,7 & 33,8 & 63,6 \\
\hline 58 & 2 & 77,8 & 84,2 & $-1,5$ & 70,2 & 102,8 & 7,6 & 6,6 & 35,9 & 44,9 & 70,5 \\
\hline 59 & 2 & 83,1 & 83,3 & $-2,2$ & 76,7 & 110,9 & 6,4 & 8,1 & 36,7 & 39,6 & 75,8 \\
\hline 60 & 2 & 78,6 & 74,2 & $-2,2$ & 76,4 & 98,1 & 2,2 & $-1,2$ & 33,3 & 40,3 & 61,7 \\
\hline
\end{tabular}


TABELA A-7

\begin{tabular}{|c|c|c|c|c|c|c|c|c|c|c|}
\hline $\mathbf{N}$ & Grupo & 1.PP T1 & 1-ENAperp T1 & 1-pp T1 & 6-pp T1 & 6-ENAperp T1 & IMPA T1 & 1.NB T1 & 1-NB T1 & 1-pog per T1 \\
\hline 1 & 1 & 119 & 5,5 & 31,8 & 27,3 & $-25,3$ & 91,3 & 26,2 & 9,3 & -9 \\
\hline 2 & 1 & 107,8 & $-3,3$ & 29,5 & 23 & $-31,6$ & 97,3 & 23,8 & 3,9 & $-11,5$ \\
\hline 3 & 1 & 109,1 & $-3,9$ & 27,1 & 22,8 & $-30,4$ & 92,2 & 22,1 & 4,3 & $-7,8$ \\
\hline 4 & 1 & 116,9 & $-2,4$ & 30,7 & 26,9 & $-31,5$ & 84 & 14,6 & 2,7 & $-13,3$ \\
\hline 5 & 1 & 113,8 & $-1,8$ & 24 & 20,1 & $-26,8$ & 93,2 & 27,8 & 5,5 & $-9,5$ \\
\hline 6 & 1 & 112,9 & $-2,8$ & 24,5 & 18,8 & -29 & 106 & 33,3 & 5,6 & $-3,4$ \\
\hline 7 & 1 & 99,8 & $-3,9$ & 29,2 & 22,6 & -29 & 96,3 & 21,4 & 2,4 & -8 \\
\hline 8 & 1 & 104,4 & $-3,9$ & 27,8 & 22,2 & $-26,3$ & 90,8 & 21,9 & 3,3 & $-10,1$ \\
\hline 9 & 1 & 109,2 & $-1,9$ & 29,8 & 25,5 & -29 & 83 & 20,8 & 4,3 & $-13,7$ \\
\hline 10 & 1 & 109,4 & $-2,4$ & 30,1 & 25,5 & $-27,5$ & 91,8 & 19 & 2,8 & $-11,1$ \\
\hline 11 & 1 & 111 & 0,7 & 32,2 & 23,3 & $-25,9$ & 95,5 & 29,3 & 7,3 & $-8,7$ \\
\hline 12 & 1 & 96,3 & $-6,6$ & 29,9 & 22,4 & $-29,4$ & 88,2 & 20,3 & 2,9 & $-12,7$ \\
\hline 13 & 1 & 98,3 & $-4,4$ & 27,1 & 18,1 & $-28,9$ & 91,6 & 25,5 & 6,9 & -8 \\
\hline 14 & 1 & 112,8 & $-0,3$ & 29,6 & 22,7 & $-29,8$ & 95,1 & 24,8 & 4,6 & $-10,4$ \\
\hline 15 & 1 & 120,2 & 2,9 & 27,1 & 23 & $-26,3$ & 94 & 25,2 & 3,8 & $-12,6$ \\
\hline 16 & 1 & 102,9 & $-3,2$ & 35,8 & 30,3 & $-25,7$ & 91,9 & 29,9 & 7,1 & $-11,7$ \\
\hline 17 & 1 & 110,8 & $-3,3$ & 26,6 & 22,6 & $-30,4$ & 97,4 & 23,4 & 2 & $-12,3$ \\
\hline 18 & 1 & 110,8 & 0,4 & 28,4 & 24,3 & $-27,8$ & 102 & 30,7 & 5 & $-8,5$ \\
\hline 19 & 1 & 111,2 & 0,6 & 27,1 & 23,1 & $-28,6$ & 102,1 & 33,8 & 6,8 & -5 \\
\hline 20 & 1 & 127,7 & 1,4 & 25,9 & 25,8 & $-24,4$ & 92,2 & 26,6 & 6,2 & -13 \\
\hline 21 & 1 & 121,1 & 6,3 & 28,4 & 23,7 & $-26,7$ & 101,8 & 32,3 & 7,7 & $-4,9$ \\
\hline 22 & 1 & 124,1 & 2,8 & 24 & 21,4 & -27 & 88,1 & 14,3 & 0,5 & -12 \\
\hline 23 & 1 & 110,2 & 1,6 & 27 & 24,5 & $-25,7$ & 107,7 & 35,4 & 8,7 & $-3,4$ \\
\hline 24 & 1 & 116 & $-0,4$ & 29,1 & 26,5 & $-27,3$ & 89,9 & 19,5 & 1,5 & $-15,6$ \\
\hline 25 & 1 & 116,1 & 0,1 & 25,9 & 19,2 & $-24,7$ & 87 & 17,1 & 1,7 & $-11,4$ \\
\hline 26 & 1 & 99,5 & $-0,6$ & 30,7 & 21,5 & $-29,2$ & 88,3 & 25,3 & 4,6 & $-11,9$ \\
\hline 27 & 1 & 118,1 & 1,2 & 28,2 & 21,4 & $-27,8$ & 89,5 & 24,8 & 4,5 & $-12,7$ \\
\hline 28 & 1 & 116,7 & 0,5 & 29,3 & 24 & $-30,2$ & 105,2 & 39,3 & 8,4 & $-7,6$ \\
\hline 29 & 1 & 118 & 1,2 & 27,3 & 21,3 & $-32,1$ & 102,5 & 36,2 & 10,2 & $-6,6$ \\
\hline 30 & 1 & 116,1 & $-1,2$ & 29,9 & 23,1 & $-32,8$ & 98,9 & 17 & 1,5 & $-9,2$ \\
\hline
\end{tabular}


TABELA A-8

\begin{tabular}{|c|c|c|c|c|c|c|c|c|c|c|}
\hline $\mathrm{N}$ & Grupo & 1,PP T1 & 1-ENAperp T1 & 1-pp T1 & 6-pp T1 & 6-ENAperp T1 & $\begin{array}{c}\text { IMPA } \\
\text { T1 }\end{array}$ & 1,NB T1 & 1-NB T1 & 1-pog per T1 \\
\hline 31 & 2 & 110,2 & $-2,9$ & 30,3 & 24,9 & $-29,2$ & 92,9 & 31 & 6,6 & $-10,1$ \\
\hline 32 & 2 & 107,2 & $-3,5$ & 27,8 & 21,7 & $-24,8$ & 84,4 & 22,5 & 5 & $-14,8$ \\
\hline 33 & 2 & 119,6 & 2,8 & 22,6 & 21 & $-25,5$ & 95,6 & 25,9 & 4,6 & $-5,8$ \\
\hline 34 & 2 & 116,4 & 2,7 & 27,5 & 25,2 & $-25,1$ & 109,9 & 28,8 & 7,4 & 0,5 \\
\hline 35 & 2 & 123,7 & 4 & 32,6 & 25,5 & $-27,8$ & 94 & 31,6 & 7,8 & -9 \\
\hline 36 & 2 & 121 & $-3,3$ & 27,9 & 20,8 & $-29,3$ & 79,8 & 20,1 & 5 & $-16,3$ \\
\hline 37 & 2 & 117,5 & 2,8 & 27,4 & 22,3 & $-23,7$ & 96,7 & 32,5 & 11,5 & $-6,3$ \\
\hline 38 & 2 & 120,6 & 4,9 & 27,8 & 23,7 & $-22,8$ & 90,9 & 26 & 7,8 & $-11,8$ \\
\hline 39 & 2 & 115,3 & 5,8 & 32,9 & 26,2 & -27 & 98,5 & 32,6 & 10,6 & $-7,4$ \\
\hline 40 & 2 & 116 & $-4,5$ & 33,7 & 29,9 & $-33,4$ & 90,8 & 22,7 & 5,8 & $-12,9$ \\
\hline 41 & 2 & 112 & $-2,9$ & 30,6 & 24,8 & $-29,9$ & 78,3 & 20,1 & 4,4 & -17 \\
\hline 42 & 2 & 122 & 2,7 & 28,1 & 24,2 & $-22,7$ & 94,9 & 30,8 & 7,9 & $-7,3$ \\
\hline 43 & 2 & 129,1 & 5,2 & 23,3 & 22,8 & $-29,6$ & 96 & 20,9 & 2,5 & $-5,1$ \\
\hline 44 & 2 & 130,1 & 0,2 & 27,4 & 27,2 & $-32,6$ & 87,7 & 23,1 & 7 & $-16,4$ \\
\hline 45 & 2 & 113,1 & $-1,1$ & 28 & 23,1 & $-29,1$ & 92,4 & 24 & 5,2 & $-9,4$ \\
\hline 46 & 2 & 113,2 & 1,2 & 27,6 & 21,1 & $-23,6$ & 107,2 & 37,5 & 8,2 & $-1,7$ \\
\hline 47 & 2 & 129,7 & 2,6 & 23,4 & 21,9 & -29 & 99,3 & 22,9 & 4 & $-5,1$ \\
\hline 48 & 2 & 117,6 & 0 & 31,1 & 25,2 & $-29,2$ & 93,9 & 34 & 7 & $-10,8$ \\
\hline 49 & 2 & 102,4 & -4 & 29,6 & 22,8 & $-28,7$ & 87,4 & 20,5 & 4,3 & $-12,5$ \\
\hline 50 & 2 & 128,2 & 5,9 & 27,3 & 22,1 & $-30,6$ & 90 & 27 & 6 & -8 \\
\hline 51 & 2 & 123,3 & 3,6 & 26,4 & 21,8 & -27 & 99,3 & 28,2 & 6,2 & $-7,3$ \\
\hline 52 & 2 & 116,9 & 0,9 & 26 & 24,2 & $-27,4$ & 96,1 & 29,1 & 5,5 & $-11,2$ \\
\hline 53 & 2 & 107 & $-2,5$ & 27,3 & 23,7 & $-26,2$ & 91,5 & 24,1 & 5,4 & $-9,7$ \\
\hline 54 & 2 & 124,2 & 2,8 & 25,8 & 21,2 & $-22,7$ & 94,8 & 22,9 & 3,9 & $-7,8$ \\
\hline 55 & 2 & 122,1 & $-1,3$ & 26,6 & 22,5 & -30 & 86,5 & 22,5 & 3,4 & $-12,1$ \\
\hline 56 & 2 & 125,9 & 0,7 & 24,9 & 20,1 & -29 & 89,8 & 25,2 & 3,6 & $-9,3$ \\
\hline 57 & 2 & 114,2 & 0,4 & 27,6 & 22,4 & $-28,5$ & 90,1 & 20,5 & 3,1 & $-11,3$ \\
\hline 58 & 2 & 108,4 & $-3,5$ & 31,2 & 23,9 & $-32,2$ & 91,1 & 28,1 & 6,6 & $-12,9$ \\
\hline 59 & 2 & 113,8 & $-3,6$ & 30,1 & 26,6 & $-29,5$ & 84,7 & 22,7 & 7 & $-17,3$ \\
\hline 60 & 2 & 102,6 & $-2,8$ & 25,9 & 20,3 & $-22,2$ & 77,8 & 16,2 & 2,8 & -15 \\
\hline
\end{tabular}


TABELA A-9

\begin{tabular}{|c|c|c|c|c|c|c|c|c|}
\hline $\mathbf{N}$ & Grupo & 1-GoMe T1 & 6-pogper T1 & 6-GoMe T1 & T hor T1 & T ver T1 & Rel mol T1 & Rel can T1 \\
\hline 1 & 1 & 44,6 & $-29,7$ & 29,3 & 8,3 & 4,4 & 2,9 & 3,9 \\
\hline 2 & 1 & 42,4 & $-33,1$ & 30,6 & 8,3 & 8,6 & 2,5 & 5,3 \\
\hline 3 & 1 & 39,1 & $-28,5$ & 27,5 & 5,6 & 5,1 & 3,3 & 1,8 \\
\hline 4 & 1 & 43,2 & $-30,2$ & 31,3 & 11,7 & 3,5 & 3,4 & 4,8 \\
\hline 5 & 1 & 37,7 & $-31,9$ & 28,4 & 3,9 & 2,8 & 3,9 & 4,7 \\
\hline 6 & 1 & 36,7 & $-25,9$ & 27,5 & 7,3 & 7,2 & 4,8 & 2,4 \\
\hline 7 & 1 & 37,2 & $-30,4$ & 27,8 & 5,9 & 7,3 & 3,8 & 3,3 \\
\hline 8 & 1 & 34,3 & $-29,4$ & 24,9 & 5,6 & 6,1 & 4,5 & 4,1 \\
\hline 9 & 1 & 39,9 & $-35,8$ & 26 & 4,5 & 2,9 & 3,7 & 4,6 \\
\hline 10 & 1 & 40,8 & $-30,1$ & 30 & 6,1 & 5,1 & 3 & 4,7 \\
\hline 11 & 1 & 39,3 & $-29,1$ & 28 & 7 & 4 & 3,2 & 7,6 \\
\hline 12 & 1 & 37,7 & $-32,1$ & 26,3 & 5,4 & 7,2 & 4,6 & 4,3 \\
\hline 13 & 1 & 38,4 & $-29,2$ & 27,7 & 5,1 & 5,9 & 3,7 & 3,6 \\
\hline 14 & 1 & 38,7 & -32 & 28,8 & 9,4 & 4,3 & 4,2 & 8,3 \\
\hline 15 & 1 & 37 & $-34,2$ & 24,9 & 7,2 & 4,2 & 3,4 & 4,4 \\
\hline 16 & 1 & 40,5 & $-30,2$ & 29,2 & 5 & 2,5 & 4,2 & 1,8 \\
\hline 17 & 1 & 40,6 & $-34,6$ & 31 & 6,7 & 7,2 & 3,4 & 2,8 \\
\hline 18 & 1 & 40,7 & $-30,8$ & 30,5 & 6,6 & 4,6 & 3,3 & 5,2 \\
\hline 19 & 1 & 38,7 & $-27,9$ & 28,5 & 7 & 2,4 & 3,6 & 2,4 \\
\hline 20 & 1 & 39,5 & $-33,2$ & 31 & 6,5 & $-3,2$ & 3,9 & 4,7 \\
\hline 21 & 1 & 40,8 & $-27,4$ & 27,9 & 11,2 & 6,2 & 4,2 & 3,7 \\
\hline 22 & 1 & 35,4 & $-30,9$ & 25,5 & 11,1 & 6,9 & 4,2 & 3,5 \\
\hline 23 & 1 & 38,5 & $-26,2$ & 28,5 & 5,1 & 5 & 3,8 & 3,7 \\
\hline 24 & 1 & 36,1 & $-33,7$ & 26,4 & 8,9 & 0,7 & 3,6 & 2 \\
\hline 25 & 1 & 34 & $-30,6$ & 25,3 & 9,5 & 3,8 & 5,7 & 3 \\
\hline 26 & 1 & 38 & $-32,8$ & 27 & 8,5 & 6,1 & 3,4 & 4,7 \\
\hline 27 & 1 & 38 & $-30,4$ & 28,3 & 10,4 & 6,2 & 3,4 & 3 \\
\hline 28 & 1 & 42,9 & $-31,6$ & 30,2 & 5,9 & 4,8 & 3 & 3,9 \\
\hline 29 & 1 & 41,3 & $-30,7$ & 31,5 & 7,7 & $-1,8$ & 3,4 & 3,9 \\
\hline 30 & 1 & 35,5 & $-29,7$ & 26 & 13,8 & 7,4 & 3,9 & 4,6 \\
\hline
\end{tabular}


TABELA A-10

\begin{tabular}{|c|c|c|c|c|c|c|c|c|}
\hline $\mathrm{N}$ & Grupo & 1-GoMe T1 & 6-pogper T1 & 6-GoMe T1 & T hor T1 & T ver T1 & Rel mol T1 & Rel can T1 \\
\hline 32 & 2 & 39,7 & $-30,9$ & 29,5 & 4,9 & 4,3 & 2,6 & 3,3 \\
\hline 34 & 2 & 40,2 & $-21,1$ & 30,9 & 9 & 5,6 & 4,2 & 4,4 \\
\hline 35 & 2 & 39,9 & $-28,6$ & 29,2 & 11,8 & 1,7 & 3,6 & 3,5 \\
\hline 37 & 2 & 41,5 & $-23,3$ & 29,5 & 8,6 & 5,3 & 3,7 & 3,4 \\
\hline 38 & 2 & 41,8 & $-30,2$ & 29,3 & 8,5 & 7 & 3,9 & 3,8 \\
\hline 39 & 2 & 48 & $-26,5$ & 30,5 & 12,4 & 8,4 & 4,7 & 5,7 \\
\hline 40 & 2 & 45,4 & $-31,6$ & 33,9 & 9,4 & 1,6 & 3,8 & 2,8 \\
\hline 41 & 2 & 40,3 & $-32,8$ & 25,9 & 7,9 & 5,2 & 3,3 & 4,8 \\
\hline 45 & 2 & 40 & $-29,1$ & 29,1 & 8,3 & 5,9 & 3,1 & 4 \\
\hline 46 & 2 & 37,6 & $-22,4$ & 29,5 & 6 & 5 & 2,8 & 4,3 \\
\hline 47 & 2 & 37,5 & $-25,5$ & 27,3 & 10,9 & 5,4 & 2,2 & 3 \\
\hline 48 & 2 & 44 & $-30,2$ & 33,3 & 8,2 & 0,1 & 2,1 & 2,5 \\
\hline 49 & 2 & 40,8 & $-33,3$ & 29,8 & 4,6 & 4,7 & 3,5 & 2,4 \\
\hline 50 & 2 & 42,8 & $-27,8$ & 26,7 & 11,4 & 4,3 & 3,3 & 5,1 \\
\hline 51 & 2 & 39,2 & $-28,9$ & 27,8 & 8,7 & 6,3 & 3,7 & 4,3 \\
\hline 52 & 2 & 37,8 & $-29,8$ & 26,3 & 8,6 & 3,3 & 3,6 & 1,9 \\
\hline 53 & 2 & 40,5 & -30 & 29,6 & 4,6 & 4,2 & 4,4 & 2,2 \\
\hline 60 & 2 & 36,4 & $-31,7$ & 26,5 & 3,1 & 2,9 & 3,2 & 2,2 \\
\hline
\end{tabular}


TABELA A-11

\begin{tabular}{|c|c|c|c|c|c|c|c|c|c|c|c|}
\hline $\mathbf{N}$ & Grupo & SNA T2 & CoA T2 & A-Nperp T2 & SNB T2 & CoGn T2 & ANB T2 & Wits T2 & FMA T2 & SNGoGn T2 & AFAI T2 \\
\hline 1 & 1 & 75,9 & 76,7 & $-3,6$ & 75,3 & 109,1 & 0,6 & 0,8 & 30,6 & 39,1 & 71,1 \\
\hline 2 & 1 & 81,7 & 93,3 & 1,1 & 79,7 & 122,4 & 2 & 2,6 & 14,9 & 22,6 & 65,7 \\
\hline 3 & 1 & 80,3 & 86,1 & 1,9 & 76 & 105,9 & 4,4 & 1,4 & 22,4 & 32,1 & 63,1 \\
\hline 4 & 1 & 71,7 & 89,4 & $-8,4$ & 70,6 & 119,1 & 1,2 & 2,5 & 30,7 & 39,2 & 77,3 \\
\hline 5 & 1 & 81,2 & 81,4 & 1,1 & 78,2 & 108,6 & 2,9 & 1,9 & 27 & 34,8 & 61,2 \\
\hline 6 & 1 & 85,4 & 96,1 & 1,6 & 80,1 & 114 & 5,3 & 3,5 & 19,5 & 23,9 & 57,6 \\
\hline 7 & 1 & 77,5 & 89,6 & $-3,4$ & 76,3 & 117,9 & 1,2 & 2,7 & 21 & 28,3 & 68,3 \\
\hline 8 & 1 & 73,1 & 75,8 & $-9,5$ & 72,5 & 99,4 & 0,7 & $-0,6$ & 33,6 & 38,2 & 63,3 \\
\hline 9 & 1 & 77,2 & 82 & $-6,3$ & 78,2 & 114,5 & -1 & -2 & 30,8 & 34,7 & 71,3 \\
\hline 10 & 1 & 79 & 88,3 & $-5,1$ & 78,2 & 114,2 & 0,8 & 4,3 & 21,5 & 25,3 & 67,1 \\
\hline 11 & 1 & 76,8 & 80,7 & $-2,1$ & 75 & 107,3 & 1,7 & 1,2 & 29,3 & 38,1 & 70,6 \\
\hline 12 & 1 & 78,5 & 83,8 & $-7,7$ & 74,7 & 107,8 & 3,7 & 4,5 & 34 & 34,9 & 68 \\
\hline 13 & 1 & 77,6 & 80,6 & $-2,2$ & 71,2 & 101,9 & 6,4 & 6,6 & 34,5 & 42 & 67,5 \\
\hline 14 & 1 & 79,5 & 91,5 & $-4,3$ & 77,2 & 117,8 & 2,3 & 4,9 & 27,1 & 31,8 & 69 \\
\hline 15 & 1 & 78,8 & 82 & $-1,4$ & 76,5 & 106,7 & 2,3 & 3,7 & 26,2 & 33,8 & 63,9 \\
\hline 16 & 1 & 82,7 & 84,5 & 0,7 & 80,1 & 112,5 & 2,6 & 0,8 & 28,3 & 35 & 73,2 \\
\hline 17 & 1 & 81,6 & 87,9 & $-0,9$ & 79,8 & 119 & 1,8 & 2,2 & 16 & 21,9 & 62,9 \\
\hline 18 & 1 & 82,1 & 91,7 & $-4,9$ & 80,4 & 121,5 & 1,7 & 2,7 & 20,1 & 21,8 & 67,7 \\
\hline 19 & 1 & 86,1 & 90,5 & 3,8 & 79,5 & 111,3 & 6,7 & 6,1 & 26,9 & 33,2 & 67,3 \\
\hline 20 & 1 & 76 & 91,2 & $-0,2$ & 71,4 & 119,9 & 4,6 & 3,5 & 27,7 & 40 & 69,8 \\
\hline 21 & 1 & 80,3 & 88,5 & 0,6 & 73,9 & 104,5 & 6,4 & 6,1 & 27,1 & 35,9 & 62,7 \\
\hline 22 & 1 & 78,6 & 80,6 & $-8,4$ & 76,7 & 102 & 1,8 & 4,6 & 27,2 & 27,3 & 58,7 \\
\hline 23 & 1 & 81,6 & 88,1 & 0,8 & 76,5 & 109,8 & 5 & 6,1 & 24,1 & 32,3 & 62,4 \\
\hline 24 & 1 & 78,6 & 82 & -4 & 78,6 & 112,1 & 0 & 1,3 & 23,3 & 29,1 & 67,1 \\
\hline 25 & 1 & 78,6 & 80,8 & $-5,2$ & 77,1 & 105,3 & 1,5 & 1,9 & 28,4 & 31,5 & 65,7 \\
\hline 26 & 1 & 84 & 92,8 & 5,1 & 78,3 & 120,7 & 5,7 & 0,4 & 30,4 & 39,8 & 73,6 \\
\hline 27 & 1 & 80,2 & 81,4 & $-4,1$ & 75,5 & 109,1 & 4,8 & 3,3 & 36,2 & 38,1 & 67,8 \\
\hline 28 & 1 & 82 & 94,2 & $-0,9$ & 79 & 120 & 3 & 3,3 & 30 & 35 & 71,8 \\
\hline 29 & 1 & 81,4 & 91,3 & $-1,7$ & 75,6 & 111,9 & 5,8 & 2,5 & 32 & 36,2 & 72,7 \\
\hline 30 & 1 & 73,8 & 85,2 & $-8,6$ & 74,3 & 112,1 & $-0,5$ & 3,4 & 17,9 & 21,7 & 65,6 \\
\hline
\end{tabular}


TABELA A-12

\begin{tabular}{|c|c|c|c|c|c|c|c|c|c|c|c|}
\hline $\mathbf{N}$ & Grupo & SNA T2 & CoA T2 & A-Nperp T2 & SNB T2 & CoGn T2 & ANB T2 & $\begin{array}{c}\text { Wits } \\
\text { T2 }\end{array}$ & $\begin{array}{c}\text { FMA } \\
\text { T2 }\end{array}$ & SNGoGn T2 & AFAI T2 \\
\hline 31 & 2 & 82,6 & 86,1 & 1,3 & 73,7 & 104,4 & 8,9 & 4,1 & 35,3 & 41,2 & 72,1 \\
\hline 32 & 2 & 75,4 & 80 & $-4,2$ & 73,5 & 106,6 & 2 & 2,1 & 34,7 & 42,4 & 67,5 \\
\hline 33 & 2 & 86 & 89,7 & 6,3 & 82,6 & 113,2 & 3,4 & $-3,6$ & 13,8 & 22,7 & 60,4 \\
\hline 34 & 2 & 82,3 & 95,7 & 0,1 & 75,6 & 113 & 6,7 & 7,9 & 13,9 & 20,1 & 62,7 \\
\hline 35 & 2 & 78,6 & 84,1 & 0,7 & 75,9 & 113,4 & 2,7 & $-1,4$ & 27,9 & 38,2 & 71 \\
\hline 36 & 2 & 80,2 & 81,2 & $-0,5$ & 73,8 & 108,4 & 6,3 & 4,9 & 38,3 & 45,1 & 73,4 \\
\hline 37 & 2 & 81,2 & 75 & $-1,4$ & 72,6 & 101,6 & 8,7 & 3,4 & 36,8 & 42,6 & 69,6 \\
\hline 38 & 2 & 82,7 & 89,4 & $-3,5$ & 78,3 & 116,2 & 4,4 & 0 & 33 & 35,2 & 67,7 \\
\hline 39 & 2 & 73,3 & 82,5 & $-11,4$ & 72 & 114,9 & 1,3 & $-1,8$ & 34,9 & 37,8 & 75,1 \\
\hline 40 & 2 & 75,9 & 86,2 & $-5,7$ & 74,2 & 117,3 & 1,7 & 2,4 & 29 & 34,2 & 83,1 \\
\hline 41 & 2 & 77,4 & 79,4 & $-4,8$ & 75 & 113,7 & 2,4 & $-0,8$ & 39,8 & 45,9 & 76,8 \\
\hline 42 & 2 & 77,4 & 81 & $-7,4$ & 76,3 & 102,8 & 1,1 & 2,8 & 34,2 & 36,4 & 65,2 \\
\hline 43 & 2 & 84,2 & 95,8 & 1,9 & 83 & 117,2 & 1,2 & 2 & 15,2 & 19,6 & 58,3 \\
\hline 44 & 2 & 82,5 & 91,9 & $-1,4$ & 75,8 & 117,8 & 6,8 & 8,5 & 33,6 & 38 & 78,1 \\
\hline 45 & 2 & 75,6 & 82,6 & $-3,4$ & 71,7 & 106,1 & 4 & 5,5 & 28,3 & 36,5 & 68,6 \\
\hline 46 & 2 & 79,1 & 83,6 & 0 & 76,2 & 104,5 & 2,9 & 0,5 & 21,8 & 30,8 & 58,1 \\
\hline 47 & 2 & 79,5 & 82,3 & $-2,2$ & 76,8 & 101,8 & 2,7 & 0,8 & 18,3 & 24,6 & 54,8 \\
\hline 48 & 2 & 83,4 & 91,8 & $-4,7$ & 78,8 & 122,8 & 4,7 & 3,6 & 39,8 & 38,6 & 78,3 \\
\hline 49 & 2 & 77,2 & 83,5 & $-1,4$ & 75,2 & 110,7 & 2 & $-0,5$ & 25,7 & 35,1 & 68,3 \\
\hline 50 & 2 & 80,9 & 86,1 & 0 & 76,5 & 109,6 & 4,3 & 0,1 & 33,5 & 40,1 & 69,7 \\
\hline 51 & 2 & 74 & 78,9 & $-5,9$ & 72,6 & 101,3 & 1,4 & 0 & 27,1 & 34,8 & 62,8 \\
\hline 52 & 2 & 79 & 85,3 & 2 & 71,2 & 107,7 & 7,8 & 6,6 & 29,1 & 40,2 & 67,3 \\
\hline 53 & 2 & 74,1 & 83,9 & $-3,4$ & 72,2 & 116,6 & 1,9 & 8 & 27,7 & 38,5 & 68,6 \\
\hline 54 & 2 & 70,4 & 82,1 & $-8,1$ & 69,9 & 106,6 & 0,5 & 5,3 & 29,8 & 39,5 & 63 \\
\hline 55 & 2 & 78 & 78,6 & 1,5 & 72,2 & 103,3 & 5,8 & 2,6 & 28,1 & 38,7 & 67,2 \\
\hline 56 & 2 & 78,3 & 81,1 & 0,3 & 71,8 & 99,8 & 6,5 & 3,8 & 32,4 & 40,8 & 63,6 \\
\hline 57 & 2 & 76 & 77,2 & -5 & 71,3 & 103,1 & 4,7 & 0,5 & 31,7 & 37,5 & 67,9 \\
\hline 58 & 2 & 72,8 & 84,4 & $-4,4$ & 68,2 & 107,4 & 4,6 & 0,2 & 35,1 & 46,4 & 71,3 \\
\hline 59 & 2 & 83,1 & 82,1 & $-3,4$ & 76,1 & 110,1 & 7 & 6,9 & 38,6 & 39,9 & 77,8 \\
\hline 60 & 2 & 75,1 & 75,4 & $-5,8$ & 75,6 & 103 & $-0,5$ & $-5,1$ & 33,6 & 39,9 & 66,4 \\
\hline
\end{tabular}


TABELA A-13

\begin{tabular}{|c|c|c|c|c|c|c|c|c|c|}
\hline $\mathbf{N}$ & Grupo & 1,PP T2 & 1-ENA per T2 & 1-pp T2 & 6-pp T2 & Ms-ENA perp T2 & IMPA T2 & 1,NB T2 & 1-NB T2 \\
\hline 1 & 1 & 104,1 & 1,3 & 32,1 & 28 & $-20,4$ & 89,6 & 25,6 & 7,9 \\
\hline 2 & 1 & 126 & $-2,3$ & 25,7 & 24,5 & -28 & 113,9 & 37,8 & 5,2 \\
\hline 3 & 1 & 109,2 & $-4,6$ & 25,9 & 22 & -27 & 93,4 & 23,5 & 5,4 \\
\hline 4 & 1 & 99,3 & $-5,9$ & 33,1 & 27,5 & $-25,4$ & 81 & 12,2 & 2,1 \\
\hline 5 & 1 & 126 & $-0,4$ & 21,4 & 20,9 & -25 & 90,3 & 25,4 & 5,7 \\
\hline 6 & 1 & 110,7 & $-3,7$ & 23,6 & 20,4 & $-27,7$ & 107,1 & 32,9 & 5,1 \\
\hline 7 & 1 & 114,7 & $-5,4$ & 27,6 & 25,4 & $-28,5$ & 96,5 & 22,7 & 4,2 \\
\hline 8 & 1 & 112,8 & $-1,2$ & 28,6 & 24,7 & $-22,9$ & 96,6 & 29,4 & 4,8 \\
\hline 9 & 1 & 111 & -1 & 29,8 & 25,2 & $-25,8$ & 83,2 & 18,4 & 4,5 \\
\hline 10 & 1 & 110,6 & $-3,4$ & 27,1 & 25,4 & -23 & 98 & 23,4 & 4 \\
\hline 11 & 1 & 110,6 & $-0,8$ & 31,8 & 26,1 & $-23,9$ & 97,7 & 32,9 & 9,4 \\
\hline 12 & 1 & 103,2 & $-6,3$ & 28,1 & 23,5 & $-29,7$ & 89,4 & 21,8 & 3,4 \\
\hline 13 & 1 & 113,3 & $-4,1$ & 25,3 & 21,8 & $-26,7$ & 88,6 & 24,6 & 8 \\
\hline 14 & 1 & 116,4 & $-2,7$ & 26,5 & 25,3 & $-26,2$ & 89,3 & 20,1 & 4,1 \\
\hline 15 & 1 & 116,3 & 2,1 & 25,8 & 24,7 & $-23,1$ & 104,6 & 36,9 & 6,1 \\
\hline 16 & 1 & 107,4 & 0,8 & 35,9 & 30 & $-22,8$ & 96,6 & 33,1 & 8,6 \\
\hline 17 & 1 & 124,6 & $-1,3$ & 23,6 & 23,1 & $-25,6$ & 99 & 22,4 & 3,1 \\
\hline 18 & 1 & 120,1 & $-1,9$ & 25,8 & 24,7 & -29 & 95,7 & 19,5 & 3,5 \\
\hline 19 & 1 & 113,1 & $-1,7$ & 26,7 & 25 & $-24,1$ & 99 & 33,1 & 7,3 \\
\hline 20 & 1 & 118,8 & $-4,6$ & 26,8 & 25 & $-24,3$ & 87,1 & 20,1 & 5,6 \\
\hline 21 & 1 & 113,8 & $-3,5$ & 26,9 & 24,2 & $-26,9$ & 108,8 & 40,1 & 8 \\
\hline 22 & 1 & 119,4 & $-2,7$ & 23,8 & 23,9 & $-24,4$ & 90,1 & 16 & 1,5 \\
\hline 23 & 1 & 115,9 & 0,7 & 27,1 & 26,2 & $-21,7$ & 102,1 & 32 & 8,2 \\
\hline 24 & 1 & 105,2 & $-4,5$ & 29,1 & 25,7 & $-24,7$ & 90,6 & 19,8 & 2,8 \\
\hline 25 & 1 & 114 & $-2,1$ & 26,9 & 23 & $-23,6$ & 94 & 24,8 & 6,3 \\
\hline 26 & 1 & 103,4 & $-3,8$ & 32 & 25,6 & $-26,7$ & 90,9 & 30,3 & 6,9 \\
\hline 27 & 1 & 115,6 & $-4,2$ & 26,9 & 23,1 & $-24,8$ & 87,4 & 24,5 & 4,7 \\
\hline 28 & 1 & 122,2 & $-1,3$ & 27,2 & 26,8 & $-25,5$ & 94,1 & 30,3 & 8,1 \\
\hline 29 & 1 & 110,4 & $-4,3$ & 29,5 & 23 & -27 & 100,3 & 34,8 & 9,4 \\
\hline 30 & 1 & 100,6 & $-5,8$ & 29,5 & 26,5 & $-27,8$ & 106,1 & 25 & 2,6 \\
\hline
\end{tabular}


TABELA A-14

\begin{tabular}{|c|c|c|c|c|c|c|c|c|c|}
\hline $\mathbf{N}$ & Grupo & 1,PP T2 & 1-ENA per T2 & 1-pp T2 & 6-pp T2 & Ms-ENA perp T2 & IMPA T2 & 1,NB T2 & 1-NB T2 \\
\hline 31 & 2 & 99,7 & $-5,6$ & 30 & 24,7 & $-25,9$ & 90,9 & 28,7 & 5,6 \\
\hline 32 & 2 & 110,3 & $-4,5$ & 28 & 24,7 & -27 & 85,1 & 23,6 & 3,3 \\
\hline 33 & 2 & 110,7 & $-0,7$ & 27,3 & 20,5 & $-24,1$ & 101,5 & 28,6 & 3,8 \\
\hline 34 & 2 & 97,6 & $-1,7$ & 28,5 & 23,3 & $-26,2$ & 109,9 & 27,2 & 6,9 \\
\hline 35 & 2 & 113,2 & $-1,1$ & 33,5 & 27,9 & $-25,3$ & 94,6 & 30,5 & 5,5 \\
\hline 36 & 2 & 91,8 & $-12,7$ & 30,2 & 23,2 & $-31,4$ & 87,2 & 28,7 & 5,8 \\
\hline 37 & 2 & 100,4 & -4 & 30,6 & 25 & $-23,1$ & 99,5 & 36,2 & 10,6 \\
\hline 38 & 2 & 114,1 & 1,8 & 30,1 & 25,1 & $-24,8$ & 94,4 & 29,7 & 8,7 \\
\hline 39 & 2 & 107,8 & $-4,9$ & 33,8 & 26,5 & $-27,4$ & 88,3 & 21,5 & 3 \\
\hline 40 & 2 & 103,8 & $-9,2$ & 35,1 & 29,2 & $-30,7$ & 87,7 & 19,6 & 4,7 \\
\hline 41 & 2 & 114 & $-3,1$ & 32,3 & 26,3 & $-27,4$ & 81 & 24 & 5,8 \\
\hline 42 & 2 & 118,1 & 1,4 & 26,9 & 23,5 & $-23,2$ & 91 & 26,1 & 6,1 \\
\hline 43 & 2 & 105,2 & $-5,4$ & 25,9 & 24,9 & $-28,2$ & 87,5 & 13,4 & $-1,2$ \\
\hline 44 & 2 & 102,7 & $-9,6$ & 32,7 & 29,7 & $-30,9$ & 87,4 & 22,9 & 5,1 \\
\hline 45 & 2 & 111,7 & $-4,2$ & 28,8 & 26,9 & $-27,3$ & 89,9 & 21 & 2,6 \\
\hline 46 & 2 & 112,5 & $-3,4$ & 23,7 & 19,5 & $-24,5$ & 90,5 & 19,4 & 2,4 \\
\hline 47 & 2 & 110,6 & $-5,1$ & 23,4 & 19,1 & $-25,8$ & 102,5 & 25,8 & 2 \\
\hline 48 & 2 & 112,3 & $-4,6$ & 32 & 28,7 & $-28,3$ & 87,1 & 27,6 & 4,5 \\
\hline 49 & 2 & 101,1 & $-4,5$ & 31,5 & 24,7 & $-28,7$ & 95 & 27,3 & 3,8 \\
\hline 50 & 2 & 110,3 & $-2,5$ & 32,9 & 24,4 & $-27,9$ & 93,3 & 32,4 & 7,7 \\
\hline 51 & 2 & 110,8 & $-3,2$ & 27,7 & 23 & -24 & 92,9 & 22,4 & 3,7 \\
\hline 52 & 2 & 108,2 & $-6,9$ & 28,5 & 23,1 & $-29,7$ & 86,7 & 20 & 5,5 \\
\hline 53 & 2 & 124,8 & 1,3 & 27,3 & 27,7 & $-22,2$ & 87,4 & 20,2 & 4,9 \\
\hline 54 & 2 & 109,8 & $-6,3$ & 25,6 & 25,6 & $-27,3$ & 80 & 11,3 & 1 \\
\hline 55 & 2 & 107,6 & $-8,4$ & 28,5 & 25,4 & $-27,5$ & 87,6 & 21,5 & 3,6 \\
\hline 56 & 2 & 112 & $-5,2$ & 26,7 & 21,2 & $-26,4$ & 91,9 & 28,1 & 5,1 \\
\hline 57 & 2 & 95,3 & $-8,6$ & 29,9 & 23,9 & -27 & 93,7 & 25,5 & 3,2 \\
\hline 58 & 2 & 104,1 & -10 & 32,2 & 24,5 & $-31,1$ & 89,2 & 25,8 & 3,9 \\
\hline 59 & 2 & 98,5 & $-11,4$ & 32,7 & 27,7 & $-30,7$ & 91,1 & 29,2 & 5,8 \\
\hline 60 & 2 & 108,2 & $-1,7$ & 29,1 & 22,8 & -22 & 87,7 & 24,9 & 4,2 \\
\hline
\end{tabular}


TABELA A-15

\begin{tabular}{|c|c|c|c|c|c|c|c|c|c|}
\hline $\mathbf{N}$ & Grupo & 1-pog per T2 & 1-GoMe T2 & 6-pogper T2 & 6-GoMe T2 & T hor T2 & T vert T2 & Rel mol T2 & Rel can T2 \\
\hline 1 & 1 & $-8,4$ & 41,9 & $-28,2$ & 30,4 & 3 & 1,9 & 3,8 & $-1,6$ \\
\hline 2 & 1 & $-10,6$ & 39,9 & $-34,7$ & 33,2 & 2,8 & 0,8 & 2,8 & $-1,8$ \\
\hline 3 & 1 & $-5,6$ & 37,5 & -28 & 29,8 & 2,3 & 1,2 & 4,4 & $-2,5$ \\
\hline 4 & 1 & $-15,4$ & 43,9 & $-31,8$ & 34,5 & 4,8 & 3,4 & 4,4 & $-2,2$ \\
\hline 5 & 1 & $-11,7$ & 39,9 & $-32,8$ & 29,6 & 4 & 1,5 & 3,6 & $-2,4$ \\
\hline 6 & 1 & $-3,7$ & 36,2 & $-29,3$ & 28,9 & 2,7 & 3,2 & 5,6 & $-2,1$ \\
\hline 7 & 1 & $-10,8$ & 41,5 & $-32,2$ & 32,9 & 3,8 & 2,4 & 4,3 & -2 \\
\hline 8 & 1 & $-10,2$ & 36,2 & $-29,8$ & 27,1 & 3,8 & 2,8 & 5 & -1 \\
\hline 9 & 1 & $-14,8$ & 41,6 & $-36,9$ & 30,1 & 3 & 1,8 & 4,1 & $-2,9$ \\
\hline 10 & 1 & $-10,5$ & 39,6 & $-28,9$ & 31,7 & 2,4 & 0,6 & 4 & $-1,9$ \\
\hline 11 & 1 & $-9,3$ & 41,3 & -30 & 30,5 & 3,1 & 0,2 & 3,9 & $-1,9$ \\
\hline 12 & 1 & $-12,9$ & 40,4 & $-33,4$ & 28,9 & 3,7 & 3,6 & 4,2 & $-1,3$ \\
\hline 13 & 1 & $-9,2$ & 42,4 & -29 & 31,3 & 3,7 & 1,8 & 4,6 & $-2,1$ \\
\hline 14 & 1 & $-12,5$ & 42,5 & $-33,3$ & 31,7 & 3,7 & 1,5 & 4,4 & $-2,1$ \\
\hline 15 & 1 & -10 & 39,1 & $-32,7$ & 27,7 & 3,1 & 1,1 & 4 & $-3,3$ \\
\hline 16 & 1 & -9 & 41,7 & $-29,6$ & 29,9 & 3,9 & 2,9 & 4,1 & $-2,5$ \\
\hline 17 & 1 & $-7,8$ & 39,8 & $-31,2$ & 33,2 & 4 & 1,7 & 3,9 & $-1,8$ \\
\hline 18 & 1 & $-11,1$ & 41,8 & $-34,8$ & 34,4 & 4,1 & 1,5 & 2,5 & $-1,8$ \\
\hline 19 & 1 & $-6,8$ & 41,8 & -27 & 31,7 & 3 & 1,1 & 4,2 & $-1,9$ \\
\hline 20 & 1 & $-15,3$ & 41,9 & $-34,3$ & 33,7 & 3 & 1,7 & 4,9 & 1,6 \\
\hline 21 & 1 & $-5,1$ & 37,3 & $-26,4$ & 27,9 & 2,7 & 1,9 & 3,5 & $-0,4$ \\
\hline 22 & 1 & $-11,8$ & 35,3 & $-30,3$ & 27 & 4,9 & 2,7 & 4,6 & $-2,6$ \\
\hline 23 & 1 & $-3,8$ & 38,8 & $-24,7$ & 28,4 & 2,3 & 2,9 & 3,9 & -2 \\
\hline 24 & 1 & $-12,5$ & 36,9 & $-32,7$ & 28,3 & 2,6 & 1 & 4,6 & $-3,7$ \\
\hline 25 & 1 & $-10,3$ & 39,6 & $-31,9$ & 30,1 & 2,1 & 1,4 & 4,2 & $-2,9$ \\
\hline 26 & 1 & -12 & 43,2 & $-33,4$ & 33 & 3,4 & 3,2 & 4,4 & $-1,4$ \\
\hline 27 & 1 & $-12,6$ & 40,5 & $-31,4$ & 29,9 & 3,2 & 2,3 & 4,6 & -2 \\
\hline 28 & 1 & $-8,5$ & 45,3 & -31 & 32,9 & 1,4 & 0,1 & 3,7 & $-2,7$ \\
\hline 29 & 1 & -8 & 44,2 & -31 & 34,7 & 2,2 & 1 & 5,2 & $-2,3$ \\
\hline 30 & 1 & $-8,4$ & 36,7 & $-30,1$ & 30 & 2,7 & 2,3 & 3,7 & $-2,4$ \\
\hline
\end{tabular}


TABELA A-16

\begin{tabular}{|c|c|c|c|c|c|c|c|c|c|}
\hline $\mathbf{N}$ & Grupo & 1-pog per T2 & 1-GoMe T2 & 6-pogper T2 & 6-GoMe T2 & T hor T2 & T vert T2 & Rel mol T2 & Rel can T2 \\
\hline 31 & 2 & $-10,9$ & 41,7 & $-25,3$ & 34,7 & 2,6 & 1,9 & $-0,5$ & $-2,2$ \\
\hline 32 & 2 & $-17,7$ & 39,5 & $-31,2$ & 29 & 3 & 3 & $-1,6$ & $-1,8$ \\
\hline 33 & 2 & $-5,1$ & 35,9 & $-23,3$ & 32,8 & 4,2 & 3,3 & $-1,5$ & 1,2 \\
\hline 34 & 2 & 0,7 & 39,9 & $-19,4$ & 33,4 & 4,1 & 5,9 & $-0,1$ & $-2,3$ \\
\hline 35 & 2 & $-10,7$ & 38,5 & $-27,3$ & 31,3 & 4,7 & 1,5 & $-1,7$ & $-1,9$ \\
\hline 36 & 2 & $-15,7$ & 40,6 & $-27,4$ & 30,6 & 3 & 3 & $-0,5$ & $-1,7$ \\
\hline 37 & 2 & -6 & 41,1 & $-21,2$ & 34,4 & 2,3 & 2,2 & 0,2 & $-1,3$ \\
\hline 38 & 2 & $-11,5$ & 41,5 & -29 & 32,7 & 4,6 & 4,5 & $-1,2$ & $-1,2$ \\
\hline 39 & 2 & -15 & 42 & $-31,4$ & 33,9 & 4 & 4 & $-0,5$ & 0,5 \\
\hline 40 & 2 & $-13,9$ & 46,1 & $-29,3$ & 37,4 & 2,9 & 2,2 & $-0,9$ & -2 \\
\hline 41 & 2 & -20 & 41,5 & $-34,6$ & 31,9 & 4,4 & 1,3 & $-1,2$ & $-1,5$ \\
\hline 42 & 2 & $-10,1$ & 40,9 & $-26,3$ & 30,2 & 3,4 & 2,2 & $-1,1$ & $-1,8$ \\
\hline 43 & 2 & $-10,7$ & 33,2 & $-26,6$ & 26,1 & 4 & 2,7 & $-1,6$ & 0,7 \\
\hline 44 & 2 & $-17,5$ & 43,8 & $-29,9$ & 34,2 & 3,6 & 3,4 & $-1,3$ & $-1,6$ \\
\hline 45 & 2 & $-13,4$ & 40,3 & -27 & 32 & 5 & 3,1 & $-1,2$ & $-2,6$ \\
\hline 46 & 2 & $-6,9$ & 35,7 & $-22,4$ & 29,6 & 3,4 & 2,5 & $-0,9$ & $-1,2$ \\
\hline 47 & 2 & $-6,2$ & 32,8 & $-23,2$ & 28,4 & 3,7 & 2,8 & 0,5 & 0,7 \\
\hline 48 & 2 & $-17,9$ & 44,6 & $-32,2$ & 34 & 3,5 & 1,7 & $-1,1$ & -1 \\
\hline 49 & 2 & $-12,3$ & 38,8 & $-30,1$ & 30,7 & 3,3 & 3,5 & $-1,5$ & $-2,6$ \\
\hline 50 & 2 & $-6,8$ & 40,2 & $-26,7$ & 28,8 & 3,7 & 3,2 & 0,3 & $-0,7$ \\
\hline 51 & 2 & $-11,4$ & 36,9 & $-27,2$ & 29,9 & 2,6 & 3,1 & $-0,2$ & $-1,8$ \\
\hline 52 & 2 & $-12,4$ & 40,6 & $-26,7$ & 32 & 5 & 4,9 & $-1,4$ & $-2,6$ \\
\hline 53 & 2 & $-14,1$ & 42 & $-26,9$ & 30,7 & 4 & 2,4 & $-2,2$ & $-2,6$ \\
\hline 54 & 2 & $-16,1$ & 38,3 & $-27,6$ & 28,2 & 2,6 & 3,7 & $-2,2$ & $-2,8$ \\
\hline 55 & 2 & $-11,3$ & 38,1 & $-24,7$ & 31,5 & 3,7 & 3,2 & 0,3 & 1,3 \\
\hline 56 & 2 & $-9,6$ & 37 & $-24,4$ & 28,6 & 3,5 & 2 & 0,1 & 0,1 \\
\hline 57 & 2 & $-12,4$ & 35,9 & $-27,4$ & 30,5 & 2,4 & 1,5 & 0,1 & 1 \\
\hline 58 & 2 & $-14,9$ & 39,5 & $-30,6$ & 31,5 & 3,3 & 4,3 & $-0,4$ & $-1,5$ \\
\hline 59 & 2 & $-16,9$ & 44,4 & $-28,1$ & 34,9 & 2,9 & 4 & $-1,4$ & $-2,5$ \\
\hline 60 & 2 & -15 & 37,4 & $-28,4$ & 30,4 & 3,1 & 2 & $-1,8$ & $-2,6$ \\
\hline
\end{tabular}


TABELA A-17

\begin{tabular}{|c|c|c|c|c|c|c|c|c|c|c|c|}
\hline $\mathbf{N}$ & Grupo & SNA T3 & Co-A T3 & A-Nperp T3 & SNB T3 & CoGn T3 & ANB T3 & Wits T3 & FMA T3 & SN-GoGn T3 & AFAI T3 \\
\hline 1 & 1 & 79,7 & 81,4 & 0,3 & 73,9 & 106,4 & 5,8 & 6,9 & 29,2 & 37,7 & 70 \\
\hline 2 & 1 & 82,2 & 92,4 & $-1,7$ & 80,4 & 120,5 & 1,8 & 3,3 & 15,6 & 19,5 & 63,7 \\
\hline 3 & 1 & 79,7 & 86,9 & 2,2 & 75,3 & 106,9 & 4,4 & 1,8 & 20,8 & 31,9 & 64 \\
\hline 4 & 1 & 71,7 & 87,2 & $-5,6$ & 70 & 117,4 & 1,7 & 4 & 28,8 & 39,2 & 76,4 \\
\hline 5 & 1 & 82,4 & 86,3 & 1,3 & 80,8 & 118,1 & 1,6 & 3,2 & 21,6 & 28,1 & 63,1 \\
\hline 6 & 1 & 88,7 & 93,1 & 0,2 & 83,6 & 111,2 & 5,2 & 3,2 & 17,9 & 17,7 & 54,5 \\
\hline 7 & 1 & 80,8 & 92,9 & $-1,2$ & 79,3 & 121,8 & 1,5 & 2,5 & 17,9 & 23,5 & 67,6 \\
\hline 8 & 1 & 78,5 & 81,9 & $-2,2$ & 72,8 & 101,2 & 5,7 & 4,3 & 29,5 & 36,8 & 63,5 \\
\hline 9 & 1 & 81,8 & 88,8 & $-2,7$ & 79,2 & 118,8 & 2,7 & 5,1 & 28,2 & 30,6 & 74,9 \\
\hline 10 & 1 & 80 & 87,7 & $-4,1$ & 79,2 & 113,7 & 0,8 & 3,2 & 21,3 & 25,2 & 65,6 \\
\hline 11 & 1 & 83,9 & 84,2 & 1,9 & 77,9 & 105,8 & 6 & 4,3 & 26,4 & 31,2 & 72,2 \\
\hline 12 & 1 & 79,7 & 85,7 & $-4,3$ & 75,6 & 114,5 & 4,1 & 5,1 & 27,7 & 31,8 & 72 \\
\hline 13 & 1 & 79,2 & 83,3 & $-1,5$ & 73,3 & 109,6 & 6 & 5,2 & 32,5 & 39,8 & 68,2 \\
\hline 14 & 1 & 81,7 & 95,5 & 2,6 & 78,2 & 123,5 & 3,5 & 5,6 & 19,7 & 28,2 & 70 \\
\hline 15 & 1 & 82,1 & 82,8 & 1,6 & 76,7 & 108 & 5,4 & 5 & 25,8 & 33 & 66 \\
\hline 16 & 1 & 84,6 & 87,7 & 5,3 & 79,4 & 114,2 & 5,2 & 5,1 & 26,5 & 33,4 & 73,4 \\
\hline 17 & 1 & 84,6 & 87,9 & $-3,9$ & 82,8 & 117,3 & 1,8 & 1,3 & 18 & 17,3 & 64 \\
\hline 18 & 1 & 84,8 & 97,9 & $-1,4$ & 82,3 & 125,4 & 2,5 & 3,9 & 18,8 & 20,6 & 65,2 \\
\hline 19 & 1 & 85,6 & 91,5 & 2,6 & 80,8 & 115,8 & 4,8 & 4,1 & 21,4 & 26,1 & 68,3 \\
\hline 20 & 1 & 76,4 & 92,6 & 2,4 & 71,5 & 120,6 & 4,8 & 3,2 & 26,4 & 40,4 & 70,3 \\
\hline 21 & 1 & 80,4 & 87,5 & 2,1 & 74,1 & 106,4 & 6,3 & 2,5 & 24,1 & 33,4 & 61,5 \\
\hline 22 & 1 & 80 & 82,2 & $-3,2$ & 77,1 & 105,1 & 2,9 & 2,5 & 23,5 & 27,2 & 57,9 \\
\hline 23 & 1 & 82,9 & 88,3 & 1,7 & 77,1 & 107,3 & 5,8 & 1,7 & 23,5 & 30,5 & 61,5 \\
\hline 24 & 1 & 79,1 & 80,4 & $-5,6$ & 76,7 & 112,7 & 2,3 & 4,4 & 30,4 & 33,2 & 71,5 \\
\hline 25 & 1 & 77,7 & 84,2 & 2 & 75,2 & 111,9 & 2,5 & 3,5 & 19,6 & 31,3 & 66,2 \\
\hline 26 & 1 & 85,3 & 96,2 & 6,9 & 79,1 & 124,8 & 6,2 & 1,3 & 28,6 & 36,6 & 77,1 \\
\hline 27 & 1 & 80,7 & 84,9 & 0,1 & 74,5 & 109,7 & 6,2 & 2,4 & 35,8 & 43,1 & 68,9 \\
\hline 28 & 1 & 83,7 & 98,6 & 2,1 & 81 & 126,6 & 2,7 & 3,3 & 27 & 33,2 & 73,6 \\
\hline 29 & 1 & 83,7 & 90,4 & $-0,4$ & 77,9 & 114,3 & 5,8 & 2,5 & 28,2 & 30,7 & 74,7 \\
\hline 30 & 1 & 77,1 & 88,1 & $-1,7$ & 75,2 & 115,1 & 1,9 & 4,9 & 12,3 & 22,3 & 64 \\
\hline
\end{tabular}


TABELA A-18

\begin{tabular}{|c|c|c|c|c|c|c|c|c|c|c|c|}
\hline $\mathbf{N}$ & Grupo & SNA T3 & Co-A T3 & A-Nperp T3 & SNB T3 & CoGn T3 & ANB T3 & Wits T3 & FMA T3 & SN-GoGn T3 & AFAI T3 \\
\hline 31 & 2 & 77,9 & 83 & $-4,7$ & 76,3 & 110,9 & 1,6 & 4,2 & 30,7 & 35,4 & 64,1 \\
\hline 32 & 2 & 77,6 & 78,4 & $-4,8$ & 75,1 & 104,8 & 2,5 & 1,1 & 33,7 & 37,8 & 65,8 \\
\hline 33 & 2 & 85,9 & 93,8 & 4,8 & 82,6 & 116,8 & 3,3 & $-0,8$ & 16,1 & 23,7 & 61,8 \\
\hline 34 & 2 & 84,2 & 96,2 & $-1,6$ & 76,7 & 110,8 & 7,5 & 8,1 & 17,5 & 19,4 & 63,7 \\
\hline 35 & 2 & 80,4 & 86,9 & 4 & 76,4 & 113,3 & 4 & 1,5 & 24,8 & 36,1 & 69,6 \\
\hline 36 & 2 & 80,3 & 82,9 & 1,3 & 73 & 105,5 & 7,3 & 5,3 & 40,1 & 48,1 & 70,5 \\
\hline 37 & 2 & 77,4 & 73,7 & 1,3 & 68,3 & 97,4 & 9,1 & 8,9 & 33,9 & 45,8 & 66,1 \\
\hline 38 & 2 & 79,6 & 89,8 & 0,5 & 76,3 & 120,5 & 3,2 & $-0,6$ & 27,6 & 36,8 & 68,5 \\
\hline 39 & 2 & 73,2 & 82,5 & $-11,5$ & 74,8 & 120,6 & $-1,6$ & $-0,7$ & 30,8 & 33,7 & 76,2 \\
\hline 40 & 2 & 77,7 & 87,6 & $-2,3$ & 73,6 & 117,1 & 4,1 & 5,2 & 26,2 & 34 & 79,7 \\
\hline 41 & 2 & 78,2 & 82,2 & -3 & 75,9 & 117 & 2,3 & 0 & 38,7 & 45,4 & 77,5 \\
\hline 42 & 2 & 78,8 & 83,8 & 2,7 & 76,4 & 107,6 & 2,4 & 2,3 & 20 & 31,4 & 60,7 \\
\hline 43 & 2 & 84,2 & 95,5 & 1,7 & 84,5 & 119,2 & $-0,4$ & 1,2 & 13,3 & 18 & 55,7 \\
\hline 44 & 2 & 83,4 & 92,9 & 2 & 76,6 & 119,5 & 6,9 & 6,9 & 29,5 & 35,5 & 77,3 \\
\hline 45 & 2 & 72,9 & 88,6 & $-6,4$ & 72,1 & 119,2 & 0,8 & 1,4 & 25,3 & 32,8 & 71,6 \\
\hline 46 & 2 & 81 & 86,7 & 1,6 & 76,3 & 105,3 & 4,7 & 1,6 & 21,4 & 29,8 & 58 \\
\hline 47 & 2 & 80,7 & 84,2 & 1,6 & 78,1 & 102,9 & 2,6 & 1,6 & 12,8 & 22 & 55,2 \\
\hline 48 & 2 & 82,1 & 85,9 & $-3,2$ & 79,7 & 118 & 2,4 & $-0,6$ & 34,6 & 36,2 & 76,4 \\
\hline 49 & 2 & 79,4 & 90,5 & 0,3 & 78,8 & 126,1 & 0,6 & $-2,3$ & 17,7 & 26,6 & 73,1 \\
\hline 50 & 2 & 80,7 & 89,1 & 0,7 & 77,8 & 118,1 & 2,9 & 2,3 & 29,7 & 37,4 & 73,9 \\
\hline 51 & 2 & 75,2 & 85,2 & $-3,3$ & 71,9 & 106,9 & 3,3 & 2,6 & 22 & 32,2 & 64,1 \\
\hline 52 & 2 & 77,7 & 87,9 & 1,5 & 69,5 & 110,2 & 8,2 & 7,7 & 31 & 42,4 & 68,6 \\
\hline 53 & 2 & 73,7 & 84,6 & $-2,7$ & 71,5 & 117,4 & 2,2 & 2,8 & 25,8 & 37 & 68,4 \\
\hline 54 & 2 & 71,3 & 80,5 & $-5,4$ & 71,6 & 104,9 & $-0,2$ & 0,5 & 24 & 34,6 & 61 \\
\hline 55 & 2 & 78,7 & 79,2 & 0,1 & 72,1 & 105,9 & 6,5 & 6,7 & 29,2 & 37,8 & 66,2 \\
\hline 56 & 2 & 77,3 & 81 & $-0,9$ & 71,3 & 100,5 & 6,1 & 5,9 & 36,6 & 44,3 & 67,5 \\
\hline 57 & 2 & 76,8 & 78,1 & $-6,7$ & 72,5 & 105,6 & 4,3 & 0,7 & 33,5 & 36,4 & 70,2 \\
\hline 58 & 2 & 77,1 & 82,2 & 0,7 & 69,6 & 107,8 & 7,5 & 7,9 & 32,8 & 43,8 & 73,3 \\
\hline 59 & 2 & 83,2 & 86,9 & $-0,7$ & 76,1 & 118 & 7,1 & 9 & 35,9 & 40,4 & 75,9 \\
\hline 60 & 2 & 76,8 & 75,9 & $-3,4$ & 75,4 & 102,4 & 1,4 & $-3,4$ & 34,3 & 41,2 & 64,6 \\
\hline
\end{tabular}


TABELA A-19

\begin{tabular}{|c|c|c|c|c|c|c|c|c|c|c|c|}
\hline $\mathbf{N}$ & Grupo & $\begin{array}{c}\text { SN-GoGn } \\
\text { T3 }\end{array}$ & $\begin{array}{c}\text { AFAI } \\
\text { T3 }\end{array}$ & $\begin{array}{c}\text { 1,PP } \\
\text { T3 }\end{array}$ & $\begin{array}{c}\text { 1-ENAPerp } \\
\text { T3 }\end{array}$ & $\begin{array}{c}\text { 1-PP } \\
\text { T3 }\end{array}$ & $\begin{array}{c}\text { 6-PP } \\
\text { T3 }\end{array}$ & 6-ENAPerp T3 & IMPA T3 & Rel mol T3 & Rel can T3 \\
\hline 1 & 1 & 37,7 & 70 & 113,4 & $-1,6$ & 30,3 & 27,5 & $-24,5$ & 93,8 & 4,3 & $-1,1$ \\
\hline 2 & 1 & 19,5 & 63,7 & 123,3 & $-2,4$ & 26,2 & 24,4 & $-25,9$ & 110 & 4,3 & $-0,9$ \\
\hline 3 & 1 & 31,9 & 64 & 117 & $-5,1$ & 26,9 & 23,4 & $-26,2$ & 95,7 & 4,4 & 1,6 \\
\hline 4 & 1 & 39,2 & 76,4 & 101,3 & $-9,5$ & 33,2 & 28,5 & $-28,3$ & 83,4 & 6,8 & $-0,1$ \\
\hline 5 & 1 & 28,1 & 63,1 & 125,8 & $-0,5$ & 22,3 & 24,6 & $-22,6$ & 93,4 & 2,3 & $-1,1$ \\
\hline 6 & 1 & 17,7 & 54,5 & 115 & $-3,6$ & 22,7 & 19 & $-25,5$ & 103,5 & 4,6 & 0,4 \\
\hline 7 & 1 & 23,5 & 67,6 & 118,5 & -4 & 25,7 & 24,5 & $-25,8$ & 97,8 & 3 & $-4,4$ \\
\hline 8 & 1 & 36,8 & 63,5 & 110,7 & $-2,7$ & 29 & 23,7 & $-25,2$ & 101,3 & 4,4 & $-1,5$ \\
\hline 9 & 1 & 30,6 & 74,9 & 108 & $-5,6$ & 28,7 & 26,3 & $-24,6$ & 80,5 & 4,2 & 0,2 \\
\hline 10 & 1 & 25,2 & 65,6 & 112,5 & $-3,6$ & 26,5 & 24,7 & -24 & 92,5 & 4 & $-0,7$ \\
\hline 11 & 1 & 31,2 & 72,2 & 109,3 & -4 & 33,4 & 25,9 & $-24,1$ & 98,9 & 3,6 & 0 \\
\hline 12 & 1 & 31,8 & 72 & 98 & $-9,7$ & 30,6 & 26,3 & $-28,6$ & 91,1 & 4,5 & 0,7 \\
\hline 13 & 1 & 39,8 & 68,2 & 109,1 & $-3,4$ & 27 & 22,4 & $-24,1$ & 90,3 & 5,2 & -1 \\
\hline 14 & 1 & 28,2 & 70 & 111,9 & -6 & 28,4 & 26 & $-26,3$ & 92,1 & 4,8 & 0,1 \\
\hline 15 & 1 & 33 & 66 & 117,8 & $-1,6$ & 28 & 24 & $-24,6$ & 97,6 & 4,7 & 0,1 \\
\hline 16 & 1 & 33,4 & 73,4 & 112 & 0,2 & 34,4 & 30,3 & $-22,6$ & 94,7 & 4,1 & $-4,2$ \\
\hline 17 & 1 & 17,3 & 64 & 124,9 & $-0,7$ & 24,1 & 22,7 & $-25,2$ & 101,5 & 3,6 & $-1,1$ \\
\hline 18 & 1 & 20,6 & 65,2 & 125,4 & 0,1 & 24,4 & 24,5 & $-23,7$ & 98,6 & 3,8 & 0,5 \\
\hline 19 & 1 & 26,1 & 68,3 & 111,4 & 0,9 & 27,1 & 25,8 & $-20,1$ & 101,1 & 5,5 & $-1,2$ \\
\hline 20 & 1 & 40,4 & 70,3 & 116 & $-3,9$ & 29,1 & 25,2 & $-21,9$ & 85 & 4,4 & 0,5 \\
\hline 21 & 1 & 33,4 & 61,5 & 117,1 & $-2,3$ & 27,9 & 21,8 & $-25,3$ & 106,2 & 4 & $-1,3$ \\
\hline 22 & 1 & 27,2 & 57,9 & 113,5 & $-3,2$ & 24,1 & 21,4 & -24 & 92,8 & 4,3 & $-0,1$ \\
\hline 23 & 1 & 30,5 & 61,5 & 113,6 & 1,6 & 27,9 & 24,1 & $-19,2$ & 107,1 & 5,5 & 0,6 \\
\hline 24 & 1 & 33,2 & 71,5 & 107 & $-2,1$ & 30,6 & 28,2 & $-23,1$ & 87,6 & 5,9 & $-0,9$ \\
\hline 25 & 1 & 31,3 & 66,2 & 113,9 & $-1,2$ & 27,2 & 23,4 & $-22,5$ & 100,5 & 3,4 & $-1,2$ \\
\hline 26 & 1 & 36,6 & 77,1 & 106,7 & $-7,1$ & 33,8 & 26,6 & $-29,1$ & 88 & 4,8 & $-1,1$ \\
\hline 27 & 1 & 43,1 & 68,9 & 115,9 & $-3,2$ & 29,9 & 23,9 & $-22,7$ & 95,5 & 4,6 & $-0,7$ \\
\hline 28 & 1 & 33,2 & 73,6 & 123,6 & 1,2 & 28,1 & 27,9 & $-23,6$ & 90,6 & 2,6 & $-2,5$ \\
\hline 29 & 1 & 30,7 & 74,7 & 108,7 & $-5,2$ & 31,2 & 24,5 & $-26,9$ & 100,3 & 3,6 & $-1,4$ \\
\hline 30 & 1 & 22,3 & 64 & 99,8 & $-7,9$ & 29,2 & 24,1 & $-27,8$ & 99,8 & 3,2 & $-1,1$ \\
\hline
\end{tabular}


TABELA A-20

\begin{tabular}{|c|c|c|c|c|c|c|c|c|c|c|c|}
\hline $\mathbf{N}$ & Grupo & $\begin{array}{l}\text { SN-GoGn } \\
\text { T3 }\end{array}$ & $\begin{array}{c}\text { AFAl } \\
\text { T3 }\end{array}$ & $\begin{array}{c}\text { 1,PP } \\
\text { T3 }\end{array}$ & $\begin{array}{c}\text { 1-ENAPerp } \\
\text { T3 }\end{array}$ & $\begin{array}{c}\text { 1-PP } \\
\text { T3 }\end{array}$ & 6-PP T3 & 6-ENAPerp T3 & IMPA T3 & Rel mol T3 & Rel can T3 \\
\hline 31 & 2 & 35,4 & 64,1 & 111,2 & $-4,9$ & 26,7 & 26,3 & $-24,9$ & 89,6 & $-0,4$ & $-2,4$ \\
\hline 32 & 2 & 37,8 & 65,8 & 112,4 & $-5,7$ & 26,4 & 22,7 & $-25,9$ & 85,7 & $-1,9$ & $-0,6$ \\
\hline 33 & 2 & 23,7 & 61,8 & 108,7 & $-2,5$ & 27,8 & 22,9 & $-25,9$ & 102,4 & $-1,5$ & $-3,1$ \\
\hline 34 & 2 & 19,4 & 63,7 & 96,3 & $-5,3$ & 29,6 & 22,9 & $-27,9$ & 103,2 & 2 & 2,1 \\
\hline 35 & 2 & 36,1 & 69,6 & 118,1 & $-2,4$ & 31,9 & 25,6 & -26 & 99,8 & $-0,6$ & $-0,8$ \\
\hline 36 & 2 & 48,1 & 70,5 & 106,2 & $-5,8$ & 32,9 & 24,8 & $-26,5$ & 87,5 & $-0,1$ & $-0,1$ \\
\hline 37 & 2 & 45,8 & 66,1 & 102,1 & -3 & 28,6 & 25,1 & $-20,3$ & 92,8 & 1,1 & $-0,3$ \\
\hline 38 & 2 & 36,8 & 68,5 & 115,1 & 2,8 & 28,3 & 25,3 & $-18,8$ & 95,9 & 0 & 0 \\
\hline 39 & 2 & 33,7 & 76,2 & 112,9 & 2,1 & 32,9 & 28,4 & $-22,4$ & 90,5 & $-1,6$ & $-0,5$ \\
\hline 40 & 2 & 34 & 79,7 & 100,3 & $-9,4$ & 34,9 & 28,5 & $-29,3$ & 90,4 & 0,2 & 1,1 \\
\hline 41 & 2 & 45,4 & 77,5 & 116 & $-3,4$ & 31,9 & 27,6 & $-26,4$ & 77,7 & $-0,7$ & $-0,3$ \\
\hline 42 & 2 & 31,4 & 60,7 & 113,9 & 1,1 & 28,4 & 24,8 & $-21,4$ & 97,8 & $-0,2$ & $-2,1$ \\
\hline 43 & 2 & 18 & 55,7 & 109,6 & $-1,5$ & 25,7 & 25,6 & -23 & 84,8 & $-1,5$ & 0 \\
\hline 44 & 2 & 35,5 & 77,3 & 100,3 & $-11,5$ & 32,9 & 28,2 & $-31,2$ & 91,5 & $-0,2$ & $-0,2$ \\
\hline 45 & 2 & 32,8 & 71,6 & 108,8 & $-5,3$ & 31,2 & 27,2 & $-28,6$ & 90,1 & $-1,4$ & 0,5 \\
\hline 46 & 2 & 29,8 & 58 & 112,4 & $-2,7$ & 24,8 & 20,1 & $-24,3$ & 94,7 & $-0,5$ & 2,1 \\
\hline 47 & 2 & 22 & 55,2 & 110,7 & $-4,5$ & 24,2 & 20,8 & $-25,2$ & 101,2 & 0,7 & 0,7 \\
\hline 48 & 2 & 36,2 & 76,4 & 108,2 & $-4,7$ & 32,1 & 28 & $-25,8$ & 85,7 & $-0,9$ & $-0,2$ \\
\hline 49 & 2 & 26,6 & 73,1 & 108,8 & $-4,1$ & 30,9 & 27 & $-25,8$ & 94,9 & $-1,4$ & $-0,7$ \\
\hline 50 & 2 & 37,4 & 73,9 & 110,6 & $-0,9$ & 34,2 & 28,6 & $-25,3$ & 97,6 & 0 & 0,4 \\
\hline 51 & 2 & 32,2 & 64,1 & 107,2 & $-6,1$ & 28,2 & 22,9 & -25 & 97,7 & 0,7 & 2,1 \\
\hline 52 & 2 & 42,4 & 68,6 & 105,4 & $-8,3$ & 29 & 22,9 & $-30,4$ & 86,3 & $-0,3$ & 0,9 \\
\hline 53 & 2 & 37 & 68,4 & 122,9 & 0,5 & 25,1 & 24,7 & $-20,9$ & 92,8 & $-1,2$ & $-0,1$ \\
\hline 54 & 2 & 34,6 & 61 & 114,5 & 1 & 26,8 & 24 & $-19,3$ & 90,5 & $-1,4$ & 0 \\
\hline 55 & 2 & 37,8 & 66,2 & 117,2 & $-2,1$ & 27,2 & 23,6 & $-24,1$ & 88,5 & 1,7 & 2,3 \\
\hline 56 & 2 & 44,3 & 67,5 & 107,4 & $-5,2$ & 29,5 & 24,2 & $-25,6$ & 85,8 & 0,2 & 1 \\
\hline 57 & 2 & 36,4 & 70,2 & 96 & $-9,9$ & 31,6 & 25,4 & $-28,2$ & 86,9 & 0,5 & 0,5 \\
\hline 58 & 2 & 43,8 & 73,3 & 107 & $-8,5$ & 32 & 26,5 & $-31,9$ & 89,9 & 0,5 & 0,3 \\
\hline 59 & 2 & 40,4 & 75,9 & 100,5 & $-4,5$ & 31,3 & 26,6 & $-27,7$ & 84,9 & 1,4 & 2,7 \\
\hline 60 & 2 & 41,2 & 64,6 & 111,5 & $-2,5$ & 27,5 & 22,2 & $-23,1$ & 87,4 & $-1,4$ & $-0,6$ \\
\hline
\end{tabular}


TABELA 21

\begin{tabular}{|c|c|c|c|c|c|c|c|c|c|}
\hline $\mathbf{N}$ & Grupo & SNA T2-T1 & Co-A T2-T1 & A-Nperp T2-T1 & SNB T2-T1 & CoGn T2-T1 & ANB T2-T1 & Wits T2-T1 & FMA T2-T1 \\
\hline 1 & 1 & 0,3 & $-3,6$ & $-0,2$ & 2 & $-0,8$ & $-1,7$ & $-4,6$ & $-0,4$ \\
\hline 2 & 1 & $-4,3$ & $-0,5$ & $-3,7$ & $-0,5$ & 3,2 & $-3,8$ & $-3,9$ & $-2,8$ \\
\hline 3 & 1 & 1,5 & 1,6 & 1,3 & 1,9 & 4,6 & $-0,3$ & $-3,8$ & $-1,6$ \\
\hline 4 & 1 & $-1,6$ & 0,5 & $-1,6$ & 0,1 & 5,7 & $-1,6$ & $-7,3$ & 0,5 \\
\hline 5 & 1 & $-1,7$ & 1,4 & 0,7 & 0,1 & 6 & $-1,9$ & 0,7 & -2 \\
\hline 6 & 1 & $-1,5$ & $-0,2$ & $-2,6$ & 1,8 & 5,4 & $-3,3$ & -3 & $-2,1$ \\
\hline 7 & 1 & $-0,7$ & 4 & 0 & 0,1 & 10,9 & $-0,8$ & 1 & $-0,2$ \\
\hline 8 & 1 & -5 & $-3,6$ & $-6,4$ & $-1,9$ & 1,8 & -3 & -2 & 5,3 \\
\hline 9 & 1 & $-1,7$ & 1,8 & $-3,4$ & 1,4 & 5,3 & $-3,1$ & $-4,2$ & $-2,3$ \\
\hline 10 & 1 & $-1,7$ & $-2,1$ & $-3,7$ & 0,1 & 0,3 & $-1,8$ & -1 & 0,2 \\
\hline 11 & 1 & $-5,6$ & $-5,3$ & $-6,7$ & $-0,1$ & 0,9 & $-5,6$ & -5 & 3,1 \\
\hline 12 & 1 & $-3,4$ & 1,7 & $-4,6$ & $-1,3$ & 6,9 & $-2,3$ & $-0,1$ & 2,7 \\
\hline 13 & 1 & $-1,7$ & 1,4 & $-2,2$ & 0,7 & 8,2 & $-2,4$ & 0,9 & 1,8 \\
\hline 14 & 1 & $-3,3$ & 0 & $-6,8$ & 0,3 & 7,7 & $-3,6$ & $-0,2$ & 4,1 \\
\hline 15 & 1 & 0,6 & $-0,9$ & 0 & -1 & $-1,1$ & 1,6 & 2,1 & 2,9 \\
\hline 16 & 1 & -1 & $-0,6$ & $-0,6$ & 0,9 & 0,7 & $-1,9$ & -2 & $-2,8$ \\
\hline 17 & 1 & $-2,1$ & $-0,9$ & $-3,4$ & 1,7 & 5,3 & $-3,7$ & $-2,3$ & -3 \\
\hline 18 & 1 & $-1,9$ & $-2,1$ & $-5,4$ & 1,2 & 6,7 & $-3,2$ & $-2,2$ & -3 \\
\hline 19 & 1 & $-0,5$ & 3,6 & $-2,4$ & 1,6 & 8,7 & -2 & $-0,5$ & 3,5 \\
\hline 20 & 1 & $-1,1$ & $-0,1$ & $-3,7$ & $-0,7$ & -1 & $-0,4$ & -2 & 1,6 \\
\hline 21 & 1 & 1,2 & 0,9 & 1,5 & 0,1 & $-1,1$ & 1,1 & $-0,6$ & 0,3 \\
\hline 22 & 1 & $-0,4$ & $-0,7$ & 0,3 & $-0,6$ & 1,7 & 0,2 & 1,5 & $-0,9$ \\
\hline 23 & 1 & $-3,9$ & $-3,9$ & $-3,1$ & $-0,5$ & 0,7 & $-3,5$ & -2 & 2,1 \\
\hline 24 & 1 & 0,1 & $-2,6$ & $-0,5$ & 0,7 & $-1,4$ & $-0,5$ & $-3,2$ & $-0,4$ \\
\hline 25 & 1 & $-0,2$ & 2 & $-2,6$ & 1,2 & 6,7 & $-1,4$ & $-1,3$ & 2,3 \\
\hline 26 & 1 & $-2,8$ & 4,4 & $-2,5$ & $-0,5$ & 9,6 & $-2,3$ & $-2,5$ & 3,2 \\
\hline 27 & 1 & $-1,2$ & $-2,5$ & $-1,8$ & 1,4 & 6,5 & $-2,5$ & $-1,5$ & 1,2 \\
\hline 28 & 1 & $-1,8$ & 0,4 & $-1,4$ & 0,6 & 8,3 & $-2,5$ & -1 & 1 \\
\hline 29 & 1 & $-3,7$ & 0,4 & $-4,1$ & $-0,3$ & 5,5 & $-3,4$ & $-5,9$ & 1,6 \\
\hline 30 & 1 & $-5,3$ & $-2,1$ & $-5,6$ & $-0,2$ & 4,6 & $-5,1$ & $-5,3$ & 1,8 \\
\hline
\end{tabular}


TABELA A-22

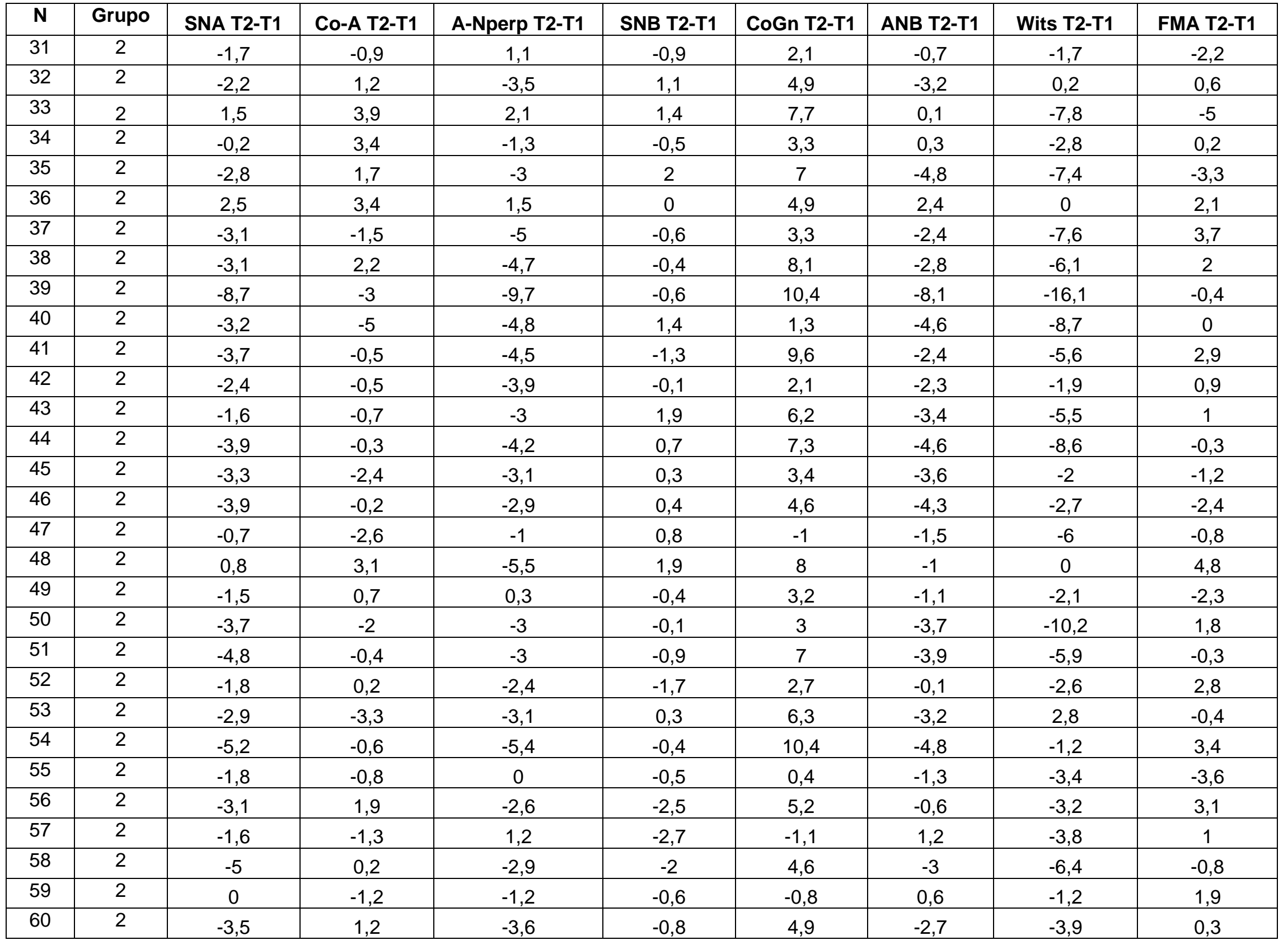


TABELA A-23

\begin{tabular}{|c|c|c|c|c|c|c|c|c|}
\hline $\mathbf{N}$ & Grupo & SN-GoGn T2-T1 & AFAI T2-T1 & 1,PP T2-T1 & 1-ENAPerp T2-T1 & 1-PP T2-T1 & 6-PP T2-T1 & 6-ENAPerp T2-T1 \\
\hline 1 & 1 & $-0,7$ & 0,1 & $-14,9$ & $-4,2$ & 0,3 & 0,7 & 4,9 \\
\hline 2 & 1 & $-2,3$ & 0,4 & 18,2 & 1 & $-3,8$ & 1,5 & 3,6 \\
\hline 3 & 1 & $-2,1$ & 0,2 & 0,1 & $-0,7$ & $-1,2$ & $-0,8$ & 3,4 \\
\hline 4 & 1 & 0,9 & 3,5 & $-17,6$ & $-3,5$ & 2,4 & 0,6 & 6,1 \\
\hline 5 & 1 & 0,4 & 0,5 & 12,2 & 1,4 & $-2,6$ & 0,8 & 1,8 \\
\hline 6 & 1 & $-2,6$ & 1,4 & $-2,2$ & $-0,9$ & $-0,9$ & 1,6 & 1,3 \\
\hline 7 & 1 & 1,4 & 7,8 & 14,9 & $-1,5$ & $-1,6$ & 2,8 & 0,5 \\
\hline 8 & 1 & 3,7 & 5,4 & 8,4 & 2,7 & 0,8 & 2,5 & 3,4 \\
\hline 9 & 1 & $-4,1$ & 2,4 & 1,8 & 0,9 & 0 & $-0,3$ & 3,2 \\
\hline 10 & 1 & $-1,5$ & 0,2 & 1,2 & -1 & -3 & $-0,1$ & 4,5 \\
\hline 11 & 1 & 1,9 & 4,1 & $-0,4$ & $-1,5$ & $-0,4$ & 2,8 & 2 \\
\hline 12 & 1 & 1,7 & 4,3 & 6,9 & 0,3 & $-1,8$ & 1,1 & $-0,3$ \\
\hline 13 & 1 & 0 & 6,3 & 15 & 0,3 & $-1,8$ & 3,7 & 2,2 \\
\hline 14 & 1 & 0,5 & 4,6 & 3,6 & $-2,4$ & $-3,1$ & 2,6 & 3,6 \\
\hline 15 & 1 & 2,2 & 3,6 & $-3,9$ & $-0,8$ & $-1,3$ & 1,7 & 3,2 \\
\hline 16 & 1 & $-1,8$ & 0,1 & 4,5 & 4 & 0,1 & $-0,3$ & 2,9 \\
\hline 17 & 1 & -4 & 0,8 & 13,8 & 2 & -3 & 0,5 & 4,8 \\
\hline 18 & 1 & $-6,3$ & 2,4 & 9,3 & $-2,3$ & $-2,6$ & 0,4 & $-1,2$ \\
\hline 19 & 1 & 0,5 & 4,1 & 1,9 & $-2,3$ & $-0,4$ & 1,9 & 4,5 \\
\hline 20 & 1 & $-0,2$ & $-0,5$ & $-8,9$ & -6 & 0,9 & $-0,8$ & 0,1 \\
\hline 21 & 1 & 0,7 & $-0,1$ & $-7,3$ & $-9,8$ & $-1,5$ & 0,5 & $-0,2$ \\
\hline 22 & 1 & $-0,2$ & 2,7 & $-4,7$ & $-5,5$ & $-0,2$ & 2,5 & 2,6 \\
\hline 23 & 1 & 2,9 & 1,9 & 5,7 & $-0,9$ & 0,1 & 1,7 & 4 \\
\hline 24 & 1 & $-0,6$ & 0,7 & $-10,8$ & $-4,1$ & 0 & $-0,8$ & 2,6 \\
\hline 25 & 1 & $-0,9$ & 7,4 & $-2,1$ & $-2,2$ & 1 & 3,8 & 1,1 \\
\hline 26 & 1 & 3,5 & 9,3 & 3,9 & $-3,2$ & 1,3 & 4,1 & 2,5 \\
\hline 27 & 1 & $-1,2$ & 4,2 & $-2,5$ & $-5,4$ & $-1,3$ & 1,7 & 3 \\
\hline 28 & 1 & 1,3 & 4,6 & 5,5 & $-1,8$ & $-2,1$ & 2,8 & 4,7 \\
\hline 29 & 1 & 0,6 & 2,1 & $-7,6$ & $-5,5$ & 2,2 & 1,7 & 5,1 \\
\hline 30 & 1 & $-0,1$ & 5,3 & $-15,5$ & $-4,6$ & $-0,4$ & 3,4 & 5 \\
\hline
\end{tabular}


TABELA A-24

\begin{tabular}{|c|c|c|c|c|c|c|c|c|}
\hline $\mathbf{N}$ & Grupo & SN-GoGn T2-T1 & AFAI T2-T1 & 1,PP T2-T1 & 1-ENAPerp T2-T1 & 1-PP T2-T1 & 6-PP T2-T1 & 6-ENAPerp T2-T1 \\
\hline 31 & 2 & 0,1 & $-0,9$ & $-10,5$ & $-2,7$ & $-0,3$ & $-0,2$ & 3,3 \\
\hline 32 & 2 & $-2,2$ & 2,3 & 3,1 & -1 & 0,2 & 3 & $-2,2$ \\
\hline 33 & 2 & $-3,1$ & 5,1 & $-8,9$ & $-3,5$ & 4,7 & $-0,5$ & 1,4 \\
\hline 34 & 2 & $-1,8$ & 0,5 & $-18,8$ & $-4,4$ & 1 & $-1,9$ & $-1,1$ \\
\hline 35 & 2 & $-3,7$ & $-0,3$ & $-10,5$ & $-5,1$ & 0,9 & 2,4 & 2,5 \\
\hline 36 & 2 & 0,9 & 5,6 & $-29,2$ & $-9,4$ & 2,3 & 2,4 & $-2,1$ \\
\hline 37 & 2 & 2,1 & 5,7 & $-17,1$ & $-6,8$ & 3,2 & 2,7 & 0,6 \\
\hline 38 & 2 & 1 & 4,7 & $-6,5$ & $-3,1$ & 2,3 & 1,4 & -2 \\
\hline 39 & 2 & -1 & 3,2 & $-7,5$ & $-10,7$ & 0,9 & 0,3 & $-0,4$ \\
\hline 40 & 2 & $-2,3$ & 1,8 & $-12,2$ & $-4,7$ & 1,4 & $-0,7$ & 2,7 \\
\hline 41 & 2 & 2,7 & 7,2 & 2 & $-0,2$ & 1,7 & 1,5 & 2,5 \\
\hline 42 & 2 & $-1,5$ & 1,8 & $-3,9$ & $-1,3$ & $-1,2$ & $-0,7$ & $-0,5$ \\
\hline 43 & 2 & $-1,5$ & 3,7 & $-23,9$ & $-10,6$ & 2,6 & 2,1 & 1,4 \\
\hline 44 & 2 & $-0,2$ & 4,3 & $-27,4$ & $-9,8$ & 5,3 & 2,5 & 1,7 \\
\hline 45 & 2 & $-0,1$ & 4,4 & $-1,4$ & $-3,1$ & 0,8 & 3,8 & 1,8 \\
\hline 46 & 2 & $-0,8$ & $-1,5$ & $-0,7$ & $-4,6$ & $-3,9$ & $-1,6$ & $-0,9$ \\
\hline 47 & 2 & $-0,6$ & $-2,4$ & $-19,1$ & $-7,7$ & 0 & $-2,8$ & 3,2 \\
\hline 48 & 2 & $-1,1$ & 1,7 & $-5,3$ & $-4,6$ & 0,9 & 3,5 & 0,9 \\
\hline 49 & 2 & 0,3 & 0,8 & $-1,3$ & $-0,5$ & 1,9 & 1,9 & 0 \\
\hline 50 & 2 & 2,6 & 3,5 & $-17,9$ & $-8,4$ & 5,6 & 2,3 & 2,7 \\
\hline 51 & 2 & 1,4 & 2,7 & $-12,5$ & $-6,8$ & 1,3 & 1,2 & 3 \\
\hline 52 & 2 & 2,6 & 4,8 & $-8,7$ & $-7,8$ & 2,5 & $-1,1$ & $-2,3$ \\
\hline 53 & 2 & $-0,4$ & 3,9 & 17,8 & 3,8 & 0 & 4 & 4 \\
\hline 54 & 2 & 3,7 & 5,7 & $-14,4$ & $-9,1$ & $-0,2$ & 4,4 & $-4,6$ \\
\hline 55 & 2 & $-2,5$ & 1,4 & $-14,5$ & $-7,1$ & 1,9 & 2,9 & 2,5 \\
\hline 56 & 2 & 2,1 & 3 & $-13,9$ & $-5,9$ & 1,8 & 1,1 & 2,6 \\
\hline 57 & 2 & 3,7 & 4,3 & $-18,9$ & -9 & 2,3 & 1,5 & 1,5 \\
\hline 58 & 2 & 1,5 & 0,8 & $-4,3$ & $-6,5$ & 1 & 0,6 & 1,1 \\
\hline 59 & 2 & 0,3 & 2 & $-15,3$ & $-7,8$ & 2,6 & 1,1 & $-1,2$ \\
\hline 60 & 2 & $-0,4$ & 4,7 & 5,6 & 1,1 & 3,2 & 2,5 & 0,2 \\
\hline
\end{tabular}


TABELA A-25

\begin{tabular}{|c|c|c|c|c|c|c|c|c|}
\hline $\mathbf{N}$ & Grupo & IMPA T2-T1 & 1,NB T2-T1 & 1-NB T2-T1 & 1-PogPerp T2-T1 & 1-GoMe T2-T1 & 6-PogPerp T2-T1 & 6-GoMe T2-T1 \\
\hline 1 & 1 & $-1,7$ & $-0,6$ & $-1,4$ & 0,6 & $-2,7$ & 1,5 & 1,1 \\
\hline 2 & 1 & 16,6 & 14 & 1,3 & 0,9 & $-2,5$ & $-1,6$ & 2,6 \\
\hline 3 & 1 & 1,2 & 1,4 & 1,1 & 2,2 & $-1,6$ & 0,5 & 2,3 \\
\hline 4 & 1 & -3 & $-2,4$ & $-0,6$ & $-2,1$ & 0,7 & $-1,6$ & 3,2 \\
\hline 5 & 1 & $-2,9$ & $-2,4$ & 0,2 & $-2,2$ & 2,2 & $-0,9$ & 1,2 \\
\hline 6 & 1 & 1,1 & $-0,4$ & $-0,5$ & $-0,3$ & $-0,5$ & $-3,4$ & 1,4 \\
\hline 7 & 1 & 0,2 & 1,3 & 1,8 & $-2,8$ & 4,3 & $-1,8$ & 5,1 \\
\hline 8 & 1 & 5,8 & 7,5 & 1,5 & $-0,1$ & 1,9 & $-0,4$ & 2,2 \\
\hline 9 & 1 & 0,2 & $-2,4$ & 0,2 & $-1,1$ & 1,7 & $-1,1$ & 4,1 \\
\hline 10 & 1 & 6,2 & 4,4 & 1,2 & 0,6 & $-1,2$ & 1,2 & 1,7 \\
\hline 11 & 1 & 2,2 & 3,6 & 2,1 & $-0,6$ & 2 & $-0,9$ & 2,5 \\
\hline 12 & 1 & 1,2 & 1,5 & 0,5 & $-0,2$ & 2,7 & $-1,3$ & 2,6 \\
\hline 13 & 1 & -3 & $-0,9$ & 1,1 & $-1,2$ & 4 & 0,2 & 3,6 \\
\hline 14 & 1 & $-5,8$ & $-4,7$ & $-0,5$ & $-2,1$ & 3,8 & $-1,3$ & 2,9 \\
\hline 15 & 1 & 10,6 & 11,7 & 2,3 & 2,6 & 2,1 & 1,5 & 2,8 \\
\hline 16 & 1 & 4,7 & 3,2 & 1,5 & 2,7 & 1,2 & 0,6 & 0,7 \\
\hline 17 & 1 & 1,6 & -1 & 1,1 & 4,5 & $-0,8$ & 3,4 & 2,2 \\
\hline 18 & 1 & $-6,3$ & $-11,2$ & $-1,5$ & $-2,6$ & 1,1 & -4 & 3,9 \\
\hline 19 & 1 & $-3,1$ & $-0,7$ & 0,5 & $-1,8$ & 3,1 & 0,9 & 3,2 \\
\hline 20 & 1 & $-5,1$ & $-6,5$ & $-0,6$ & $-2,3$ & 2,4 & $-1,1$ & 2,7 \\
\hline 21 & 1 & 7 & 7,8 & 0,3 & $-0,2$ & $-3,5$ & 1 & 0 \\
\hline 22 & 1 & 2 & 1,7 & 1 & 0,2 & $-0,1$ & 0,6 & 1,5 \\
\hline 23 & 1 & $-5,6$ & $-3,4$ & $-0,5$ & $-0,4$ & 0,3 & 1,5 & $-0,1$ \\
\hline 24 & 1 & 0,7 & 0,3 & 1,3 & 3,1 & 0,8 & 1 & 1,9 \\
\hline 25 & 1 & 7 & 7,7 & 4,6 & 1,1 & 5,6 & $-1,3$ & 4,8 \\
\hline 26 & 1 & 2,6 & 5 & 2,3 & $-0,1$ & 5,2 & $-0,6$ & 6 \\
\hline 27 & 1 & $-2,1$ & $-0,3$ & 0,2 & 0,1 & 2,5 & -1 & 1,6 \\
\hline 28 & 1 & $-11,1$ & -9 & $-0,3$ & $-0,9$ & 2,4 & 0,6 & 2,7 \\
\hline 29 & 1 & $-2,2$ & $-1,4$ & $-0,8$ & $-1,4$ & 2,9 & $-0,3$ & 3,2 \\
\hline 30 & 1 & 7,2 & 8 & 1,1 & 0,8 & 1,2 & $-0,4$ & 4 \\
\hline
\end{tabular}




\section{TABELA A-26}

\begin{tabular}{|c|c|c|c|c|c|c|c|c|}
\hline $\mathbf{N}$ & Grupo & IMPA T2-T1 & 1,NB T2-T1 & 1-NB T2-T1 & 1-PogPerp T2-T1 & 1-GoMe T2-T1 & 6-PogPerp T2-T1 & 6-GoMe T2-T1 \\
\hline 31 & 2 & -2 & $-2,3$ & -1 & $-0,8$ & $-0,6$ & 5,1 & 1,7 \\
\hline 32 & 2 & 0,7 & 1,1 & $-1,7$ & $-2,9$ & $-0,2$ & $-0,3$ & $-0,5$ \\
\hline 33 & 2 & 5,9 & 2,7 & $-0,8$ & 0,7 & $-0,6$ & 4,4 & 7,9 \\
\hline 34 & 2 & 0 & $-1,6$ & $-0,5$ & 0,2 & $-0,3$ & 1,7 & 2,5 \\
\hline 35 & 2 & 0,6 & $-1,1$ & $-2,3$ & $-1,7$ & $-1,4$ & 1,3 & 2,1 \\
\hline 36 & 2 & 7,4 & 8,6 & 0,8 & 0,6 & $-0,9$ & 3,1 & 2,2 \\
\hline 37 & 2 & 2,8 & 3,7 & $-0,9$ & 0,3 & $-0,4$ & 2,1 & 4,9 \\
\hline 38 & 2 & 3,5 & 3,7 & 0,9 & 0,3 & $-0,3$ & 1,2 & 3,4 \\
\hline 39 & 2 & $-10,2$ & $-11,1$ & $-7,6$ & $-7,6$ & -6 & $-4,9$ & 3,4 \\
\hline 40 & 2 & $-3,1$ & $-3,1$ & $-1,1$ & -1 & 0,7 & 2,3 & 3,5 \\
\hline 41 & 2 & 2,7 & 3,9 & 1,4 & -3 & 1,2 & $-1,8$ & 6 \\
\hline 42 & 2 & $-3,9$ & $-4,7$ & $-1,8$ & $-2,8$ & 1,4 & 0,6 & 3,3 \\
\hline 43 & 2 & $-8,5$ & $-7,5$ & $-3,7$ & $-5,6$ & -3 & 0 & 2,1 \\
\hline 44 & 2 & $-0,3$ & $-0,2$ & $-1,9$ & $-1,1$ & 0,2 & 2 & 3,8 \\
\hline 45 & 2 & $-2,5$ & -3 & $-2,6$ & -4 & 0,3 & 2,1 & 2,9 \\
\hline 46 & 2 & $-16,7$ & $-18,1$ & $-5,8$ & $-5,2$ & $-1,9$ & 0 & 0,1 \\
\hline 47 & 2 & 3,2 & 2,9 & -2 & $-1,1$ & $-4,7$ & 2,3 & 1,1 \\
\hline 48 & 2 & $-6,8$ & $-6,4$ & $-2,5$ & $-7,1$ & 0,6 & -2 & 0,7 \\
\hline 49 & 2 & 7,6 & 6,8 & $-0,5$ & 0,2 & -2 & 3,2 & 0,9 \\
\hline 50 & 2 & 3,3 & 5,4 & 1,7 & 1,2 & $-2,6$ & 1,1 & 2,1 \\
\hline 51 & 2 & $-6,4$ & $-5,8$ & $-2,5$ & $-4,1$ & $-2,3$ & 1,7 & 2,1 \\
\hline 52 & 2 & $-9,4$ & $-9,1$ & 0 & $-1,2$ & 2,8 & 3,1 & 5,7 \\
\hline 53 & 2 & $-4,1$ & $-3,9$ & $-0,5$ & $-4,4$ & 1,5 & 3,1 & 1,1 \\
\hline 54 & 2 & $-14,8$ & $-11,6$ & $-2,9$ & $-8,3$ & 0,7 & $-4,1$ & 0,9 \\
\hline 55 & 2 & 1,1 & -1 & 0,2 & 0,8 & $-0,5$ & 2,4 & 3,1 \\
\hline 56 & 2 & 2,1 & 2,9 & 1,5 & $-0,3$ & 1,5 & 3 & 3,7 \\
\hline 57 & 2 & 3,6 & 5 & 0,1 & $-1,1$ & $-1,4$ & 2,7 & 3,6 \\
\hline 58 & 2 & $-1,9$ & $-2,3$ & $-2,7$ & -2 & $-1,4$ & 1,9 & 2,6 \\
\hline 59 & 2 & 6,4 & 6,5 & $-1,2$ & 0,4 & $-0,8$ & 5,8 & 2,3 \\
\hline 60 & 2 & 9,9 & 8,7 & 1,4 & 0 & 1 & 3,3 & 3,9 \\
\hline
\end{tabular}


TABELA A-27

\begin{tabular}{|c|c|c|c|c|c|}
\hline $\mathbf{N}$ & Grupo & T hor T2-T1 & T Vert T2-T1 & Rel mol T2-T1 & Rel can T2-T1 \\
\hline 1 & 1 & $-5,3$ & $-2,5$ & 0,9 & $-5,5$ \\
\hline 2 & 1 & $-5,5$ & $-7,8$ & 0,3 & $-7,1$ \\
\hline 3 & 1 & $-3,3$ & $-3,9$ & 1,1 & $-4,3$ \\
\hline 4 & 1 & $-6,9$ & $-0,1$ & 1 & -7 \\
\hline 5 & 1 & 0,1 & $-1,3$ & $-0,3$ & $-7,1$ \\
\hline 6 & 1 & $-4,6$ & -4 & 0,8 & $-4,5$ \\
\hline 7 & 1 & $-2,1$ & $-4,9$ & 0,5 & $-5,3$ \\
\hline 8 & 1 & $-1,8$ & $-3,3$ & 0,5 & $-5,1$ \\
\hline 9 & 1 & $-1,5$ & $-1,1$ & 0,4 & $-7,5$ \\
\hline 10 & 1 & $-3,7$ & $-4,5$ & 1 & $-6,6$ \\
\hline 11 & 1 & $-3,9$ & $-3,8$ & 0,7 & $-9,5$ \\
\hline 12 & 1 & $-1,7$ & $-3,6$ & $-0,4$ & $-5,6$ \\
\hline 13 & 1 & $-1,4$ & $-4,1$ & 0,9 & $-5,7$ \\
\hline 14 & 1 & $-5,7$ & $-2,8$ & 0,2 & $-10,4$ \\
\hline 15 & 1 & $-4,1$ & $-3,1$ & 0,6 & $-7,7$ \\
\hline 16 & 1 & $-1,1$ & 0,4 & $-0,1$ & $-4,3$ \\
\hline 17 & 1 & $-2,7$ & $-5,5$ & 0,5 & $-4,6$ \\
\hline 18 & 1 & $-2,5$ & $-3,1$ & $-0,8$ & -7 \\
\hline 19 & 1 & -4 & $-1,3$ & 0,6 & $-4,3$ \\
\hline 20 & 1 & $-3,5$ & 4,9 & 1 & $-3,1$ \\
\hline 21 & 1 & $-8,5$ & $-4,3$ & $-0,7$ & $-4,1$ \\
\hline 22 & 1 & $-6,2$ & $-4,2$ & 0,4 & $-6,1$ \\
\hline 23 & 1 & $-2,8$ & $-2,1$ & 0,1 & $-5,7$ \\
\hline 24 & 1 & $-6,3$ & 0,3 & 1 & $-5,7$ \\
\hline 25 & 1 & $-7,4$ & $-2,4$ & $-1,5$ & $-5,9$ \\
\hline 26 & 1 & $-5,1$ & $-2,9$ & 1 & $-6,1$ \\
\hline 27 & 1 & $-7,2$ & $-3,9$ & 1,2 & -5 \\
\hline 28 & 1 & $-4,5$ & $-4,7$ & 0,7 & $-6,6$ \\
\hline 29 & 1 & $-5,5$ & 2,8 & 1,8 & $-6,2$ \\
\hline 30 & 1 & $-11,1$ & $-5,1$ & $-0,2$ & -7 \\
\hline
\end{tabular}


TABELA A-28

\begin{tabular}{|c|c|c|c|c|c|}
\hline $\mathbf{N}$ & Grupo & T hor T2-T1 & T Vert T2-T1 & Rel mol T2-T1 & Rel can T2-T1 \\
\hline 31 & 2 & -4 & 0,3 & $-5,2$ & -6 \\
\hline 32 & 2 & $-1,9$ & $-1,3$ & $-4,2$ & $-5,1$ \\
\hline 33 & 2 & $-1,9$ & $-0,2$ & $-3,5$ & $-3,5$ \\
\hline 34 & 2 & $-4,9$ & 0,3 & $-4,3$ & $-6,7$ \\
\hline 35 & 2 & $-7,1$ & $-0,2$ & $-5,3$ & $-5,4$ \\
\hline 36 & 2 & -7 & $-2,4$ & $-4,2$ & $-7,1$ \\
\hline 37 & 2 & $-6,3$ & $-3,1$ & $-3,5$ & $-4,7$ \\
\hline 38 & 2 & $-3,9$ & $-2,5$ & $-5,1$ & -5 \\
\hline 39 & 2 & $-8,4$ & $-4,4$ & $-5,2$ & $-5,2$ \\
\hline 40 & 2 & $-6,5$ & 0,6 & $-4,7$ & $-4,8$ \\
\hline 41 & 2 & $-3,5$ & $-3,9$ & $-4,5$ & $-6,3$ \\
\hline 42 & 2 & -2 & $-0,6$ & $-4,8$ & $-4,8$ \\
\hline 43 & 2 & $-7,9$ & $-2,7$ & $-2,4$ & $-6,3$ \\
\hline 44 & 2 & $-11,3$ & 1 & $-5,6$ & $-3,9$ \\
\hline 45 & 2 & $-3,3$ & $-2,8$ & $-4,3$ & $-6,6$ \\
\hline 46 & 2 & $-2,6$ & $-2,5$ & $-3,7$ & $-5,5$ \\
\hline 47 & 2 & $-7,2$ & $-2,6$ & $-1,7$ & $-2,3$ \\
\hline 48 & 2 & $-4,7$ & 1,6 & $-3,2$ & $-3,5$ \\
\hline 49 & 2 & $-1,3$ & $-1,2$ & -5 & -5 \\
\hline 50 & 2 & $-7,7$ & $-1,1$ & -3 & $-5,8$ \\
\hline 51 & 2 & $-6,1$ & $-3,2$ & $-3,9$ & $-6,1$ \\
\hline 52 & 2 & $-3,6$ & 1,6 & -5 & $-4,5$ \\
\hline 53 & 2 & $-0,6$ & $-1,8$ & $-6,6$ & $-4,8$ \\
\hline 54 & 2 & $-9,2$ & $-4,7$ & -7 & $-7,4$ \\
\hline 55 & 2 & $-7,4$ & $-0,7$ & $-1,7$ & $-3,2$ \\
\hline 56 & 2 & $-7,4$ & 0,3 & $-2,4$ & $-3,1$ \\
\hline 57 & 2 & $-5,7$ & $-2,5$ & $-2,4$ & $-2,3$ \\
\hline 58 & 2 & $-4,8$ & $-0,6$ & $-4,1$ & $-4,4$ \\
\hline 59 & 2 & -5 & 0,4 & $-5,7$ & $-5,6$ \\
\hline 60 & 2 & 0 & $-0,9$ & -5 & $-4,8$ \\
\hline
\end{tabular}


TABELA A-29

\begin{tabular}{|c|c|c|c|c|c|c|c|c|c|}
\hline $\mathbf{N}$ & Grupo & SNA T3-T2 & Co-A T3-T2 & A-Nperp T3-T2 & SNB T3-T2 & CoGn T3-T2 & ANB T3-T2 & Wits T3-T2 & FMA T3-T2 \\
\hline 1 & 1 & 3,8 & 4,7 & 3,9 & $-1,4$ & $-2,7$ & 5,2 & 6,1 & $-1,4$ \\
\hline 2 & 1 & 0,5 & $-0,9$ & $-2,8$ & 0,7 & $-1,9$ & $-0,2$ & 0,7 & 0,7 \\
\hline 3 & 1 & $-0,6$ & 0,8 & 0,3 & $-0,7$ & 1 & 0 & 0,4 & $-1,6$ \\
\hline 4 & 1 & 0 & $-2,2$ & 2,8 & $-0,6$ & $-1,7$ & 0,5 & 1,5 & $-1,9$ \\
\hline 5 & 1 & 1,2 & 4,9 & 0,2 & 2,6 & 9,5 & $-1,3$ & 1,3 & $-5,4$ \\
\hline 6 & 1 & 3,3 & -3 & $-1,4$ & 3,5 & $-2,8$ & $-0,1$ & $-0,3$ & $-1,6$ \\
\hline 7 & 1 & 3,3 & 3,3 & 2,2 & 3 & 3,9 & 0,3 & $-0,2$ & $-3,1$ \\
\hline 8 & 1 & 5,4 & 6,1 & 7,3 & 0,3 & 1,8 & 5 & 4,9 & $-4,1$ \\
\hline 9 & 1 & 4,6 & 6,8 & 3,6 & 1 & 4,3 & 3,7 & 7,1 & $-2,6$ \\
\hline 10 & 1 & 1 & $-0,6$ & 1 & 1 & $-0,5$ & 0 & $-1,1$ & $-0,2$ \\
\hline 11 & 1 & 7,1 & 3,5 & 4 & 2,9 & $-1,5$ & 4,3 & 3,1 & $-2,9$ \\
\hline 12 & 1 & 1,2 & 1,9 & 3,4 & 0,9 & 6,7 & 0,4 & 0,6 & $-6,3$ \\
\hline 13 & 1 & 1,6 & 2,7 & 0,7 & 2,1 & 7,7 & $-0,4$ & $-1,4$ & -2 \\
\hline 15 & 1 & 3,3 & 0,8 & 3 & 0,2 & 1,3 & 3,1 & 1,3 & $-0,4$ \\
\hline 16 & 1 & 1,9 & 3,2 & 4,6 & $-0,7$ & 1,7 & 2,6 & 4,3 & $-1,8$ \\
\hline 17 & 1 & 3 & 0 & -3 & 3 & $-1,7$ & 0 & $-0,9$ & 2 \\
\hline 18 & 1 & 2,7 & 6,2 & 3,5 & 1,9 & 3,9 & 0,8 & 1,2 & $-1,3$ \\
\hline 19 & 1 & $-0,5$ & 1 & $-1,2$ & 1,3 & 4,5 & $-1,9$ & -2 & $-5,5$ \\
\hline 20 & 1 & 0,4 & 1,4 & 2,6 & 0,1 & 0,7 & 0,2 & $-0,3$ & $-1,3$ \\
\hline 21 & 1 & 0,1 & -1 & 1,5 & 0,2 & 1,9 & $-0,1$ & $-3,6$ & -3 \\
\hline 22 & 1 & 1,4 & 1,6 & 5,2 & 0,4 & 3,1 & 1,1 & $-2,1$ & $-3,7$ \\
\hline 23 & 1 & 1,3 & 0,2 & 0,9 & 0,6 & $-2,5$ & 0,8 & $-4,4$ & $-0,6$ \\
\hline 24 & 1 & 0,5 & $-1,6$ & $-1,6$ & $-1,9$ & 0,6 & 2,3 & 3,1 & 7,1 \\
\hline 25 & 1 & $-0,9$ & 3,4 & 7,2 & $-1,9$ & 6,6 & 1 & 1,6 & $-8,8$ \\
\hline 26 & 1 & 1,3 & 3,4 & 1,8 & 0,8 & 4,1 & 0,5 & 0,9 & $-1,8$ \\
\hline 27 & 1 & 0,5 & 3,5 & 4,2 & -1 & 0,6 & 1,4 & $-0,9$ & $-0,4$ \\
\hline 30 & 1 & 3,3 & 2,9 & 6,9 & 0,9 & 3 & 2,4 & 1,5 & $-5,6$ \\
\hline
\end{tabular}


TABELA A-30

\begin{tabular}{|c|c|c|c|c|c|c|c|c|c|}
\hline $\mathbf{N}$ & Grupo & SNA T3-T2 & Co-A T3-T2 & A-Nperp T3-T2 & SNB T3-T2 & CoGn T3-T2 & ANB T3-T2 & Wits T3-T2 & FMA T3-T2 \\
\hline 31 & 2 & $-4,7$ & $-3,1$ & -6 & 2,6 & 6,5 & $-7,3$ & 0,1 & $-4,6$ \\
\hline 32 & 2 & 2,2 & $-1,6$ & $-0,6$ & 1,6 & $-1,8$ & 0,5 & -1 & -1 \\
\hline 33 & 2 & $-0,1$ & 4,1 & $-1,5$ & 0 & 3,6 & $-0,1$ & 2,8 & 2,3 \\
\hline 34 & 2 & 1,9 & 0,5 & $-1,7$ & 1,1 & $-2,2$ & 0,8 & 0,2 & 3,6 \\
\hline 35 & 2 & 1,8 & 2,8 & 3,3 & 0,5 & $-0,1$ & 1,3 & 2,9 & $-3,1$ \\
\hline 36 & 2 & 0,1 & 1,7 & 1,8 & $-0,8$ & $-2,9$ & 1 & 0,4 & 1,8 \\
\hline 38 & 2 & $-3,1$ & 0,4 & 4 & -2 & 4,3 & $-1,2$ & $-0,6$ & $-5,4$ \\
\hline 39 & 2 & $-0,1$ & 0 & $-0,1$ & 2,8 & 5,7 & $-2,9$ & 1,1 & $-4,1$ \\
\hline 40 & 2 & 1,8 & 1,4 & 3,4 & $-0,6$ & $-0,2$ & 2,4 & 2,8 & $-2,8$ \\
\hline 41 & 2 & 0,8 & 2,8 & 1,8 & 0,9 & 3,3 & $-0,1$ & 0,8 & $-1,1$ \\
\hline 42 & 2 & 1,4 & 2,8 & 10,1 & 0,1 & 4,8 & 1,3 & $-0,5$ & $-14,2$ \\
\hline 43 & 2 & 0 & $-0,3$ & $-0,2$ & 1,5 & 2 & $-1,6$ & $-0,8$ & $-1,9$ \\
\hline 45 & 2 & $-2,7$ & 6 & -3 & 0,4 & 13,1 & $-3,2$ & $-4,1$ & -3 \\
\hline 46 & 2 & 1,9 & 3,1 & 1,6 & 0,1 & 0,8 & 1,8 & 1,1 & $-0,4$ \\
\hline 47 & 2 & 1,2 & 1,9 & 3,8 & 1,3 & 1,1 & $-0,1$ & 0,8 & $-5,5$ \\
\hline 48 & 2 & $-1,3$ & $-5,9$ & 1,5 & 0,9 & $-4,8$ & $-2,3$ & $-4,2$ & $-5,2$ \\
\hline 49 & 2 & 2,2 & 7 & 1,7 & 3,6 & 15,4 & $-1,4$ & $-1,8$ & -8 \\
\hline 50 & 2 & $-0,2$ & 3 & 0,7 & 1,3 & 8,5 & $-1,4$ & 2,2 & $-3,8$ \\
\hline 51 & 2 & 1,2 & 6,3 & 2,6 & $-0,7$ & 5,6 & 1,9 & 2,6 & $-5,1$ \\
\hline 52 & 2 & $-1,3$ & 2,6 & $-0,5$ & $-1,7$ & 2,5 & 0,4 & 1,1 & 1,9 \\
\hline 53 & 2 & $-0,4$ & 0,7 & 0,7 & $-0,7$ & 0,8 & 0,3 & $-5,2$ & $-1,9$ \\
\hline 54 & 2 & 0,9 & $-1,6$ & 2,7 & 1,7 & $-1,7$ & $-0,7$ & $-4,8$ & $-5,8$ \\
\hline 55 & 2 & 0,7 & 0,6 & $-1,4$ & $-0,1$ & 2,6 & 0,7 & 4,1 & 1,1 \\
\hline 56 & 2 & -1 & $-0,1$ & $-1,2$ & $-0,5$ & 0,7 & $-0,4$ & 2,1 & 4,2 \\
\hline 57 & 2 & 0,8 & 0,9 & $-1,7$ & 1,2 & 2,5 & $-0,4$ & 0,2 & 1,8 \\
\hline 60 & 2 & 1,7 & 0,5 & 2,4 & $-0,2$ & $-0,6$ & 1,9 & 1,7 & 0,7 \\
\hline
\end{tabular}




\section{TABELA A-31}

\begin{tabular}{|c|c|c|c|c|c|c|c|c|}
\hline $\mathbf{N}$ & Grupo & SN-GoGn T3-T2 & AFAI T3-T2 & 1,PP T3-T2 & 1-ENAPerp T3-T2 & 1-PP T3-T2 & 6-PP T3-T2 & 6-ENAPerp T3-T2 \\
\hline 1 & 1 & $-1,4$ & $-1,1$ & 9,3 & $-2,9$ & $-1,8$ & $-0,5$ & $-4,1$ \\
\hline 2 & 1 & $-3,1$ & -2 & $-2,7$ & $-0,1$ & 0,5 & $-0,1$ & 2,1 \\
\hline 3 & 1 & $-0,2$ & 0,9 & 7,8 & $-0,5$ & 1 & 1,4 & 0,8 \\
\hline 4 & 1 & 0 & $-0,9$ & 2 & $-3,6$ & 0,1 & 1 & $-2,9$ \\
\hline 5 & 1 & $-6,7$ & 1,9 & $-0,2$ & $-0,1$ & 0,9 & 3,7 & 2,4 \\
\hline 6 & 1 & $-6,2$ & $-3,1$ & 4,3 & 0,1 & $-0,9$ & $-1,4$ & 2,2 \\
\hline 7 & 1 & $-4,8$ & $-0,7$ & 3,8 & 1,4 & $-1,9$ & $-0,9$ & 2,7 \\
\hline 8 & 1 & $-1,4$ & 0,2 & $-2,1$ & $-1,5$ & 0,4 & -1 & $-2,3$ \\
\hline 9 & 1 & $-4,1$ & 3,6 & -3 & $-4,6$ & $-1,1$ & 1,1 & 1,2 \\
\hline 10 & 1 & $-0,1$ & $-1,5$ & 1,9 & $-0,2$ & $-0,6$ & $-0,7$ & -1 \\
\hline 11 & 1 & $-6,9$ & 1,6 & $-1,3$ & $-3,2$ & 1,6 & $-0,2$ & $-0,2$ \\
\hline 12 & 1 & $-3,1$ & 4 & $-5,2$ & $-3,4$ & 2,5 & 2,8 & 1,1 \\
\hline 13 & 1 & $-2,2$ & 0,7 & $-4,2$ & 0,7 & 1,7 & 0,6 & 2,6 \\
\hline 14 & 1 & $-3,6$ & 1 & $-4,5$ & $-3,3$ & 1,9 & 0,7 & $-0,1$ \\
\hline 15 & 1 & $-0,8$ & 2,1 & 1,5 & $-3,7$ & 2,2 & $-0,7$ & $-1,5$ \\
\hline 16 & 1 & $-1,6$ & 0,2 & 4,6 & $-0,6$ & $-1,5$ & 0,3 & 0,2 \\
\hline 17 & 1 & $-4,6$ & 1,1 & 0,3 & 0,6 & 0,5 & $-0,4$ & 0,4 \\
\hline 18 & 1 & $-1,2$ & $-2,5$ & 5,3 & 2 & $-1,4$ & $-0,2$ & 5,3 \\
\hline 19 & 1 & $-7,1$ & 1 & $-1,7$ & 2,6 & 0,4 & 0,8 & 4 \\
\hline 20 & 1 & 0,4 & 0,5 & $-2,8$ & 0,7 & 2,3 & 0,2 & 2,4 \\
\hline 21 & 1 & $-2,5$ & $-1,2$ & 3,3 & 1,2 & 1 & $-2,4$ & 1,6 \\
\hline 22 & 1 & $-0,1$ & $-0,8$ & $-5,9$ & $-0,5$ & 0,3 & $-2,5$ & 0,4 \\
\hline 23 & 1 & $-1,8$ & $-0,9$ & $-2,3$ & 0,9 & 0,8 & $-2,1$ & 2,5 \\
\hline 24 & 1 & 4,1 & 4,4 & 1,8 & 2,4 & 1,5 & 2,5 & 1,6 \\
\hline 25 & 1 & $-0,2$ & 0,5 & $-0,1$ & 0,9 & 0,3 & 0,4 & 1,1 \\
\hline 26 & 1 & $-3,2$ & 3,5 & 3,3 & $-3,3$ & 1,8 & 1 & $-2,4$ \\
\hline 27 & 1 & 5 & 1,1 & 0,3 & 1 & 3 & 0,8 & 2,1 \\
\hline 28 & 1 & $-1,8$ & 1,8 & 1,4 & 2,5 & 0,9 & 1,1 & 1,9 \\
\hline 29 & 1 & $-5,5$ & 2 & $-1,7$ & $-0,9$ & 1,7 & 1,5 & 0,1 \\
\hline 30 & 1 & 0,6 & $-1,6$ & $-0,8$ & $-2,1$ & $-0,3$ & $-2,4$ & 0 \\
\hline
\end{tabular}


TABELA A-32

\begin{tabular}{|c|c|c|c|c|c|c|c|c|}
\hline $\mathbf{N}$ & Grupo & SN-GoGn T3-T2 & AFAI T3-T2 & 1,PP T3-T2 & 1-ENAPerp T3-T2 & 1-PP T3-T2 & 6-PP T3-T2 & 6-ENAPerp T3-T2 \\
\hline 31 & 2 & $-5,8$ & -8 & 11,5 & 0,7 & $-3,3$ & 1,6 & 1 \\
\hline 32 & 2 & $-4,6$ & $-1,7$ & 2,1 & $-1,2$ & $-1,6$ & -2 & 1,1 \\
\hline 33 & 2 & 1 & 1,4 & -2 & $-1,8$ & 0,5 & 2,4 & $-1,8$ \\
\hline 34 & 2 & $-0,7$ & 1 & $-1,3$ & $-3,6$ & 1,1 & $-0,4$ & $-1,7$ \\
\hline 35 & 2 & $-2,1$ & $-1,4$ & 4,9 & $-1,3$ & $-1,6$ & $-2,3$ & $-0,7$ \\
\hline 36 & 2 & 3 & $-2,9$ & 14,4 & 6,9 & 2,7 & 1,6 & 4,9 \\
\hline 37 & 2 & 3,2 & $-3,5$ & 1,7 & 1 & -2 & 0,1 & 2,8 \\
\hline 38 & 2 & 1,6 & 0,8 & 1 & 1 & $-1,8$ & 0,2 & 6 \\
\hline 39 & 2 & $-4,1$ & 1,1 & 5,1 & 7 & $-0,9$ & 1,9 & 5 \\
\hline 40 & 2 & $-0,2$ & $-3,4$ & $-3,5$ & $-0,2$ & $-0,2$ & $-0,7$ & 1,4 \\
\hline 41 & 2 & $-0,5$ & 0,7 & 2 & $-0,3$ & $-0,4$ & 1,3 & 1 \\
\hline 42 & 2 & -5 & $-4,5$ & $-4,2$ & $-0,3$ & 1,5 & 1,3 & 1,8 \\
\hline 43 & 2 & $-1,6$ & $-2,6$ & 4,4 & 3,9 & $-0,2$ & 0,7 & 5,2 \\
\hline 44 & 2 & $-2,5$ & $-0,8$ & $-2,4$ & $-1,9$ & 0,2 & $-1,5$ & $-0,3$ \\
\hline 45 & 2 & $-3,7$ & 3 & $-2,9$ & $-1,1$ & 2,4 & 0,3 & $-1,3$ \\
\hline 46 & 2 & -1 & $-0,1$ & $-0,1$ & 0,7 & 1,1 & 0,6 & 0,2 \\
\hline 47 & 2 & $-2,6$ & 0,4 & 0,1 & 0,6 & 0,8 & 1,7 & 0,6 \\
\hline 48 & 2 & $-2,4$ & $-1,9$ & $-4,1$ & $-0,1$ & 0,1 & $-0,7$ & 2,5 \\
\hline 49 & 2 & $-8,5$ & 4,8 & 7,7 & 0,4 & $-0,6$ & 2,3 & 2,9 \\
\hline 50 & 2 & $-2,7$ & 4,2 & 0,3 & 1,6 & 1,3 & 4,2 & 2,6 \\
\hline 51 & 2 & $-2,6$ & 1,3 & $-3,6$ & $-2,9$ & 0,5 & $-0,1$ & -1 \\
\hline 52 & 2 & 2,2 & 1,3 & $-2,8$ & $-1,4$ & 0,5 & $-0,2$ & $-0,7$ \\
\hline 53 & 2 & $-1,5$ & $-0,2$ & $-1,9$ & $-0,8$ & $-2,2$ & -3 & 1,3 \\
\hline 54 & 2 & $-4,9$ & -2 & 4,7 & 7,3 & 1,2 & $-1,6$ & 8 \\
\hline 55 & 2 & $-0,9$ & -1 & 9,6 & 6,3 & $-1,3$ & $-1,8$ & 3,4 \\
\hline 56 & 2 & 3,5 & 3,9 & $-4,6$ & 0 & 2,8 & 3 & 0,8 \\
\hline 57 & 2 & $-1,1$ & 2,3 & 0,7 & $-1,3$ & 1,7 & 1,5 & $-1,2$ \\
\hline 58 & 2 & $-2,6$ & 2 & 2,9 & 1,5 & $-0,2$ & 2 & $-0,8$ \\
\hline 59 & 2 & 0,5 & $-1,9$ & 2 & 6,9 & $-1,4$ & $-1,1$ & 3 \\
\hline 60 & 2 & 1,3 & $-1,8$ & 3,3 & $-0,8$ & $-1,6$ & $-0,6$ & $-1,1$ \\
\hline
\end{tabular}




\section{TABELA A-33}

\begin{tabular}{|c|c|c|c|c|c|c|c|c|}
\hline $\mathbf{N}$ & Grupo & IMPA T3-T2 & 1,NB T3-T2 & 1-NB T3-T2 & 1-PogPerp T3-T2 & 1-GoMe T3-T2 & 6-PogPerp T3-T2 & 6-GoMe T3-T2 \\
\hline 1 & 1 & 4,2 & 1,8 & $-0,1$ & 1,5 & $-0,3$ & 1,3 & 0,2 \\
\hline 2 & 1 & $-3,9$ & $-5,6$ & $-1,4$ & 0,6 & $-0,1$ & 2,9 & $-1,2$ \\
\hline 3 & 1 & 2,3 & 1 & $-0,2$ & $-0,4$ & 1 & 0,9 & 1,5 \\
\hline 4 & 1 & 2,4 & 2,9 & $-0,4$ & 0,7 & $-1,1$ & $-1,1$ & $-2,4$ \\
\hline 5 & 1 & 3,1 & $-0,8$ & -1 & $-0,9$ & 0,2 & 0,6 & 0,6 \\
\hline 6 & 1 & $-3,6$ & $-6,5$ & $-2,8$ & $-2,2$ & $-1,8$ & 3,3 & 0,3 \\
\hline 7 & 1 & 1,3 & 0,4 & $-0,9$ & 2,2 & 1,3 & 2,3 & 2,1 \\
\hline 8 & 1 & 4,7 & 3,6 & 1,4 & 2,4 & 0,2 & 1,7 & 0,3 \\
\hline 9 & 1 & $-2,7$ & $-4,9$ & $-1,4$ & 1 & 3,5 & 5,8 & 4,3 \\
\hline 10 & 1 & $-5,5$ & $-4,6$ & $-0,6$ & 0,6 & 1,7 & 0 & 0,3 \\
\hline 11 & 1 & 1,2 & $-1,5$ & 0,2 & 3,7 & 0,8 & 5,4 & 2,4 \\
\hline 12 & 1 & 1,7 & $-1,1$ & 0 & $-0,9$ & 1,3 & 2,1 & 3,7 \\
\hline 13 & 1 & 1,7 & 0,8 & 0,3 & 1 & 1,8 & 1,6 & 1,4 \\
\hline 14 & 1 & 2,8 & 0,6 & 0,1 & 4,6 & 0,6 & 5,1 & 1,3 \\
\hline 15 & 1 & -7 & $-7,2$ & $-0,3$ & 0 & 0,9 & 2,5 & 1,9 \\
\hline 16 & 1 & $-1,9$ & -2 & 0,3 & 1,8 & 0,7 & 2,4 & 0,6 \\
\hline 17 & 1 & 2,5 & 1,5 & 0,1 & -3 & 1,7 & $-2,9$ & 2,1 \\
\hline 18 & 1 & 2,9 & 4 & $-0,5$ & 2,1 & 2,1 & 4,8 & 0,6 \\
\hline 19 & 1 & 2,1 & $-2,8$ & -1 & 2,8 & 2,1 & 1,7 & 3,5 \\
\hline 20 & 1 & $-2,1$ & $-1,5$ & 0,4 & $-0,1$ & $-0,9$ & 1,9 & $-0,6$ \\
\hline 21 & 1 & $-2,6$ & -4 & $-0,3$ & 2,2 & $-0,2$ & 2,6 & 2,3 \\
\hline 22 & 1 & 2,7 & 4 & 1,5 & 2 & 0 & 0,8 & 0,5 \\
\hline 23 & 1 & 5 & 4,6 & $-0,4$ & 2 & $-1,6$ & 1,4 & 2,5 \\
\hline 24 & 1 & -3 & 0,3 & 0 & $-0,9$ & 0,9 & 1,2 & 1,3 \\
\hline 25 & 1 & 6,5 & 4,9 & $-0,5$ & $-1,3$ & 1,3 & 1,1 & 1,3 \\
\hline 26 & 1 & $-2,9$ & $-4,1$ & $-0,7$ & 1,2 & 0,6 & 2,1 & 1,4 \\
\hline 27 & 1 & 8,1 & 10,6 & 2 & 1,1 & 0,4 & 2,5 & 1,6 \\
\hline 28 & 1 & $-3,5$ & $-3,5$ & $-1,3$ & $-0,2$ & 1,7 & 1 & 1,5 \\
\hline 29 & 1 & 0 & $-2,5$ & $-0,3$ & 2,7 & 1,4 & 3,8 & 2,1 \\
\hline 30 & 1 & $-6,3$ & $-6,5$ & $-0,5$ & $-0,4$ & 1,7 & 1,9 & 0,4 \\
\hline
\end{tabular}


TABELA A-34

\begin{tabular}{|c|c|c|c|c|c|c|c|c|}
\hline $\mathbf{N}$ & Grupo & IMPA T3-T2 & 1,NB T3-T2 & 1-NB T3-T2 & 1-PogPerp T3-T2 & 1-GoMe T3-T2 & 6-PogPerp T3-T2 & 6-GoMe T3-T2 \\
\hline 31 & 2 & $-1,3$ & $-4,7$ & $-3,5$ & $-1,8$ & $-3,3$ & 0,6 & $-6,5$ \\
\hline 32 & 2 & 0,6 & $-1,7$ & $-1,4$ & 3,5 & $-0,4$ & 5,1 & 2,5 \\
\hline 33 & 2 & 0,9 & 1,6 & $-0,1$ & $-0,1$ & 0,7 & $-0,4$ & $-1,4$ \\
\hline 34 & 2 & $-6,7$ & $-5,7$ & -3 & $-2,3$ & $-0,6$ & $-0,9$ & $-0,7$ \\
\hline 35 & 2 & 5,2 & 3,9 & 0,8 & 0,7 & 1,3 & 1 & 0,1 \\
\hline 36 & 2 & 0,3 & 2,7 & 0,2 & 1,4 & 0,4 & 2,4 & $-0,2$ \\
\hline 37 & 2 & $-6,7$ & $-7,4$ & $-1,5$ & 0,5 & $-0,9$ & 4 & $-2,2$ \\
\hline 38 & 2 & 1,5 & 1,1 & $-0,7$ & 2,4 & 0,6 & 3,8 & 1,9 \\
\hline 39 & 2 & 2,2 & 1,2 & 1,9 & 0,9 & 3,6 & 1,9 & 1,8 \\
\hline 40 & 2 & 2,7 & 0,7 & $-0,9$ & 2,1 & $-0,9$ & 3,3 & $-0,8$ \\
\hline 41 & 2 & $-3,3$ & $-2,6$ & $-0,8$ & 1,2 & 1,7 & 3 & 1,2 \\
\hline 42 & 2 & 6,8 & 2,2 & $-1,9$ & 3,2 & $-4,7$ & 3,5 & $-2,9$ \\
\hline 43 & 2 & $-2,7$ & $-3,2$ & $-1,4$ & $-1,9$ & $-0,3$ & 0,2 & -1 \\
\hline 44 & 2 & 4,1 & 3,1 & $-2,1$ & 3,4 & 0,9 & 3,6 & 1 \\
\hline 45 & 2 & 0,2 & $-2,4$ & $-0,1$ & 1,2 & 2,4 & $-0,1$ & 2,5 \\
\hline 46 & 2 & 4,2 & 3,7 & 1 & 0,5 & 0,5 & 0,4 & 0,7 \\
\hline 47 & 2 & $-1,3$ & $-2,7$ & $-0,8$ & $-0,4$ & 1,7 & $-0,1$ & 0,5 \\
\hline 48 & 2 & $-1,4$ & $-2,9$ & $-0,4$ & 4,5 & $-0,7$ & 4,1 & 0,8 \\
\hline 49 & 2 & $-0,1$ & -5 & $-2,2$ & 0,5 & 3,6 & 2,6 & 6,9 \\
\hline 50 & 2 & 4,3 & 2,8 & 0,4 & 0,7 & 4,1 & 3,2 & 3,8 \\
\hline 51 & 2 & 4,8 & 0,7 & $-0,1$ & 2,8 & 2 & 4,3 & 2,8 \\
\hline 52 & 2 & $-0,4$ & 0,5 & -1 & 0,7 & 0,7 & 1,5 & $-0,3$ \\
\hline 53 & 2 & 5,4 & 3,9 & 0 & 2,5 & 0,4 & 0,9 & 4,8 \\
\hline 54 & 2 & 10,5 & 8,1 & 0,7 & 5,6 & $-0,5$ & 5,5 & 2,1 \\
\hline 55 & 2 & 0,9 & $-0,2$ & $-0,7$ & $-1,3$ & 1,7 & 0,9 & 0,1 \\
\hline 56 & 2 & $-6,1$ & $-2,6$ & $-0,1$ & $-1,5$ & 1,9 & 1,9 & 0,7 \\
\hline 57 & 2 & $-6,8$ & $-6,5$ & $-2,2$ & $-1,6$ & 0,6 & 1,4 & 0,6 \\
\hline 58 & 2 & 0,7 & 0 & 0,4 & 1,8 & 2 & 2,4 & $-0,7$ \\
\hline 59 & 2 & $-6,2$ & $-6,2$ & $-2,1$ & $-0,2$ & 0,3 & $-2,6$ & $-2,7$ \\
\hline 60 & 2 & $-0,3$ & 1,4 & 0 & 4,2 & $-1,6$ & 3,6 & $-1,9$ \\
\hline
\end{tabular}


TABELA A-35

\begin{tabular}{|c|c|c|c|c|c|}
\hline $\mathbf{N}$ & Grupo & T hor T3-T2 & T Vert T3-T2 & Rel mol T3-T2 & Rel can T3-T2 \\
\hline 1 & 1 & 1,3 & 0,6 & 0,5 & 0,5 \\
\hline 2 & 1 & 1,4 & 2,8 & 1,5 & 0,9 \\
\hline 3 & 1 & 0,7 & 1,2 & 0 & 4,1 \\
\hline 4 & 1 & 0,2 & 0,1 & 2,4 & 2,1 \\
\hline 5 & 1 & $-1,9$ & $-0,9$ & $-1,3$ & 1,3 \\
\hline 6 & 1 & 2,7 & 1,2 & -1 & 2,5 \\
\hline 7 & 1 & $-1,8$ & $-0,5$ & $-1,3$ & $-2,4$ \\
\hline 8 & 1 & 0,6 & 0,5 & $-0,6$ & $-0,5$ \\
\hline 9 & 1 & $-0,3$ & $-0,1$ & 0,1 & 3,1 \\
\hline 10 & 1 & 1 & 3 & 0 & 1,2 \\
\hline 11 & 1 & 0,5 & 2,5 & $-0,3$ & 1,9 \\
\hline 12 & 1 & 0,1 & 0,9 & 0,3 & 2 \\
\hline 13 & 1 & $-0,2$ & 2,3 & 0,6 & 1,1 \\
\hline 14 & 1 & $-0,3$ & 1,6 & 0,4 & 2,2 \\
\hline 15 & 1 & 1,8 & 1,7 & 0,7 & 3,4 \\
\hline 16 & 1 & $-0,1$ & $-0,9$ & 0 & $-1,7$ \\
\hline 17 & 1 & $-0,8$ & 1 & $-0,3$ & 0,7 \\
\hline 18 & 1 & 0,2 & 2,6 & 1,3 & 2,3 \\
\hline 19 & 1 & 0,2 & 1,3 & 1,3 & 0,7 \\
\hline 20 & 1 & 0,4 & 0,7 & $-0,5$ & $-1,1$ \\
\hline 21 & 1 & 2,2 & 2,2 & 0,5 & $-0,9$ \\
\hline 22 & 1 & $-1,5$ & 0,5 & $-0,3$ & 2,5 \\
\hline 23 & 1 & 0,6 & $-0,2$ & 1,6 & 2,6 \\
\hline 24 & 1 & 3,4 & $-2,1$ & 1,3 & 2,8 \\
\hline 25 & 1 & 1,4 & 1,3 & $-0,8$ & 1,7 \\
\hline 26 & 1 & 1,3 & 0,5 & 0,4 & 0,3 \\
\hline 27 & 1 & 1,2 & 1,4 & 0 & 1,3 \\
\hline 28 & 1 & 0,9 & 1,4 & $-1,1$ & 0,2 \\
\hline 29 & 1 & 0,2 & 1,3 & $-1,6$ & 1,3 \\
\hline 30 & 1 & 1,1 & 3,4 & $-0,5$ & \\
\hline & & & & & 0,9 \\
\hline
\end{tabular}




\section{TABELA A-36}

\begin{tabular}{|c|c|c|c|c|c|}
\hline $\mathbf{N}$ & Grupo & T hor T3-T2 & T Vert T3-T2 & Rel mol T3-T2 & Rel can T3-T2 \\
\hline 31 & 2 & 1,2 & 2 & 0,1 & $-0,2$ \\
\hline 32 & 2 & 0,9 & 0,3 & $-0,3$ & 1,2 \\
\hline 33 & 2 & $-1,1$ & 0 & 0 & $-4,3$ \\
\hline 34 & 2 & 2,1 & 0,9 & 2,1 & 4,4 \\
\hline 35 & 2 & 0,2 & 0,9 & 1,1 & 1,1 \\
\hline 36 & 2 & 4 & 3,4 & 0,4 & 1,6 \\
\hline 37 & 2 & 1,4 & 1 & 0,9 & 1 \\
\hline 38 & 2 & $-1,4$ & $-2,4$ & 1,2 & 1,2 \\
\hline 39 & 2 & 0,7 & 0,5 & $-1,1$ & -1 \\
\hline 40 & 2 & 1,7 & 1,4 & 1,1 & 3,1 \\
\hline 41 & 2 & 0,6 & 0,1 & 0,5 & 1,2 \\
\hline 42 & 2 & 1,4 & 1,6 & 0,9 & $-0,3$ \\
\hline 43 & 2 & 0,7 & 1,8 & 0,1 & $-0,7$ \\
\hline 44 & 2 & 0,8 & 2 & 1,1 & 1,4 \\
\hline 45 & 2 & $-0,2$ & 1,6 & $-0,2$ & 3,1 \\
\hline 46 & 2 & 1,2 & 1,8 & 0,4 & 3,3 \\
\hline 47 & 2 & 0,5 & 2 & 0,2 & 0 \\
\hline 48 & 2 & $-0,5$ & 0,7 & 0,2 & 0,8 \\
\hline 49 & 2 & 0,6 & $-1,3$ & 0,1 & 1,9 \\
\hline 50 & 2 & 0,6 & 0,7 & $-0,3$ & 1,1 \\
\hline 51 & 2 & 1,8 & 1,7 & 0,9 & 3,9 \\
\hline 52 & 2 & 0,8 & 0,8 & 1,1 & 3,5 \\
\hline 53 & 2 & $-1,2$ & $-1,9$ & 1 & 2,5 \\
\hline 54 & 2 & 2,2 & 1,5 & 0,8 & 2,8 \\
\hline 55 & 2 & 5,7 & 1,4 & 1,4 & 1 \\
\hline 56 & 2 & 2,1 & 1,8 & 0,1 & 0,9 \\
\hline 57 & 2 & 2,6 & 1,6 & 0,4 & $-0,5$ \\
\hline 58 & 2 & 1,7 & 0 & 0,9 & 1,8 \\
\hline 59 & 2 & 3,9 & 1,3 & 2,8 & 5,2 \\
\hline 60 & 2 & $-0,1$ & $-0,8$ & 0,4 & 2 \\
\hline
\end{tabular}

